\title{
Metabolic and developmental functions of the transcription factor Gcn4p of Saccharomyces cerevisiae
}

\author{
Dissertation \\ zur Erlangung des Doktorgrades \\ der Mathematisch-Naturwissenschaftlichen Fakultäten \\ der Georg-August-Universität zu Göttingen
}

vorgelegt von

Britta Herzog

aus

Nürnberg

Göttingen 2010 
Die vorliegende Arbeit wurde von Juni 2005 bis September 2010 in der Abteilung für Molekulare Mikrobiologie und Genetik unter Anleitung von Prof. Dr. Gerhard H. Braus am Institut für Mikrobiologie und Genetik der Georg-August-Universität zu Göttingen angefertigt.

D7

Referent: $\quad$ Prof. Dr. G. H. Braus

Korreferent: $\quad$ PD Dr. M. Hoppert

Tag der mündlichen Prüfung: $\quad 27.10 .2010$ 


\section{DANKSAGUNG}

Zunächst möchte ich mich herzlich bei meinem Doktorvater Gerhard Braus bedanken. Er hat mir das Thema dieser Arbeit überlassen und mir die Möglichkeit gegeben, sie in seiner Abteilung anzufertigen. Er hat kontinuierliches Interesse an den bearbeiteten Themen gezeigt und mich vor allem beim Schreiben des Manuskriptes unterstützt.

Für die Übernahme des Korreferats bedanke ich mich recht herzlich bei Herrn PD Dr. Michael Hoppert.

Ein ganz großes Dankeschön haben meine Laborkollegen Nicole, Verena, Ingo und Ole verdient, die nicht nur Arbeitskollegen waren, sondern auch zu Freunden geworden sind, welche ich nicht missen möchte. Ihr hattet einen großen Anteil daran, dass ich gerne zur Arbeit gekommen bin. Während des ein oder anderen Tiefs hattet ihr immer ein offenes Ohr für meine Probleme und standet mir mit Rat und Tat zur Seite. Über den Laboralltag hinaus erinnere ich mich gerne an die gemeinsamen Essen, Sportkurse und Grillabende, sowie unseren Bowling-Abend, obwohl es für mich ja eher schlecht ausging. Ihr seid mir in den letzten Jahren sehr ans Herz gewachsen und ich weiß jetzt schon, dass ich euch sehr vermissen werde. Ohne Euch wäre die Zeit nur halb so schön gewesen.

Durch ihre Praktika, Bachelor- und Diplomarbeiten waren mir Antonia Jakobshagen, Katharina Tabke und Nadine Thiede eine große Hilfe und haben viele Ergebnisse geliefert, die in diese Arbeit eingeflossen sind.

Für das gewissenhafte Korrekturlesen der Arbeit danke ich Sabine März, Özgür Bayram und Nicole Rachfall.

Weiterhin möchte ich mich bei der gesamten Arbeitsgruppe für die nette Atmosphäre und stete Hilfsbereitschaft bedanken, aber auch bei ehemaligen Mitarbeitern der AG Braus, die zum Gelingen dieser Arbeit beigetragen haben. Olaf Grundmann und Friederike Hüttenrauch haben durch ihren Screen die Grundsteine für diese Arbeit geliefert und ich konnte des Öfteren auf den ein oder anderen Stamm aus Olafs HefeStammsammlung zurückgreifen. Katrin Streckfuß-Bömeke hat mir während meiner Diplomarbeit viel beigebracht und durch die Überlassung ihres Themas in den Anfängen meiner Doktorarbeit sehr geholfen. Meine ehemaligen Weggefährten Christoph Sasse und Karen Laubinger haben mir nicht nur den Laboralltag durch den ein oder anderen 'Schnack' verschönert. Ich erinnere mich auch gerne an unsere gemeinsamen Kinoabende, unsere Spanischkurse in der Volkshochschule und letztendlich unseren gemeinsamen Sprachurlaub in Malaga.

Mein größter Dank gilt meinen Eltern, die mich während der letzten Jahre stets moralisch unterstützt haben und mir immer das Gefühl gegeben haben, dass ich mich in allen Lebenslagen auf sie verlassen kann.

$\mathrm{Zu}$ guter Letzt möchte ich mich aber auch bei meinen Freundinnen Nadine, Anna und Annika bedanken, die mich während der gesamten Zeit unterstützt, motiviert und abgelenkt haben und immer mich für da waren. 



\section{TABLE OF CONTENTS}

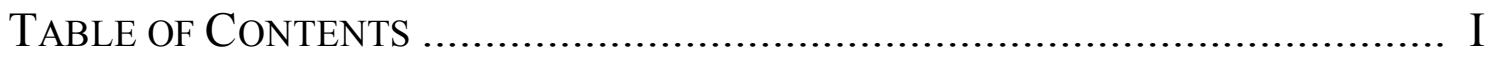

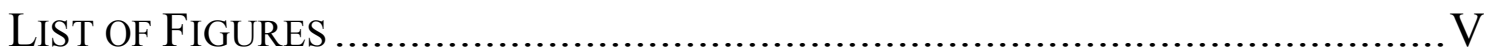

LIST OF TABLES ................................................................................. VII

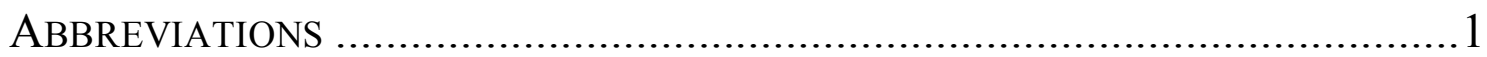

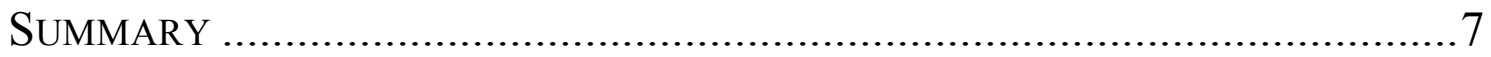

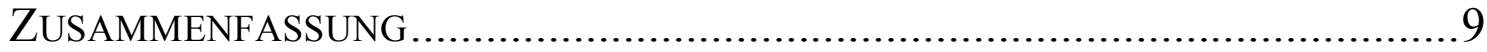

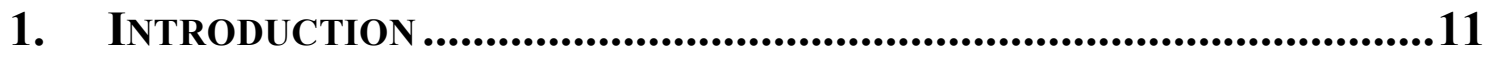

1.1 Regulation of dimorphism in Saccharomyces cerevisiae ................................ 11

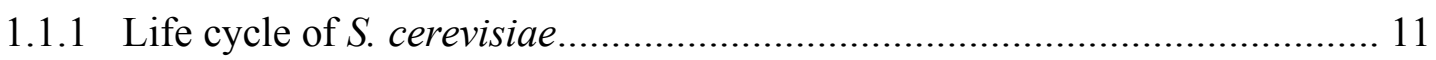

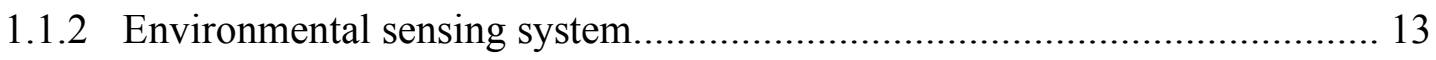

1.1.3 Cell surface adhesion in S. cerevisiae .................................................... 14

1.1.4 Signal transduction pathways for adhesion ....................................... 15

1.2 Relevance of dimorphism and adhesion.............................................................. 18

1.3 Regulation of amino acid biosynthesis in $S$. cerevisiae ................................ 19

1.3.1 The general amino acid control in S. cerevisiae ........................................ 19

1.3.2 The transcription factor Gcn $4 p$ of $S$. cerevisiae ..................................... 21

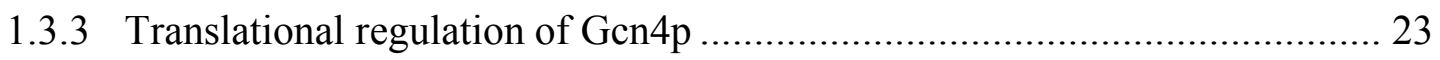

1.3.4 Regulation of Gen4 protein stability ................................................... 25

1.4 The 'Unfolded Protein Response' .......................................................................... 26

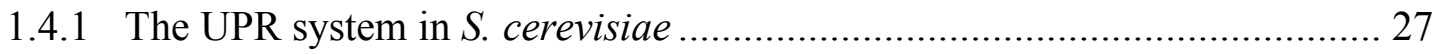

1.4.2 Role of Gen4p in the UPR system of $S$. cerevisiae ................................... 29

1.4.3 The UPR system of higher eukaryotes................................................ 30

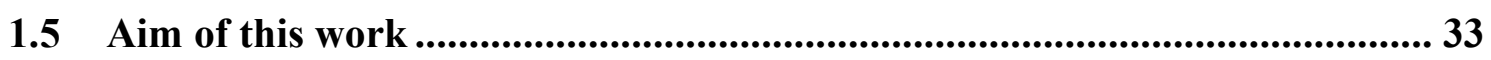

2. MATERIALS AND MethodS............................................................34

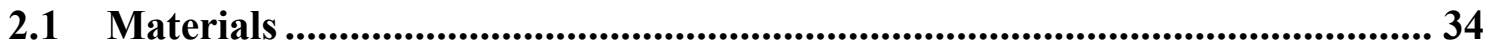

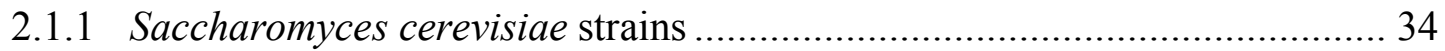

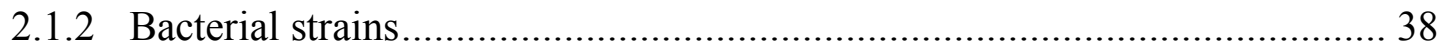

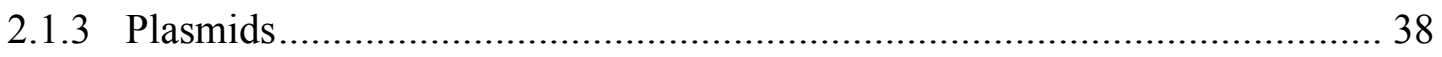

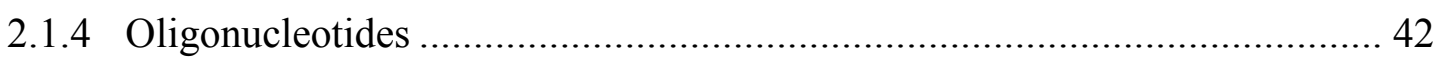


2.2 Cultivation of microorganisms ................................................................... 44

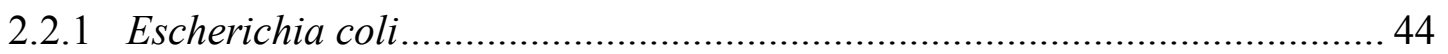

2.2.2 Saccharomyces cerevisiae ................................................................. 44

2.3 Isolation of nucleic acids................................................................... 45

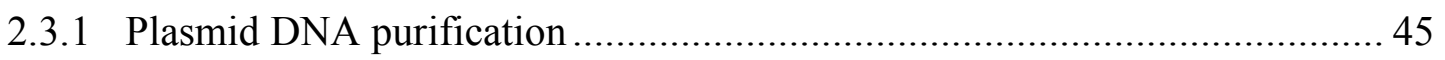

2.3.2 Isolation of DNA from yeast cells by 'Smash \& Grab' .............................. 45

2.3.3 Pure DNA isolation for yeast cells via glass capillary .............................. 46

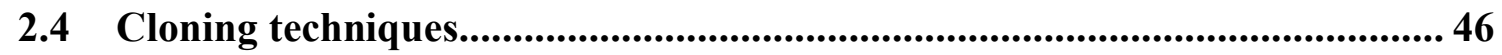

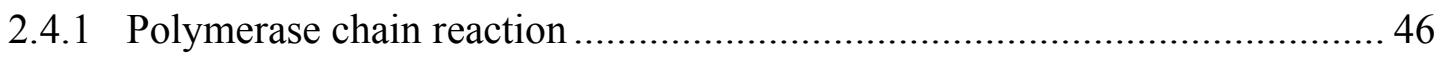

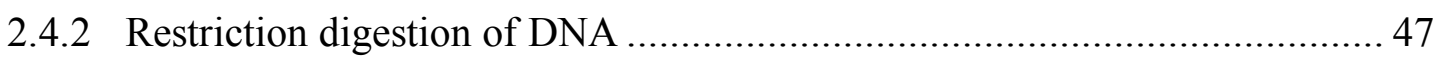

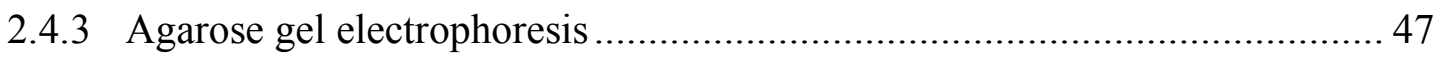

2.4.4 Isolation of DNA fragments from agarose gels ...................................... 47

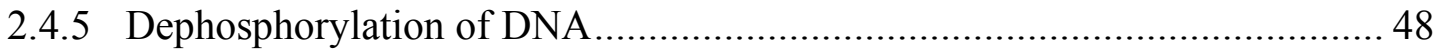

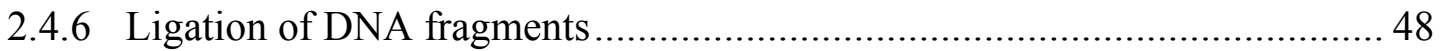

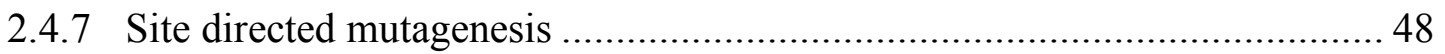

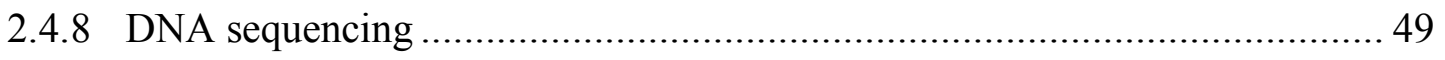

2.5 Methods of transformation...................................................................... 49

2.5.1 Preparation of chemically competent $E$. coli cells ................................... 49

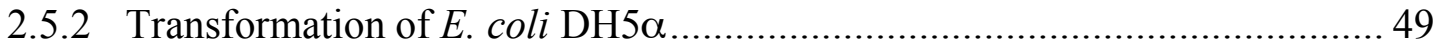

2.5.3 Preparation of $\mathrm{CaCl}_{2}$-competent E. coli $\mathrm{FHK} 12$ cells ............................... 50

2.5.4 Transformation of $E$. coli FHK12 …......................................................... 50

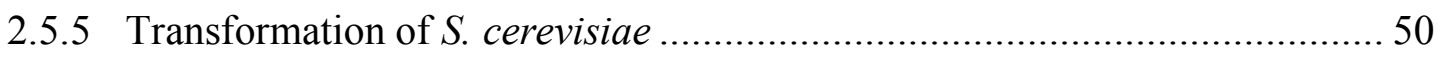

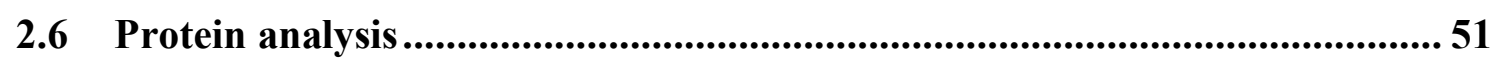

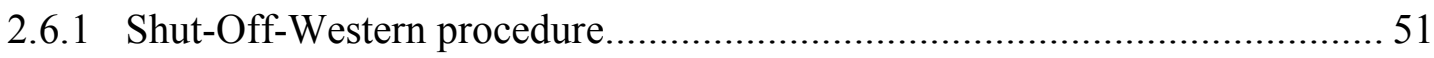

2.6.2 Protein Synthesis Shut-Off Assay …......................................................... 52

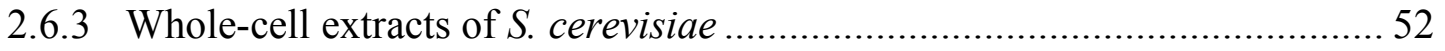

2.6.4 SDS-Polyacrylamide Gel Electrophoresis (Laemmli, 1970) ....................... 52

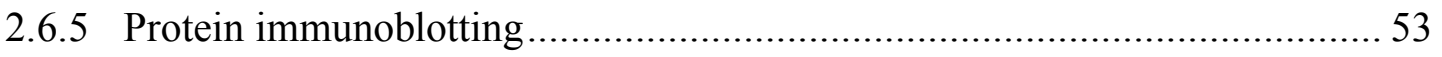

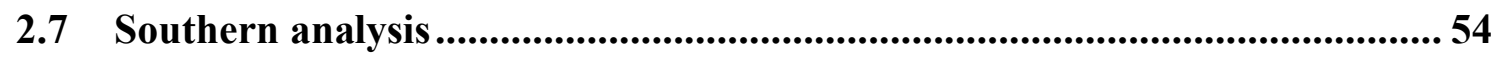

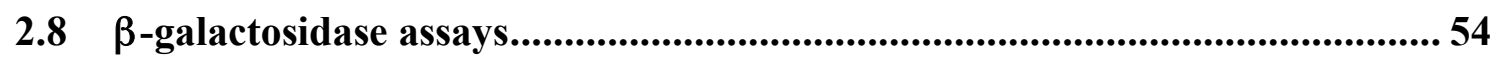

2.8.1 $\beta$-galactosidase assay in $S$. cerevisiae .................................................... 54

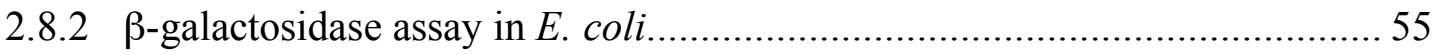

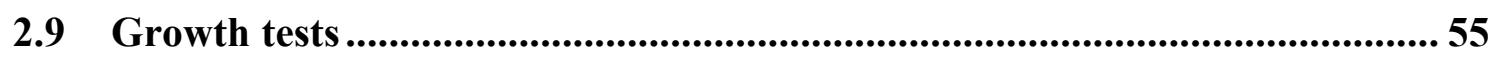


2.10 Adhesive growth ………………........................................................................... 55

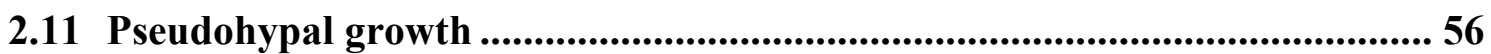

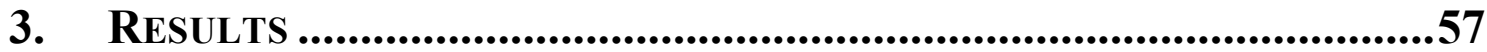

3.1 A feedback circuit between transcriptional activation and selfdestruction of Gcn4p separates its metabolic and morphogenic

function in diploid yeasts ................................................................................. 57

3.1.1 The GCN4 $4^{L 267 S}$ mutant allele separates the metabolic and the developmental function of a transcription factor in diploids

3.1.2 Transcriptional activity of Gen $4 \mathrm{p}^{\mathrm{L} 267 \mathrm{~S}}$ in starved diploids is significantly lower for FLO11: :lacZ in comparison to Gcn4p target gene expression....... 59

3.1.3 The separation of the dual function of Gcn4p is diploid-specific................ 61

3.1.4 Dimerization of Gen $4 p^{\text {L267S }}$ is reduced compared to wild type Gen4p......... 62

3.1.5 Various amino acid substitutions of zipper leucines lead to a separation of the metabolic and developmental Gen $4 p$ function

3.1.6 Protein stability of Gen $4 \mathrm{p}^{\mathrm{L} 267 \mathrm{~S}}$ and other dimerization variants is increased in comparison to the wild type protein

3.1.7 Gen $4 p$ activates its own destruction and therefore Gen $4 p$ transcriptional activity reciprocally correlates to its own protein stability

\subsection{The UPR transcription factor Hac1p mediates Flo11p-dependent} adhesion and dimorphism in diploid yeasts.

3.2.1 Haclp is required for inducing a general control reporter gene whereas

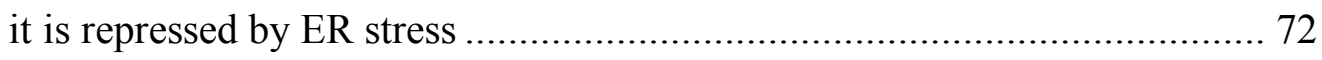

3.2.2 ER stress represses GCN4 mRNA translation ....................................... 74

3.2.3 Repression of Gen4p-dependent gene expression in diploid homozygous

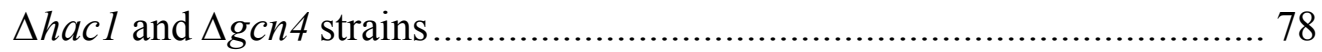

3.2.4 Hac1p reduces FLO11 expression and adhesive growth in haploid cells ...... 79

3.2.5 Diploid homozygous hacl and gcn4 deletion strains repress FLO11::lacZ expression and adhesive growth in response to amino acid starvation......... 81

3.2.6 Identification of FLO11 promoter elements mediating regulation by Hac1p and Gen $4 p$ in response to amino acid starvation

3.2.7 Reduced Hac1 protein levels upon amino acid starvation are independent of the Pho85p-Pcl5p complex 87

3.2.8 Stabilization of Hac $1 \mathrm{p}$ by sumoylation 


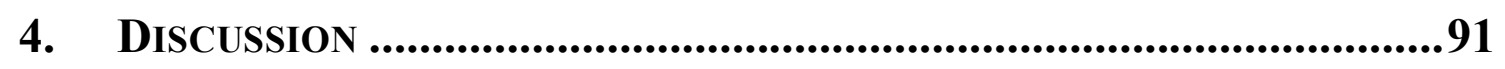

4.1. Dissection of the dual function of Gen4p ......................................................... 91

4.1.1 Gcn4p as conserved global transcription factor .................................... 92

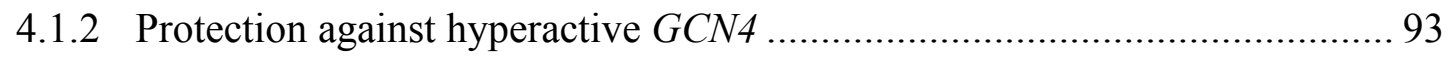

4.1.3 A fine-tuned circuit of self-control of a leucine zipper transcription factor... 94

4.2. Crosstalk between the 'Unfolded Protein Response' and the

'General Amino Acid Control' via their regulators Hac1p and Gcn4p......... 96

4.2.1 Analysis of FLO11 promoter elements ............................................... 96

4.2.2 Role of Hac1p in the 'general amino acid control' of $S$. cerevisiae.............. 99

4.2.3 Consequences of phosphorylation and sumoylation ................................ 100

5. REFERENCES.....................................................................................104

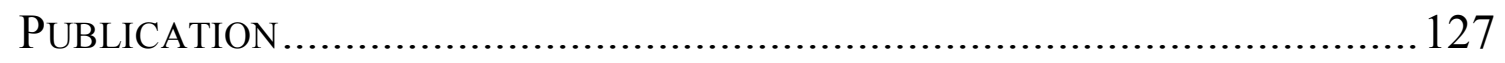

Curriculum VitaE ................................................................ 129 


\section{LIST OF FIGURES}

Fig. 1: Life cycle of Saccharomyces cerevisiae .............................................. 12

Fig. 2: Model of signalling pathways regulating adherence and pseudohyphal growth in $S$. cerevisiae.

Fig. 3: Model for the major mechanisms regulating Gen4p levels and GAAC target genes in $S$. cerevisiae . 20

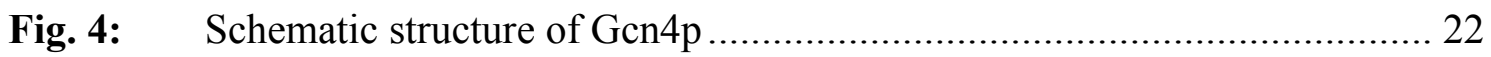

Fig. 5: Translational control of GCN4 expression in S. cerevisiae ........................ 24

Fig. 6: Schematic illustration of the UPR system in S. cerevisiae ......................... 28

Fig. 7: Diploid $G C N 4^{L 267 S}$ yeasts are able to grow under amino acid starvation, but do not adhere to agar................................................................... 58

Fig. 8: $\quad F L O 11$ and Gcn4p-dependent reporter gene expression in diploid $G C N 4^{L 267 S}$ yeasts.

Fig. 9: $\quad G C N 4^{L 267 S}$ mediates adhesive growth of haploid yeasts, which are starved for amino acids.

Fig. 10: Decreased dimerization of Gen $4 p^{\mathrm{L} 267 \mathrm{~S}}$

Fig. 11: Impairment of diploid adhesive growth and FLO11 expression in yeast strains expressing GCN4 with various amino acid substitutions of zipper leucines. 65

Fig. 12: Constricted pseudohyphal growth of diploid yeast strains expressing different alleles of GCN4.

Fig. 13: Increased protein stability of Gcn $4 p$ variants compared to wild type Gcn $4 p$

Fig. 14: Correlation between transcriptional activity of Gcn $4 p$ and protein stability. 70

Fig. 15: Gcn $4 p$-dependent reporter gene expression is governed by Haclp and repressed by ER stress in haploids

Fig. 16: Gen $4 p$-dependent reporter gene expression and eIF2 $\alpha p$ phosphorylation are reduced upon ER stress

Fig. 17: Repression of GCN4 mRNA translation by ER stress is independent of Haclp. 76

Fig. 18: Repression of GCN4 expression by ER stress in haploid S288c cells 77 
Fig. 19: Gcn4p-dependent reporter gene expression is repressed in diploid homozygous $\Delta h a c 1$ and $\Delta g c n 4$ cells

Fig. 20: FLO11::lacZ expression and adhesive growth is partially reduced in haploid $\Delta$ hacl cells.

Fig. 21: FLO11::lacZ expression, adhesion and pseudohyphal growth are repressed in diploid homozygous $\Delta h a c 1$ and $\Delta g c n 4$ strains 83

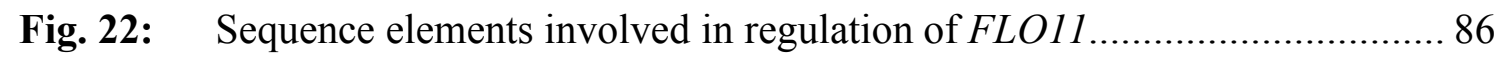

Fig. 23: Haclp is hardly detectable upon amino acid starvation ........................... 88

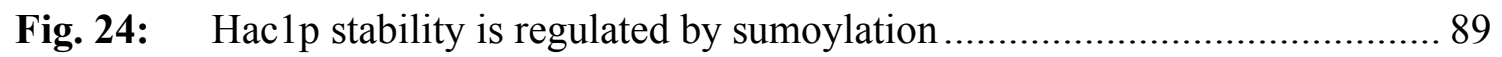

Fig. 25: Model for self-regulation of Gen4p ................................................... 91

Fig. 26: Summary of FLO11 promoter elements regulated by Gcn4p and Haclp in response to amino acid starvation as well as by other transcription factors

Fig. 27: Current model for the developmental and metabolic regulation conferred by Gen $4 p$ and Hac1p. 


\section{LIST OF TABLES}

Table I: Saccharomyces cerevisiae strains used in this study.............................. 35

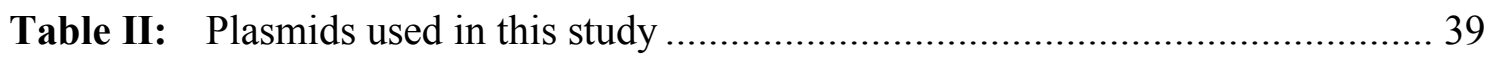

Table III: List of oligonucleotides used in this study.......................................... 42

Table IV: $\beta$-Galactosidase assays of individual $400 \mathrm{bp}$ FLO11 promoter elements cloned into the UAS of a CYC1::lacZ reporter construct......... 85

Table V: Documented and potential target genes of Gen4p and Hac1p................. 98 



\section{ABbreviations}

$\alpha$

$\lambda$

$\Delta$

$\varnothing$

${ }^{\circ} \mathrm{C}$

$\mu \mathrm{g}$

$\mu 1$

$\mu \mathrm{M}$

3AT

$5 \mathrm{MT}$

aa

A, Ala

$\mathrm{Amp}^{\mathrm{R}}$

ATP

bp

bZIP

C, Cys

CAAD

$\mathrm{CaCl}_{2}$

cAMP

CDK

$\mathrm{CH}_{2} \mathrm{Cl}_{2}$

$\mathrm{Cm}^{\mathrm{R}}$

CPC

C-terminus

DB

DMSO

DNA

dNTP

DTT
Alpha

Wavelength

Deletion

Diameter

Degree Celsius

Microgram

Microlitre

Micromolar

3-Amino-1,2,4-triazol

5-Methyl-tryptophan

Amino acid

Alanine

Ampicillin resistance

Adenosine triphosphate

Base pairs

Basic-region leucine zipper

Cysteine

Central acidic activation domain

Calcium chloride

Cyclic adenosine monophosphate

Cyclin-dependent kinase

Methylene chloride

Chloramphenicol resistance

Cross-pathway control

Carboxy terminus

DNA binding domain

Dimethyl sulfoxide

Deoxyribonucleic acid

Deoxynucleotide triphosphate

Dithiothreitol 


\begin{tabular}{|c|c|}
\hline ECL & Enhanced chemiluminescence \\
\hline EDTA & Ethylene diamine tetra acetic acid \\
\hline e.g. & For example \\
\hline ER & Endoplasmic reticulum \\
\hline $\mathrm{EtBr}$ & Ethidium bromide \\
\hline Fig. & Figure \\
\hline FRE & Filamentous response element \\
\hline g & Gram \\
\hline G, Gly & Glycine \\
\hline GAAC & General amino acid control \\
\hline GCD & General control derepressed \\
\hline GCN & General control non-derepressable \\
\hline GCRE & Gcn4 protein recognition element \\
\hline GDP & Guanosine diphosphate \\
\hline GFP & Green fluorescent protein \\
\hline GPI & Glycosyl-phosphatidylinositol \\
\hline GTP & Guanosine triphosphate \\
\hline IgG & Immunoglobuline $\mathrm{G}$ \\
\hline IPTG & Isopropyl-thio- $\beta$-D-galactoside \\
\hline $\mathrm{h}$ & Hour \\
\hline $\mathrm{HCl}$ & Hydrochloric acid \\
\hline $\mathrm{H}_{2} \mathrm{O}$ & Water \\
\hline $\mathrm{H}_{2} \mathrm{O}_{2}$ & Hydrogen peroxide \\
\hline $\mathrm{K}$ & Lysine \\
\hline kanMX4 & Kanamycin resistance \\
\hline $\mathrm{kb}$ & Kilobase pairs \\
\hline $\mathrm{KCl}$ & Potassium chloride \\
\hline $\mathrm{kDa}$ & Kilodalton \\
\hline $\mathrm{KOH}$ & Potassium hydroxide \\
\hline 1 & Liter \\
\hline L, Leu & Leucine \\
\hline LB & Luria-Bertani \\
\hline LiOAc & Lithium acetate \\
\hline
\end{tabular}




\begin{tabular}{|c|c|}
\hline LZ & Leucine zipper domain \\
\hline M & Molar \\
\hline MAPK & Mitogen-activated protein kinase \\
\hline MAT & Mating type \\
\hline $\mathrm{mg}$ & Milligram \\
\hline $\mathrm{MgCl}_{2}$ & Magnesium chloride \\
\hline $\mathrm{MgSO}_{4}$ & Magnesium sulfate \\
\hline $\min$ & Minute \\
\hline $\mathrm{ml}$ & Milliliter \\
\hline $\mathrm{mM}$ & Millimolar \\
\hline MMS & Methyl methansulfonate \\
\hline $\mathrm{MnCl}$ & Manganese chloride \\
\hline mRNA & Messenger RNA \\
\hline $\mathrm{n}$ & Chromosome set \\
\hline $\mathrm{NaCl}$ & Sodium choride \\
\hline $\mathrm{Na}_{2} \mathrm{HPO}_{4}$ & Disodium hydrogen phosphate \\
\hline $\mathrm{NaH}_{2} \mathrm{PO}_{4}$ & Sodium dihydrogen phosphate \\
\hline natMX4 & Nourseothricin resistance \\
\hline ng & Nanogram \\
\hline$\left(\mathrm{NH}_{4}\right)_{2} \mathrm{SO}_{4}$ & Ammonium sulfate \\
\hline NLS & Nuclear localization sequence \\
\hline $\mathrm{nm}$ & Nanometer \\
\hline $\mathrm{nM}$ & Nanomolar \\
\hline $\mathrm{nt}$ & Nucleotide \\
\hline NTAD & N-terminal activation domain \\
\hline N-terminus & Amino terminus \\
\hline OD & Optical density \\
\hline ORF & Open reading frame \\
\hline ori & Origin of replication \\
\hline PAGE & Polyacrylamide gel electrophoresis \\
\hline PBS & Phosphate buffered saline \\
\hline PCR & Polymerase chain reaction \\
\hline PEG & Polyethylene glycol \\
\hline
\end{tabular}




\begin{tabular}{|c|c|}
\hline Pfu Polymerase & Pyrococcus furiosus Polymerase \\
\hline $\mathrm{pH}$ & Potentia hydrogenii \\
\hline PIPES & Piperazine-N, N'-bis(2-ethane sulfonic acid) \\
\hline PKA & Protein kinase $\mathrm{A}$ \\
\hline prom. & Promoter \\
\hline RNA & Ribonucleic acid \\
\hline RNase & Ribonuclease \\
\hline rpm & Rotations per minute \\
\hline RT & Room temperature \\
\hline S & Svedberg unit \\
\hline S, Ser & Serine \\
\hline SAP & Shrimp alkaline phosphatase \\
\hline sec & Second \\
\hline SOB & Bacteria complex medium \\
\hline SOC & SOB with glucose \\
\hline SDS & Sodium dodecyl sulfate \\
\hline SNP & Single nucleotide polymorphism \\
\hline SUMO & Small ubiquitin-like modifier \\
\hline $\mathrm{T}, \mathrm{Thr}$ & Threonine \\
\hline TAE & Tris / acetate / EDTA \\
\hline Taq Polymerase & Thermus aquaticus Polymerase \\
\hline $\mathrm{TE}$ & Tris EDTA buffer \\
\hline term. & Terminator \\
\hline $\operatorname{Tm}$ & Tunicamycin \\
\hline Tris & Tris(-hydroxymethyl)-aminomethane \\
\hline t-RNA & Transfer RNA \\
\hline Trp & Tryptophan \\
\hline $\mathrm{U}$ & Unit \\
\hline UAS & Upstream activation site \\
\hline uORF & Upstream open reading frame \\
\hline UPR & Unfolded protein response \\
\hline UPRE & Unfolded protein response element \\
\hline Ura & Uracil \\
\hline
\end{tabular}




$\begin{array}{ll}\text { URS } & \text { Upstream repression site } \\ \text { UV } & \text { Ultraviolet } \\ \text { V } & \text { Volt } \\ \text { v/v } & \text { Volume per volume } \\ \text { w/o } & \text { Without } \\ \text { WT } & \text { Wild type } \\ \text { w/v } & \text { Weight per volume } \\ \text { YEPD } & \text { Yeast extract peptone dextrose (rich medium) } \\ \text { YNB } & \text { Yeast nitrogen base (minimal medium) }\end{array}$





\section{SUMMARY}

The bakers' yeast Saccharomyces cerevisiae executes two well established pathways, the 'General Amino Acid Control' (GAAC) and the 'Unfolded Protein Response' (UPR), which are in contrast to mammals not essential but enable yeast cells to adapt to environmental changes and different stress conditions.

The bZIP transcription factor Gcn4p represents the global key regulator of the GAAC and herein regulates transcription of numerous metabolic genes of amino acid or purine biosynthesis in response to amino acid starvation. Gcn $4 p$ is also involved in the regulation of the developmental cell-surface flocculin Flo11p, which is required for diploid pseudohyphae formation and for adhesion upon nutrient starvation. This dual function as metabolic and developmental activator could be separated by a Gen $4 p$ variant carrying a single amino acid substitution in its leucine zipper, Gcn $4 \mathrm{p}^{\mathrm{L} 267 \mathrm{~S}}$. This mutation abolishes FLO11 expression and results in a reduced but sufficient transcriptional activity for the induction of amino acid biosynthetic genes. Gcn $4 \mathrm{p}^{\mathrm{L} 267 \mathrm{~S}}$ is impaired in homodimer formation and presents a significantly more stable protein compared to wild type Gcn4p. A helix breaker substitution in Leu253 results in a transcriptionally inactive, but highly stable protein variant. This is due to a feedback circuit between transcriptional activity of Gen $4 p$ and its own stability, which depends on the Gen4p-controlled cyclin Pcl5p. Gcn4p p $^{\text {L253G }}$ reduces the expression of Pc15p and therefore its own degradation.

Haclp plays an important role in the yeast UPR system and represents a bZIP transcription factor, alike Gcn $4 p$. This work presents first evidence for a so far unknown function of Haclp in the GAAC. Haclp is not only able to activate Gcn $4 p$ specific target genes, but also FLO11 expression is reduced in yeast cells deleted for $\mathrm{HACl}$ and diploids can neither grow adhesively when starved for amino acids nor develop pseudohyhae upon nitrogen starvation. Promoter analysis of FLO11 identified a promoter element influenced by both, Haclp and Gcn4p, in response to amino acid starvation that was previously identified to confer regulation by amino acid starvation. Transcription factor specific stress situations result in repression of the respective antagonist. First results indicate novel evidence in Hac1p regulation, which might be of clinical interest due to the involvement of the UPR system in tumorogenesis in mammalian. 



\section{ZUSAMMENFASSUNG}

In der Bäckerhefe Saccharomyces cerevisiae existieren zwei gut erforschte Signalwege, die 'Allgemeine Kontrolle der Aminosäurebiosynthese' (GAAC) und die 'Antwort auf ungefaltete Proteine' (UPR), die im Vergleich zu Säugetieren zwar nicht essentiell, aber für die Hefe dennoch von großer Bedeutung sind, um sich an unterschiedliche Umwelt- und Stressbedingungen anzupassen.

Der bZIP Transkriptionsfaktor Gen4p ist der zentrale Regulator der GAAC und aktiviert unter Aminosäuremangel die Transkription vieler Gene aus Aminosäure- und Purinbiosynthesewegen. Des Weiteren ist Gcn $4 p$ an der Regulation des Zellwandproteins Flo11p beteiligt, das sowohl für das diploide Pseudohyphenwachstum, als auch für das adhäsive Wachstum unter Nährstoffmangel erforderlich ist. Diese doppelte Funktion als metabolischer und Entwicklungsaktivator konnte durch eine Gcn4p Variante getrennt werden, welche eine einzige Aminosäuresubstitution im Leucin-Zipper aufweist, Gcn $4 p^{\text {L267S }}$. Diese Mutation führt dazu, dass die FLO11 Expression zwar unterdrückt wird, aber die transkriptionelle Aktivität für die Induktion der Aminosäurebiosynthesegene ausreicht. Gcn $4 \mathrm{p}^{\mathrm{L267S}}$ beeinträchtig die Homodimerbildung und stellt, verglichen zum Wildtyp-Protein, ein stabileres Protein dar. Der Austausch von Leu253 gegen einen Helixbreaker führt zu einem inaktiven, aber sehr stabilen Transkriptionsfaktor. Dies ist auf eine Feedback-Regulation zurückzuführen, in der Gcn4p an der Regulation von Pcl5p beteiligt ist, welches wiederum für den Abbau von Gcn4p benötigt wird. Da Gcn4p $p^{\text {L253G }}$ nicht in der Lage ist, Pcl5p zu aktivieren, unterdrückt es folglich seinen eigenen Abbau.

Hac1p gehört wie Gcn4p zu der Gruppe der bZIP Transkriptionsfaktoren und nimmt eine wichtige Rolle im UPR System der Hefe ein. Die Ergebnisse dieser Arbeit weisen auf eine bisher unbekannte Rolle von Haclp im Netzwerk der GAAC hin. Hac1p ist nicht nur in der Lage Gen $4 p$ spezifische Zielgene zu aktivieren, sondern ist auch an der Regulation von Flo11p beteiligt. Aufgrund der reduzierten FLO11 Expression können diploide haclDeletionsstämme weder unter Aminosäuremangel adhäsiv wachsen, noch unter Stickstoffmangel Pseudohyphen ausbilden. Analysen des FLO11 Promotors weisen auf ein Promotorelement hin, dass von Hac1p und Gcn4p unter Aminosäuremangel beeinflusst wird. Für dieses Element wurde schon zuvor eine Aminsäuremangel-abhängige Funktion beschrieben. Spezifische Stresssituationen des jeweiligen Transkriptionsfaktor bewirken die Repression des jeweils anderen. Erste Ergebnisse deuten auf neue Erkenntnisse bzgl. der Hac1p Regulation hin, die von klinischem Interesse sein könnte, da das UPR System auch an der Tumorentwicklung in Säugern beteiligt ist. 



\section{INTRODUCTION}

\subsection{Regulation of dimorphism in Saccharomyces cerevisiae}

Regulated dimorphism and adherence are essential virulence factors for a variety of human or plant pathogenic fungi, which threaten human health or agricultural products. Dimorphic fungi are able to attach to and penetrate into a host but also to propagate in liquid media including body fluids (San-Blas et al., 2000; SánchezMartínez and Pérez-Martín, 2001; Klein and Tebbets, 2007). The non-pathogenic fungus Saccharomyces cerevisiae represents an established unicellular model system for the eukaryotic cell. In contrast to common laboratory strains, most natural yeasts are dimorphic diploids and are able to switch between a unicellular yeast and a multicellular filamentous pseudohyphal growth mode (Mortimer, 2000).

\subsubsection{Life cycle of $S$. cerevisiae}

Conjugation of two haploid cells ( $1 \mathrm{n}$ to $2 \mathrm{n}$ ) or sporulation of one diploid cell ( $2 \mathrm{n}$ to $1 n$ ) enables the budding yeast $S$. cerevisiae to live either as a haploid (1n) or as a diploid (2n) organism (Fig. 1). The existence of two different mating types, called $M A T a$ and $M A T \alpha$, is the basic prerequisite for conjugation of haploids cells, which enables them to conjugate with the respective mating partner to form diploid (MATa/ $\alpha)$ yeast cells. Both haploid and diploid cells can grow vegetatively in the yeast form, switch to an invasive and adhesive growth modus or arrest growth in stationary phase. Haploid cells constitutively secrete small peptide pheromones into the medium, which is perceived by haploid cells with respective opposite mating type. This in turn leads to an activation of a signal cascade which induces alterations in different cellular processes including cell cycle arrest, polarity and morphology changes, and adherence. The initial contact of the ' $a$ ' and ' $\alpha$ ' cells is mediated amongst others by adhesion and finally results in cell and nuclear fusion (Roy et al., 1991; Cappellaro et al., 1994). Haploid cells show an unicellular ellipsoid cell morphology, called yeast form. During prolonged growth upon glucose limitation haploid cells penetrate into the substrate, also referred as haploid invasive growth (Cullen and Sprague, 2000). 


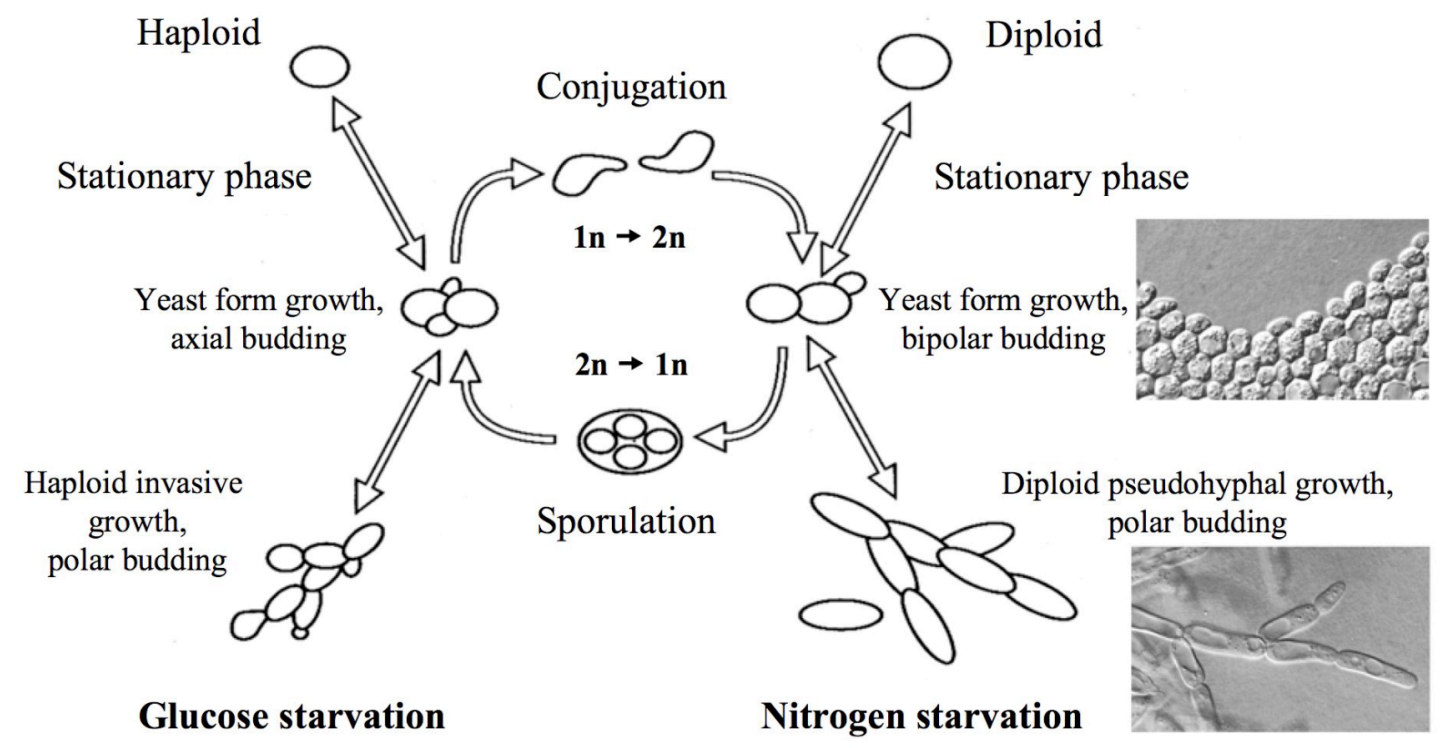

Fig. 1: Life cycle of Saccharomyces cerevisiae (adapted from Mösch (2000)).

Both haploid and diploid yeast cells have three growth options. They can either grow vegetatively in the yeast form or arrest growth in the stationary phase and switch to an invasive growth mode, respectively. Haploid cells (1n) are able to conjugate with respective mating partner to form diploids $(2 \mathrm{n})$ which in turn can sporulate to form haploids. Nitrogen starvation causes the formation of multicellular, filamtentous networks of diploids, called pseudohyphae. Haploid invasive growth occurs during glucose limitation leading to the formation of small microfilaments.

Diploid yeast cells can either grow as yeast with unicellular ellipsoid cell morphology or switch into filamentous growth upon nitrogen starvation. Diploid pseudohyphal growth of $S$. cerevisiae is characterized by chains of long, thin and elongated cells, which are attached to each other (Gimeno et al., 1992; Mösch, 2000). The switch from yeast to pseudohyphae is accompanied by changes in several distinct processes. The budding pattern changes from bipolar to unipolar distal, which results in linear filamentous chains of cells. Furthermore, incomplete cell separation in pseudohyphal cells leads to formation of long multicellular chains where cells remain attached to each other.

The dimorphic switch in haploid yeast cells and diploid filamentous growth includes cell-cell adhesion and a direct substrate invasion whereas haploids show only limited changes in cell morphology (Roberts and Fink, 1994; Cullen and Sprague, 2000). The filamentous growth form of $S$. cerevisiae depends on its nutritional state and there are significant differences in triggering for haploid or diploid filaments. 


\subsubsection{Environmental sensing system}

Cellular development of $S$. cerevisiae is tightly controlled according to the nutrient availability. For optimal growth conditions haploid or diploid yeast cells are usually cultivated in media that provide an excess of all required nutrients. On such media containing a fermentable carbon source such as glucose and abundant nitrogen, both haploid and diploid cells favor growth in the yeast form. Upon nitrogen depletion diploid cells develop pseudohyphae, even in the presence of a fermentable carbon source. This growth mode can be suppressed using standard concentrations of ammonium, arginine, glutamine or glutamate. In contrast, standard amounts of proline, histidine or uracil act permissive for the pseudohyphal growth (Gimeno et al., 1992). The responsible sensor system, that differentiates between divers nitrogen components and therefore control pseudohyphal growth is not completely understood. The fungal high affinity permease Mep2p was identified to function as ammonium sensor in this system. Cells lacking Mep2p do not undergo pseudohyphal growth or exhibit any change in the activity of nitrogen metabolic enzymes (Lorenz and Heitman, 1998). In addition to Mep2p, invasive growth requires the Npr1 kinase, and elements of the PKA and the mitogen-activated protein (MAP) kinase pathway, which finally acts as downstream effector of the ammonium receptor function of Mep2p (Rutherford et al., 2008).

Beside nitrogen, carbon is a further nutrient relevant for pseudohyphal differentiation. The fermentable carbon sources that promote filamentous growth are glucose, galactose, sucrose, maltose and raffinose (Gimeno et al., 1992; Kron et al., 1994; Lorenz et al., 2000b). One sensor for different carbon sources represents Gpr1p, which encodes a cell surface G-protein coupled receptor and interacts with the heterotrimeric GTP-binding protein alpha subunit Gpa2p and with Plc1p, a phosphatidyl-inositol-specific phospholipase C (Yun et al., 1998; Ansari et al., 1999; Kraakman et al., 1999). This trimeric complex regulates pseudohyphal growth via the cAMP pathway. Furthermore, components of the Ras/cAMP pathway are involved in glucose sensing (Broach, 1991a, b). Upon nitrogen starvation, small GTP-binding protein Ras $2 p$ is activated which in turn induces hyperfilamentous growth in diploids (Mösch et al., 1996). Filament formation can also be induced by growth in the presence of low concentrations of fusel alcohols (Dickinson, 1996; Lorenz et al., 2000a; Dickinson, 2008). 
Haploid yeasts also change their growth phenotype upon environmental stimuli. Contrary to diploid strains, Ras $2 p$ is required for haploid invasive growth differentiation under non-starvation conditions (Mösch et al., 1999). However, glucose starvation also induces haploid invasive growth and biofilm formation (Cullen and Sprague, 2000; Reynolds and Fink, 2001).

Additionally, amino acid limitation represents a further nutritional signal that triggers adhesive growth in both haploid and diploid cells. This signal even overrides the presence of the adhesion suppressors nitrogen and glucose (Braus et al., 2003). Adhesive growth during amino acid starvation requires the two proteins Gen $4 p$ and Gen2p, key factors of a genetic network called the 'general amino acid control' (GAAC). Deletion of either GCN2 or GCN4 results in an adhesion deficient phenotype when cells are starved for amino acids. Furthermore, Gcn $4 p$ is also required for pseudohyphal growth upon nitrogen starvation (Braus et al., 2003).

\subsubsection{Cell surface adhesion in $S$. cerevisiae}

The linkage between metabolic and developmental processes is less pronounced in S. cerevisiae, but described for various multicellular organisms. Developmental processes in Candida albicans such as morgphogenesis and biofilm formation are directly connected with the response to the availability of amino acids (Tripathi et al., 2002; Brega et al., 2004).

A prerequisite for dimorphism of $S$. cerevisiae cells is the expression of the FLO gene family that encode for specific glycosyl-phosphatidylinositol (GPI)-linked cellsurface glycoproteins which include the five FLO (flocculation) genes FLO1, FLO5, FLO9, FLO10 and FLO11. 'Flocculins' or rather 'adhesins' are characterized by a C-terminal GPI-anchor for adhesion, which is trimmed off at the plasma membrane before incorporation in the cell wall (Lipke and Ovalle, 1998; Pittet and Conzelmann, 2007). The central part is variable in length and consists of highly repeated amino acid sequences that are heavily $\mathrm{N}$ - and O-glycosylated (Dranginis et al., 2007). These unstable repeats drive slippage and recombination reactions within and between FLO genes leading to a constant generation of novel FLO alleles and pseudogenes (Verstrepen et al., 2004; Verstrepen et al., 2005). The N-terminal part of the protein is required for ligand binding and thus is thought to confer the specificity of adhesion phenotypes (Kobayashi et al., 1998; Zupancic et al., 2008). 
The FLO gene family evolves and diverges very quickly (Hahn et al., 2005), and in contrast to the common domain structure, different families of adhesins are expressed in different yeasts. The laboratory strain S288c, for example is impaired in adhesion, biofilm formation and pseudohyphal development, as it carries a nonsense mutation in the FLO8 regulatory gene encoding one of the main transcriptional activators of the FLO genes (Liu et al., 1996). Repair of FLO8 results in the expression of FLO1 and FLO11, whereas the other FLO genes are transcriptionally silenced (Halme et al., 2004; Verstrepen et al., 2004; Fichtner et al., 2007). In the S. cerevisiae laboratory strain $\Sigma 1278$ b the Flo8p binding site in the FLO1 promoter has been mutated and therefore only FLO11 can be induced during pseudohyphal growth of this yeast strain (Fichtner et al., 2007).

The FLO11 gene, which is also named MUCl (Lambrechts et al., 1996), encodes a (GPI)-anchored cell wall adhesin, which does not only mediate diploid pseudohyphal development (Gimeno et al., 1992; Mösch and Fink, 1997), but also haploid invasive growth (Roberts and Fink, 1994; Guo et al., 2000) or biofilm formation (Reynolds and Fink, 2001). FLO11 is almost silenced in diploids growing in the yeast form resulting in hardly any detectable mRNA (Braus et al., 2003). The level of FLO11 gene expression reflects differences in nutrient supply for diploids and haploids (Braus et al., 2003). In diploids, nitrogen starvation causes activation of FLO11 and subsequently leads to pseudohyphal growth enabling the penetration of substrates in order to forage for nutrients (Liu et al., 1993; Lo and Dranginis, 1998; Robertson and Fink, 1998; Gagiano et al., 2002). In haploids, glucose starvation leads to an activation of FLO11 expression and causes invasive growth and biofilm formation (Cullen and Sprague, 2000; Reynolds and Fink, 2001). Amino acid limitation is a further nutritional signal that activates FLO11 expression and therefore haploid invasive growth and diploid pseudohyphal development of S. cerevisiae (Braus et al., 2003).

\subsubsection{Signal transduction pathways for adhesion}

Regulation of FLO11 expression is relatively complex as its promoter covers a region of approximately $3 \mathrm{~kb}$ and therefore is one of the largest promoters to be found in S. cerevisiae. It integrates multiple inputs from different pathways such as the cAMP pathway, the MAPK cascade, the mating type, and nutritional signals (Rupp et al., 1999). The two main signal transduction pathways required for the regulation of haploid 
invasive growth and diploid pseudohyphal filamentous growth are the cAMP-dependent (PKA) pathway and the highly conserved mitogen-activated protein kinase (MAPK) cascade (Fig. 2) (Kronstad et al., 1998; Mösch, 2000; Elion et al., 2005; Qi and Elion, 2005; Sengupta et al., 2007).

The small GTP-binding protein Ras $2 p$ possesses a prominent role in both pathways. Activated Ras2p stimulates the adenylate cyclase Cyr1p, and therefore, leads to increased intracellular cAMP levels. High levels of cAMP in turn activate the protein kinase $\underline{A}$ (PKA) by removing the inhibitory subunit Bcylp from one of the three catalytic subunits named Tpk1p, Tpk2 and Tpk3p (Broach, 1991a). Although, all three subunits are redundant for viability, only Tpk $2 p$ is required for activating filamentous growth and pseudohyphal development (Robertson and Fink, 1998; Robertson et al., 2000). The antagonistic acting transcription factors Flo8p and Sfl1p are known targets of the PKA. Phosphorylation activates Flo8p and thus FLO11 expression (Pan and Heitman, 1999; Rupp et al., 1999; Pan and Heitman, 2002) whereas Sfllp acts as repressor (Robertson and Fink, 1998).

Activated Ras $2 p$ also affects filamentous growth via a further GTP-binding protein, Cdc42p, which plays an essential role in regulating proliferation and differentiation in all eukaryotes (Mösch et al., 1996; Johnson, 1999). Cdc42p in turn stimulates the MAPK cascade consisting of the protein kinases Ste20p (MAPKKKK), Ste11p (MAPKKK), Ste7p (MAPKK) and Kss1p (MAPK). Finally, the cascade results in phosphorylation of the transcription factor Ste12p in response to environmental stimuli (Madhani and Fink, 1997). Ste12p teams up with Tec1p and together they activate target genes required for diploid pseudohyphal growth and haploid invasive growth (Bürglin, 1991; Madhani and Fink, 1997; Mösch and Fink, 1997) by binding as heterodimer to filamentous response elements (FREs) in the promoter regions, including TEC1 itself (Madhani and Fink, 1997) and FLO11 (Lo and Dranginis, 1998). Additionally, Tec1p alone is able to activate target genes via Tec1p binding sites (TCS) (Köhler et al., 2002; Heise et al., 2010). In the absence of stimuli, Kss1p remains unphosphorylated and thus binds to Ste12p and therefore prevents Ste12p-dependent activation of FLO11 expression or other target genes (Bardwell et al., 1998).

Mss11p has been described as the pivotal element underlying all of these regulatory networks controlling FLO11 expression. Mss $11 \mathrm{p}$ is essential for functionality of Tpk $2 p$, Flo8p and Tec1p, respectively, and thus plays an important role in both 
MAPK cascade and cAMP pathway (van Dyk et al., 2005). In Saccharomyces diastaticus Mss11p forms a heterodimer with Flo8p, which activates expression of STA1 harbouring a similar promoter as FLO11 in S. cerevisiae (Kim et al., 2004). Furthermore, Flo8p and Mss11p are the major regulators of FLO1 expression (Fichtner et al., 2007).

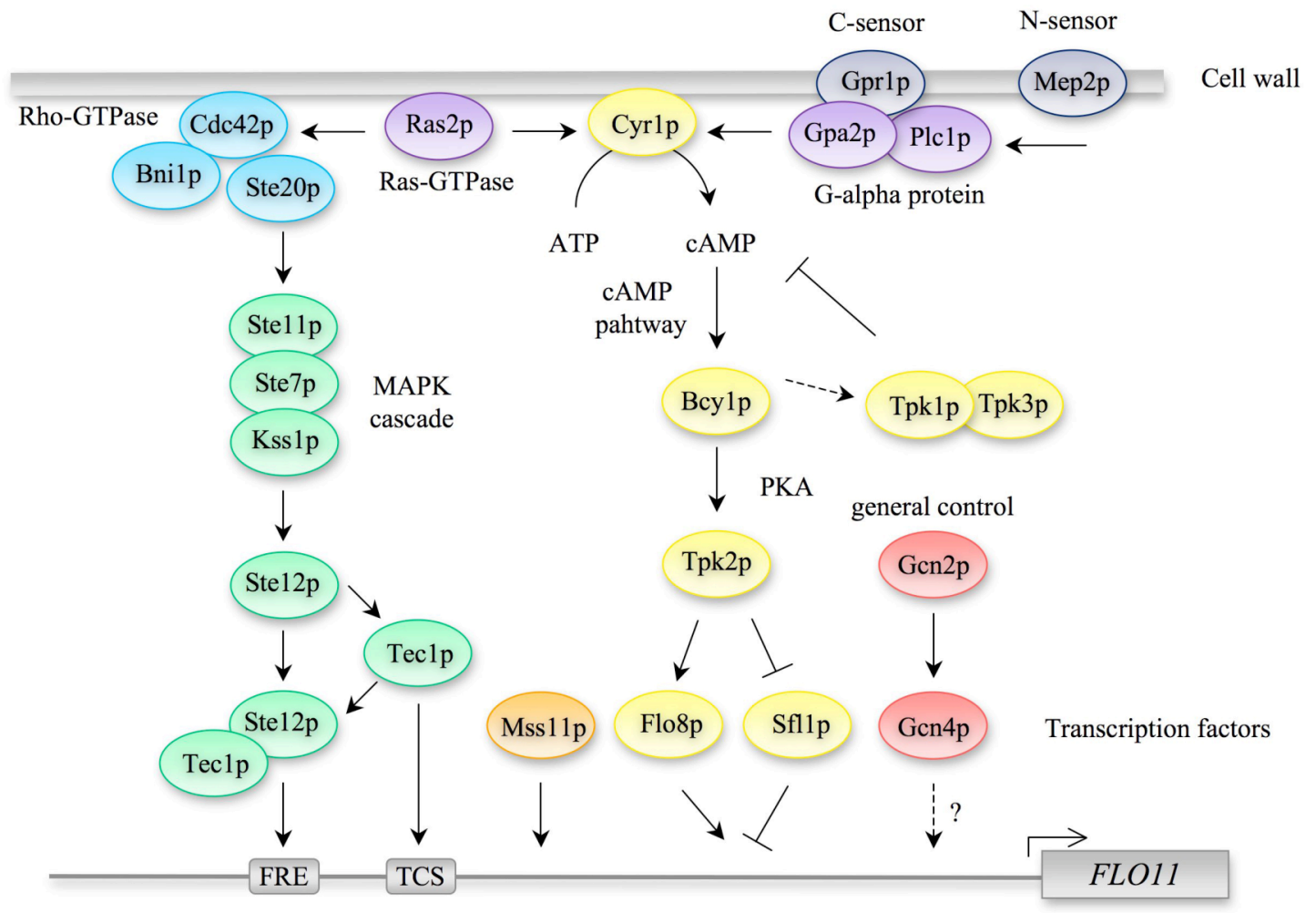

Fig. 2: Model of signalling pathways regulating adherence and pseudohyphal growth in S. cerevisiae (modified according to Mösch (2000) (see text for details).

In addition to the Mss11p-related networks, FLO11 is also regulated by amino acid starvation via elements of the 'general amino acid control'. Amino acid starvationinduced adhesion is independent of the pseudohyphal MAPK cascade, but requires the proteins Tpk2p and Flo8p which represent the central elements of the cAMP pathway. Upon amino acid starvation uncharged tRNAs accumulate in the cell and activate the sensor kinase Gcn2p which in turn phosphorylates the eukaryotic translational initiation factor 2 (eIF2) and finally results in a translational derepression of GCN4 (Hinnebusch, 1997) (described in more detail in section 1.3.3). Both Gcn2p and Gcn $4 p$ are necessary for adhesion and FLO11 expression in response to amino acid starvation. Furthermore, Gen $4 p$ is also required for haploid invasive growth and diploid pseudohyphal 
development (Braus et al., 2003). So far, no direct binding of Gen4p to the FLO11 promoter has been shown which suggests an indirect regulation of FLO11 expression or in concert with other transcription factors. A connection between the 'general amino acid control' and adherence-dependent differentiation processes has also been described for the human pathogen C. albicans (Tripathi et al., 2002; Tournu et al., 2005). Herein, both Ras-cAMP pathway and MAPK cascade are involved in cellular differentiation (Lo et al., 1997; Ernst, 2000; Brown et al., 2007).

Additionally, the G $\beta$-WD40-protein Cpc2p/Asc1p was identified to be involved in regulation of FLO11 expression and therefore deletion of CPC2 results in nonadherent cells and pseudohyphal growth is impaired (Valerius et al., 2007). These findings are in contrast to its predicted role as inhibitor of the Go-protein Gpa2p and therefore its resulting role in the cAMP pathway (Zeller et al., 2007).

\subsection{Relevance of dimorphism and adhesion}

Phenotypic switching from a nonpathogenic mold in the soil to a pathogenic fungus not only depends on its nutrient supply as in S. cerevisiae, but can also be caused by temperature changes as in Candida spp., Histoplasma capsulatum or Coccidioides immitis. Furthermore, alterations in $\mathrm{pH}$ and addition of serum can induce the switch between saprophytic and pathogenic growth forms (Sánchez-Martínez and PérezMartín, 2001; Klein and Tebbets, 2007). Dimorphic pathogenic fungi are responsible for primary mycoses such as histoplasmosis or coccidioidomycosis in human, and include opportunistic pathogens as C. albicans or Penicillium marneffei, which cause diseases in immuno-compromised individuals. Beside ascomycetes, some basidiomycetes also represent dimorphic pathogenic fungi. Cryptococcus neoformans, for example, is an encapsulated pathogenic yeast which can cause cryptococcocal disease in healthy and immuno-compromised people (San-Blas et al., 2000). The basidiomycete Ustilago maydis in turn is a dimorphic phytopathogen which causes corn smut disease by infection through a dikaryotic mycelium (Martínez-Espinoza et al., 1997; Sánchez-Martínez and Pérez-Martín, 2001). 


\subsection{Regulation of amino acid biosynthesis in S. cerevisiae}

Beside these developmental changes, starvation for nutrients also activates systems to ensure a satisfactory amino acid supply. Those systems sense the intra- and extracellular amino acid availability and enable yeast cells to adapt to changes by a direct amino acid uptake from the environment, recycling them through protein degradation and synthesizing all 20 amino acids de novo, respectively (Braus et al., 2004). Such regulatory networks were first described for the filamentous fungi Neurospora crassa and Aspergillus nidulans and known as 'cross-pathway control' (CPC) (Carsiotis and Jones, 1974; Carsiotis et al., 1974; Piotrowska et al., 1980). The lack of one single amino acid stimulates the activation of mostly all 20 amino acid pathways in N. crassa (Barthelmess and Kolanus, 1990; Kolanus et al., 1990). In the bakers' yeast $S$. cerevisiae this regulatory network is known as 'general amino acid control' (GAAC) and stimulates the transcription of more than 70 amino acid biosynthetic genes of 12 different pathways, pathway specific activators and genes encoding diverse aminoacyl-tRNA synthetases (Natarajan et al., 2001; Hinnebusch, 2005).

\subsubsection{The general amino acid control in $S$. cerevisiae}

The GAAC regulatory network is not only induced by amino acid starvation or imbalances but also by other environmental stimuli including limited supply of glucose (Yang et al., 2000), purines (Mösch et al., 1991) and tRNA synthetases (Meussdoerffer and Fink, 1983), respectively. Furthermore, diverse stress conditions such as UV radiation (Engelberg et al., 1994), high salinity (Goossens et al., 2001), oxidative stress (Mascarenhas et al., 2008) and treatment with rapamycin or methyl methanesulfonate (MMS) (Natarajan et al., 2001; Valenzuela et al., 2001) stimulate the activity of the GAAC network (Fig. 3). Under laboratory conditions, amino acid analogs such as 3-amino-1,2,4-triazole (3AT) (Klopotowski and Wiater, 1965) or 5-methyl-tryptophan (5MT) (Schürch et al., 1974) were used to mimic amino acid starvation since the GAAC is not induced by growth on minimal medium. Yeast cells have a high basal expression of amino acid biosynthesis genes and therefore are able to synthesize all 20 amino acids de novo. Alternatively, the general amino acid control can be activated by mutations of biosynthetic enzymes resulting in auxotropic or bradytropic mutant strains (Kornitzer et al., 1994). 
In S. cerevisiae numerous trans-acting factors were identified required for regulation of the GAAC and subdivided into two groups. They were classified as positive regulatory $G C N$ genes (general control non-derepressable) if mutations lead to a loss of transcriptional activation of the GAAC upon amino amino acid starvation. In contrast, they were described as negative regulator GCD genes (general control derepressed) in case of resulting in constitutive active general amino acid control (Harashima and Hinnebusch, 1986).

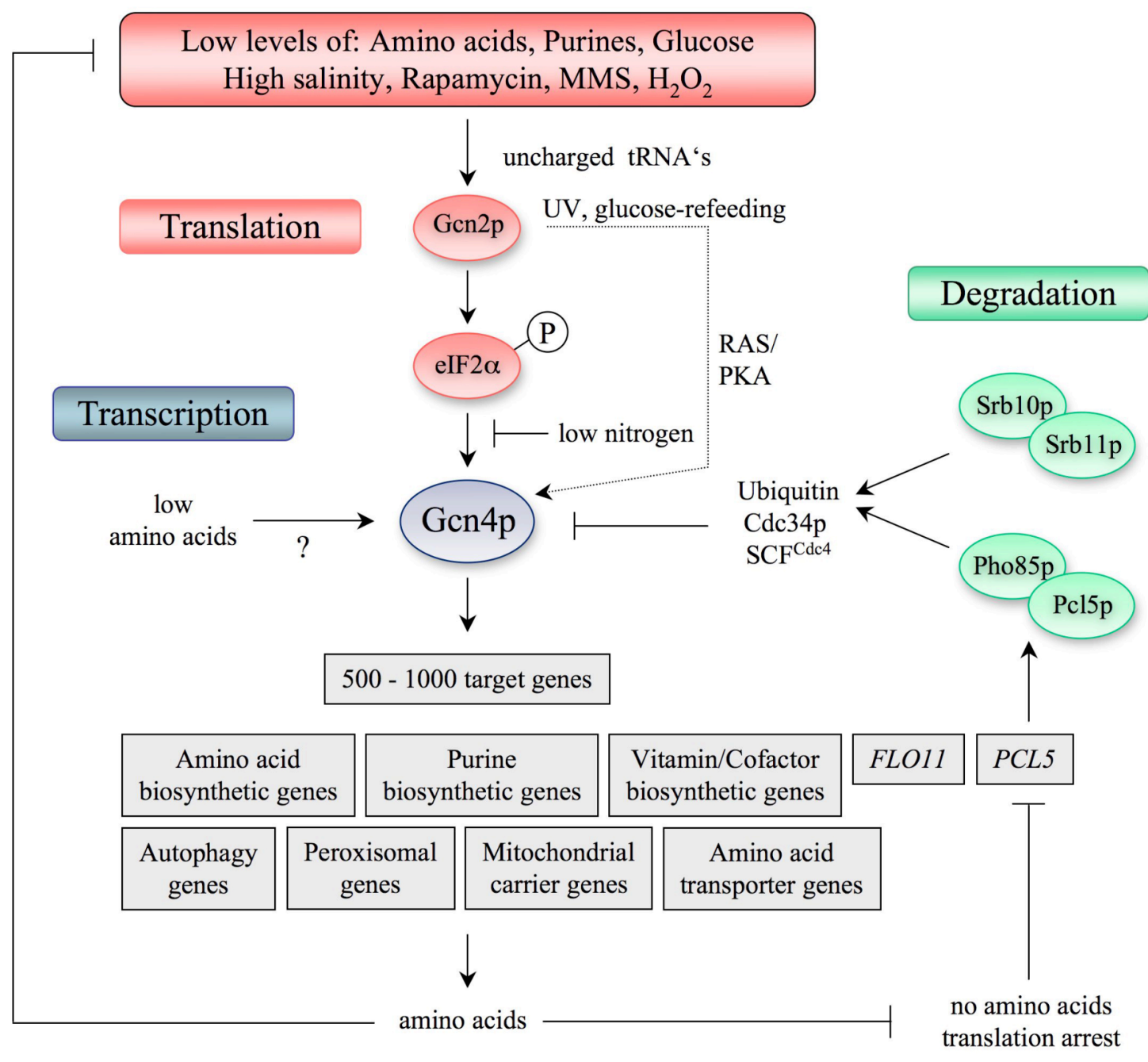

Fig. 3: Model for the major mechanisms regulating Gen4p levels and GAAC target genes in S. cerevisiae.

In response to different environmental stimuli the transcriptional activator Gen $4 p$ is regulated at levels of translation, transcription and protein degradation. This results in transcriptional regulation of more than 500 genes belonging to different biosynthetic pathways (see text for details). 
Synthesis of Gen $4 p$, the global transcription factor of this regulatory network, is associated with the activation of the GAAC in the yeast $S$. cerevisiae. In amino acid starved cells Gcn $4 p$ function is required, directly or indirectly, for the transcription of at least 539 genes whereas its targets are not only involved in amino acid and nitrogen metabolism but also in vitamin or cofactor biosynthesis, peroxisome proliferation, autophagy, amino acid transporting, mitochondrial carrying and much more (Fig. 3) (Natarajan et al., 2001). Gcn4p represents the functional homologue to CpcA in A. nidulans and A. fumigatus, CPC-1 in N. crassa and ATF4 in higher eukaryotes, respectively.

\subsubsection{The transcription factor Gcn $4 p$ of $S$. cerevisiae}

Gcn4p represents the central element of the GAAC network. This transcription factor encodes a polypeptide comprising 281 amino acids with a molecular weight of 31 $\mathrm{kDa}$ (Hinnebusch, 1984; Thireos et al., 1984). It is the prototype of the family of alkaline leucine zipper transcription factors and structurally resembles a coiled coil (Weiss et al., 1990). The sixty C-terminal amino acids of Gcn4p include the leucine zipper domain (LZ, aa 249 - 281) that mediates dimerization and the basic DNA binding domain (DB, aa 221 - 249) where interactions with DNA occur (Hope and Struhl, 1987) (Fig. 4). The leucine zipper motif is characterized by 4 or 5 leucine residues separated by 7 amino acids (Landschulz et al., 1988). The highly conserved bZIP structural motif is found in many other eukaryotic transcription factors including the mammalian proteins JUN and FOS and is also present in ATF4 (Chevray and Nathans, 1992). In contrast to its mammalian homologues, yeast Gen4p can only bind as a homodimer to a specific 9 bp palindromic nucleotide sequence (5'$\left.\operatorname{ATGA}(\mathrm{C} / \mathrm{G}) \mathrm{TCAT}-3^{\prime}\right)$ (termed Gcn4 protein recognition element (GCRE)) located upstream of many genes induced by amino acid starvation (Hope and Struhl, 1986; Oliphant et al., 1989). Gcn $4 p$ can also bind to naturally occurring variants of this sequence (TGATTCA, TGACTCT, TGACTGA, TGACTAT and ATGACTCT) and therefore using computer algorithm this consensus site was generalized to RRRWGASTCA (with $\mathrm{R}=$ purine, $\mathrm{W}=\mathrm{T}$ or $\mathrm{A}$, and $\mathrm{S}=\mathrm{G}$ or $\mathrm{C}$ ) (Natarajan et al., 2001). Furthermore, it was shown that Gen $4 p$ also bind to GCRE half-sites with high affinity in vitro (Hollenbeck and Oakley, 2000; Chan et al., 2007). 
Transcriptional induction of the respective target genes is mediated by an activation domain, which exists in the N-terminus of Gen $4 p$ and spans approximately half of the protein (Drysdale et al., 1995). This activation domain is subdivided into the $\underline{N}$-terminal activation domain $((\mathrm{NTAD})$ aa 17 - 98) and the central acidic activation domain ((CAAD) aa $107-144)$. Consisting of mainly acidic and 8 hydrophobic amino acids, important for activation, both subdomains have nearly identical activation potential (Drysdale et al., 1995). Furthermore, a so-called PEST region is located between these two domains, consisting of the amino acids 99 to 106 . This region is named according to characteristic amino acids (Rechsteiner and Rogers, 1996) and is along with phosphorylation of threonine 165 by the cyclin-dependent kinase Pho85p responsible for the instability of Gcn $4 p$ in sated cells (Kornitzer et al., 1994). The regulation of Gen4 protein stability is described in more detail in section 1.3.4.

Finally there are two different nuclear localization sequences (NLS) to ensure a nuclear localization of Gen4p and in turn transcriptional activity (Pries et al., 2002). NLS1 consists of the amino acids $167-200$ and acts as an ancillary motif. NLS2 is located in the DNA binding domain (aa 231 - 249) and resembles a classical bipartite NLS-motif. Nuclear import of Gen4p requires also the presence of the karyopherins Srp1p and Kap95p (Pries et al., 2004).

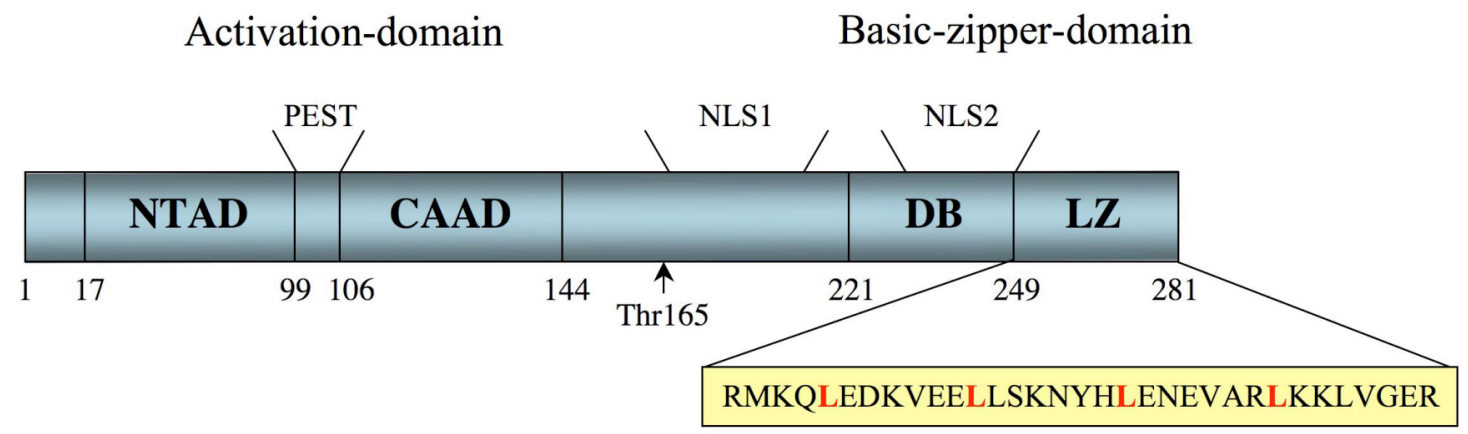

Fig. 4: Schematic structure of Gcn4p.

The transcription factor Gcn4p comprises 281 amino acids and consists of an $\underline{N}$-terminal activation domain (NTAD, aa 17 - 98), a central acidic activation domain (CAAD, aa 107 144), a DNA binding domain (DB, aa 221 - 249) and a dimerization domain (LZ, leucine zipper, aa 249 - 281). The PEST region (aa 99 - 106) spans between both N-terminal domains, which is responsible for the instability of the protein. Threonine 165 represents a site of phosphorylation for the protein kinase Pho85p, which is necessary for rapid protein degradation. The nuclear localization sequences NLS1 (aa 167 - 200) and NLS2 (aa 231 - 249) are required for nuclear import of Gen $4 p$. 


\subsubsection{Translational regulation of $G \mathrm{cn} 4 \mathrm{p}$}

The amount of Gen $4 p$ in the cell is controlled by multiple mechanisms and the translational control is herein an important step (Fig. 5). The regulation of GCN4 mRNA translation in the cytoplasm is mediated by four small upstream open reading frames (uORFs) present in its 5'-untranslated region (Hinnebusch, 1984; Thireos et al., 1984). When amino acids are abundant these uORFs prevent the translation of GCN4 mRNA by limiting the flow of scanning ribosomes from the cap site to the GCN4 initiation codon (Hinnebusch, 1997, 2005). The first and the fourth uORF are sufficient for nearly wild type translational control, whereas the second and the third uORF have only weak influence on GCN4 translation (Mueller and Hinnebusch, 1986). Translational initiation starts with binding of the small 40S ribosomal subunit to the capped 5'-end of the GCN4 mRNA and results in a competent $43 \mathrm{~S}$ pre-initiation complex consisting of the small ribosomal subunit and a ternary complex (eIF2-GTP and the initiation tRNA (Met-tRNA $\left.{ }_{i}^{\text {Met }}\right)$ ). This pre-initiation complex starts downstream migration and at the AUG start codon of uORF1 teams up with the $60 \mathrm{~S}$ ribosomal subunit to form an $80 \mathrm{~S}$ initiation complex and in turn translation of uORF1 is initiated. During this process, the GTP bound to eIF2 is hydrolyzed resulting in an inactive eIF2GDP binary complex. Accordingly, the $80 \mathrm{~S}$ ribosome dissociates at the stop codon of uORF1 from the mRNA and about half of the small ribosomal subunits remain attached to the GCN4 mRNA. The guanine nucleotide exchange factor eIF2B has to recycle eIF2-GDP to eIF2-GTP before the 40S ribosomal subunit reaches uORF4 to re-initiate translation. After translation of uORF4 the $80 \mathrm{~S}$ dissociates again, preventing therefore translation of the real GCN4-ORF.

Starving or stress conditions lead to an accumulation of uncharged tRNAs in the cell which in turn activate the C-terminal histidyl-tRNA synthetase (HisRS) related domain of the sensor kinase Gcn2p (Dever et al., 1992; Lanker et al., 1992). For full activation of Gen2p, the N-terminal protein kinase domain has to interact with the Gcn1p-Gen20p protein complex (Garcia-Barrio et al., 2000; Sattlegger and Hinnebusch, 2005). Activated Gen2p phosphorylates the $\alpha$-subunit of eIF2-GDP on Ser51, which inhibits the guanine nucleotide exchange factor eIF2B and thus prevents recycling of eIF2-GDP to eIF2-GTP. Consequently, the amounts of ternary complexes are reduced and as a consequence many ribosomes scan the distance between uORF1 and uORF2 without rebinding the ternary complex. The bypass of uORF4 enables the ribosomes to 
re-initiate at the AUG start codon of the GCN4-ORF. Therefore, uORF1 is described as positive regulator for translation because translational initiation of GCN4 is increased (Hinnebusch, 1997, 2005). In contrast, global protein synthesis is inhibited under such conditions to save nutrient resources. Cell division processes are also reduced.

A

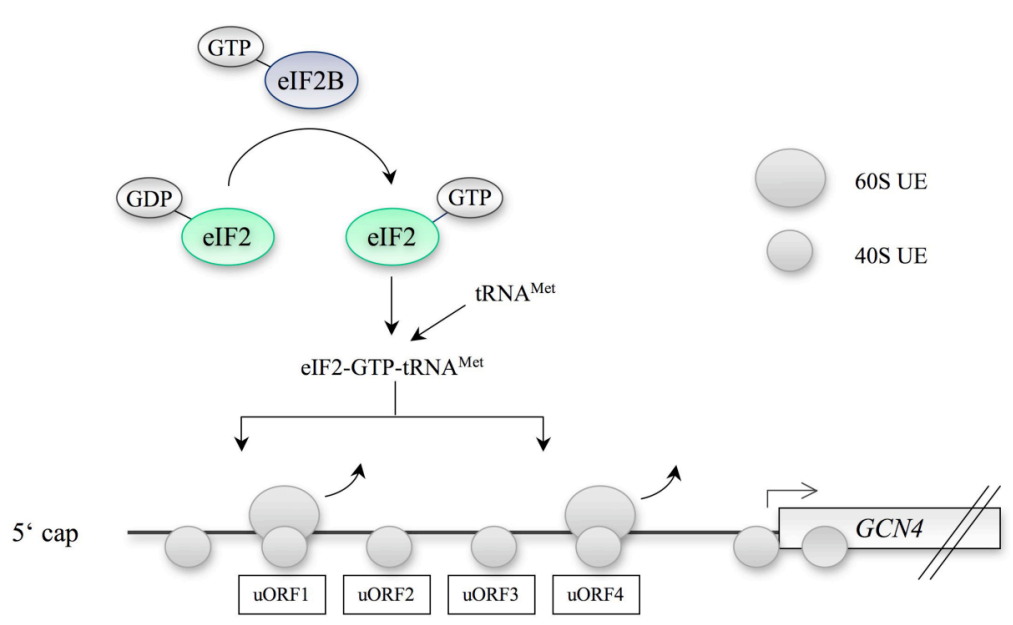

B

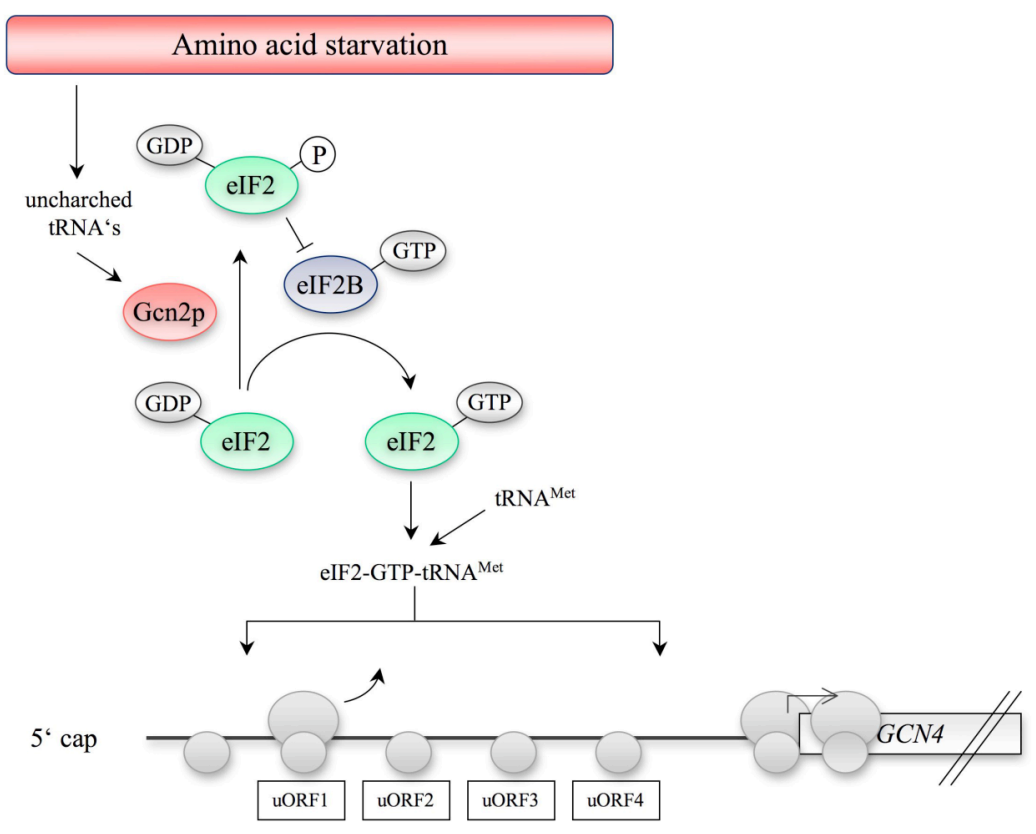

Fig. 5: Translational control of GCN4 expression in S. cerevisiae.

(A) Under non-starvation conditions high levels of ternary complexes (eIF2-GTP-tRNA ${ }^{\mathrm{Met}}$ ) result in a re-initiation of translation at uORF4 whereas the real GCN4-ORF is not translated. This is due to the dissociation of the $80 \mathrm{~S}$ ribosome, which happens after translation of uORF1 and uORF4.

(B) Amino acid starvation leads to an accumulation of uncharged tRNAs inside the cell which are in turn recognized by the sensor kinase Gcn2p. Activated Gen2p thus inactivates the $\alpha$-subunit of eIF2-GDP by phosphorlyation. This reduction leads to low levels of ternary complexes and that followed delayed re-initiation of the reassembled ribosome at uORF4. Thereupon, ribosomes bypass UORF4 and initiate GCN4 translation. 
A similar regulation was described for CpcA and ATF4, the Gcn4p homologues proteins in Aspergilli spp. and mammals. In response to stress stimuli phosphorylated eIF $2 \alpha$ accumulates in the cell resulting in a bypass of uORF2 and thus uORF1 acts here also as positive regulator. Beside $m G c n 2 p$ (mammalian Gcn2p) three further kinases exist in mammals, which are able to phosphorylate eIF2 $\alpha$ upon different stress conditions such as amino acid starvation, ER stress and virus infections (Harding et al., 2000; Hinnebusch, 2005).

\subsubsection{Regulation of Gen4 protein stability}

The level of Gen $4 p$ is not only regulated by a translational control in the cytoplasm but also underlies a tight protein stability control in the nucleus (Pries et al., 2002). Under non-starvation conditions Gen $4 p$ is a highly unstable protein with a half life of only a few minutes, whereas a limitation of amino acids increases the Gcn $4 p$ half life to up to 20 minutes (Kornitzer et al., 1994). Its degradation is initiated by phosphorylation which is followed by the ubiquitin-proteasome system (Irniger and Braus, 2003). Two cyclin-dependent kinases (CDK), Pho85p and Srb10p, can initiate the Gcn4p degradation pathway (Meimoun et al., 2000; Chi et al., 2001). For activation of CDKs specific cyclin subunits are required whereby the specificity to the respective substrate is mediated (Jeffrey et al., 1995; Huang et al., 1998). The specific cyclins that mediate Gcn $4 p$ degradation in sated $S$. cerevisiae cells are Pcl5p and Srb11p (Shemer et al., 2002). The initial step of rapid Gcn4p turnover in sated cells is the phosphorylation of Gen $4 p$ at specific residues by the CDKs Pho85p and Srb10p in interaction with their specific cyclins. Phosphorylation marks Gcn4p for Lys48-poly-ubiquitination mediated by the $\mathrm{SCF}^{\mathrm{Cdc} 4} \mathrm{E} 3$ ubiquitin ligase complex. The ubiquitin system ligates ubiquitin via an isopeptide bond to an internal lysine residue on the target protein. The specific Gcn4p E2 ubiquitin conjugating enzyme is Cdc34p which interacts with the ubiquitin ligase $\mathrm{SCF}^{\mathrm{Cdc} 4}$. Finally the polyubiquitinated $\mathrm{Gcn} 4 \mathrm{p}$ is degraded by the $26 \mathrm{~S}$ proteasome (Kornitzer et al., 1994; Meimoun et al., 2000). This process is mediated by polyubiquitin receptors which bind to ubiquitinated proteins and target them to the $26 \mathrm{~S}$ proteasome for degradation (Mayor et al., 2005). Seong and co-workers identified the polyubiquitin receptor Rpn10p as receptor for ubiquitinated Gen4p (Seong et al., 2007). In addition to these specific phosphorylation and ubiquitination sites, a PEST region located between both activation domains is also responsible for the rapid turnover of 
Gen $4 p$ in sated cells. A deletion of this region results in stabilized Gen $4 p$ (Kornitzer et al., 1994).

Srb10p-dependent phosphorylation is constitutive and occurs independently of the availability of amino acids whereas phosphorylation by Pho85p-Pcl5p depends on the availability of amino acids (Meimoun et al., 2000; Chi et al., 2001). When amino acids are limited, Gcn $4 p$ gets stabilized with an increased half life of up to 20 minutes (Kornitzer et al., 1994). The dissociation of the Pho85p-Pcl5p complex was identified as initial step leading to a stabilization of Gcn4p in amino acid starved cells (Bömeke et al., 2006; Streckfuss-Bömeke et al., 2009). In contrast, other studies predict that metabolic instability of Pcl5p is important for the proper response to amino acid starvation conditions (Shemer et al., 2002). Furthermore, they suggest an autophosporylation-induced degradation of Pcl5p, which ensures that activity of the Pho85p-Pcl5p complex is self-limiting in vivo (Aviram et al., 2008).

\subsection{The 'Unfolded Protein Response'}

The endoplasmic reticulum (ER) represents the first compartment of the secretory pathway and most of all cellular secretory and transmembrane proteins are folded and modified in the ER. Molecular chaperones and folding catalyzes which are resident in the ER lumen ensure the correct folding and oligomerziation (Gething and Sambrook, 1992; Ellgaard and Helenius, 2003). A variety of physiological or environmental stress conditions such as calcium depletion, glucose deprivation, hypoxia or misfolded proteins lead to an accumulation of misfolded or unfolded proteins in the ER lumen, which results in the induction of the 'unfolded protein response' (UPR) (Kozutsumi et al., 1988; Patil and Walter, 2001; Ron, 2002; Schröder and Kaufman, 2005). Misfolded proteins are characterized by exoteric hydrophobic amino acids, which are recognized by the molecular Hsp70-chaperone BiP/Grp78 (binding protein/glucose regulated protein $78-\mathrm{Hsc} 3$, in Drosophila; homologues to Kar2p in S. cerevisiae). At non-stress conditions Bip/Grp78 associates to different receptor proteins present in the ER lumen (Hendershot, 2004). In case of an accumulation of misfolded proteins in response to ER stress BiP preferably binds to the hydrophobic regions of unfolded or incompletely folded proteins to assist their refolding and preventing interactions of these proteins with surrounding molecules (Munro and Pelham, 1986; Bertolotti et al., 2000; Rasheva and Domingos, 2009). As a consequence, 
free receptor proteins are activated and this in turn triggers the UPR leading to a reduction in global protein synthesis and a specific up-regulation of stress-response proteins involved in divers processes including protein translocation, glycosylation, folding and degradation, lipid/inositol metabolism, vesicular trafficking, vacuolar protein sorting and cell wall biogenesis (Prostko et al., 1993; Bertolotti et al., 2000; Travers et al., 2000; Kaufman, 2004). Finally, the UPR represents a signal transduction pathway that communicates between the ER and the nucleus and is conserved from yeast to mammals (Patil and Walter, 2001).

\subsubsection{The UPR system in $S$. cerevisiae}

Conserved from yeast to mammals is the sensing and response pathway that is transduced by Ire1p leading to an up-regulation of transcription levels of approximately 400 genes, i.e., 7\% to 8\% of the yeast genome (Cox et al., 1993; Mori et al., 1993; Travers et al., 2000; van Anken and Braakman, 2005) (Fig. 6).

In $S$. cerevisiae, Ire1p senses the stress and mediates a signalling cascade to upregulate responsive genes through an unusual $H A C l$ mRNA splicing. Irelp encodes a bifunctional transmembrane kinase/endoribonuclease consisting of an unfolded protein sensor domain in the ER lumen, a transmembrane domain and a cytosolic effector domain which contains an intrinsic serine/threonine kinase as well as an endoribonuclease in its C-terminus (Nikawa and Yamashita, 1992; Cox et al., 1993; Mori et al., 1993; Sidrauski and Walter, 1997; Liu et al., 2002). Under basal conditions the chaperone $\mathrm{BiP} / \mathrm{Kar} 2 \mathrm{p}$ associates with the luminal domain of Ire1p thereby preventing homodimerization of Ire1p. Upon ER stress BiP/Kar2p preferably binds to unfolded proteins and thus the $\mathrm{BiP} / \mathrm{Kar} 2 \mathrm{p}$-Ire $1 \mathrm{p}$ complex dissociates and $\mathrm{BiP} / \mathrm{Kar} 2 \mathrm{p}$ is titrated away (Bertolotti et al., 2000; Kimata et al., 2003). Thereupon, Ire1p is able to oligomerize and to trans-autophosphorylate (Shamu and Walter, 1996; Tirasophon et al., 1998) resulting in an activated cytosolic endonuclease effector domain (Sidrauski and Walter, 1997; Kohno, 2007). Though, activation of Ire1p is not dependent on $\mathrm{BiP} / \mathrm{Kar} 2 \mathrm{p}$ dissociation per se, because Ire1p lacking the region specific for $\mathrm{BiP} / \mathrm{Kar} 2 \mathrm{p}$ binding can still sense and signal ER stress (Kimata et al., 2004; Oikawa et al., 2007). In fact, there are indications for activation of Ire $1 \mathrm{p}$ by direct binding to unfolded proteins (Credle et al., 2005; Bernales et al., 2006; Ron and Walter, 2007). 


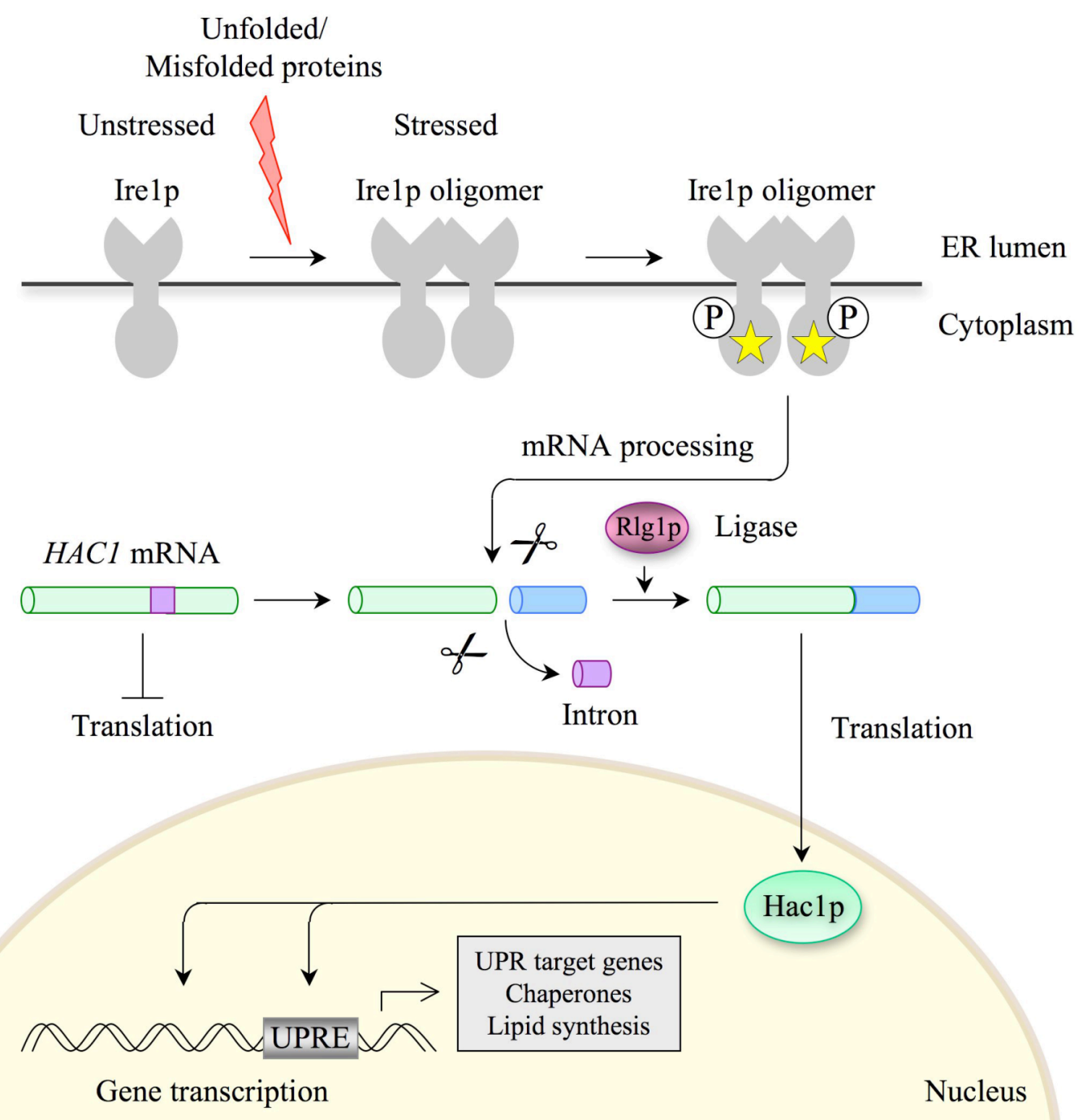

Fig. 6: Schematic illustration of the UPR system in S. cerevisiae.

The transmembrane endonuclease Ire1p is activated by ER stress, which in turn oligomerizes and trans-autophosphorylates. The endonuclease effector domain of Ire1p splices the HACl mRNA in a non-canonical fashion. The tRNA ligase Rlg1p religates the $H A C l$ transcript, which is then efficiently translated to the bZIP transcription factor Haclp. Haclp travels into the nucleus and increases the transcription of its target genes.

However, the only known substrate of Ire $1 p$ endoribonuclease activity is the HAC1 mRNA (Niwa et al., 2005) which encodes for a basic leucine zipper (bZIP) transcription factor that trans-activates target genes of the UPR (Cox and Walter, 1996; Mori et al., 1996; Patil et al., 2004). HAC1 mRNA is constitutively synthesized as a precursor bearing a 252-nucleotide intron that blocks translation as the result of base pairing with a sequence in the 5'-untranslated region of the mRNA (Chapman and Walter, 1997; Kawahara et al., 1997; Ruegsegger et al., 2001). Ire1p recognizes two 'loop' structures in the HAC1 mRNA and the endonuclease effector domain of Ire1p 
splices the HAC1 mRNA. Subsequently, the tRNA ligase Rlg1p religates causing exons to produce the mature, efficiently translated HACl mRNA (Kawahara et al., 1997; Sidrauski and Walter, 1997). As the level of Haclp rises in the cell, the genes that harbor unfolded protein response elements (UPREs) within their promoters are induced at the transcriptional level (Cox and Walter, 1996). In yeast, there are approximately 381 transcriptional targets of the UPR that encode functions ranging from protein folding, protein translocation, and protein transport, to protein degradation within the secretory pathway (Travers et al., 2000). UPRE was first identified as a 22-bp sequence that is necessary und sufficient for the induction of the UPR target gene Kar2p upon ER stress (Mori et al., 1992). This consensus sequence was abbreviated to a partial

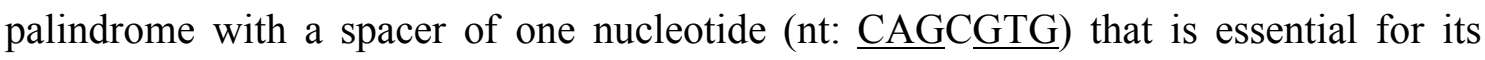
function (Mori et al., 1996). An additional transcriptional induction of $H A C l$ can be achieved by increasing temperature parallel to UPR stress conditions (Leber et al., 2004). This so-called super-UPR (S-UPR) response results in three- to four-fold increased amounts of $H A C 1 \mathrm{mRNA}$ and is independent of Ire1p.

The synthesis of Haclp in response to ER stress is not only regulated on its translational level but also by mechanisms that regulate the rate of turnover of Hac1p, similar as described for the bZIP transcription factor Gen4p (see section 1.3.4). Like Gcn4p, Hac1p is ubiquitinated by the $\mathrm{SCF}^{\mathrm{Cdc} 4} \mathrm{E} 3$ ligase complex resulting in degradation by the $26 \mathrm{~S}$ proteasome. Furthermore, phosphorylation by the CDK Srb10p marks Hac1p for ubiquitination, similar to Gen $4 p$, whereas phosphorylation by Pho $85 p$ was not observed so far. Haclp also contains a PEST region, which is typically for rapid turnover transcription factors (Pal et al., 2007).

In contrast to $S$. cerevisiae, the HACl mRNA of $C$. albicans and higher eukaryotes only contains a 19 to 26 nucleotide long intron, which is also removed by non-canonical splicing in response to ER stress (Cox and Walter, 1996; Mulder et al., 2004; Wimalasena et al., 2008).

\subsubsection{Role of Gen4p in the UPR system of $S$. cerevisiae}

At least 381 UPR target genes were identified in yeast whereas the predicted UPRE-1 consensus sequence ( $\underline{\mathrm{CAGNGTG}}$ ) was absent in most of them (Travers et al., 2000). Thereupon, Patil and co-workers identified two further UPR elements, which are recognized by Hac1p (UPRE-2, consensus sequence TACGTG; UPRE-3, consensus 
sequence AGGAACAAC) (Patil et al., 2004). Apart from its role as transcriptional activator of the GAAC, Gen $4 p$ and its activator Gen2p are required for induction of a majority of UPR target genes upon ER stress. A direct binding of Gen $4 p$ could be demonstrated for UPRE-1 and UPRE-2 whereupon binding to UPRE-1 was Hac1pdependent. In contrast, Gen $4 p$ is not necessary for the regulation of genes without a recognizable UPRE, which represent half of all UPR targets. Both Hac1p and Gen $4 p$ are bZIP transcription factors. Although a binding to DNA as heterodimer was speculated but it has not been proven yet (Patil et al., 2004). A heterodimer consisting of ATF4 and XBP1, the mammalian homologous of Gcn4p and Hac1p, was also not detected so far.

Furthermore, Gcn $4 p$ levels rise soon after induction of ER stress whereas GCN4 translation remains unaffected. Therefore, a stabilization of Gen $4 p$ by forming a heterodimer with Haclp is proposed. Due to the fact that eIF $2 \alpha$ is phosphorylated under ER stress conditions (Cherkasova and Hinnebusch, 2003) an indirect activation of Gen2p in response to ER stress is suggested (van Anken and Braakman, 2005). Although, Gcn $4 p$ levels increase in response to ER stress, it is underdosed to activate the GAAC nevertheless it is supposed that Gcn4p has a kind of 'fine-tuning' function in the UPR system (Patil et al., 2004).

\subsubsection{The UPR system of higher eukaryotes}

The activation of the UPR in mammals is mediated by three distinct ER stress sensors: inositol-requiring protein 1 (IRE1), activating transcription factor 6 (ATF6) and protein kinase RNA (PKR)-like ER kinase (PERK). All of them are integral membrane proteins carrying a sensor domain in the ER lumen and a cytosolic effector domain (Rasheva and Domingos, 2009). The most conserved branch of the UPR is the sensing and response pathway, which is regulated by IRE1. In response to ER stress, IRE1 is activated in the same way as described for yeast and by unconventional splicing a 26 nucleotide long intron is removed from the XBP1-mRNA (X-box binding protein) which is the functional homolog to Haclp in S. cerevisiae. The removal of the intron introduces a frame-shift and results in the active transcription factor XBP1(S) (Yoshida et al., 1998; Shen et al., 2001; Calfon et al., 2002). Enzyme(s), which are responsible for religation of the exons have not been identified in higher eukaryotes. In contrast to yeast, where unspliced $H A C 1$ mRNA represses translation, both the precursor and 
spliced form of XBP1 are translated in higher eukaryotes whereas the unspliced form (XBP1(U)) is not active as transcription factor. In fact, the unspliced form functions as negative feedback regulator of IRE1 signalling by binding and targeting XBP1(S) for degradation (Calfon et al., 2002; Yoshida et al., 2006). While in yeast Ire1p and Hac1p act in a linear pathway this is not the case for higher eukaryotes. Beside XBP1, IRE1 binds to other activators such as Traf2 (tumor necrosis factor receptor-associated factor 2), an upstream activator of the c-JUN N-terminal kinase (JNK) signalling pathway (Urano et al., 2000). In addition, in Drosophila IRE1 promotes the degradation of specific mRNAs encoding ER target proteins which are located to the ER after ER stress to reduce protein synthesis (Hollien and Weissman, 2006). Both processes are independent of XBP1. Recent studies identified 13 novel mRNAs as targets of IRE1 (Oikawa et al., 2010). Furthermore, analysis of the cleavage sites revealed a consensus sequence (CUGCAG) accompanied by a stem-loop structure, which is also present in known cleavage targets, such as XBP1.

Activation of ATF6 (activating transcription factor 6), a founding member of a novel class of metazoan specific ER stress transducers, represents a more rapid response to ER stress. The transmembrane precursor protein ATF6 consists of a cytosolic domain containing a bZIP motif, a transcription activation domain and an ER luminal domain that binds to BiP (Haze et al., 1999; Wang et al., 2000; Yoshida et al., 2000; Shen et al., 2005). Under ER stress, ATF6 is transported from the ER to the Golgi where it is successively cleaved by Golgi resident proteases (Ye et al., 2000). The released cytosolic DNA-binding domain of ATF6 moves to the nucleus and activates the transcription of its target genes (Yoshida et al., 1998; Haze et al., 1999; Kokame et al., 2001).

PERK (PKR-like ER kinase) represents the third ER stress transducer and resembles IRE1. Both PERK and IRE1 are transmembrane proteins consisting of a luminal stress sensing domain and a cytosolic domain with kinase activity. Similar to IRE1, PERK oligomerizes and trans-autophosphorylates upon ER stress, however, unlike IRE1, PERK phosphorylates the $\alpha$-subunit of eukaryotic translation initiation factor 2 (eIF2 $\alpha$ ) (Shi et al., 1998; Shi et al., 1999). As consequence, the global translational rate of newly synthesized proteins is reduced to protect the already stressed ER lumen (Harding et al., 1999). Similar to yeast, phosphorylation of eIF2 $\alpha$ leads to the translational up-regulation of specific mRNAs, such as the transcription factor ATF4 
(activating transcription factor 4), the mammalian homologue of Gcn4p (for more details, see section 1.3.3) (Lu et al., 2004; Vattem and Wek, 2004). Although there are many parallel translational controls upon eIF $2 \alpha$ phosphorylation in all eukaryotes but in contrast, Gen $2 p$ is not localized to the ER in yeast. Admittedly, it is shown that activation of the UPR is incomplete in S. cerevisiae cells deleted for GCN2 (Patil et al., 2004).

The protective mechanisms activated by the UPR are essential for viability of higher eukaryotes and is also involved in differentiation processes. In the case when misfolded proteins are not degraded they can aggregate into insoluble high order structures, which are associated with numerous neurodegenerative human diseases, such as Alzheimer's disease (Koo et al., 1999; Petkova et al., 2002). In contrast, activation of these mechanisms frequently correlates with tumorogenesis. For instance, several UPR downstream targets have been reported to be overexpressed in a variety of human tumors (Lee, 2001; Ma and Hendershot, 2004). Recent studies identified IRE1 as key regulator of angiogenesis and invasion in malignant glioma (Auf et al., 2010). Both XBP1 and PERK are also involved in tumorogenesis (Romero-Ramirez et al., 2004; Bi et al., 2005; Koong et al., 2006). In contrast, ATF4 mediates ER stress-induced cell death of neuroectodermal tumor cells in response to hemotherapeutic agents (Armstrong et al., 2010).

In lower eukaryotes, such as $S$. cerevisiae or $C$. albicans, Hac1p/XBP1 is not essential for viability per se, but for C. albicans plays an important role in regulating the morphology and the expression of genes encoding cell surface proteins during ER stress factors that are important for virulence of this fungal pathogen (Wimalasena et al., 2008). Furthermore, HacA is required for virulence of A. fumigatus (Richie et al., 2009). In contrast, Hac1p/XBP1 represses differentiation processes in $S$. cerevisiae (Schröder et al., 2000). 


\subsection{Aim of this work}

In response to nutrient starvation, the bZIP transcription factor Gcn $4 p$ not only has a metabolic function as activator of the 'general amino acid control' but also is involved in adhesive growth and pseudohyphal development. Both developmental processes are regulated by the cell-surface flocculin Flo11p. One aim of this work was to separate these two functions. Therefore, specific leucines of the leucine zipper of Gcn $4 p$ were substituted and their functionality was determined using GCRE6- and FLO11::lacZ reporter. Developmental consequences were also documented by pseudohyphal development or adhesive growth tests. The stability of the Gen4 mutant proteins was analyzed by promoter shut-off experiments.

In addition, the interplay of Gen $4 p$ and Haclp and therefore the connection between the 'general amino acid control' and the 'unfolded protein response' should be investigated. It is demonstrated that Gcn $4 p$ is required for Hac1p target gene expression under ER stress. Therefore, the role of Hac1p for the control of Gen $4 p$ specific target gene expression in response to amino acid starvation was analyzed using lac $Z$ reporter assays. The influence of Haclp on the expression of FLO11, an unspecific target gene of Gen $4 p$, was also determined by reporter gene expression experiments and phenotypical tests, respectively, and a Haclp-dependet UAS (upstream activation site) in the promoter of FLO11 was defined. The rapid turnover of Haclp bears a resemblance to the degradation of Gcn $4 p$. Therefore so far not documented aspects were examined by protein synthesis shut-off assays. 


\section{MATERIALS AND METHODS}

\subsection{Materials}

\subsubsection{Saccharomyces cerevisiae strains}

All yeast strains used in this study are listed in Table I. They are derivates of the S. cerevisiae $\Sigma 1278$ b genetic background (Gimeno et al., 1992) unless otherwise stated. The hacl and pho85 deletion strains RH3351, RH3352, RH3402, RH3403 and RH3426 were obtained by amplification of the kanamycin resistance cassette from the Euroscarf strain collection (Brachmann et al., 1998) containing sequence homologous to the upand downstream regions of the relevant gene and integration of deletion cassettes by homologous recombination in yeast strains RH2676, RH2816, RH2819 and RH3401. Positive transformants could be selected on YEPD medium supplemented with 200 $\mu \mathrm{g} / \mathrm{ml}$ Geneticin G418 sulfate (CARL ROTH GmbH, Karlsruhe, Germany). For genetic crosses the kanamycin resistance cassette of RH3352 and RH3403 was replaced by a nourseothricin resistance cassette, which was amplified from plasmid pAG25 and transformants (RH3404 and RH3405) could be selected on YEPD medium containing $100 \mu \mathrm{g} / \mathrm{ml}$ Nourseothricin (clonNAT, Werner BIoAgENTS, Jena, Germany). Homoand heterozygous diploid strains RH3412 - RH3416 were obtained by crossing RH2676, RH3351 or RH3402 with strain RH2819, RH3404 or RH3405. Haploid yeast strains RH3360, RH3406, RH3407 and RH3408 were obtained by introducing the FLO11::lacZ::URA3-cassette, using ApaI linearized plasmid pME2213, into the URA3 locus of yeast strains RH2676, RH2816, RH3351 and RH3402. The GCRE6::lacZ::URA3 reporter gene cassette was introduced in the same four haploid yeast strains by transformation with StuI linearized GCRE6::lacZ reporter construct pME1112 to obtain yeast strains RH3363, RH3409, RH3410 and RH3411. The haploid FLO11- and GCRE6::lacZ containing MATa strains were crossed with MAT $\alpha$ strains RH2819, RH3352, RH3404 or RH3405 to produce diploid strains RH3349, RH3350, RH3362 and RH3417 - RH3425. All gene deletions, integrations, or replacements were confirmed by PCR and Southern blot analysis (Southern, 1975). 
Table I. Saccharomyces cerevisiae strains used in this study.

\begin{tabular}{|c|c|c|}
\hline Strain & Genotype & Source \\
\hline BY4741 & $\begin{array}{l}\text { MATa, his } 3:: \text { his } G, \text { leu } 2:: h i s G, \text { met } 15:: \text { his } G, \text { ura } 3:: h i s G \\
\text { (S288c-background) }\end{array}$ & (Brachmann et al., 1998) \\
\hline Y00249 & $\begin{array}{l}\text { MATa, his } 3:: \text { his } G, \text { leu } 2:: \text { his } G, \text { met } 15:: \text { his } G, \text { ura } 3: \text { his } G \\
\text { Dgcn } 4: \text { kanMX4 (S288c-background) }\end{array}$ & (Brachmann et al., 1998) \\
\hline Y02797 & 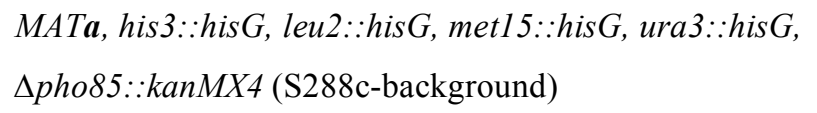 & (Brachmann et al., 1998) \\
\hline Y05650 & $\begin{array}{l}\text { MATa, his } 3:: \text { his } G, \text { leu } 2:: \text { his } G, \text { met } 15:: \text { his } G, \text { ura } 3:: h i s G \\
\text { Dhacl }:: \text { kanMX4 (S288c-background) }\end{array}$ & (Brachmann et al., 1998) \\
\hline RH2398 & 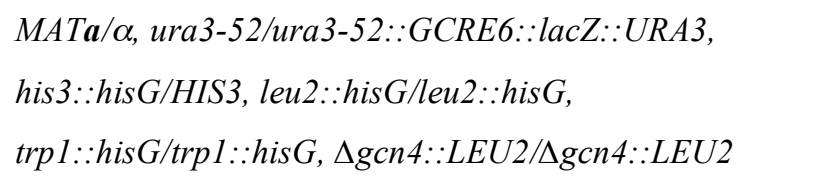 & (Grundmann et al., 2001) \\
\hline RH2520 & MATa, ura3-52 (S288c-background) & (Grundmann et al., 2001) \\
\hline RH2656 & 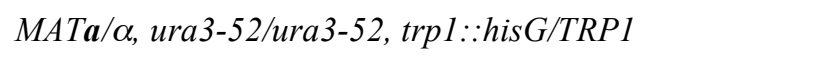 & (Braus et al., 2003) \\
\hline RH2658 & 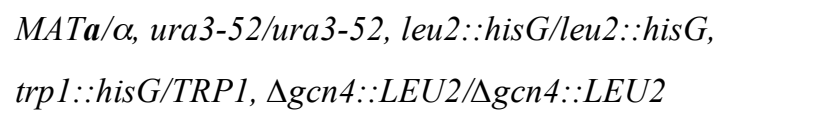 & (Braus et al., 2003) \\
\hline RH2661 & 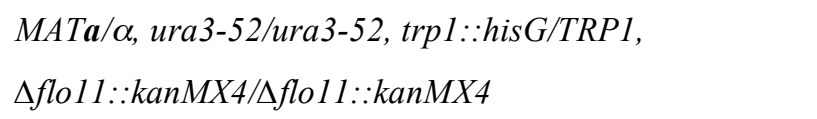 & (Braus et al., 2003) \\
\hline RH2676 & MATa, ura3-52, leu2::hisG, trp1::hisG, $\Delta g c n 4: \because L E U 2$ & Grundmann, pers. comm. \\
\hline RH2681 & MATa, ura3-52, trp1::hisG, $\Delta$ flo11::kanMX4 & Grundmann, pers. comm. \\
\hline RH2693 & $\begin{array}{l}\text { MAT } \alpha, \text { ura3-52::FLO11::lacZ::URA3, leu } 2:: h i s G \\
\operatorname{trp} 1: \because h i s G, \Delta g c n 4: \because L E U 2\end{array}$ & Grundmann, pers. comm. \\
\hline RH2694 & 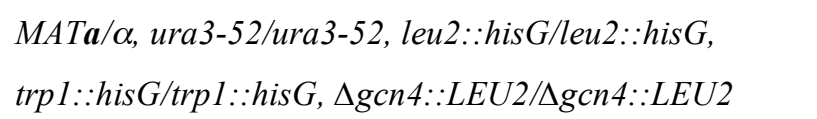 & Grundmann, pers. comm. \\
\hline RH2695 & 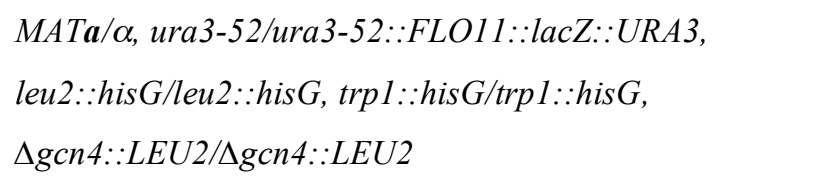 & Gundmann, pers. comm. \\
\hline RH2697 & 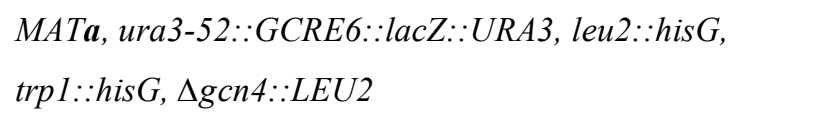 & Grundmann, pers. comm. \\
\hline RH2816 & MATa, ura3-52, his3::hisG::HIS3, trp1::hisG & (Strittmatter et al., 2006) \\
\hline RH2819 & 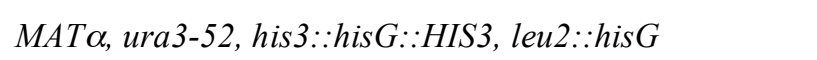 & (Strittmatter et al., 2006) \\
\hline
\end{tabular}


Table I. Saccharomyces cerevisiae strains used in this study, continued.

\begin{tabular}{|c|c|c|}
\hline Strain & Genotype & Source \\
\hline RH3278 & 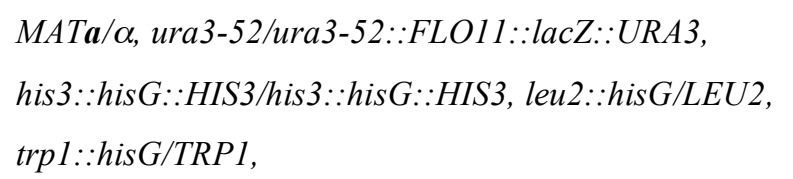 & (Bömeke, 2006) \\
\hline RH3279 & MAT $\alpha$, ura3-52, his $3::$ hisG, trp $1::$ his $G, \Delta p c l 5: \because H I S 5$ & (Bömeke, 2006) \\
\hline RH3349 & 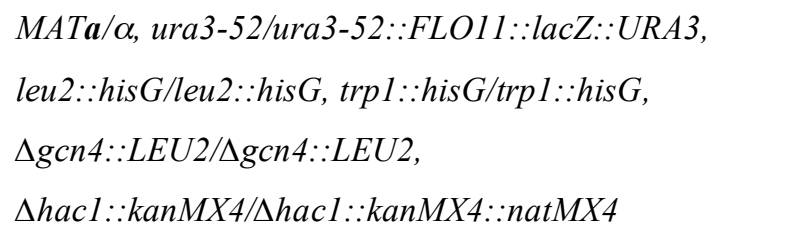 & This study \\
\hline RH3350 & 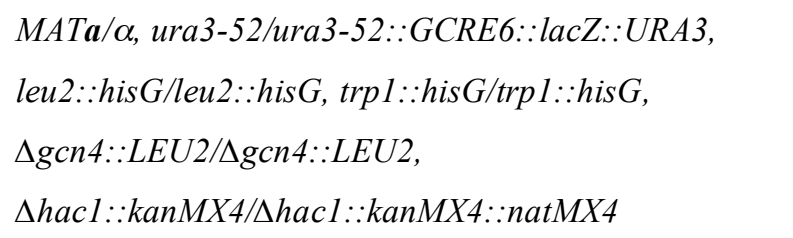 & This study \\
\hline RH3351 & MATa, ura3-52, trp $1: \because h i s G, \Delta$ hacl $: \because \operatorname{kan} M X 4$ & This study \\
\hline RH3352 & MAT $\alpha$, ura3-52, leu $2:: h i s G$, hacl $:: \operatorname{kan} M X 4$ & This study \\
\hline RH3360 & $\begin{array}{l}\text { MATa, ura3-52::FLO11::lacZ::URA3, trp } 1: \because \text { hisG, } \\
\text { Dhac1 ::kanMX4 }\end{array}$ & This study \\
\hline RH3362 & 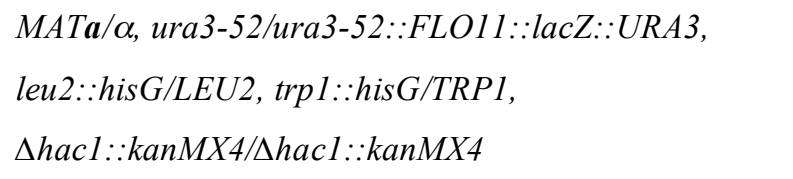 & This study \\
\hline RH3363 & $\begin{array}{l}\text { MATa, ura3-52::GCRE6::lacZ::URA3, trp } 1:: \text { hisG, } \\
\text { Shac1::kanMX4 }\end{array}$ & This study \\
\hline RH3401 & 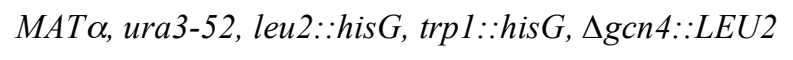 & Grundmann, pers. comm. \\
\hline RH3402 & $\begin{array}{l}\text { MATa, ura3-52, leu2::hisG, trp } 1:: \text { hisG, } \Delta g c n 4: \because L E U 2, \\
\Delta h a c 1:: \operatorname{kanMX} 4\end{array}$ & This study \\
\hline RH3403 & $\begin{array}{l}\text { MAT } \alpha, \text { ura3-52, leu } 2:: h i s G, \operatorname{trp} 1:: h i s G, \Delta g c n 4:: L E U 2, \\
\Delta h a c 1:: \text { kanMX4 }\end{array}$ & This study \\
\hline RH3404 & MAT $\alpha$, ura3-52, leu2::hisG, $\Delta$ hac1::kanMX4::natMX4 & This study \\
\hline RH3405 & 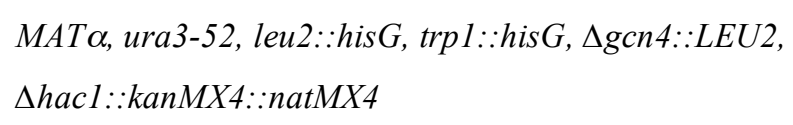 & This study \\
\hline RH3406 & MATa, ura3-52::FLO11::lacZ::URA3, trp1::hisG & This study \\
\hline RH3407 & $\begin{array}{l}\text { MATa, ura3-52::FLO11::lacZ::URA3, leu } 2:: \text { his } G \\
\operatorname{trp1}: \because \text { hisG, } \Delta \text { gcn } 4: \because L E U 2\end{array}$ & This study \\
\hline
\end{tabular}


Table I. Saccharomyces cerevisiae strains used in this study, continued.

\begin{tabular}{|c|c|c|}
\hline Strain & Genotype & Source \\
\hline RH3408 & $\begin{array}{l}\text { MATa, ura3-52::FLO11::lacZ::URA3, leu } 2: \text { hisG, } \\
\text { trp1::hisG, } \Delta \text { gcn } 4:: L E U 2, \text { Lhac1::kanMX4 }\end{array}$ & This study \\
\hline RH3409 & MATa, ura3-52::GCRE6::lacZ::URA3, trp $1: \because$ hisG & This study \\
\hline RH3410 & $\begin{array}{l}\text { MATa, ura3-52::GCRE6::lacZ::URA3, leu2::hisG, } \\
\operatorname{trp} 1: \because \text { hisG, } \Delta \text { gcn } 4: \because L E U 2\end{array}$ & This study \\
\hline RH3411 & $\begin{array}{l}\text { MATa, ura3-52::GCRE6::lacZ::URA3, leu2::hisG, } \\
\operatorname{trp1}: \because \text { hisG, } \Delta \text { gcn } 4: \because L E U 2, \text { Lhac1 ::kanMX4 }\end{array}$ & This study \\
\hline RH3412 & 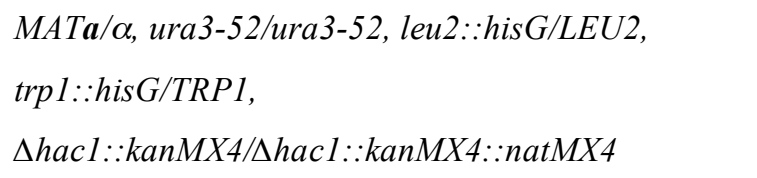 & This study \\
\hline RH3413 & 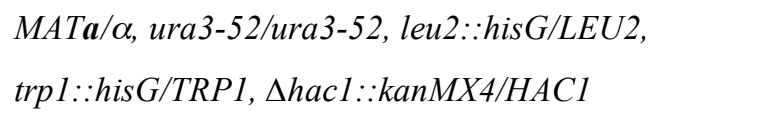 & This study \\
\hline RH3414 & 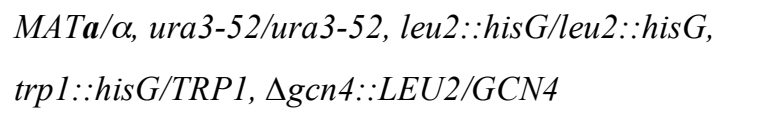 & This study \\
\hline RH3415 & 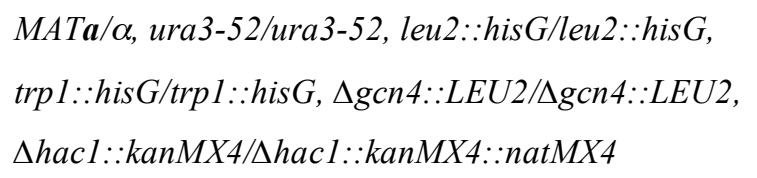 & This study \\
\hline RH3416 & 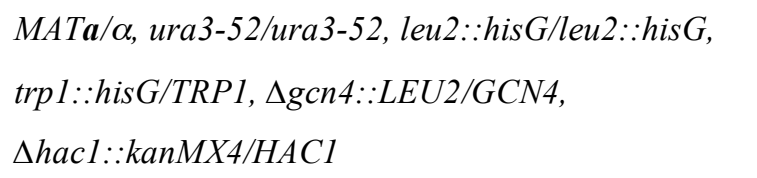 & This study \\
\hline RH3417 & 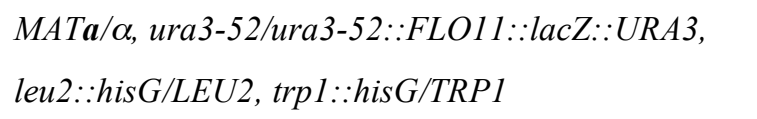 & This study \\
\hline RH3418 & 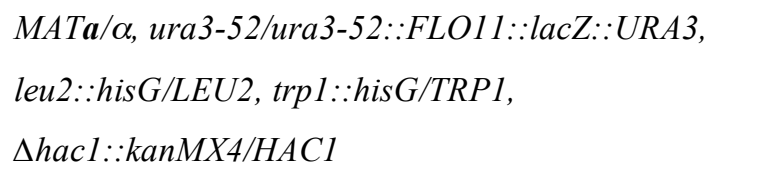 & This study \\
\hline RH3419 & 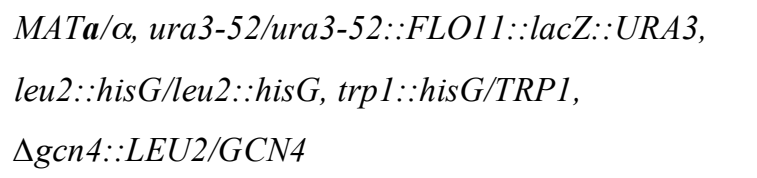 & This study \\
\hline RH3420 & 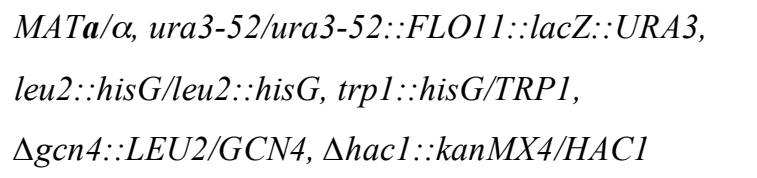 & This study \\
\hline RH3421 & 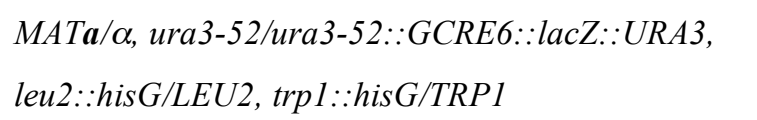 & This study \\
\hline
\end{tabular}


Table I. Saccharomyces cerevisiae strains used in this study, continued.

\begin{tabular}{|c|c|c|}
\hline Strain & Genotype & Source \\
\hline RH3422 & 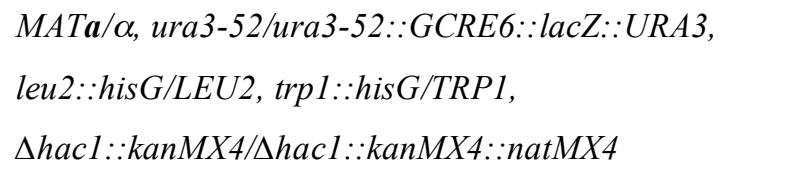 & This study \\
\hline RH3423 & 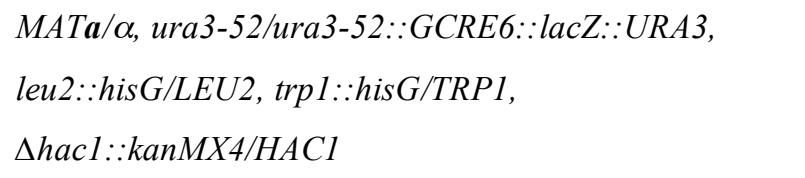 & This study \\
\hline RH3424 & 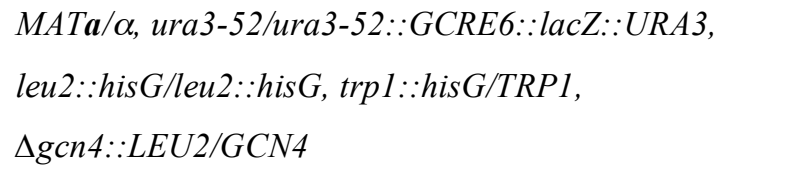 & This study \\
\hline RH3425 & 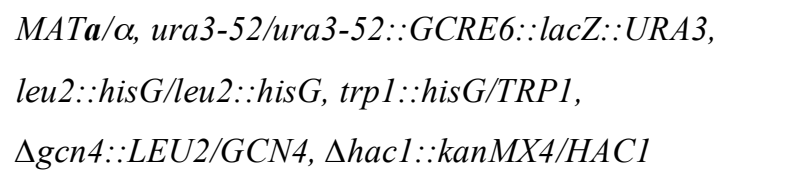 & This study \\
\hline RH3426 & MATa, ura3-52, trp $1:: h i s G, \Delta p h o 85:: k a n M X 4$ & This study \\
\hline S001 & $\begin{array}{l}\text { W303-1A wild type strain } \\
\text { MATa, ade2-1, trp1-1, can1-100, leu2-3,112, his3-11, } \\
\text { 15, ura3, GAL }\end{array}$ & (Dieckhoff et al., 2004) \\
\hline S099 & $M A T \alpha, u b c 9:: T R P 1, u b c 9-2 / \Lambda E Y 2$ (W303-background) & (Dieckhoff et al., 2004) \\
\hline S542 & $M A T \alpha$, smt3-331 (W303-background) & (Dieckhoff et al., 2004) \\
\hline
\end{tabular}

\subsubsection{Bacterial strains}

The Escherichia coli strain DH5 $\alpha$ was used for preparation of plasmid DNA [F',

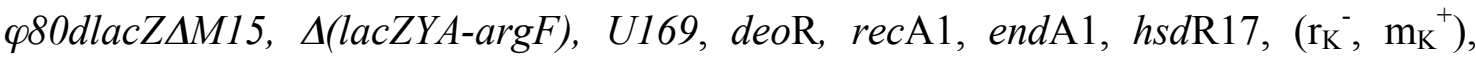
supE44, $\lambda$-, thi-1, gyrA96, relA1] (Woodcock et al., 1989). E. coli strain FHK12 was employed for dimerization studies using the ToxR system $\left[\mathrm{F}^{\prime}, \operatorname{lac}^{\mathrm{q}} \operatorname{lacZ} \mathrm{Z} \mathrm{M} 15\right.$, $\operatorname{proA}^{+} \mathrm{B}^{+}$, ara $, \Delta($ lac-pro $\mathrm{AB}), \operatorname{rpsL},\left(\phi 80 \mathrm{~d} l a c \mathrm{Z} \Delta \mathrm{M} 15\right.$, attB::(ctx::lacZ), (amp $\left.\left.{ }^{r}\right)\right]($ Kolmar et al., 1995b).

\subsubsection{Plasmids}

All plasmids used in this study are listed in Table II. Plasmid pME2898 expressing wild type GCN4 was constructed by amplifying the GCN4-ORF with Pfu polymerase from plasmid pME2214, and introducing it as NheI/AatII-fragment into 
equally digested pBluescript vector. The mutagenesis of plasmids pME2899, and pME3373 - pME3377 was arranged by using the 'QuickChange ${ }^{\circledR}$ site-directed mutagenesis Kit' (Stratagene, La Jolla, USA). Instead of PfuUltra HF DNA Polymerase (Promega, Mannheim, Germany) the KOD Hifi DNA Polymerase (Novagen, Darmstadt, Germany) was used to insert the substitutions. Plasmid pME2898 was amplified with two oligonucleotide primers (listed in Table III), which are complementary to the reverse strand of the vector and contain the favored substitutions. Plasmids pME2901 and pME3378 - pME3382, expressing different substituted forms of GCN4 under the control of the GCN4 promoter, were obtained by digestion of the corresponding pBluescript plasmids with NheI and AatII and replacing the respective GCN4 fragments in pME2214. Plasmids pME2923, pME2925, pME3383, pME3384, and pME3386 expressing a three-fold myc epitope tagged version of the GCN4 alleles under the control of the GAL1 promoter were obtained by amplifying the different GCN4 alleles with $P f u$ polymerase from plasmids pME2214, pME2901, pME3378, pME3379, and pME3381 and inserting them as NheI/ClaIfragments into SpeI/ClaI restricted p426GAL1. A 120 bp BglII-fragment carrying the three-fold myc epitope was introduced into a BglII restriction site directly after the ATG of Gen4p, Gen4p ${ }^{\mathrm{L} 267 \mathrm{~S}}, \mathrm{Gcn} 4 \mathrm{p}^{\mathrm{L} 253 \mathrm{G}}, \mathrm{Gcn} 4 \mathrm{p}^{\mathrm{L} 267 \mathrm{G}}$, and Gen4 $\mathrm{p}^{\mathrm{L} 267 \mathrm{~A}}$, respectively. Wild type GCN4 and $G C N 4^{L 253 G}$ were amplified from pME2923 or pME3383 and ligated as SpeI/ClaI-fragment into equally restricted plasmid p424GAL1 to get pME2918 or pME3388. Plasmid pME3389 was constructed by substitution of leucine 267 with serine in the leucine zipper domain of pHKToxR'MalE/ZIP.

Table II. Plasmids used in this study.

\begin{tabular}{|c|c|c|}
\hline Plasmid & Description & Source \\
\hline B3782 & $3 \mathrm{~kb}-F L O 11:: l a c Z$ in YEp355 & (Rupp et al., 1999) \\
\hline pBKSII ${ }^{\circledast}$ & $2.96 \mathrm{~kb}$ vector, $A m p^{R}$, lac $Z$, ori & $\begin{array}{l}\text { STRATAGENE (La Jolla, } \\
\text { USA) }\end{array}$ \\
\hline pRS314 & $T R P, C E N, A m p^{R}$, ori & $\begin{array}{l}\text { (Sikorski and Hieter, } \\
\text { 1989) }\end{array}$ \\
\hline pRS424 & $T R P, 2 \mu m, A m p^{R}$, ori & $\begin{array}{l}\text { (Sikorski and Hieter, } \\
1989 \text { ) }\end{array}$ \\
\hline
\end{tabular}


Table II. Plasmids used in this study, continued.

\begin{tabular}{|c|c|c|}
\hline Plasmid & Description & Source \\
\hline pRS426 & URA3, $2 \mu m, A m p^{R}$, ori & $\begin{array}{l}\text { (Sikorski and Hieter, } \\
\text { 1989) }\end{array}$ \\
\hline p424GAL1 & $\begin{array}{l}\text { pRS } 424 \text { containing } G A L 1 \text { promoter, } C Y C 1 \\
\text { terminator }\end{array}$ & (Mumberg et al., 1994) \\
\hline p426GAL1 & $\begin{array}{l}\text { pRS } 426 \text { containing } G A L 1 \text { promoter, } C Y C 1 \\
\text { terminator }\end{array}$ & (Mumberg et al., 1994) \\
\hline p426MET25 & $\begin{array}{l}\text { pRS426 containing } M E T 25 \text { promoter, } C Y C 1 \\
\text { terminator }\end{array}$ & (Mumberg et al., 1994) \\
\hline p 180 & $\begin{array}{l}\text { GCN4::lacZ reporter construct on centromere } \\
\text { vector (URA3) }\end{array}$ & (Hinnebusch, 1985) \\
\hline pAG25 & natMX4-cassettte in pFA6 & $\begin{array}{l}\text { (Goldstein and } \\
\text { McCusker, 1999) }\end{array}$ \\
\hline pLG669Z & lacZ shuttle vector & $\begin{array}{l}\text { (Guarente and Ptashne, } \\
\text { 1981) }\end{array}$ \\
\hline $\begin{array}{l}\mathrm{p} F L O 11-2 / 1 \text { to } \\
\mathrm{p} F L O 11-15 / 14\end{array}$ & $\begin{array}{l}440 \mathrm{bp} \text { sequence elements cloned into pLG669Z } \\
\text { from }-1 \text { to }-420 \mathrm{bp},-180 \text { to }-620 \mathrm{bp},-380 \text { to }-1020 \\
\text { bp until }-2580 \text { to }-2980 \mathrm{bp}\end{array}$ & (Rupp et al., 1999) \\
\hline pHK vector series & $\begin{array}{l}\text { Expression vector for } \beta \text {-galactosidase assays; } \\
P / O_{\text {toxR }}, \text { Fl ori, ColE1 ori, } \mathrm{Cm}^{R}\end{array}$ & (Kolmar et al., 1994) \\
\hline pHKToxR'MalE & toxR'malE fusion gene in $\mathrm{pHK}, \mathrm{Cm}^{R}$ & (Kolmar et al., 1995b) \\
\hline pHKToxR'MalE/ZIP & toxR'malE/ZIP fusion gene in $\mathrm{pHK}, \mathrm{Cm}^{R}$ & (Kolmar et al., 1995b) \\
\hline pHKToxR'REI-T39K & toxR'rei-T39K fusion gene in $\mathrm{pHK}, \mathrm{Cm}^{R}$ & (Kolmar et al., 1995a) \\
\hline pME1092 & $2.8 \mathrm{~kb} G C N 4$ fragment in $\mathrm{pRS} 314$ & (Albrecht et al., 1998) \\
\hline pME1112 & Integrative $G C R E 6:: l a c Z$ reporter construct & (Albrecht et al., 1998) \\
\hline pME2212 & pLG669Z without UAS & (Braus et al., 2003) \\
\hline pME2213 & Integrative $F L O 11: \because$ lacZ reporter construct & Grundmann, pers. comm. \\
\hline pME2214 & pME1092 with new restriction sites & Grundmann, pers. comm. \\
\hline pME2846 & MET25prom-PCL5-GFP-fusion in p426MET25 & $\begin{array}{l}\text { (Streckfuss-Bömeke } e t \\
a l ., 2009)\end{array}$ \\
\hline pME2898 & GCN4 wt fragment in pBKSII & This study \\
\hline
\end{tabular}


Table II. Plasmids used in this study, continued.

\begin{tabular}{|c|c|c|}
\hline Plasmid & Description & Source \\
\hline pME2899 & $G C N 4^{L 267 S}$ fragment in pBKSII & This study \\
\hline pME2901 & GCN4prom-GCN4 ${ }^{L 267 S}-G C N 4$ term in pRS314 & This study \\
\hline pME2918 & GAL1prom-myc ${ }^{3}-G C N 4$-fusion in $\mathrm{p} 424 \mathrm{GAL} 1$ & This study \\
\hline pME2923 & GAL1prom-myc ${ }^{3}-G C N 4$-fusion in $\mathrm{p} 426 \mathrm{GAL} 1$ & This study \\
\hline pME2925 & $G A L 1$ prom-myc $c^{3}-G C N 4^{L 267 S}$-fusion in p426GAL1 & This study \\
\hline pME3373 & $G C N 4^{L 253 G}$ fragment in pBKSII & This study \\
\hline pME3374 & $G C N 4^{L 267 G}$ fragment in pBKSII & This study \\
\hline pME3375 & $G C N 4^{L 267 T}$ fragment in pBKSII & This study \\
\hline pME3376 & $G C N 4^{L 267 A}$ fragment in pBKSII & This study \\
\hline pME3377 & $G C N 4^{L 267 C}$ fragment in pBKSII & This study \\
\hline pME3378 & GCN4prom-GCN4 ${ }^{L 253 G}-G C N 4$ term in pRS314 & This study \\
\hline pME3379 & GCN4prom-GCN4 ${ }^{L 267 G}-G C N 4$ term in pRS314 & This study \\
\hline pME3380 & GCN4prom-GCN4 ${ }^{L 267 T}-G C N 4$ term in pRS314 & This study \\
\hline pME3381 & GCN4prom-GCN4 ${ }^{L 267 A}-G C N 4$ term in pRS314 & This study \\
\hline pME3382 & GCN4prom-GCN4 ${ }^{L 267 C}-G C N 4$ term in pRS314 & This study \\
\hline pME3383 & $G A L 1$ prom-myc $c^{3}-G C N 4^{L 253 G}$-fusion in p426GAL1 & This study \\
\hline pME3384 & $G A L 1$ prom-myc $c^{3}-G C N 4^{L 267 G}$-fusion in p426GAL1 & This study \\
\hline pME3386 & GAL1prom-myc $c^{3}-G C N 4^{L 267 A}$-fusion in p426GAL1 & This study \\
\hline pME3388 & $G A L 1$ prom-myc $c^{3}-G C N 4^{L 253 G}$-fusion in p424GAL1 & This study \\
\hline pME3389 & $\begin{array}{l}\text { pHKToxR'MalE/ZIP containing amino acid } \\
\text { substitution L267S }\end{array}$ & This study \\
\hline
\end{tabular}




\subsubsection{Oligonucleotides}

The oligonucleotides used in this study are listed in Table III.

Table III. List of oligonucleotides used in this study.

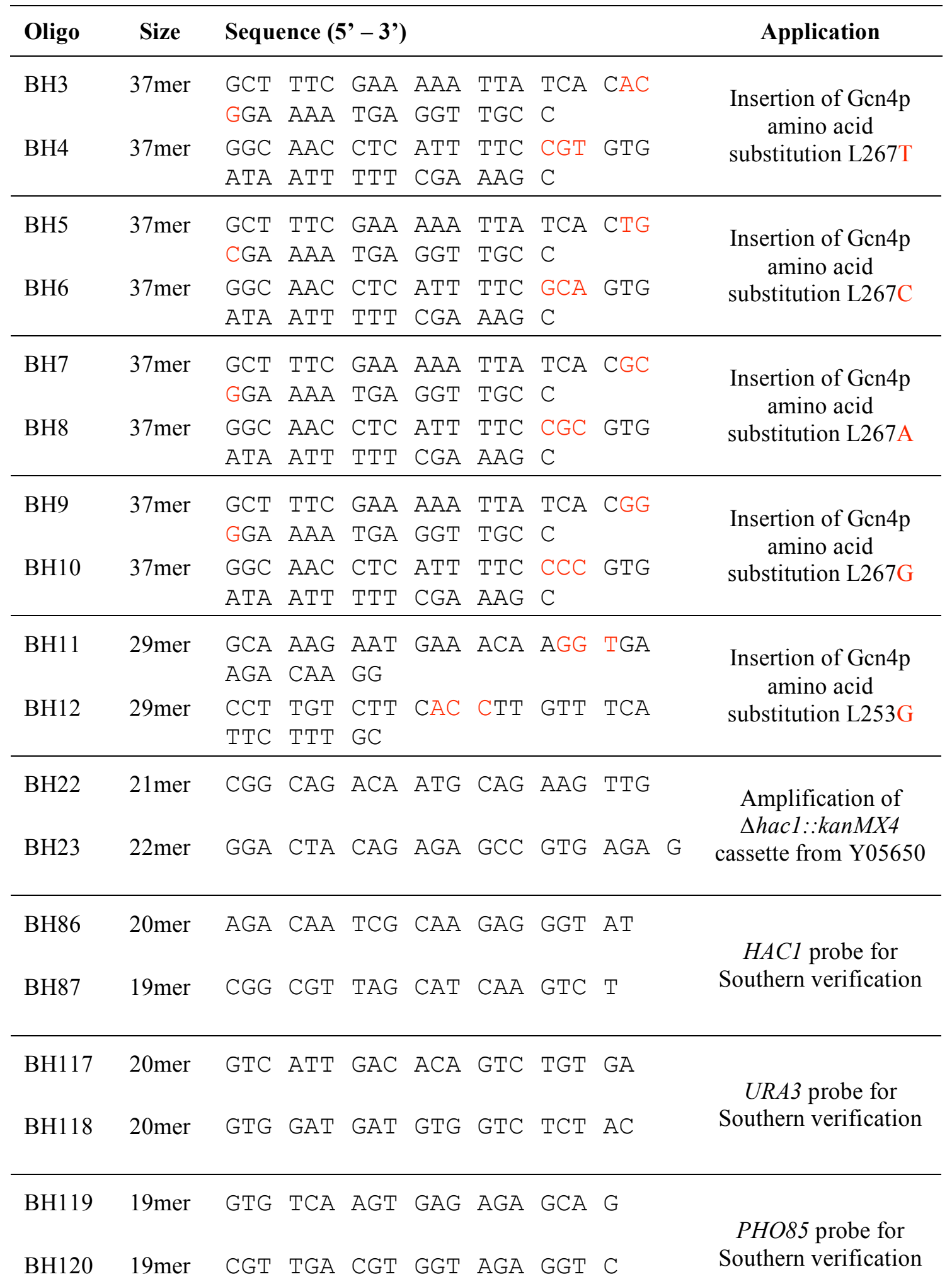


Table III. List of oligonucleotides used in this study, continued.

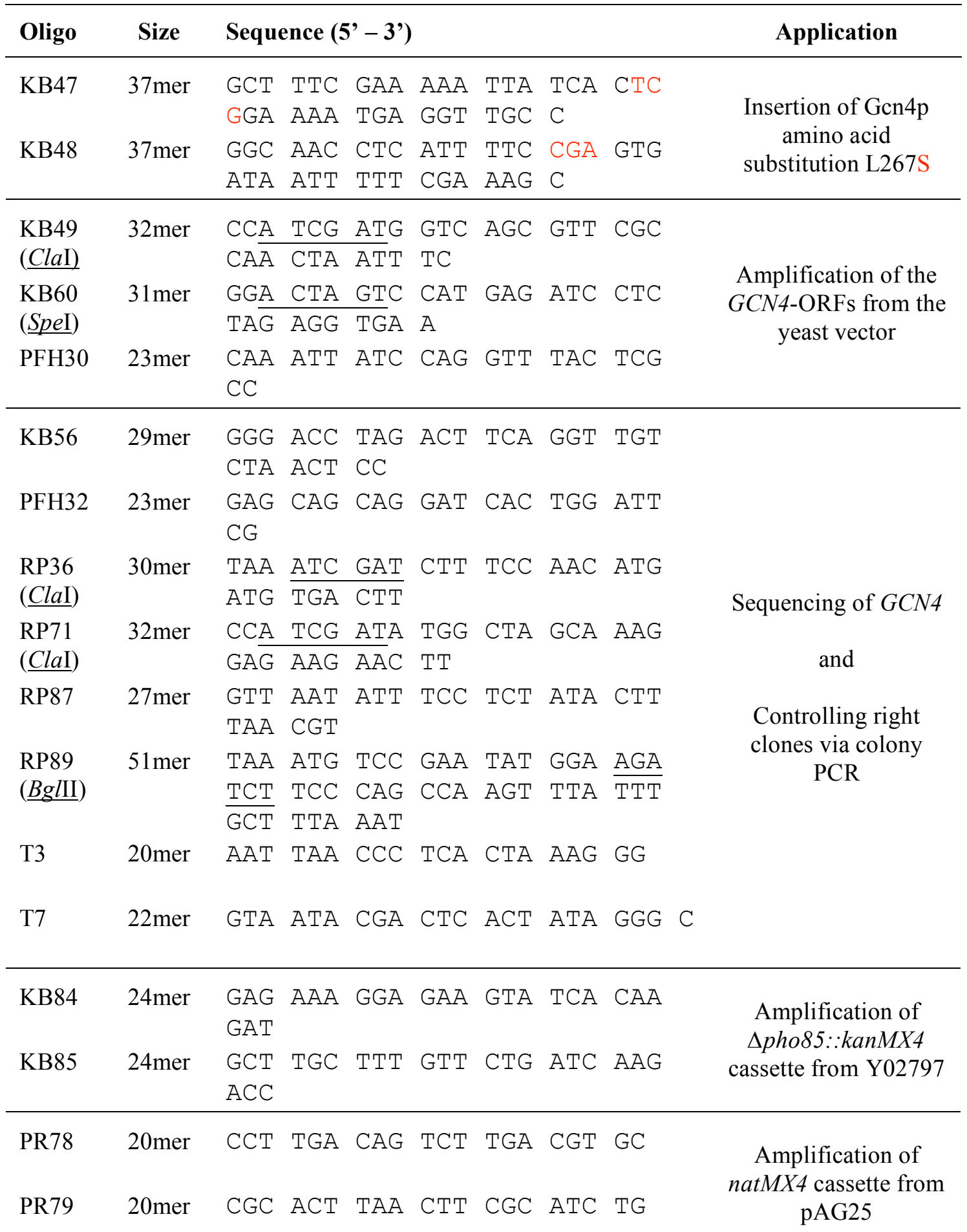




\subsection{Cultivation of microorganisms}

\subsubsection{Escherichia coli}

Cells were grown in Luria-Bertani medium (LB: 1\% tryptone, 0.5\% yeast extract, $1 \% \mathrm{NaCl}$ ) at $37^{\circ} \mathrm{C}$. Isopropyl-thio- $\beta$-D-galactoside (IPTG) was added to liquid media at a final concentration of $0.4 \mathrm{mM}$. Ampicillin and chloramphenicol were used at a final concentration of 100 or $25 \mu \mathrm{g} / \mathrm{ml}$, respectively. Solid medium contained $2 \%$ agar. SOB and SOC media for preparation of competent E. coli were prepared as described by Inoue et al. (1990).

\subsubsection{Saccharomyces cerevisiae}

The yeast strains were routinely cultivated in standard yeast extract-peptonedextrose (YEPD: 1\% yeast extract, 2\% peptone, 2\% glucose) or in minimal yeast nitrogen base media (YNB: 1,5 g/l yeast nitrogen base lacking amino acids and ammonium sulfate, $5 \mathrm{~g} / 1$ ammonium sulfate, $2 \%$ glucose or galactose, supplemented with the appropriate amino acids) at $30^{\circ} \mathrm{C}$. Temperature-sensitive strains were cultivated at permissive temperature of $23^{\circ} \mathrm{C}$ before shifting to restrictive temperature of $37^{\circ} \mathrm{C}$, respectively. Solid media were prepared by using $2 \%$ agar.

3-Amino-1,2,4-triazole (3AT) (Sigma-AldRICH, Steinheim, Germany) was added to a final concentration of 5 to $100 \mathrm{mM}$ to induce amino acid starvation. Solid media contained 5 or $10 \mathrm{mM} 3 \mathrm{AT}$ and for promoter shut-off experiments a final concentration of $100 \mathrm{mM} 3 \mathrm{AT}$ was used to mimic amino acid starvation. Tunicamycin (Tm) (CAlBIOCHEM/Merck KGaA, Darmstadt, Germany) was used in final concentrations of $0.5 \mu \mathrm{g} / \mathrm{ml}$ to $5 \mu \mathrm{g} / \mathrm{ml}$ to induce ER stress. Medium with a low concentration of ammonium (SLAD; YNB medium containing $50 \mu \mathrm{M}$ ammonium sulfate) was used to observe pseudohypal formation.

Yeast growth was followed by measuring the optical density at $600 \mathrm{~nm}$ against the corresponding medium. The $\mathrm{OD}_{600}=1$ is equivalent to a cell density of $1.5 \times 10^{7}$ cells/ml (Sherman et al., 1986). Growth times or inoculation volumes were calculated according to the following formula using a growth rate $(\mu)$ of $0.29 / \mathrm{h}$ for YNB or $0.45 / \mathrm{h}$ for YEPD, respectively: 


$$
V_{i}=\frac{V_{c} \times O D_{t} \times e^{-\mu x \Delta t}}{O D_{s}}
$$

$\mathrm{V}_{\mathrm{i}}=$ volume of inoculum [ml]

$\mathrm{OD}_{\mathrm{s}}=\mathrm{OD}$ of starter culture

$\mathrm{V}_{\mathrm{c}}=$ volume of culture $[\mathrm{ml}]$

$\mu \quad$ growth rate

$\mathrm{OD}_{\mathrm{t}}=$ desired OD at the time $\mathrm{t}$

$\Delta \mathrm{t}=$ growth time $[\mathrm{h}]$.

\subsection{Isolation of nucleic acids}

\subsubsection{Plasmid DNA purification}

Plasmid DNA was purified using the 'QIAPrep Spin Miniprep Kit' (QIAGEN, Hilden, Germany). A single colony of $E$. coli was inoculated into $5 \mathrm{ml} \mathrm{LB}$ medium supplemented with ampicillin to a final concentration of $100 \mu \mathrm{g} / \mathrm{ml}$ and incubated overnight at $37^{\circ} \mathrm{C}$ while shaking. The cells were harvested by centrifugation at 13,000 rpm and remaining steps were based on the instruction's manual provided. The isolated plasmids were stored at $-20^{\circ} \mathrm{C}$.

\subsubsection{Isolation of DNA from yeast cells by 'Smash \& Grab'}

'Smash \& Grab' was performed for rapid DNA isolation (Hoffman and Winston, 1987). Yeast cells of an overnight culture were collected by centrifugation (3,000 rpm, $4 \mathrm{~min}$ ) and the pellet was resuspended in $0.5 \mathrm{ml} \mathrm{H}_{2} \mathrm{O}$. After $5 \mathrm{sec}$ centrifugation at $13,000 \mathrm{rpm}$ supernatant was discarded and the pellet was resuspended in the residual liquid. $0.2 \mathrm{ml}$ of lysis buffer (2\% Triton X-100, 1\% SDS, $100 \mathrm{mM} \mathrm{NaCl}, 10 \mathrm{mM}$ Tris $\mathrm{pH} 8.0,1 \mathrm{mM}$ EDTA) and $0.2 \mathrm{ml}$ of phenol equilibrated with methylene chloride and isoamyl alcohol $(25: 24: 1)$ were added. Furthermore, $0.3 \mathrm{~g}$ of glass beads $(\varnothing 0.25-$ 0.50, CARL Roth GmbH, Karlsruhe, Germany) were added to disrupt the cells by vortexing for $4 \mathrm{~min}$ at $4^{\circ} \mathrm{C}$. After subsequent centrifugation for $5 \mathrm{~min}$ at $13,000 \mathrm{rpm}$ the DNA containing aqueous phase could be removed and transferred into a new reaction tube. For higher purity, extraction could be repeated, optionally. DNA was precipitated by addition of $1 \mathrm{ml}$ ice-cold absolute ethanol and subsequently the precipitated DNA was collected by centrifugation for $5 \mathrm{~min}$ at 13,000 rpm. The supernatant was discarded and precipitated DNA was resuspended in $0.4 \mathrm{ml} \mathrm{H}_{2} \mathrm{O}$ to which $3 \mu \mathrm{l}$ of RNase A 
solution $(10 \mathrm{mg} / \mathrm{ml})$ was added. After incubation for $5 \mathrm{~min}$ at $37^{\circ} \mathrm{C} 10 \mu \mathrm{l}$ of $4 \mathrm{M}$ ammonium acetate was added and DNA was precipitated again by addition of $1 \mathrm{ml}$ icecold $100 \%$ ethanol. DNA was collected by centrifugation for 2 min at 13,000 and dried at room temperature or at medium speed in a vacuum dryer (Speed Vac RC3B plus, SAVANT). Finally, DNA was dissolved in $100 \mu 1 \mathrm{H}_{2} \mathrm{O}$ and used for analytical purposes like PCR. The dissolved DNA was stored at $-20^{\circ} \mathrm{C}$.

\subsubsection{Pure DNA isolation from yeast cells via glass capillary}

For higher DNA purification a further method was used. An overnight culture of the respective yeast strain in YEPD was centrifuged and after washing the cells with $\mathrm{H}_{2} \mathrm{O}$ the pellet was resuspended in $500 \mu \mathrm{SPM}$ buffer $(0.9 \mathrm{M}$ sorbitol, $50 \mathrm{mM}$ sodium phosphate $\mathrm{pH} 7.5,140 \mathrm{mM} \beta$-mercaptoethanol). $5 \mu \mathrm{zymolyase}(10 \mathrm{mg} / \mathrm{ml})$ was added and incubated at $37^{\circ} \mathrm{C}$. After $30 \mathrm{~min} 50 \mu \mathrm{l}$ proteinase $\mathrm{K}(10 \mathrm{mg} / \mathrm{ml}), 50 \mu$ EDTA $(0.5$ M) and $150 \mu 1 \mathrm{SDS}(10 \%)$ were added and incubated for further $30 \mathrm{~min}$ at $37^{\circ} \mathrm{C}$. The solution was once extracted with an equal volume of phenol ( $\mathrm{pH} \mathrm{8.0).} \mathrm{After} \mathrm{vortexing}$ for $10 \mathrm{sec}$ and following centrifugation for $5 \mathrm{~min}$ at 13,000 rpm the DNA containing aqueous phase including the interphase could be removed and transferred into a new reaction tube. Extraction was repeated with one volume of phenol equilibrated with methylene chloride and isoamyl alcohol (25:24:1) and after centrifugation aqueous phase was removed without the interphase. Last extraction step was performed with one volume of $\mathrm{CH}_{2} \mathrm{Cl}_{2} /$ isoamyl alcohol (24:1). The aqueous phase was transferred into a new reaction tube and DNA was precipitated for 5 min on ice by adding 1.5 volumes of ethanol. Afterwards the precipitated DNA was spun on a glass capillary and resuspended in $200 \mu 1 \mathrm{H}_{2} \mathrm{O}$. Precipitation was repeated by adding another 1.5 volume of ethanol and DNA was resuspended in $100 \mu \mathrm{H}_{2} \mathrm{O}$. The DNA thus obtained was used for analytical purposes like PCR. The dissolved DNA was stored at $-20^{\circ} \mathrm{C}$.

\subsection{Cloning techniques}

\subsubsection{Polymerase chain reaction}

Polymerase chain reaction (PCR) (Saiki et al., 1985) was performed for rapid amplification of DNA for various purposes. Depending on the application, different thermostable polymerases were used as recommended in the manufacturers's protocols. 
For cloning, either KOD HiFi DNA Polymerase (Novagen, Darmstadt, Germany) or Pfu polymerase (PromegA, Mannheim, Germany) was used. For amplification of DNA for site-specific homologous recombination Phusion High-Fidelity Polymerase (FINNZYMES, Espoo, Finland) was applied. For analytical purposes the self-made Taq polymerase was used. Therefore, the following temperature profile was applied after an initial denaturation at $94^{\circ} \mathrm{C}$ for $1 \mathrm{~min}$ : $1 \mathrm{~min}$ denaturation at $94^{\circ} \mathrm{C}, 40 \mathrm{sec}$ hybridisation at a specific annealing temperature and finally elongation at $72^{\circ} \mathrm{C}$, which lasted according to the fragment size $(1 \mathrm{~min} / \mathrm{kb})$. After 25 or 30 cycles a final extension at $72^{\circ} \mathrm{C}$ for $5 \mathrm{~min}$ followed. In general, primer oligonucleotides were used in a concentration of 5 - 50 nmol. Reaction buffer, polymerase and dNTPs were added according to manufacturers's recommendations.

\subsubsection{Restriction digestion of DNA}

For cloning and analytical confirmation, approximately $1 \mu \mathrm{g}$ DNA was digested in a total volume of $20 \mu \mathrm{l}$ using restriction enzymes (FERMENTAS, St. Leon-Rot, Germany), whereas preparative amounts ranged from about 5 to $10 \mu \mathrm{g}$ DNA. Restriction buffers were used according to the manufacturers's instruction and the restrictions were performed at $37^{\circ} \mathrm{C}$ for at least $2 \mathrm{~h}$.

\subsubsection{Agarose gel electrophoresis}

Digested or amplified DNA was mixed with 0.1 volumes of loading dye $(25 \%$ w/v Ficoll 400, 0.25\% bromphenol blue sodium salt, 0.25\% w/v xylene cyanol, $200 \mathrm{mM}$ EDTA, $\mathrm{pH}$ 8.0) before fragments were separated in 1\% agarose gels containing about $0.5 \mu \mathrm{g} / \mathrm{ml}$ EtBr in TAE buffer (40 mM Tris-acetate, $20 \mathrm{mM}$ Na-acetate, $2 \mathrm{mM}$ EDTA, $\mathrm{pH}$ 8.3). Bands were visualized with an UV transilluminator $(\lambda=254 \mathrm{~nm})$. The 'GeneRuler 1kb DNA Ladder' (FERMENTAS, St. Leon-Rot, Germany) was used for size determination of fragments.

\subsubsection{Isolation of DNA fragments from agarose gels}

After separating digested or amplified DNA on a standard agarose gel, the desired bands were excised under UV light $(\lambda=366 \mathrm{~nm})$. Isolated DNA was purified using the 'QIAquick Gel Extraction Kit' (QIAGEN, Hilden, Germany). Purification was 
performed according to the instruction manual provided. The dissolved DNA was stored at $-20^{\circ} \mathrm{C}$.

\subsubsection{Dephosphorylation of DNA}

For cloning, the digested vector DNA was dephosphorylated in order to remove 5' phosphates to avoid unnecessary religation. Dephosphorylation was performed using Shrimp Alkaline Phosphatase (SAP) from Fermentas (St. Leon-Rot, Germany) and the respective buffer. The reaction mixture was incubated at $37^{\circ} \mathrm{C}$ for $1 \mathrm{~h}$. The digested and dephosphorylated vector DNA was then purified as described in 2.4.4.

\subsubsection{Ligation of DNA fragments}

Linear DNA fragments with cohesive or blunt ends were incubated overnight at $16^{\circ} \mathrm{C}$ or for two hours at room temperature in a $20 \mu 1$ mixture consisting of $2 \mu 1 \mathrm{~T} 4$ DNA ligase (FERMENTAS, St. Leon-Rot, Germany) and $2 \mu 1$ 10x ligation buffer (400 $\mathrm{mM}$ Tris-HCl, $100 \mathrm{mM} \mathrm{MgCl}$, $100 \mathrm{mM}$ DTT, $5 \mathrm{mM} \mathrm{ATP,} \mathrm{pH}$ 7.8). The ratio between digested vector DNA and digested insert DNA was 1:5 or 1:10. DNA ligase was inactivated by heating the reaction mix at $65^{\circ} \mathrm{C}$ for approximately $10 \mathrm{~min}$ before transformed in E. coli.

\subsubsection{Site directed mutagenesis}

Site directed mutagenesis was used to substitute codons encoding leucines of the leucine zipper of Gen $4 \mathrm{p}$. The mutagenesis was carried out by applying the 'QuickChange ${ }^{\circledR}$ Site-Directed Mutagenesis Kit' (StRATAGENE, La Jolla, CA, USA). A thermocycler and KOD Polymerase instead of PfuUltra HF DNA Polymerase were used to establish the favored substitution whereas $10 \mathrm{ng}$ of the pBluescript vector containing a GCN4 wild type open reading frame (GCN4-wt-ORF) (pME2898) served as template DNA. Two primers containing the desired mutations were designed spanning the target region in opposing directions (Table III). With a PCR thermocycler 16 cycles were executed: $30 \mathrm{sec}$ denaturation at $95^{\circ} \mathrm{C}, 1 \mathrm{~min}$ annealing at $55^{\circ} \mathrm{C}$ and $5 \mathrm{~min}$ elongation at $68^{\circ} \mathrm{C}$. After amplification $2 \mu \mathrm{T} 4$ ligase and appropriate volume of buffer were added and ligation was incubated at room temperature for $2.5 \mathrm{~h}$. The reaction was stopped through heat inactivation $\left(5-10 \mathrm{~min}, 65^{\circ} \mathrm{C}\right)$ and subsequently $1 \mu 1$ of $D p n I$ restriction enzyme was added to each reaction and incubated at $37^{\circ} \mathrm{C}$ for $1 \mathrm{~h}$. The $D p n \mathrm{I}$ enzyme is 
specific to methylated and hemi-methylated DNA and therefore only digests the parental template DNA. The enzyme reaction was stopped by heat inactivation and afterwards $1 \mu 1$ of undigested DNA was used to transform E. coli DH5 $\alpha$ or FHK12, respectively. Plasmids were isolated from the resulting colonies and the successful substitution was verified by sequencing with specific primers (Table III).

\subsubsection{DNA sequencing}

Crucial cloning steps and mutagenesis were validated by sequencing on an ABI Prism 310 capillary sequencer (APPALERA DeUTSCHLAND GmbH, Darmstadt, Germany) at the Göttingen Genomics Laboratory. DNA sequences were verified using the 4Peaks software (available at http://mekentosj.com/4peaks/).

\subsection{Methods of transformation}

\subsubsection{Preparation of chemically competent $E$. coli cells}

Preparation was performed according to Inoue et al. (1990). About 10 colonies of $E$. coli DH5 $\alpha$ were inoculated in $250 \mathrm{ml} \mathrm{SOB}$ medium (2\% tryptone, $0.5 \%$ yeast extract, $\left.10 \mathrm{mM} \mathrm{NaCl}, 2.5 \mathrm{mM} \mathrm{KCl}, 10 \mathrm{mM} \mathrm{MgCl}_{2}, 10 \mathrm{mM} \mathrm{MgSO}_{4}\right)$. The culture was incubated at $20^{\circ} \mathrm{C}$ for approximately $24 \mathrm{~h}$ until $\mathrm{OD}_{600}=0.6$ and cooled on ice for 10 min before centrifuging at $2,500 \mathrm{rpm}$ for $10 \mathrm{~min}$ at $4^{\circ} \mathrm{C}$. The pellet was resuspended in $80 \mathrm{ml}$ TB buffer (10 mM PIPES, $15 \mathrm{mM} \mathrm{CaCl}_{2}, 250 \mathrm{mM} \mathrm{KCl}$, adjustment of pH 6.7 with $\mathrm{KOH}, 55 \mathrm{mM} \mathrm{MnCl}$ ) and kept on ice. After 10 min incubation, cell suspension was centrifuged and the obtained pellet was resuspended gently in $20 \mathrm{ml}$ TB buffer followed by the addition of DMSO with swirling to obtain a final concentration of $7 \%$. This cell suspension was incubated for further $10 \mathrm{~min}$ on ice and dispended in 500 and $700 \mu 1$ aliquots which were first subjected to shock freezing in liquid nitrogen before storing at $-80^{\circ} \mathrm{C}$.

\subsubsection{Transformation of $E$. coli DH5 $\alpha$}

An aliquot of competent cells was carefully thawn on ice. $20 \mu 1$ of a ligation reaction was added to $200 \mu \mathrm{l}$ of competent $E$. coli DH5 $\alpha$ and incubated for $30 \mathrm{~min}$ on ice. The cells were then subjected to heat shock at $42^{\circ} \mathrm{C}$ for $90 \mathrm{sec}$ and subsequently placed on ice again for further $3 \mathrm{~min}$. The samples were mixed with $800 \mu \mathrm{LB}$ medium 
followed by recovery at $37^{\circ} \mathrm{C}$ under constant shaking for $1 \mathrm{~h}$. Afterwards cells were harvested by centrifugation at 5,000 rpm for $2 \mathrm{~min}$, resuspended in the remaining supernatant and plated on LB agar supplemented with ampicillin to a final concentration of $100 \mu \mathrm{g} / \mathrm{ml}$. Plates were incubated overnight at $37^{\circ} \mathrm{C}$.

\subsubsection{Preparation of $\mathrm{CaCl}_{2}$-competent $\boldsymbol{E}$. coli FHK12 cells}

A single colony of $E$. coli FHK12 was inoculated into $5 \mathrm{ml}$ LB medium supplemented with ampicillin to a final concentration of $100 \mu \mathrm{g} / \mathrm{ml}$, and incubated overnight at $30^{\circ} \mathrm{C}$ on a rotary shaker. $100 \mathrm{ml} \mathrm{LB}$ medium supplemented with ampicillin were inoculated with $1 \mathrm{ml}$ of this pre-culture and incubated at $30^{\circ} \mathrm{C}$ until $\mathrm{OD}_{600}=0.6-$ 0.8. Cells were harvested by centrifugation at $4,000 \mathrm{rpm}$ for $20 \mathrm{~min}$ at $4{ }^{\circ} \mathrm{C}$ and resuspended in $20 \mathrm{ml}$ sterile ice-cold $0.1 \mathrm{M} \mathrm{CaCl}_{2}$ solution. After $24 \mathrm{~h}$ incubation on ice cells were harvested again and resuspended in $3 \mathrm{ml}$ sterile ice-cold $0.1 \mathrm{M} \mathrm{CaCl}_{2}$ solution. Cell suspension was dispensed in $200 \mu 1$ aliquots, which were incubated for further $30 \mathrm{~min}$ on ice. Subsequently $7 \mu \mathrm{DMSO}$ was added to each aliquot and cells could be used for direct transformation or stored at $-80^{\circ} \mathrm{C}$.

\subsubsection{Transformation of $E$. coli FHK12}

An aliquot of competent $E$. coli FHK12 cells was carefully thawn on ice. $1 \mu \mathrm{g}$ DNA (in maximal $10 \mu \mathrm{l}$ ) was added to $200 \mu \mathrm{l}$ of the competent cells and incubated for $30 \mathrm{~min}$ on ice. Cells were subjected to heat shock at $37^{\circ} \mathrm{C}$ for $3 \mathrm{~min}$ before $800 \mu \mathrm{LB}$ medium were added to the mixture followed by recovery at $37^{\circ} \mathrm{C}$ under constant shaking for $45 \mathrm{~min}$. 50, 100 and $150 \mu 1$ of this cell suspension were plated on solid LB medium supplemented with ampicillin and chloramphenicol. Incubation was overnight at $37^{\circ} \mathrm{C}$.

\subsubsection{Transformation of $S$. cerevisiae}

Transformation was performed according to the lithium acetate method as described by Ito et al. (1983). $10 \mathrm{ml}$ cultures of S. cerevisiae were pre-grown in YEPD medium at $30^{\circ} \mathrm{C}$ overnight. $10 \mathrm{ml}$ YEPD medium was inoculated with $400 \mu \mathrm{l}$ of this pre-culture and incubated at $30^{\circ} \mathrm{C}$ for further $5-6 \mathrm{~h}$. Cells were harvested by centrifugation at 3,000 rpm for $3 \mathrm{~min}$ and resuspended in $4 \mathrm{ml} 1 \mathrm{x} \mathrm{LiOAc} / \mathrm{TE}(0.1 \mathrm{M}$ LiOAc, $10 \mathrm{mM}$ Tris-HCl, $1 \mathrm{mM}$ EDTA, $\mathrm{pH}$ 8.0). After short whirling, cells were 
harvested by centrifugation. For chromosomal integration of linear DNA fragments this whirling step was extended up to 20 - 30 min. After centrifugation cells were resuspended in $400 \mu 1 \mathrm{1x} \mathrm{LiOAc/TE}$ prior dividing it into two samples of $200 \mu 1$, respectively. Approximately $20 \mu \mathrm{l}$ of pre-warmed $\left(65^{\circ} \mathrm{C}\right)$ carrier DNA (salmon sperm DNA) $(10 \mathrm{mg} / \mathrm{ml})$ was added to each tube with $200 \mu \mathrm{l}$ competent yeast cells. For transformation of plasmid DNA $5-8 \mu$ high copy or $15 \mu 1$ low copy plasmid DNA was added to one of the tubes. The other one served as negative control. For transformation of linear DNA $20-200 \mu \mathrm{l}$ of purified PCR product were used. After addition of $800 \mu \mathrm{l}$ $50 \%$ PEG 4000 samples were vortexed and incubated at $30^{\circ} \mathrm{C}$ for $30 \mathrm{~min}$. The cells were then subjected to heat shock at $42^{\circ} \mathrm{C}$ for $20-25$ min and subsequently centrifuged at 7,000 rpm for $30 \mathrm{sec}$. The supernatant was discarded and the cell pellets were resuspended in $1 \mathrm{ml}$ YEPD and incubated at $30^{\circ} \mathrm{C}$ for $1 \mathrm{~h}$ while shaking. For chromosomal integration this step was extended up to $2-3$ h. Finally, cells were pelletized by centrifugation at 4,000 rpm for $10-20 \mathrm{sec}$ and the resuspended cells were plated on selective media and incubated at $30^{\circ} \mathrm{C}$ for about 3 days until colonies were visible. Transformation of yeast with linear DNA was plated on solid YEPD medium containing the appropriate drug for selection and incubated at $30^{\circ} \mathrm{C}$ for 4 days.

\subsection{Protein analysis}

\subsubsection{Shut-Off-Western procedure}

Yeast cells were pre-grown in selective minimal medium with glucose as carbon source to $\mathrm{OD}_{600}=0.6$. Cells were collected by centrifugation $\left(3,000 \mathrm{rpm}, 4 \mathrm{~min}, 4^{\circ} \mathrm{C}\right)$ and incubated in minimal medium containing $2 \%$ galactose and $0.5 \%$ raffinose to express $m y c^{3}-G C N 4$ from the GAL1 promoter. After 3.5 hours, cells were collected via centrifugation and half of these tryptophan-auxotrophic cells were starved for tryptophan by shifting them to minimal medium lacking tryptophan. Alternatively, 100 $\mathrm{mM} 3 \mathrm{AT}$ was used to induce amino acid starvation. 3\% glucose was added to shut-off the promoter after half an hour of starvation. Samples $(50 \mathrm{ml})$ were analyzed at the indicated time points after promoter-shut-off ( 0 -min time point). 


\subsubsection{Protein Synthesis Shut-Off Assay}

Yeast cells were cultivated in $150 \mathrm{ml}$ liquid synthetic minimal medium (YNB) or rich medium (YEPD) to $\mathrm{OD}_{600}=0.6$ at $30^{\circ} \mathrm{C}$. Temperature-sensitive yeast strains were cultivated at $25^{\circ} \mathrm{C}$ (permissive temperature). To examine the turnover of Haclp, tunicamycin (Tm) was added to a final concentration of $5 \mu \mathrm{g} / \mathrm{ml}$ in order to induce the UPR. After 90 min post Tm-induction, cycloheximide (APPLICHEM GmbH, Darmstadt, Germany) was added to a final concentration of $1 \mathrm{mg} / \mathrm{ml}$ and samples $(15 \mathrm{ml})$ were analyzed at the indicated time points after halt of protein synthesis ( 0 -min time point). Temperature-sensitive strains were shifted from $25^{\circ} \mathrm{C}$ to restrictive temperature of $37^{\circ} \mathrm{C}$ for $30 \mathrm{~min}$ before cycloheximide was added.

\subsubsection{Whole-cell extracts of $S$. cerevisiae}

Cell extracts were prepared from yeast cultures grown to exponential phase. Cells were washed in $2.5 \mathrm{ml}$ ice cold buffer B $(100 \mathrm{mM}$ Tris- $\mathrm{HCl} \mathrm{pH} 7.5,200 \mathrm{mM}$ $\mathrm{NaCl}, 5 \mathrm{mM}$ EDTA, $20 \%$ glycerine), lysed with glass beads $(\varnothing 0.25-0.50 \mathrm{~mm}, \mathrm{CARL}$ Rотн GmbH, Karlsruhe, Germany) in $500 \mu$ l of B-buffer ${ }^{+}$containing protease inhibitors (Complete, EDTA-free, Roche Diagnostics GmbH, Mannheim, Germany) and 14.3 $\mathrm{mM} \beta$-mercaptoethanol through vigorous shaking on a Ika-Vibrax-Mixer at $4^{\circ} \mathrm{C}$. To remove glass beads and large cell debris samples were spun at 13,000 rpm for $12 \mathrm{~min}$ $\left(4^{\circ} \mathrm{C}\right)$. For preparation of extracts from the protein synthesis shut-off assay $150 \mu 1$ of Bbuffer $^{+}$were used. Part of the supernatant $(10 \mu \mathrm{l})$ was used for Bradford (1976) assay to determine the protein concentration while the remaining supernatant was denatured at the ratio $3: 1$ in $3 x$ SDS loading dye $(0.25 \mathrm{M}$ Tris- $\mathrm{HCl} \mathrm{pH} 6.8,15 \% \beta$-mercaptoethanol, $30 \%$ glycerine, $7 \%$ SDS, $0.3 \%$ bromphenol blue) by heating at $65^{\circ} \mathrm{C}$ for $15 \mathrm{~min}$.

\subsubsection{SDS-Polyacrylamide Gel Electrophoresis (Laemmli, 1970)}

Yeast cell extracts were prepared for electrophoretic separation as described in section 2.6.3. Extracts containing equal amounts of protein from each sample were separated by $12 \%$ SDS-PAGE consisting of two different gel types (running gel: 375 $\mathrm{mM}$ Tris $\mathrm{pH} 6.8,3 \% \mathrm{v} / \mathrm{v}$ acrylamide, $0.08 \% \mathrm{v} / \mathrm{v}$ bisacrylamide, $0.1 \% \mathrm{SDS}$; stacking gel: $375 \mathrm{mM}$ Tris $\mathrm{pH} 8.8,12 \% \mathrm{v} / \mathrm{v}$ acrylamide, $0.4 \% \mathrm{v} / \mathrm{v}$ bisacrylamide, $0.1 \%$ SDS). Running of the gel was carried out at $200 \mathrm{~V}$ in electrophoresis buffer (25 mM Tris Base, 
$25 \mathrm{M}$ glycine, 1\% w/v SDS, 0.34\% w/v EDTA). The 'PageRuler ${ }^{\mathrm{TM}}$ Prestained Protein Ladder' (FERMENTAS GmbH, St. Leon-Rot, Germany) was used as marker.

\subsubsection{Protein immunoblotting}

For Western hybridization experiments, separated proteins were transferred onto a nitrocellulose membrane (Schleicher \& Schuell Biosciences GmbH, Dassel, Germany) by electrophoretic blotting in a 'Mini-Trans-Blot-Electrophoretic-Cell' from Bio-RAD (BIO-RAd Laboratories GmbH, Munich, Germany) in transfer buffer containing $30 \mathrm{mM}$ Tris-base, $200 \mathrm{mM}$ glycine, $0.002 \%$ SDS and 20\% methanol for 1.5 $\mathrm{h}$ at $100 \mathrm{~V}$ or overnight at $35 \mathrm{~V}$.

After protein transfer, free binding sites on the nitrocellulose membrane were blocked by treatment with $4-5 \%$ milk powder in PBS (140 mM NaCl, $10 \mathrm{mM}$ sodium phosphate, $\mathrm{pH}$ 7.5) for one hour. Afterwards the membrane was incubated for $1-2 \mathrm{~h}$ at RT or overnight at $4{ }^{\circ} \mathrm{C}$ with the respective primary antibody diluted in a suspension of $4-5 \%$ milk powder in PBS. The used primary antibodies were monoclonal mouse antiGFP (CLONTECH, Heidelberg, Germany), monoclonal mouse anti-myc (9E10) (SANTA Cruz Biotechnology, Heidelberg, Germany), polyclonal rabbit anti-Cdc42p (SANTA CRUz Biotechnology, Heidelberg, Germany), polyclonal rabbit anti-Haclp (gift from Kazutoshi Mori, Kyoto University, Japan), polyclonal rabbit anti-eIF2 $\alpha$ p [pS52] (\#44728G, InVITROGEN, Darmstadt, Germany) or rabbit anti-eIF2 $\alpha$ p (gift from Thomas Dever, MD, USA). Residual antibody was washed away by shaking the membrane $3 \mathrm{x}$ $10 \mathrm{~min}$ in PBS. Peroxidase-coupled goat anti-rabbit IgG (\#G21234, MoBITEC, Göttingen, Germany) or goat anti-mouse IgG (Invitrogen GmbH, Karlsruhe, Germany) were used as secondary antibodies. The membrane was incubated with the secondary antibodies for $60 \mathrm{~min}$ and afterwards washed as described for treatment with primary antibodies. The respective proteins were detected using 'Enhanced Chemiluminescence' (ECL) technology (Tesfaigzi et al., 1994). The ECL solution 1 (100 $\mu \mathrm{l}$ of $2.5 \mathrm{mM}$ Luminol and $44 \mu \mathrm{l}$ of $40 \mu \mathrm{M}$ Paracumaric acid in a total volume of $10 \mathrm{ml}$ of $10 \mathrm{mM}$ Tris, $\mathrm{pH} 8.5)$ was mixed with ECL solution $2\left(6.15 \mu \mathrm{l}\right.$ of $30 \% \mathrm{H}_{2} \mathrm{O}_{2}$ in $10 \mathrm{ml}$ of $10 \mathrm{mM}$ Tris, $\mathrm{pH} \mathrm{8.5)} \mathrm{just} \mathrm{prior} \mathrm{for} \mathrm{use.} \mathrm{The} \mathrm{membrane} \mathrm{was} \mathrm{incubated} \mathrm{in} \mathrm{this}$ mixture for $1 \mathrm{~min}$ and subsequently exposed to the Hyperfilm ${ }^{\mathrm{TM}}-\mathrm{ECL}^{\mathrm{TM}}$ (AMERSHAM BIOSCIENCES, Munich, Germany). Quantification of detected bands was performed 
using the KODAK MI 4.05 software (EASTMAN KODAK COMPANY, Rochester, NY, USA).

\subsection{Southern analysis}

Genetic integrations or manipulations of strains were confirmed by Southern analysis according to Southern (1975). Non-radioactive labeling of probes and detection was performed using the 'Gene Images ${ }^{\mathrm{TM}}$ Random-Prime DNA labeling kit' and the 'Gene Images ${ }^{\text {TM }}$ CDP-Star ${ }^{\text {TM }}$ Detection Kit (GE HeAlthCARE LifE ScIEnCES, Munich, Germany). The chemiluminescent signals were exposed to the Hyperfilm ${ }^{\mathrm{TM}}-\mathrm{ECL}^{\mathrm{TM}}$ (Amersham Biosciences, Munich, Germany).

\section{$2.8 \quad \beta$-galactosidase assays}

\subsection{1 $\beta$-galactosidase assay in $S$. cerevisiae}

Strains carrying either a chromosomally integrated lac $Z$ reporter or expressing a lacZ reporter from a plasmid were cultivated in liquid synthetic minimal medium (YNB) overnight at $30^{\circ} \mathrm{C}$, diluted into fresh medium, and cultivated for $6 \mathrm{~h}$ before assaying enzymatic activities. For amino acid starvation, 3AT (SIGMA-ALDRICH, Steinheim, Germany) was added to fresh diluted cultures to a final concentration of 10 $\mathrm{mM}$, and cells were incubated for $8 \mathrm{~h}$ before measuring the $\beta$-galactosidase activity. For nitrogen starvation, cells grown to logarithmic phase were washed twice with $2 \%$ glucose and incubated for $24 \mathrm{~h}$ in liquid YNB medium containing $50 \mu \mathrm{M}$ ammonium sulfate (instead of $50 \mathrm{mM}$ ) as the sole nitrogen source. Tunicamycin (Tm) (CAlbiochem/Merck KGaA, Darmstadt, Germany) was added to fresh diluted cultures to a final concentration of $1 \mu \mathrm{g} / \mathrm{ml}$ and cultures were incubated for $6 \mathrm{~h}$ to induce ER stress. Additionally, cultures grown to log phase (6 h YNB) were treated with $1 \mu \mathrm{g} / \mathrm{ml}$ Tm for 15, 30, 60 and $90 \mathrm{~min}$.

Extracts were prepared and assayed for specific $\beta$-galactosidase activity as described previously (Rose and Botstein, 1983) and normalized to the total protein concentration (Bradford, 1976), resulting in the specific enzyme activity $\left(\mathrm{OD}_{420} \mathrm{x}\right.$ $0.35) /(0.0045 \mathrm{x}$ protein concentration $\mathrm{x}$ extract volume $\mathrm{x}$ time $)$. Assays were performed at least three times from independent cultures. The standard errors of the mean values were below $15 \%$. 


\subsection{2 $\beta$-galactosidase assay in $E$. coli}

For $\beta$-galactosidase assays of chimeric protein activity E. coli strain FHK12 transformed with the respective pHKToxR' derivate was pre-grown for 4 hours at $37^{\circ} \mathrm{C}$ in LB in the presence of chloramphenicol $(25 \mu \mathrm{g} / \mathrm{ml})$ and ampicillin $(100 \mu \mathrm{g} / \mathrm{ml}) .5 \mu \mathrm{l}$ of each pre-culture was used for at least three main cultures, which were grown overnight at $30^{\circ} \mathrm{C}$ in LB in the presence of chloramphenicol, ampicillin and $0.4 \mathrm{mM}$ IPTG. $15 \mu \mathrm{l}$ of each culture were transferred into a microtiter well and $100 \mu \mathrm{l}$ chloroform-saturated Z-buffer $\left(60 \mathrm{mM} \mathrm{Na}_{2} \mathrm{HPO}_{4}, 40 \mathrm{mM} \mathrm{NaH} \mathrm{PO}_{4}, 10 \mathrm{mM} \mathrm{KCl}, 1\right.$ $\mathrm{mM} \mathrm{MgSO}_{4}, 50 \mathrm{mM} \beta$-mercaptoethanol, $\mathrm{pH}$ 7.0) was added. Afterwards, $\mathrm{OD}_{620}$ was determined using an ELISA plate reader. Further steps were performed as reported by Kolmar et al. (1995b). Assays were performed for at least three independent cultures.

\subsection{Growth tests}

For spot dilution assays, yeast strains were pre-cultured to the same optical density $\left(\mathrm{OD}_{600}=0.6\right)$ and then diluted five- or ten-fold, starting with $3 \times 10^{4}$ cells per 20 $\mu 1$. For each dilution $10 \mu \mathrm{l}$ (YEPD) or $20 \mu \mathrm{l}$ (YNB) were spotted onto solid YNB or YEPD medium with or without $0.5 \mu \mathrm{g} / \mathrm{ml}$ tunicamycin for ER stress survival assays, and on selective YNB medium with or without $5 \mathrm{mM} 3 \mathrm{AT}$ for resistance upon amino acid starvation. After incubation for 3 days at $30^{\circ} \mathrm{C}$ (temperature sensitive mutants were also incubated at 25 and $37^{\circ} \mathrm{C}$ ) plates were photographed under white light.

\subsection{Adhesive growth}

Amino acid starvation induced adhesive growth tests on solid YNB medium were performed as described previously (Roberts and Fink, 1994; Braus et al., 2003). Strains were pre-grown at $30^{\circ} \mathrm{C}$ for 20 hours on solid YNB medium containing the respective supplements. Cells were streaked on YNB medium containing fresh supplements and $10 \mathrm{mM} 3 \mathrm{AT}$ to induce amino acid starvation. After incubation for three days at $30^{\circ} \mathrm{C}$, plates were photographed to visualize total growth and then carefully washed under a stream of water. Afterwards, the plates were photographed again to document adhesive cell growth. For visualization of biofilms in wells of polystyrene plates, assays were performed as described in Reynolds and Fink (2001). Cells were pre-grown in $\mathrm{YNB}$ at $30^{\circ} \mathrm{C}$ overnight and used for inoculation of main 
cultures followed by an incubation at $30^{\circ} \mathrm{C}$. At an $\mathrm{OD}_{600}=0.6,300 \mu 1$ of each culture were transferred into a microtiter plate and incubated with or without 5-10 mM 3AT at $30^{\circ} \mathrm{C}$ for $1-2$ days. Then, $100-150 \mu$ of crystal violet was added to the cells and incubated for approximately $15 \mathrm{~min}$. Finally, the plate was carefully washed under a gentle stream of water to remove all non-adhesive cells, dried and ultimately photographed.

\subsection{Pseudohyphal growth}

For qualitative diploid pseudohyphal development assays cells were grown for five days on solid SLAD medium containing $50 \mu \mathrm{M}\left(\mathrm{NH}_{4}\right)_{2} \mathrm{SO}_{4}$ as nitrogen source (Gimeno et al., 1992). Pseudohyphal colonies were viewed with an Axiovert microscope (CARL ZEISS, Jena, Germany) and photographed using a Xillix microimager digital camera with the Improvision Openlab software (IMPROVISION, Coventry, United Kingdom). 


\section{RESULTS}

\subsection{A feedback circuit between transcriptional activation and self- destruction of Gen4p separates its metabolic and morphogenic function in diploid yeasts}

Various transcription factors, which regulate the expression of genes involved in differentiation processes, are targets for polymorphisms. Single nucleotide polymorphisms (SNPs) provoke changes in their function and activity whereby expression in different yeast strains can result in varying adaptations and phenotypes (Gerke et al., 2009; Dowell et al., 2010). We aimed to dissect the developmental from the metabolic function of the transcription factor Gen $4 p$ in diploid yeast cells.

\subsubsection{The $G C N 4^{L 267 S}$ mutant allele separates the metabolic and the developmental function of a transcription factor in diploids}

The initial step to separate the metabolic and the developmental function of Gcn $4 p$ was the generation of a GCN4 mutant library by random mutagenesis via PCR. Diploid mutants which still have an intact metabolic function and provide sufficient amounts of translational precursors were screened for growth under amino acid starvation conditions mediated by the drug 3-amino-1,2,4-triazole (3AT) (Klopotowski and Wiater, 1965). A gcn4 deletion strain is unable to grow on media containing 3AT, because it causes histidine starvation acting as false feedback-inhibitor of the corresponding amino acid biosynthetic pathway nevertheless could grew significantly reduced compared to wild type cells when $\Delta g c n 4$ cells were thickly streaked out (Fig. $7 \mathrm{~A}$ and 12B). The developmental function of Gcn4p was monitored using an additional reporter. The GCN4 mutant library was transformed into diploid $\Delta g c n 4$ mutant cells (RH2695) that carry a chromosomally integrated FLO11::lacZ reporter. Diploids were only able to adhere and form pseudohyphae when Gcn $4 p$ was active and in turn the FLO11 gene was expressed which can be visualized and quantified in this strain by $\beta$-galactosidase activity assays.

A pool of $24,000(100 \%)$ transformants was plated on solid YNB medium containing $10 \mathrm{mM}$ 3AT. 20,000 clones ( $83 \%$ ) were able to grow in the presence of $3 \mathrm{AT}$ suggesting that an intact metabolic function of Gen4p provided sufficient amounts of 
amino acids for growth. FLO11::lacZ expression was determined using a qualitative filter assay (Breeden and Nasmyth, 1987). 207 clones of primarily 24,000 (0.86\%) showed an impairment in the activation of FLO11 expression upon amino acid starvation scored by less intense colored the filters. The corresponding GCN4containing plasmids were isolated and re-introduced into the parental strain (RH2695) as secondary screen for a separation of the dual function of Gen4p. This second screen resulted in 83 transformants $(0.58 \%)$ and eight clones $(0.03 \%)$ featured a significant decrease in amino acid starvation-induced FLO11::lacZ expression. DNA sequencing of the isolated GCN4 mutant alleles revealed a shared codon exchange resulting in a Leu267Ser amino acid substitution. This amino acid represents the third of four conserved leucines of the leucine zipper region, which is located in the C-terminal region of the Gen4 protein.

A

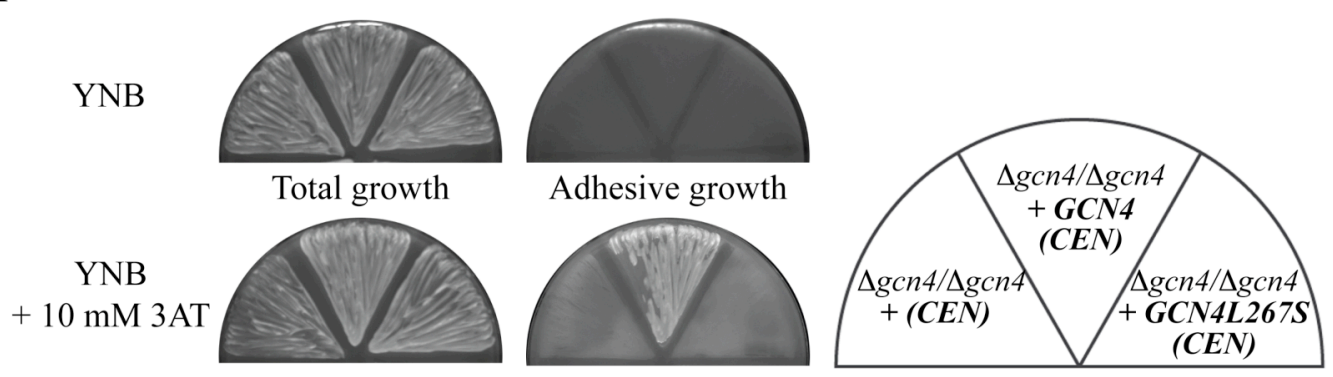

B

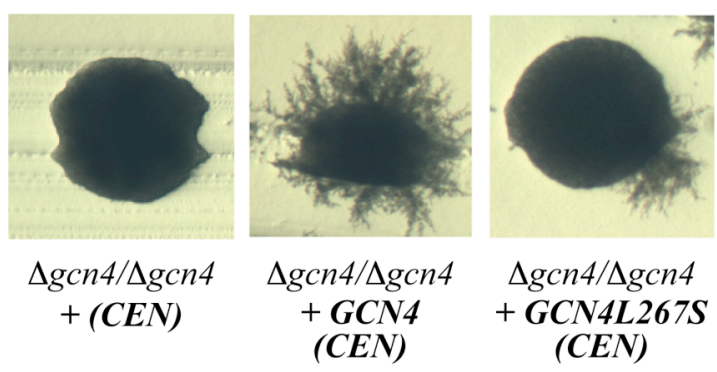

Fig. 7: Diploid $G C N 4^{L 2675}$ yeasts are able to grow under amino acid starvation, but do not adhere to agar.

(A) Diploid yeast $\Sigma 1278 \mathrm{~b}$ strain RH2695 ( $\triangle g c n 4 / \Delta g c n 4)$ carrying low copy $C E N$ plasmids with wild type GCN4 (pME1092), GCN4 $4^{L 2675}$ (pME2901) or as control ( $\triangle g c n 4$ ) the empty vector (pRS314) was streaked out on solid YNB medium (non-starved cells) and with $10 \mathrm{mM} 3 \mathrm{AT}$ (histidine starved cells), respectively. After incubation for three days at $30^{\circ} \mathrm{C}$ adhesive growth was determined. Plates were photographed prior (total growth) and after washing under a stream of water (adhesive growth) to document remaining cells on the agar surface.

(B) Strains were streaked out on solid nitrogen starvation medium (Natarajan et al., 2001) containing only $50 \mu \mathrm{M}\left(\mathrm{NH}_{4}\right)_{2} \mathrm{SO}_{4}$ as nitrogen source to induce pseudohyphal growth. After five days incubation at $30^{\circ} \mathrm{C}$ pseudohyphal colonies were visualized with an Axiovert microscope and photographed. 
The developmental phenotype was analyzed in more detail. Under nonstarvation conditions all diploid strains carrying an intact FLO11 gene and an additional FLO11::lacZ reporter were growing (Fig. 7A). The growth mode was non-adhesive, since washing detached all strains from the agar surface. In contrast, diploid cells expressing wild type GCN4 grew adhesively when treated with 3AT whereas cells containing the $G C N 4^{L 267 S}$ mutant allele were unable to adhere similar to the control strain, which expressed an empty vector and therefore mimiced a $\Delta g c n 4 / \Delta g c n 4$ mutant strain. Pseudohyphae formation of diploid $\Delta g c n 4$ yeast strains expressing wild type GCN4 or the GCN4 ${ }^{L 267 S}$ mutant allele were analyzed by streaking them on solid nitrogen starvation medium containing $50 \mu \mathrm{M}\left(\mathrm{NH}_{4}\right)_{2} \mathrm{SO}_{4}$ as nitrogen source. This reduced amount of ammonium sulfate triggered pseudohyphal growth of diploid wild type cells (GCN4). In contrast, cells expressing $G C N 4^{L 267 S}$ showed an impaired ability in pseudohyphae formation (Fig. 7B).

We conclude that a separation of the dual function of Gcn $4 p$ is possible when the amino acid starvation regulated metabolic function is still intact but the developmental function is abolished.

\subsubsection{Transcriptional activity of Gen4p $\mathrm{p}^{\mathrm{L267S}}$ in starved diploids is significantly lower for FLO11::lacZ in comparison to Gen4p target gene expression}

Our screen revealed only a single mutation in the C-terminus of the transcription factor, which allowed the separation of the metabolic and developmental function. The reason why corresponding diploid GCN4 mutant cells were unable to differentiate was investigated by measuring FLO11 expression representing the key player for adhesion and pseudohyphal growth. First, $\beta$-galactosidase activity assays were performed using the chromosomally integrated $F L O 11: \because l a c Z$ reporter.

Amino acid starvation led to a significant induction of $\beta$-galactosidase activity in diploid wild type cells carrying intact Gen4p (GCN4) (66 U) (Fig. 8). In contrast, cells containing the substitution $\left(G C N 4^{L 267 S}\right)$ showed only a partial induction corresponding to $25 \%$ of the wild type FLO11::lacZ expression (16 U) when treated with $3 \mathrm{AT}$. These data suggest that the amino acid substitution Leu267Ser of Gcn4p causes an impaired ability to induce FLO11 expression and thereby an adhesion-deficient growth phenotype in response to amino acid starvation. The $G C N 4^{L 267 S}$ mutant strains are still able to grow in the presence of 3AT starvation conditions. To analyze the 
transcriptional activity of the mutant Gcn $4 p$ on the upstream elements of metabolic

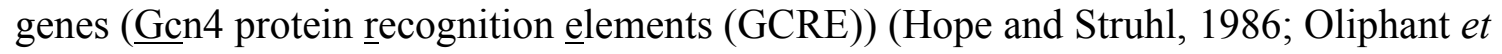
al., 1989) $\beta$-galactosidase assays of GCRE6::lacZ reporter were performed. This reporter carries six copies of the 9 base pairs nucleotide GCRE sequence representing a specific binding site for the Gen4p homodimer. Activity of wild type and mutant Gcn $4 p$ was monitored in sated and amino acid starved diploid yeast cells. Under sated conditions expression of GCRE6::lacZ was low in both diploid cells expressing $G C N 4^{L 267 S}$ and wild type GCN4. Upon $10 \mathrm{mM} 3 \mathrm{AT}$ treatment GCRE6::lacZ induction in the Gcn $4 p^{\mathrm{L} 267 \mathrm{~S}}$ mutant displayed approximately 50\% (394 U) of the expression measured in cells expressing wild type Gen4p (783 U) (Fig. 8).
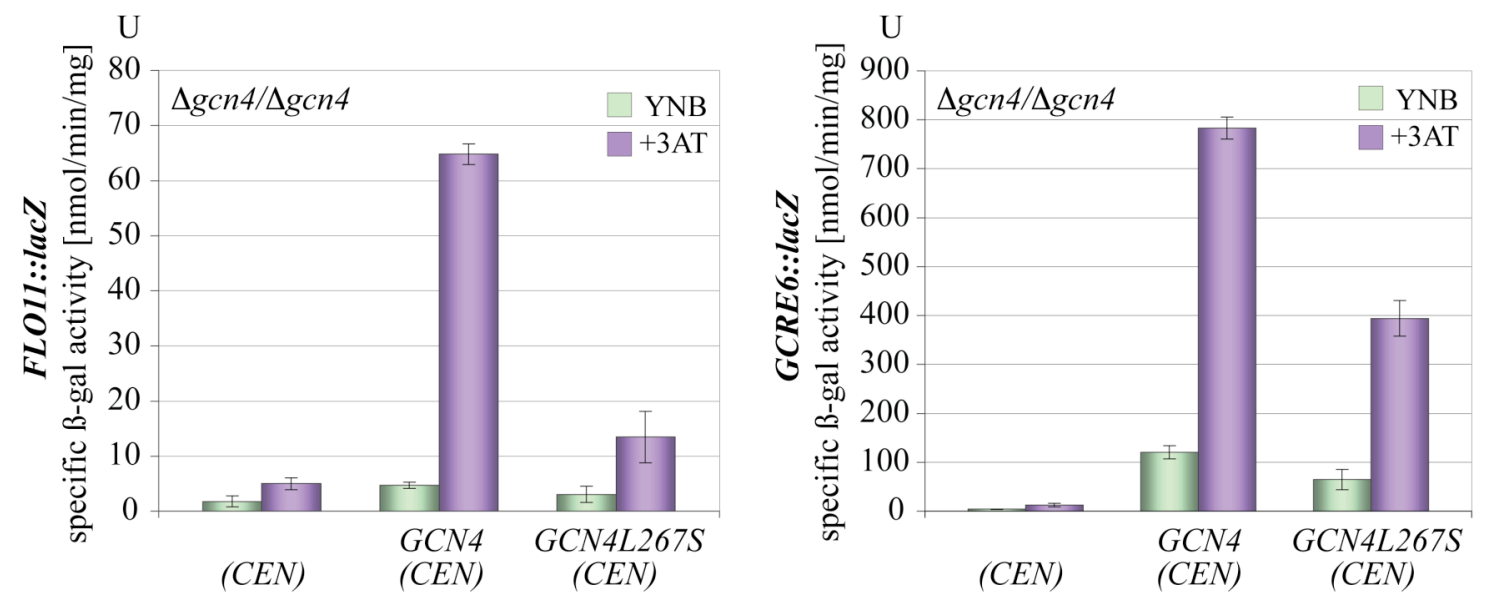

Fig. 8: FLO11 and Gcn4p-dependent reporter gene expression in diploid $G C N 4^{L 267 S}$ yeasts.

The diploid yeast strain RH2695 carrying a chromosomally FLO11::lacZ reporter transformed with plasmids expressing wild type GCN4 (pME1092), GCN4 $4^{L 2675}$ (pME2901) or as control $(\Delta g c n 4)$ the empty vector (pRS314) was grown to log-phase in YNB in absence (green bars, YNB) or presence of $10 \mathrm{mM} 3 \mathrm{AT}$ (purple bars, $+3 \mathrm{AT}$ ) before specific $\beta$-galactosidase activities were measured. Additionally, galactosidase activity was determined in diploid $\Sigma 1278 \mathrm{~b}$ strain RH2398 ( $\triangle g c n 4 / \Delta g c n 4)$ carrying a GCRE6::lacZ reporter expressing the same GCN4 plasmids. Units of specific $\beta$-galactosidase activities are shown in nanomoles per minutes per milligram. The bars represent the mean value of at least three independent measurements.

Taken together, the mutant protein Gen $4^{\mathrm{L} 267 \mathrm{~S}}$ has a significantly reduced activity in diploids compared to wild type Gcn4p. Quantitative differences of Gcn $4 p^{\mathrm{L} 267 \mathrm{~S}}$ on metabolic or developmental gene expression resulted in distinct phenotypes. The reduced activation of metabolic genes by Gen $4 p^{\text {L267S }}$ in comparison to wild type Gen $4 p$ is apparently sufficient to permit growth during amino acid starvation conditions. This 
suggests that there is a decent buffer in the basal Gen4p independent metabolic activity for GCRE controlled genes of the yeast cell. In contrast, the activity of Gen $4 p^{\mathrm{L} 267 \mathrm{~S}}$ on FLO11 expression is significantly more impaired when compared to wild type and seems to be below a threshold, which is required for adhesive and pseudohyphal growth. Therefore, only full Gen $4 p$ activity is able to provide sufficient FLO11 expression for development. This might be reflect by the fact that there is hardly any basal activity of FLO11, because this is a decision between two growth mode alternatives that are mutually exclusive and result in either yeast or pseudohyphal development.

\subsubsection{The separation of the dual function of Gen4p is diploid-specific}

Haploid cells of $S$. cerevisiae have the ability to grow adhesively when starved for either amino acids or glucose (Cullen and Sprague, 2000; Braus et al., 2003). We investigated whether the Gcn4p amino acid substitution Leu267Ser leads to a similar separation of the metabolic and developmental function of Gen $4 p$ in starved haploids as observed in diploids. A haploid $\Delta g c n 4 \Sigma 1278$ b strain (RH2693) carrying a FLO11::lacZ reporter was transformed to express wild type GCN4 or the GCN4 ${ }^{L 267 S}$ mutant allele and tested for amino acid starvation-induced adhesive growth. In contrast to diploids, cells expressing either wild type GCN4 or $G C N 4^{L 267 S}$ became adhesive upon starvation for amino acids (Fig. 9A). Consistently, FLO11::lacZ expression during amino acid starvation resulted in a significantly increased FLO11 derived $\beta$-galactosidase activity in the presence of wild type Gcn $4 p$ or mutant Gcn $4 p^{\text {L267S }}$. A direct comparison showed that the Gcn $4 p$ derived expression of FLO11::lacZ (464 U) displayed half of the expression monitored in strains expressing wild type GCN4 (1172 U) (Fig. 9B). The partial transcriptional activation of FLO11 provided by the mutant is sufficient to induce haploid adhesive growth after amino acid starvation. The GCRE6::lacZ reporter activity was measured to compare the effect of the mutated Gcn4p on metabolic genes in haploids and diploids. The transcriptional activity of Gcn $4 p^{\mathrm{L} 267 \mathrm{~S}}$ was slightly reduced to $82 \%$ (1323 U) upon amino acid starvation compared to the expression mediated by wild type Gen4p (1619 U) (Fig. 9B).

These data suggest that the impact of the Gen $4 p$ amino acid substitution Leu267Ser on haploids points to a similar direction as the impact on diploids, but the reduction in transcriptional activation capacity is less severe. Therefore the separation 
of the metabolic and the developmental function of Gcn4p by the Leu267Ser exchange is specific for diploids and reveals subtle ploidy dependent differences for the same SNPs.

A

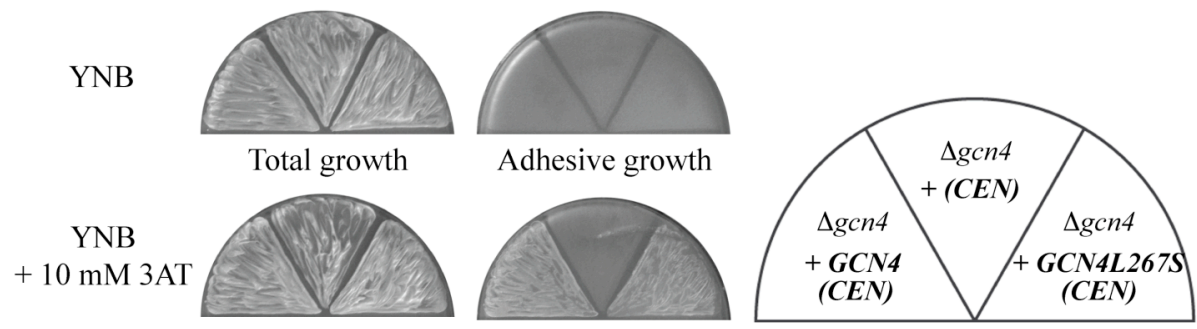

B
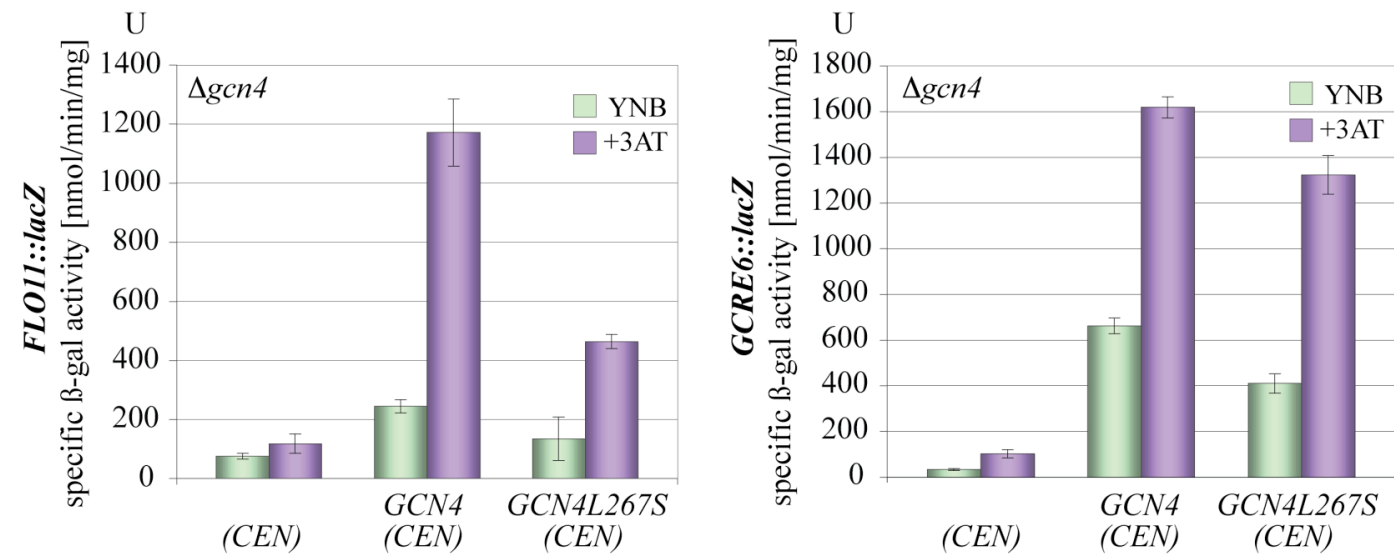

Fig. 9: $G C N 4^{L 267 S}$ mediates adhesive growth of haploid yeasts, which are starved for amino acids.

(A) Haploid yeast $\Sigma 1278$ b strain RH2693 ( $\triangle g c n 4)$ expressing wild type GCN4 (pME1092), $G C N 4^{L 267 S}$ (pME2901) or the empty vector (pRS314) as control $(\Delta g c n 4)$ was grown on solid YNB medium in the absence or presence of $10 \mathrm{mM} 3 \mathrm{AT}$ to induce amino acid starvation. Plates were incubated and documented as described in Fig. 7A.

(B) Expression of $F L O 11: \because$ lacZ reporter gene was measured with the same yeast strains as described in (A) carrying a FLO11::lacZ reporter. Yeast strain RH2697 ( $\triangle g c n 4)$ carrying a GCRE6::lacZ reporter transformed with the same plasmids was used for measurement of GCRE6::lacZ reporter gene expression. Specific $\beta$-galactosidase activities were analyzed as described in Fig. 8.

\subsubsection{Dimerization of Gen4 $p^{\mathrm{L267S}}$ is reduced compared to wild type Gen4p}

Gen $4 p$ consists of several domains for transcriptional activation, stability, DNA binding or dimerization (Landschulz et al., 1988; Kornitzer et al., 1994; Drysdale et al., 1995). The substitution Leu267Ser is located in the C-terminus in the third of four leucines of the leucine zipper dimerization region of Gcn $4 p$ (Fig. 10A). Due to this localization the impact of this substitution on Gen4p dimer formation was analyzed. 
A

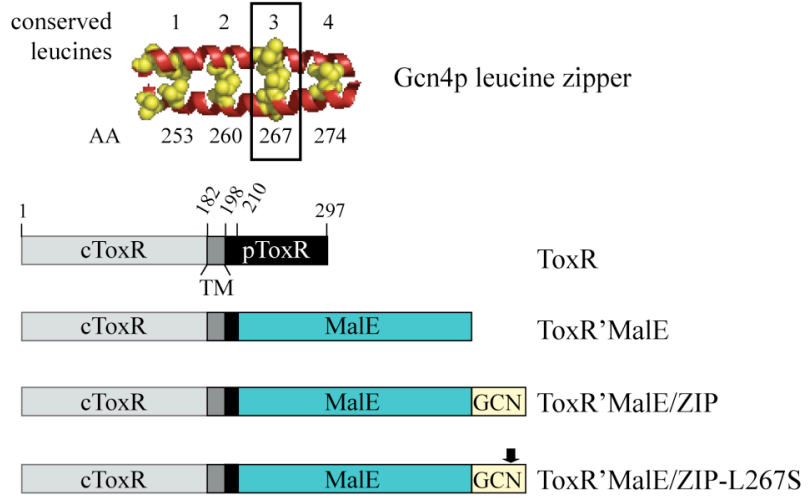

C

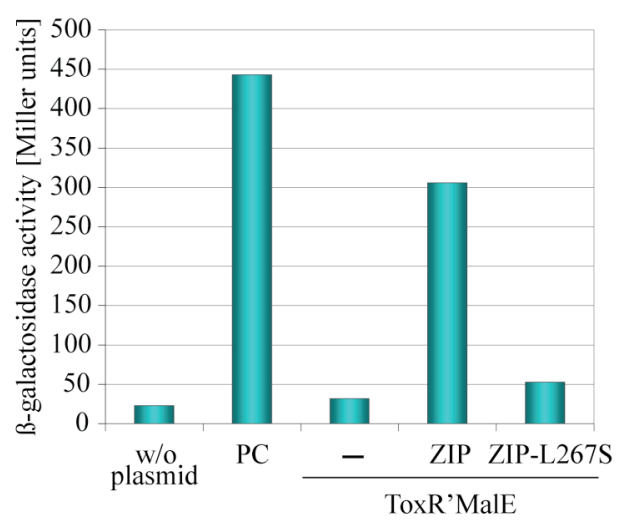

Fig. 10: Decreased dimerization of Gen4p ${ }^{\mathrm{L267S}}$.

(A) Structure of the Gen4p leucine zipper modified according to O'Shea et al. (1991). Upper numbers indicate the position of the four conserved leucines in the leucine zipper of Gen $4 p$, lower numbers the amino acid order in Gen4p (AA). L267 is framed.

(B) Modular organization of the $V$. cholerae signal transduction protein Tox $\mathrm{R}$. Numbers indicate amino acid positions. cToxR, N-terminal cytoplasmic ToxR domain (amino acids 1 - 182); TM, transmembrane segment (amino acids 183 - 198); pToxR, C-terminal, periplasmic domain (amino acids $199-297$ ). Amino acids $1-210$ of ToxR serve as the reference module in all constructs. The periplasmic domain of ToxR was replaced by the monomeric maltose binding protein MalE (ToxR'MalE). By fusing the 33 amino acids of the leucine zipper of Gcn4p to its C-terminus it can be converted from a monomer to a homodimer (ToxR'MalE/ZIP). ToxR'MalE/ZIP-L267S is mutated and contains the amino acid substitution Leu267Ser.

(C) Transcription activation at the $c t x$ promoter in $E$. coli mediated by the ToxR derivates shown in (B). Specific $\beta$-galactosidase activities of $E$. coli strain FHK12, which contains a chromosomally integrated lacZ gene under $c t x$ control, expressing ToxR'MalE without dimerization domain as control (-), ToxR'MalE with wild type dimerization domain (ToxR'MalE/ZIP) or mutated (ToxR'MalE/ZIP-L267S) (pME3389) are shown in Miller units. Additionally, the plasmid free reporter strain FHK12 (w/o plasmid) was used as a control for strains without ToxR function and E. coli strain FHK12 expressing pHKToxR'REI-T39K served as control (PC) which is noted for a strong increase in dimerization (Kolmar et al., 1995a).

The heterologous bacterial ToxR-system was applied which is based on the Vibrio cholerae protein ToxR (Fig. 10B) (Miller et al., 1987). ToxR is an integral membrane protein that acts as transcriptional activator of the $c t x$ promoter. Therefore a ctx driven lacZ reporter, which depends strictly on dimerization of the C-terminal periplasmic ToxR domains gives the opportunity to analyze the dimerization by $\beta$-galactosidase assays in an E. coli indicator strain (FHK12). The ToxR periplasmic domain was replaced by a fusion of the monomeric maltose binding protein (Richarme, 1982; Duplay et al., 1984) and the Gcn4p dimerization domain. The 33 amino acids of the leucine zipper of Gcn4p (pHKToxR'MalE/ZIP) (Blondel and Bedouelle, 1991; Kolmar et al., 1995b) or the corresponding part of the Leu267Ser mutant variant (pHKToxR'MalE/ZIP ${ }^{\mathrm{L} 267 \mathrm{~S}}$ ) were compared in their ability to dimerize and thereby 
mediating transcription of the $l a c Z$ reporter gene. Comparison of the Gen $4 p$ mutant and wild type leucine zipper revealed an approximately six-fold decrease in dimerization ability in the mutant Gcn $4 p^{\text {L267S }}$ compared to wild type, which is caused by the amino acid substitution in the leucine zipper (Fig. 10C).

These data suggest that the reduced transcriptional activator potency of the mutant Gcn4p carrying a substitution of leucine to serine at position 267 in the zipper region is due to reduced dimerization ability.

\subsubsection{Various amino acid substitutions of zipper leucines lead to a separation of the metabolic and developmental Gen4p function}

The leucine at position 267 of Gcn $4 p$ contributes to dimerization as a prerequisite for the full transcriptional activity function of the protein. Full activity neither seems to be required for growth during amino acid starvation nor for the haploid adhesive life style, but it is specifically required for diploid pseudohyphal development and adhesive growth. We introduced other amino acid substitutions at the same position as well as at another conserved leucine of the zipper to analyze whether reduced dimerization is sufficient to separate the metabolic and the developmental Gcn $4 p$ function. These Gcn4p zipper substitutions resulted in a broad range of 1.5- to 13-fold decreased FLO11 expression (41 U - $5 \mathrm{U}$ ) in comparison to wild type Gen4p (GCN4) (66 U) during amino acid starvation (Fig. 8).

Fig. 11A shows that the substitution of Leu267 to alanine (L267A) resulted in $60 \%$ wild type FLO11::lacZ expression (41 U) when treated with $3 \mathrm{AT}$, whereas a substitution of two leucines (L253G and L267G) with a helix breaking glycine nearly abolished FLO11::lacZ expression ( $5 \mathrm{U}-6 \mathrm{U}$ ) comparable to a gcn4 deletion strain (5 U). A substitution with threonine (L267T) or cysteine (L267C) was similar for FLO11 expression upon amino acid starvation like Leu267Ser. The adhesion phenotypes of each mutant strain scored by biofilm formation in wells of polystyrene plates correlated to these results (Fig. 11B). The drastic effect of the glycine substitutions on the zipper leucines was also corroborated by measuring the transcriptional activity of the Gcn $4 p$ variants onto the metabolic target GCRE6::lacZ reporter. Upon 3AT treatment GCRE6::lacZ induction by the glycine variants displayed only to $7-10 \%$ (55U and $83 \mathrm{U}$ ) of wild type induction (782 U) (Fig. 11C). Consistently, the Gcn4 mutant proteins containing a glycine in its leucine zipper were no more able to complement a gcn4 
deletion phenotype or to survive amino acid starvation in contrast to Gen4 $\mathrm{p}^{\mathrm{L} 267 \mathrm{~S}}$, Gcn $4 p^{\mathrm{L} 267 \mathrm{~T}}, \mathrm{Gen} 4 \mathrm{p}^{\mathrm{L} 267 \mathrm{~A}}$ and Gen $4 \mathrm{p}^{\mathrm{L} 267 \mathrm{C}}$, respectively (Fig. 12B). In contrast, cells expressing these four GCN4 variants allowed a $46-71 \%(358-555 \mathrm{U})$ activation of Gcn 4 p-specific target genes upon 3AT treatment (Fig. 11C) and therefore survived amino acid starvation (Fig. 12B).

A

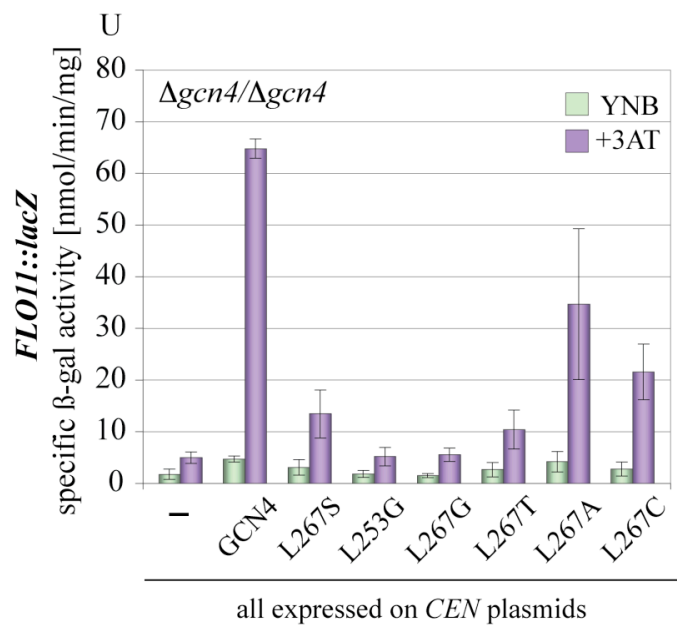

C

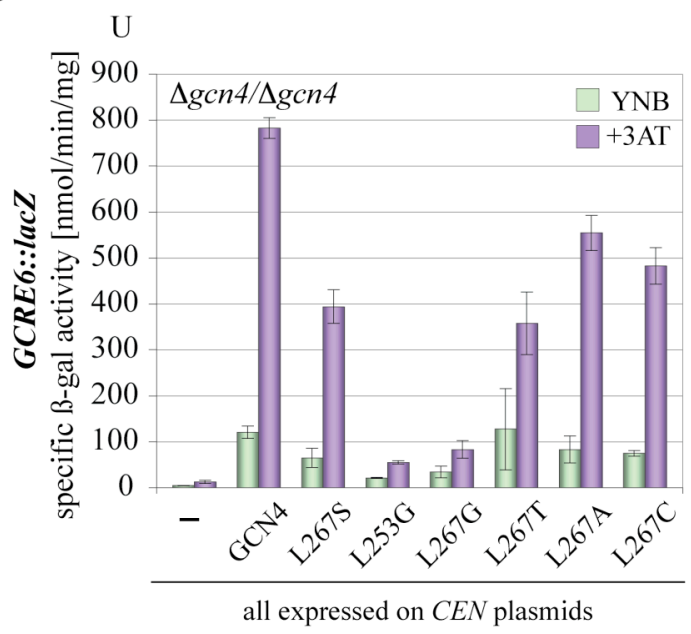

B

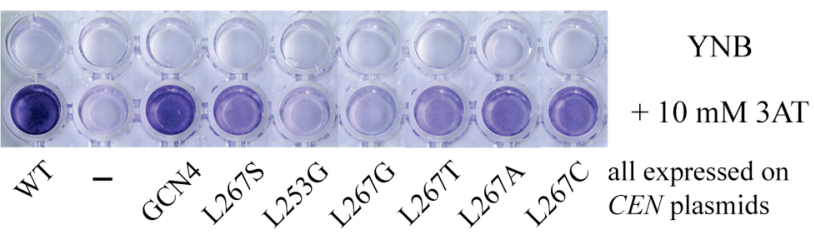

Fig. 11: Impairment of diploid adhesive growth and FLO11 expression in yeast strains expressing $G C N 4$ with various amino acid substitutions of zipper leucines.

(A) The diploid yeast $\Sigma 1278$ b strain RH2695 ( $\Delta g c n 4 / \Delta g c n 4)$ carrying a FLO11::lacZ reporter was transformed with $C E N$ plasmids to express wild type GCN4 (pME1092), GCN4 $4^{L 2675}$ (pME2901), $G C N 4^{L 253 G}$ (pME3378), GCN4 $4^{L 267 G}$ (pME3379), GCN4 ${ }^{L 267 T}$ (pME3380), GCN4 $4^{L 267 A}$ (pME3381), $G C N 4^{L 267 C}$ (pME3382) or the empty vector (pRS314) as control (-) and specific $\beta$-galactosidase activities were assayed.

(B) For testing amino acid starvation induced adhesive growth, same diploid yeast strains as described in (A), and additionally the diploid $\Sigma 1278 \mathrm{~b}$ wild type strain RH2656 as control (WT) were grown in liquid YNB media up to an optical density of 0.6 before $300 \mu 1$ of each culture were transferred in a microtiter well. Cells were grown in absence or presence of $10 \mathrm{mM} 3 \mathrm{AT}$ to induce starvation dependent adhesive growth. After incubation for 2 days at $30^{\circ} \mathrm{C}$, sedimented cells were dyed with crystal violet and carefully washed. Finally plates were photographed to document adhesive growth.

(C) GCRE6::lacZ expression was measured as described in Fig. 8. The diploid yeast strain RH2398 $(\triangle g c n 4 / \triangle g c n 4)$ carrying a chromosomally integrated GCRE6::lacZ reporter construct expressing the different Gcn $4 \mathrm{p}$ mutant plasmids described in (A). 
Next, diploid $\Delta g c n 4 / \Delta g c n 4$ yeast strains expressing one of the GCN4 mutant alleles or wild type GCN4 as control were analyzed for pseudohyphal development upon nitrogen starvation. Cells expressing GCN4 $4^{L 267 S}, G C N 4^{L 267 T}$ or $G C N 4^{L 267 G}$ showed a reduced ability to form pseudohyphae (Fig. 7B and 12A).

A

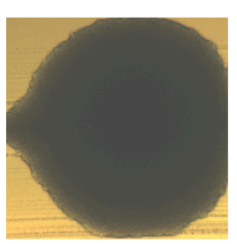

$\Delta g c n 4 / \Delta g c n 4$ $+(C E N)$

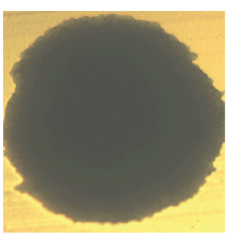

$\Delta g c n 4 / \Delta g c n 4$

+ GCN4L253G (CEN)

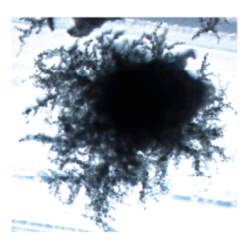

$\Delta g c n 4 / \Delta g c n 4$ + GCN 4 (CEN)

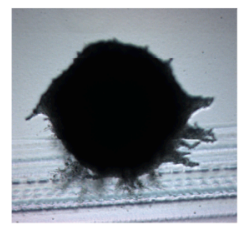

$\Delta g c n 4 / \Delta g c n 4$

+ GCN4L267G (CEN)

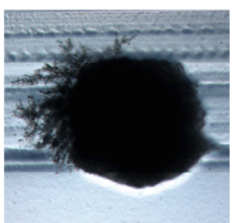

$\Delta g c n 4 / \Delta g c n 4$

+ GCN4L267 (CEN)

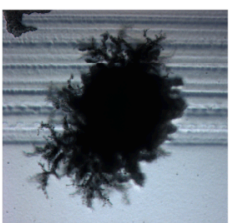

$\Delta g c n 4 / \Delta g c n 4 \quad \Delta g c n 4 / \Delta g c n 4$ $+G C N 4 L 267 A+G C N 4 L 267 C$

B

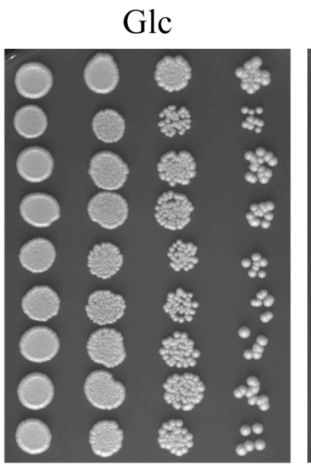
$+5 \mathrm{mM} 3 \mathrm{AT}$

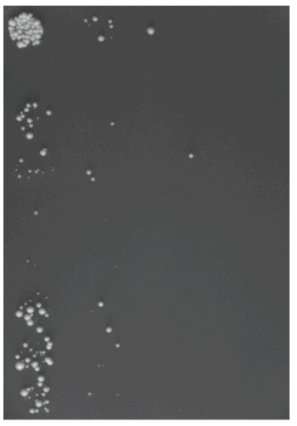

WT

CEN

GCN4 (CEN)

GCN4L267S (CEN)

GCN4L253G (CEN)

GCN4L267G (CEN)

GCN4L267T (CEN)

GCN4L267A (CEN)

GCN4L267C (CEN)

Fig. 12: Constricted pseudohyphal growth of diploid yeast strains expressing different alleles of GCN4.

(A) The diploid $g c n 4$ deletion strain RH2695 ( $\triangle g c n 4 / \Delta g c n 4)$ expressing wild type GCN4 (pME1092), the substituted GCN4 $4^{L 253 G}$ (pME3378), GCN4 $4^{L 267 G}$ (pME3379), GCN4 $4^{L 267 T}$ (pME3380), GCN4 $4^{L 267 A}$ (pME3381) or GCN4 ${ }^{L 267 C}$ (pME3382) from CEN plasmids with GCN4 promoter and terminator or as control the empty vector $(C E N)$ (pRS314) was streaked out on SLAD medium and after incubation for five days at $30^{\circ} \mathrm{C}$ pseudohyphal colonies were visualized.

(B) The same yeast strains as described in (A) and additionally the diploid strain RH2695 ( $\triangle$ gcn4/Agcn4) carrying plasmids with $G C N 4^{22675}$ (pME2901) were spotted in 5-fold dilutions on either glucose medium as control or glucose medium containing $5 \mathrm{mM} 3 \mathrm{AT}$ to induce amino acid starvation. The diploid wild type strain RH3278 (WT) served as growth control. After incubation for $3-4$ days at $30^{\circ} \mathrm{C}$ plates were photographed. 
As expected, a substitution of Leu253 with glycine resulted in a complete loss of pseudohyphae formation upon nitrogen starvation comparable with a gcn4 deletion strain (Fig. 12A). Pseudohyphal development is less affected in diploid cells expressing $G C N 4^{L 267 A}$ or $G C N 4^{L 267 C}$. In comparison to wild type cells, pseudohyphae are shorter and less branched. These two mutant proteins equally showed the highest FLO11 expression and ability to grow adhesively in response to amino acid starvation when compared with the other Gcn4 mutant proteins (Fig. 11A and B).

These results further support, that developmental function of Gen $4 p$ in diploids requires full transcriptional activity of Gcn $4 p$ and does not tolerate defects in dimerization. Diploid cells expressing a GCN4 mutant allele like $G C N 4^{L 267 S}$, which is partially impaired in dimerization, are unable to perform adhesive growth or to form pseudohyphae upon nutrient starvation. However, the same mutants are still able to complement a gcn4 deletion phenotype and protect the cells against amino acid starvation. Abolishment of the metabolic function is achieved by impairing dimerization by replacing leucines of the zipper by helix breakers like glycine which results in an almost inactive transcription factor.

\subsubsection{Protein stability of Gcn $4 p^{\mathrm{L267S}}$ and other dimerization variants is increased in comparison to the wild type protein}

Gcn $4 p$ is under tight protein stability control. Under non-starvation conditions the instable Gcn $4 p$ has a half life of a few minutes that increases up to 20 minutes when cells are starved for amino acids. Gcn $4 \mathrm{p}^{\mathrm{L} 267 \mathrm{~S}}$ dimerization is impaired, suggesting that there is an increased molecule subpopulation which is present as monomer. We analyzed how the stability of Gen $4 p^{\text {L267S }}$ or other Gen $4 p$ variants is affected by the protein degradation pathway in comparison to wild type Gen $4 p$.

A three-fold myc-tagged version of wild type GCN4 or GCN4 $4^{L 267 S}$ was expressed from the inducible GAL1 promoter in a gcn4 mutant strain. Protein levels were determined after GAL1 promoter shut-off in sated and amino acid starved cells. Western hybridization revealed that both wild type Gcn $4 p$ and Gcn $4 p^{\text {L267S }}$ were rapidly degraded in sated cells (Fig. 13). In response to amino acid starvation the substitution of Leu267 to serine was significantly more stabilized than wild type Gen4p. This stabilization was less pronounced when $m y c^{3}-G C N 4^{L 267 A}$ was expressed. Consistently, expression of GCN4 $4^{L 267 A}$ led to the weakest effects on 3AT-induced FLO11 expression 
and adhesive growth when compared with the other GCN4 alleles (Fig. 11A and B). Even the poorly active Gcn $4 \mathrm{p}^{\mathrm{L} 253 \mathrm{G}}$ mutant protein was more stable under amino acid starvation conditions, compared to wild type Gen4p, and actually more stable under non-starvation conditions since it was still detectable after 90 minutes under nonstarvation conditions (Fig. 13).

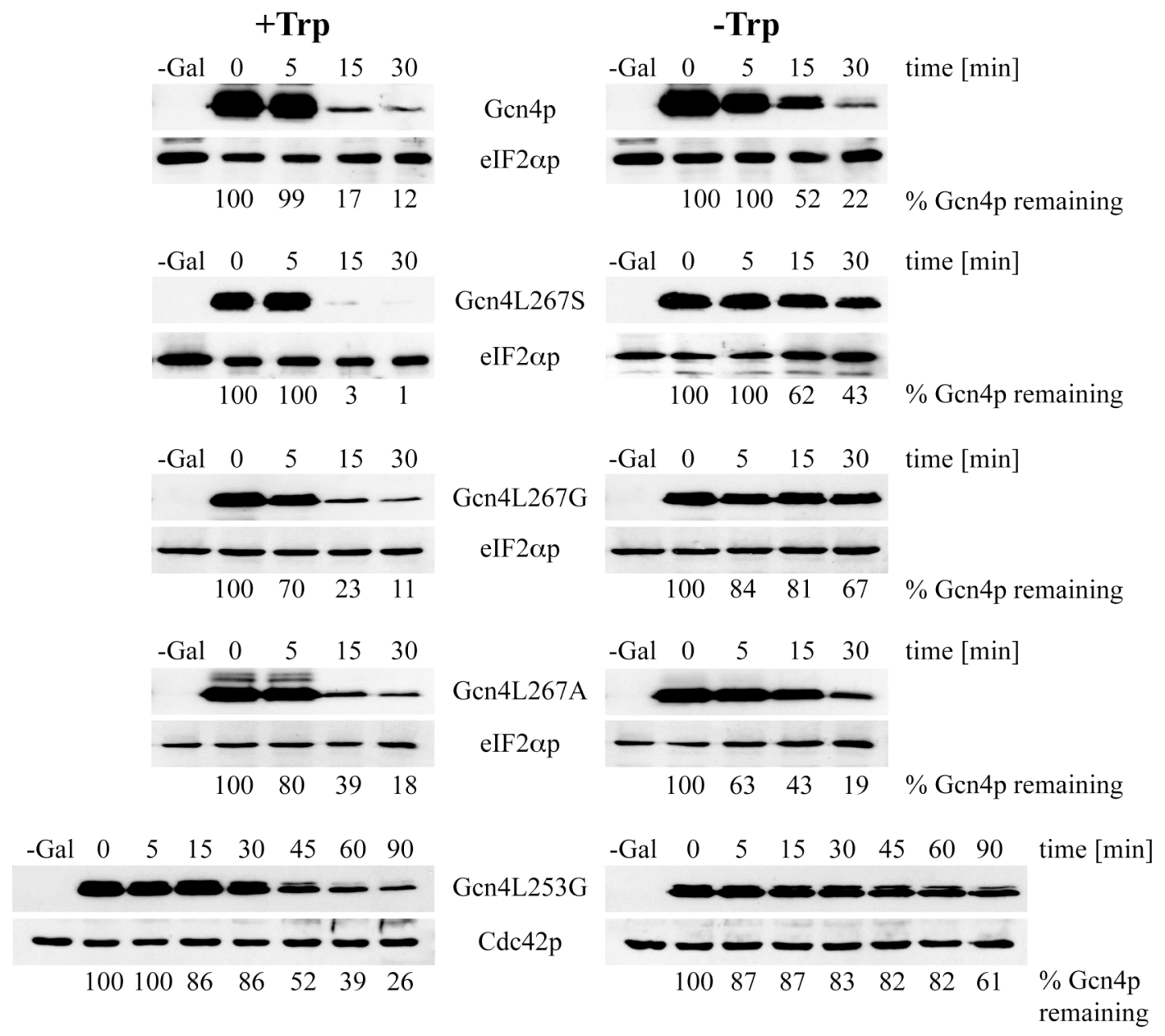

Fig. 13: Increased protein stability of Gcn4p variants compared to wild type Gcn4p.

The diploid $\Sigma 1278 \mathrm{~b}$ strain RH2694 ( $\triangle g c n 4 / \Delta g c n 4)$ was transformed to express the $G A L 1$-driven $m y c^{3}-G C N 4$ (pME2923), myc ${ }^{3}-G C N 4^{L 267 S}$ (pME2925), myc $c^{3}-G C N 4^{L 267 G}$ (pME3384), myc $c^{3}-$ $G C N 4^{L 267 A}$ (pME3386) or $m y c^{3}-G C N 4^{L 253 G}$ (pME3383) on a high copy plasmid. Protein levels of myc ${ }^{3}$-tagged Gcn $4 p$ variants in sated (+Trp) and amino acid starved cells (-Trp) were determined by immunoblotting at the indicated time points after shutting-off the GAL1 promoter by adding $3 \%$ glucose ( 0 -min time point). eIF $2 \alpha p$ or Cdc $42 p$ were used as loading controls. Numbers given below indicate remaining Gcn $4 p$ percentages when compared to eIF $2 \alpha p$ or Cdc $42 p$ as internal standards. 
These data indicate that Gcn4p variants compromised in dimerization and transcriptional activation are more stable than wild type yeast Gcn4p. Increased amino acid starvation-dependent stabilization is achieved when the hydrophobic Leu267 of the zipper is substituted for a polar amino acid. The exchange of zipper amino acid Leu253 by the helix breaker glycine even leads to a stabilization of Gcn4p under non-starvation conditions.

\subsubsection{Gen4p activates its own destruction and therefore Gen4p transcriptional activity reciprocally correlates to its own protein stability}

The results with the different variants of Gcn $4 p$ demonstrate that a decreased degree of Gcn $4 p$ dimerization correlates with increased Gcn $4 p$ stability but at the expense of a reduced transcriptional activation potential. The reason could be that the degradation pathway recognizes a dimer more efficiently than a monomer and therefore a monomeric Gen $4 p$ is a poor target for degradation. Alternatively, full transcriptional activity of Gen $4 p$ could be a prerequisite for an efficient Gen4 protein degradation pathway. The initial step of the Gen $4 p$ degradation pathway is the cyclin dependent phosphorylation by Pho85p-Pcl5p. The PCL5 gene encoding the cyclin contains a GCRE in its promoter and is therefore a Gen $4 p$ target gene.

Stability of Gen $4 \mathrm{p}^{\mathrm{L} 253 \mathrm{G}}$ was analyzed when PCL5 was constitutively expressed to discriminate between the two possibilities. Gen $4 p^{\mathrm{L} 253 \mathrm{G}}$ represents the most stable and transcriptional inactive variant of mutated Gcn $4 \mathrm{p}$. Promoter shut-off experiments were performed with a $G A L 1$ driven $m y c^{3}-G C N 4^{L 253 G}$ in the presence of high amounts of PCL5 (MET25-PCL5-GFP). The presence of Pcl5p resulted in Gcn $4 \mathrm{p}^{\mathrm{L} 253 \mathrm{G}}$ which became significantly instable (Fig. 14A) and the protein turnover was similar to that of Gen4 wild type protein (Fig. 13).

The same yeast strains were further analyzed for Gen $4 p$ toxicity. Gcn $4 p$ synthesis was repressed (glucose) or induced (galactose) by the GAL1 promoter in the presence or absence of amino acid starvation conditions. The diploid wild type strain (RH3278) and control strains expressing wild type $m y c^{3}-G C N 4$ either along with an empty vector or with independently overexpressed PCL5-GFP were used. 
A

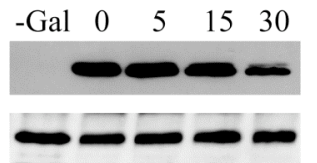

$100 \quad 96 \quad 83 \quad 48$

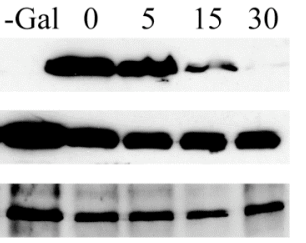

$\begin{array}{llll}100 & 81 & 43 & 1\end{array}$
$+100 \mathrm{mM} 3 \mathrm{AT}$

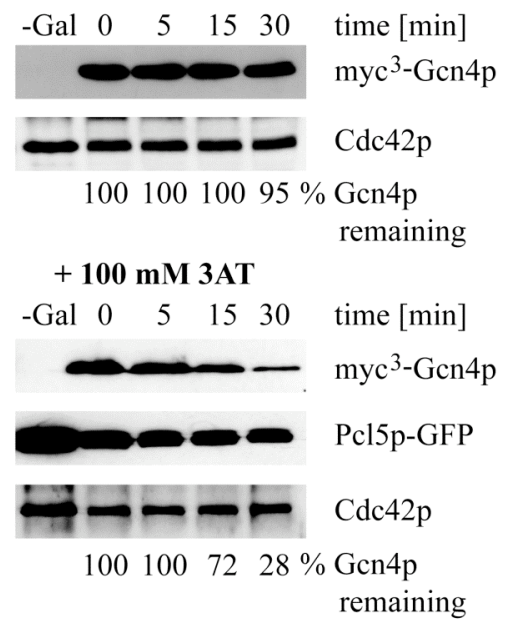

B

\begin{tabular}{|c|c|}
\hline Glc & Gal \\
\hline $\begin{array}{l}00 \\
000 \\
000 \\
00 \\
00 \\
000 \\
000\end{array}$ & 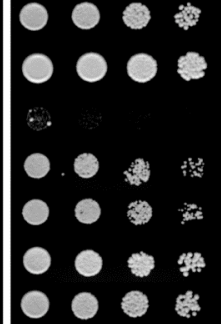 \\
\hline
\end{tabular}

$\mathrm{Gal}+5 \mathrm{mM} 3 \mathrm{AT}$

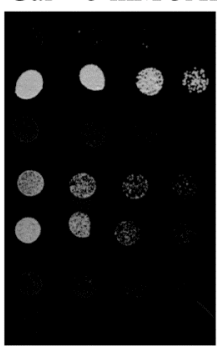

$\mathrm{p} 424 \mathrm{GAL} 1+\mathrm{p} 426 \mathrm{MET} 25$
$\mathrm{WT}$
GAL-myc3-GCN4 + p426MET25
GAL-myc3-GCN4 + MET25-PCL5-GFP
GAL-myc3-GCN4L253G+ p426MET25
GAL-myc3-GCN4L253G+ MET25-PCL5-GFP
MET25-PCL5-GFP + p424GAL1

Fig. 14: Correlation between transcriptional activity of Gcn4p and protein stability.

(A) The diploid $\Sigma 1278 \mathrm{~b}$ strain RH2694 ( $\Delta g c n 4 / \Delta g c n 4)$ was transformed to express GAL1-driven $m y c^{3}-G C N 4^{L 253 G}$ together with either independently overexpressed PCL5-GFP (pME3388 + pME2846) or an empty vector as control (pME3388 + p426MET25). $100 \mathrm{mM}$ of 3AT was used to induce amino acid starvation. Protein levels of myc ${ }^{3}-G c n 4 p$ or Pcl5p-GFP were determined by Western blotting at the indicated time points after shutting-off the GAL1 promoter by the addition of $3 \%$ glucose ( 0 -min time point). Cdc $42 \mathrm{p}$ was used as loading control. Numbers given below indicate remaining Gcn $4 p$ percentages when compared to Cdc42p as internal standard.

(B) The same yeast strains as described in (A), and additionally strain RH2694 transformed with GAL1-driven wild type $m y c^{3}-G C N 4$ in combination with either independently overexpressed PCL5-GFP (pME2918 + pME2846) or an empty vector (pME2918 + p426MET25), were spotted in five-fold dilutions on glucose (repressing conditions) and galactose medium (inducing conditions) to induce expression of GCN4. Serving as further controls, strain RH2694 was transformed with either both empty vectors (p424GAL1 + p426MET25) or independently overexpressed PCL5-GFP along with an empty vector (pME2846 + p424GAL1). The diploid strain RH3278 was used as wild type control (WT). Furthermore, strains were spotted on galactose medium containing $5 \mathrm{mM} 3 \mathrm{AT}$ to induce amino acid starvation. After incubation for 3 -4 days at $30^{\circ} \mathrm{C}$ the plates were photographed.

Yeast cells expressing wild type GCN4 from the GAL1 promoter grew neither under inducing conditions (Gal) nor under inducing conditions and additional amino acid starvation $(\mathrm{Gal}+5 \mathrm{mM} 3 \mathrm{AT})$ due to the overexpression toxicity of Gcn $4 \mathrm{p}$ (Fig. 14B) (Tavernarakis and Thireos, 1995; Shemer et al., 2002). Growth was reconstituted when PCL5 was co-expressed. In contrast, cells expressing $G C N 4^{L 253 G}$ along with an 
empty vector were able to grow in the presence of $5 \mathrm{mM} 3 \mathrm{AT}$, due to the significantly reduced transcriptional activity of this Gen4p variant (Fig. 11C). Additional overexpression of Pcl5p caused degradation of Gen $4 p^{\text {L253G }}$ (Fig. 14A) and cells were unable to grow upon amino acid starvation induced by $5 \mathrm{mM} 3 \mathrm{AT}$, similar to cells expressing wild type GCN4 along with an empty vector (Fig. 14B).

These results revealed that the identified Gcn4p variant Leu267Ser is not sufficiently active to induce its own destruction similar to wild type. Gen4p $\mathrm{p}^{\mathrm{L} 253 \mathrm{G}}$ exhibits its phenotype due to a feedback loop which connects its protein stability to its reduced transcriptional activation potential. 


\subsection{The UPR transcription factor Hac1p mediates Flo11p-dependent adhesion and dimorphism in diploid yeasts}

Amino acid starvation triggers the activation of the 'general control of amino acid biosynthesis' (GAAC) in S. cerevisiae. The transcriptional activator Gcn4p represents the key regulator of this network and activates hundreds of genes (Natarajan et al., 2001). The 'unfolded protein response' (UPR) represents a second system and is activated by unfolded proteins, which accumulate in the ER. The central regulator of this system is the transcription factor Hac1p, however, Gen $4 p$ is also required for the activation of elements of the UPR (Patil et al., 2004). Therefore we have analyzed the role of Hac1p for the control of Gcn4p specific target genes.

\subsubsection{Hac1p is required for inducing a general control reporter gene whereas it is repressed by ER stress}

We examined the influence of a hacl deletion using a Gen $4 p$ specific reporter gene which contains six GCRE-binding sites for Gen4p upstream of the CYC1::lacZ minimal promoter. Thus, expression of GCRE6::lacZ could be quantified by $\beta$-galactosidase assays. The GCRE6::lacZ gene was chromosomally integrated into the $U R A 3$ locus of haploid wild type strain as well as into $\Delta h a c l$ and $\Delta g c n 4$ single or double mutant strains. $\beta$-galactosidase activities of resulting strains were monitored under four different growth conditions as follows: non-starvation (YNB), amino acid starvation induced by the histidine analogon 3-amino-1,2,4-triazole (3AT) (Klopotowski and Wiater, 1965), ER stress by the addition of the UPR stressor tunicamycin $(\mathrm{Tm})$ that inhibits protein folding by inhibiting $\mathrm{N}$-linked glycosylation (Back et al., 2005), and starvation for nitrogen by the reduction of the ammonium sulfate concentration from $50 \mathrm{mM}$ to $50 \mu \mathrm{M}$ (Fig. 15A).

Basal expression of the GCRE6::lacZ reporter was almost identical in wild type and $\Delta h a c l$ cells under sated conditions (YNB). In contrast, upon amino acid starvation (3AT) $\Delta$ hacl cells were unable to induce the general control system of amino acid biosynthesis and remained at the basal level as in wild type cells in the presence of amino acids (Fig. 15A). Both strains containing a gcn4 deletion were not able to activate GCRE6::lacZ expression neither under non-starvation conditions nor in response to amino acid starvation. 
A

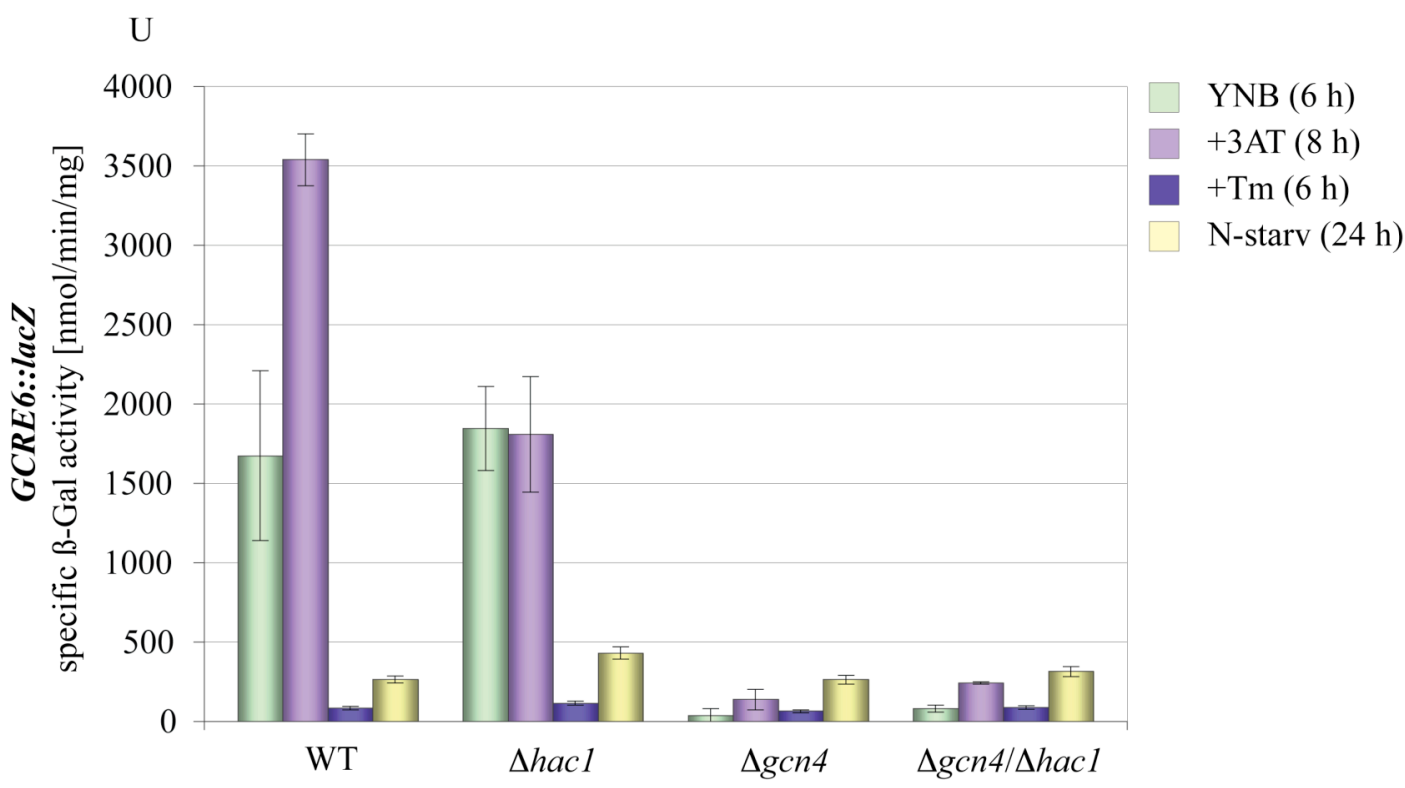

B
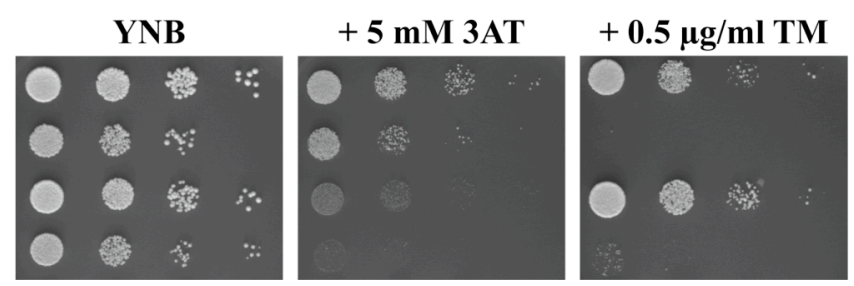

WT

$\Delta h a c 1$

$\Delta g c n 4$

$\Delta g c n 4 / \Delta h a c 1$

Fig. 15: Gcn4p-dependent reporter gene expression is governed by Hac1p and repressed by ER stress in haploids.

(A) Expression of GCRE6::lacZ was determined in haploid $\Sigma 1278 \mathrm{~b}$ wild type strain (WT) (RH3409) as well as in $\Delta h a c 1$ (RH3363), $\Delta g c n 4$ (RH3410) and $\Delta g c n 4 / \Delta h a c l$ (RH3411) mutant strains each carrying a chromosomally integrated GCRE6::lacZ reporter. Expression was measured under different nutritional conditions. Starting from one overnight culture, strains were diluted into fresh medium and further cultivated for $6-24 \mathrm{~h}$ in the respective media before specific $\beta$-galactosidase activities were assayed. Cultures were grown to log-phase in YNB under non-starvation conditions (green bars, YNB (6 h)). Amino acid starvation and ER stress conditions were induced by addition of either $10 \mathrm{mM} 3 \mathrm{AT}$ (purple bars, +3AT (8 h)) or 1 $\mu \mathrm{g} / \mathrm{ml}$ tunicamycin (dark blue bars, Tm $(6 \mathrm{~h})$ ). For nitrogen starvation (N-starv) yeast cells were washed twice with $2 \%$ glucose before incubating for $24 \mathrm{~h}$ in minimal medium containing only $50 \mu \mathrm{M}$ ammonium sulfate as the sole nitrogen source (yellow bars, N-starv $(24 \mathrm{~h})$ ). Units of specific $\beta$-galactosidase activities are shown in nanomoles per minutes per milligram. The bars represent the mean value of at least three independent measurements.

(B) Haploid $\Sigma 1278 b$ wild type strain (WT) (RH2816) as well as $\Delta$ hacl (RH3351), $\Delta$ gcn4 (RH2676) and $\Delta g c n 4 / \Delta h a c 1$ (RH3402) mutant strains were spotted in 10-fold dilutions on either glucose medium as control (YNB) or glucose medium containing $5 \mathrm{mM} 3 \mathrm{AT}$ to induce amino acid starvation. Furthermore, the cells were spotted on glucose medium containing $0.5 \mu \mathrm{g} / \mathrm{ml} \mathrm{Tm}$ to mimic ER stress. After incubation for $3-4$ days at $30^{\circ} \mathrm{C}$ plates were photographed. 
Gcn $4 p$ is a very unstable protein under non starvation conditions and half life of Gen $4 p$ increases when starved for amino acids, however, the unstable Gcn $4 p$ is sufficient to ensure basal levels of biosynthetic genes in wild type cells. In contrast, yeasts deleted for GCN4 are no longer in a position to enable this basal activity in sated cells. In addition, expression was repressed in all cells when starved for nitrogen which was already demonstrated by Grundmann et al. (2001). Interestingly, the GCRE-driven gene expression was drastically reduced upon ER stress conditions. Expression actually more decreased when compared to starvation for nitrogen. Consistent results were obtained by growth assays under non-starvation, amino acid starvation, and ER stress conditions. All parental haploid strains grew under non-starvation conditions (YNB) whereas growth of $\Delta h a c 1$ cells is reduced upon amino acid starvation (+5 mM 3AT) when compared with wild type cells (Fig. 15B). Cells containing a gcn4 deletion neither were able to activate Gen $4 p$ specific target genes under both conditions nor to grow in the presence of amino acid starvation. As expected, cells containing a hacl deletion disabled growth under ER stress conditions $(+0.5 \mu \mathrm{g} / \mathrm{ml} \mathrm{Tm})$.

These data suggest that not only Gcn4p is required for the activation of elements of the UPR upon ER stress but also Hac1p influences activation of Gen $4 p$ specific target genes in response to amino acid starvation. In contrast, ER stress represses this activation similar to nitrogen starvation.

\subsubsection{ER stress represses $G C N 4$ mRNA translation}

Our results suggest that activation of Gen $4 p$ specific target genes is repressed by ER stress. Since Patil and co-workers documented an up-regulation of Gen $4 p$ levels in response to ER stress, especially 15 and 30 minutes post tunicamycin treatment (Patil et al., 2004), we were interested whether we can confirm this short UPR-dependent upregulation of Gcn $4 \mathrm{p}$. First of all, we measured the expression of the GCRE6::lacZ reporter in haploid wild type cells under eight different conditions whereupon four were described in Fig. 15A. To analyze the activation of the reporter gene at different time points post ER stress induction cells were cultivated corresponding to non-starvation conditions before ER stress was induced for different time intervals (Fig. 16A). In fact, we could measure a short up-regulation of GCRE-driven gene expression, which is Gcn4p-dependent. When cells were treated longer time intervals with tunicamycin, 
however, expression of GCRE6::lacZ reporter gene was reduced a fortiori the longer cells were grown under ER stress conditions.

A

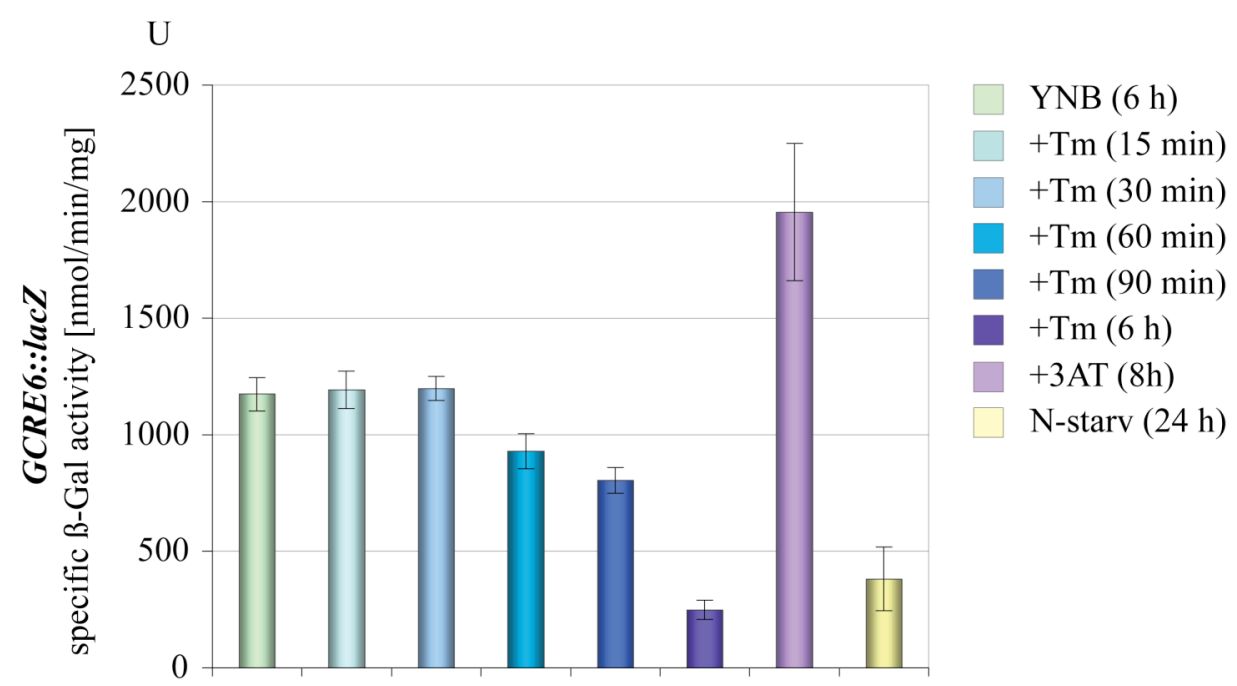

B

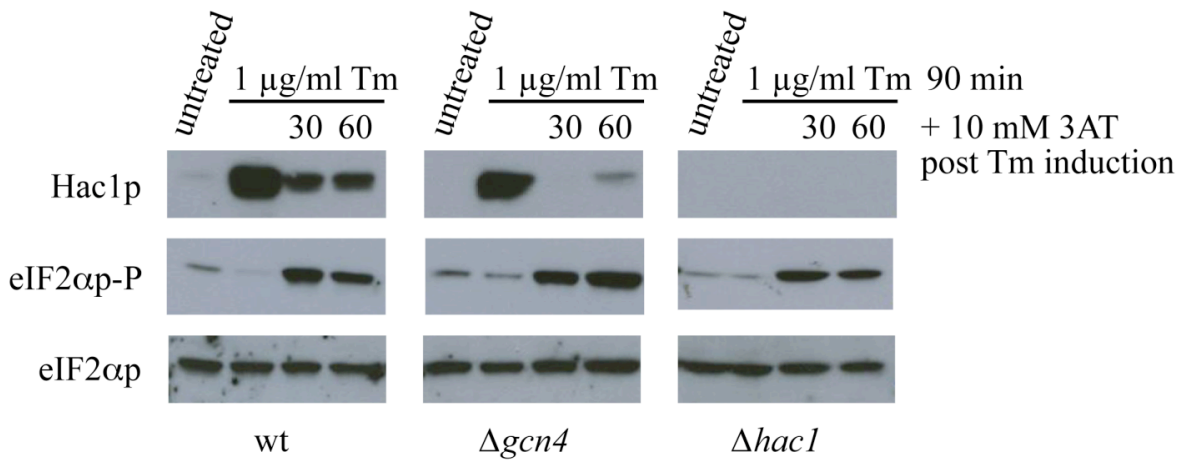

Fig. 16: Gcn4p-dependent reporter gene expression and eIF2 $\alpha$ phosphorylation are reduced upon ER stress.

(A) Expression of the GCRE6::lacZ reporter gene was determined in the haploid $\Sigma 1278 \mathrm{~b}$ wild type strain RH3409 under non-starvation (YNB, green bar) in comparison to different starvation or stress conditions. Amino acid (3AT, purple bar) and nitrogen starvation (N-starv, yellow bar) were induced as described in Fig. 15A. For ER stress conditions cells were incubated either in the presence of $1 \mu \mathrm{g} / \mathrm{ml} \mathrm{Tm}$ for $6 \mathrm{~h}$ (Tm, dark blue bar) or cells were initially grown for $6 \mathrm{~h}$ under non-stress conditions before incubating for indicated time points with $1 \mu \mathrm{g} / \mathrm{ml} \mathrm{Tm}$ (blue bars; the longer Tm induction, the deeper is the color). Specific $\beta$-galactosidase activities were analyzed as described in Fig. 15A.

(B) Crude protein extracts were prepared from haploid $\Sigma 1278 \mathrm{~b}$ wild type cells (WT) (RH2816) as well as from $\Delta g c n 4$ (RH2676) and $\Delta h a c 1$ (RH3351) mutant strains, respectively. Cells were grown either under normal conditions (untreated) or in presence of ER stress conditions induced by $1 \mu \mathrm{g} / \mathrm{ml}$ tunicamycin $(\mathrm{Tm})$. Additional amino acid starvation was obtained by adding $10 \mathrm{mM} 3 \mathrm{AT}$. Starting from one main culture with $\mathrm{OD}_{600} \sim 0.8$ at $30^{\circ} \mathrm{C}$ cultures were quartered and cultivated further 90 min under indicated conditions. Protein levels of Haclp and eIF2 $\alpha$ p-P were analyzed by immunoblotting using specific antibodies. eIF2 $\alpha p$ was used as loading control. 
Haclp is expressed in both haploid wild type and $\Delta g c n 4$ cells under ER stress conditions (Fig. 16B). This expression is reduced by concurrent presence of 3AT, which in turn is Gen4p-dependent. Furthermore, phosphorylation of eIF2 $\alpha$ p was weak in all untreated strains and weakened once more upon ER stress. In contrast, amino acid starvation overruled the suppressed influence of tunicamycin and de-repressed phosphorylation of eIF2 $\alpha$. These findings confirm our assumption that Gcn $4 p-$ dependent target gene expression is finally repressed upon ER stress conditions, which in turn is caused by reduced eIF2 $\alpha$ p phosphorylation.

Additionally, we measured translational efficiency of GCN4 mRNA using a GCN4::lacZ fusion construct which represents an accurate measure for this to further corroborate our hypothesis (Hinnebusch, 1985). Haploid wild type strain as well as $\Delta h a c 1$ and $\Delta g c n 4$ single and double mutant strains were transformed with the GCN4::lacZ fusion plasmid and $\beta$-galactosidase activities were measured likewise under eight conditions as described for GCRE6::lacZ expressions (Fig. 16A).

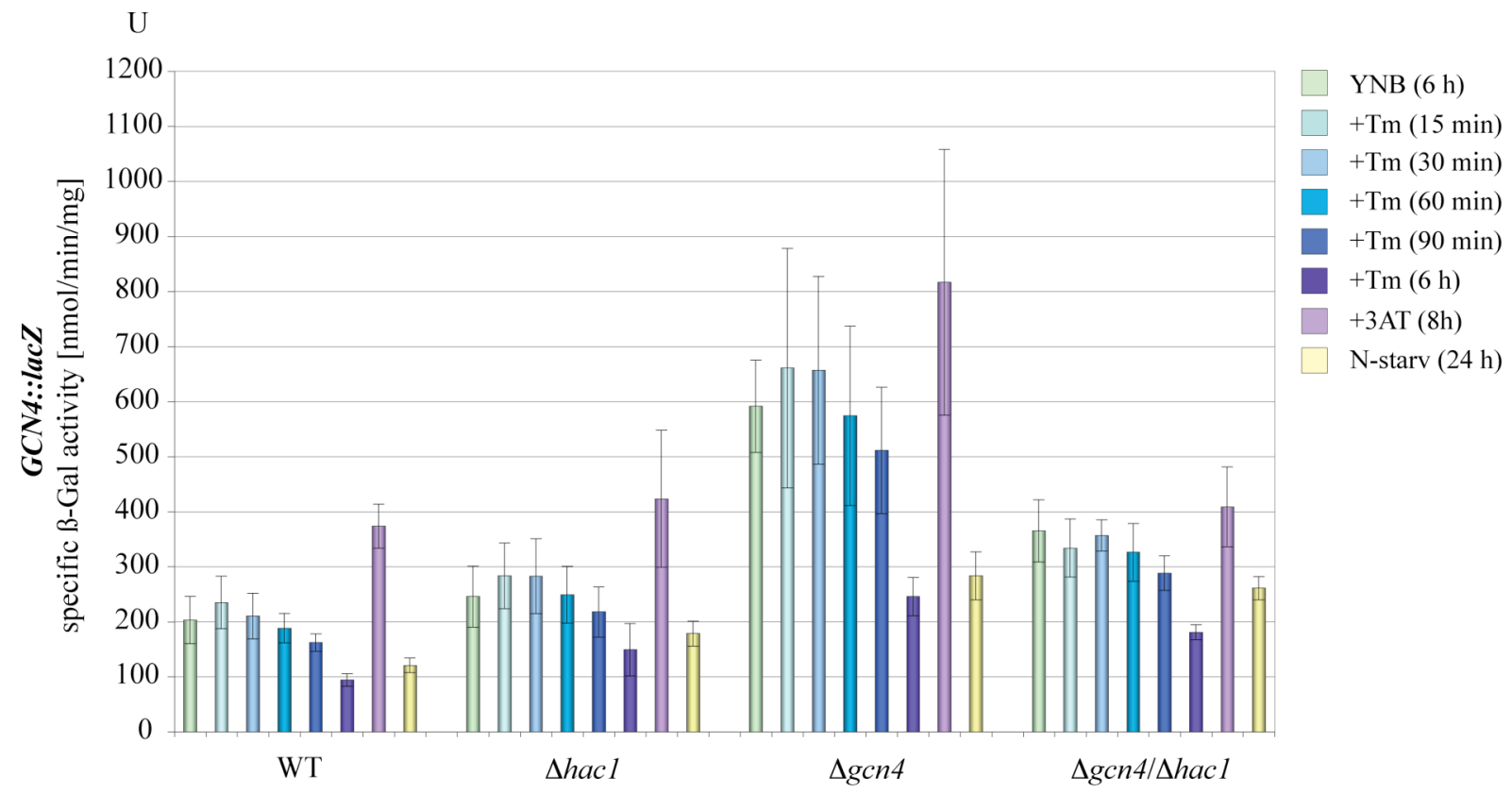

Fig. 17: Repression of GCN4 mRNA translation by ER stress is independent of Hac1p.

Expression of a GCN4::lacZ fusion gene (p180) was measured in a haploid $\Sigma 1278 \mathrm{~b}$ wild type strain (WT) (RH2816) as well as in $\Delta$ hacl (RH3351), $\Delta$ gcn4 (RH2676) and $\Delta g c n 4 / \Delta h a c l$ (RH3402) mutant strains under different nutritional conditions. Bars depict means of at least three independent measurements of $\beta$-galactosidase activities. 
GCN4::lacZ expression decreased when cells were starved for ammonium (Fig. 17) (Grundmann et al., 2001). Consistent with our previous findings, GCN4::lacZ expression increased in all strains for a short time (15 and $30 \mathrm{~min})$ post ER stress induction before decreasing after 6 hours onto the expression achieved by nitrogen starvation. However, with the exception of the $\Delta g c n 4$ strain, no prominent differences between the other strains were measured. The general increased data of the $\Delta g c n 4$ are traced back to an induced general control system and in agreement with our previous findings that nitrogen starvation represses amino acid starvation-induced activation of GCN4 expression on its translation level (Grundmann et al., 2001). We further measured the expression of the GCN4::lacZ fusion construct in haploid S288c wild type cells in which a higher activation of GCN4 expression upon amino acid starvation but not for nitrogen starvation is documented (Grundmann et al., 2001).

Amino acid starvation led to a significant induction of $\beta$-galactosidase activity in haploid S288c wild type cells. In contrast, both nitrogen starvation and ER stress abolished GCN4::lacZ expression (Fig. 18).

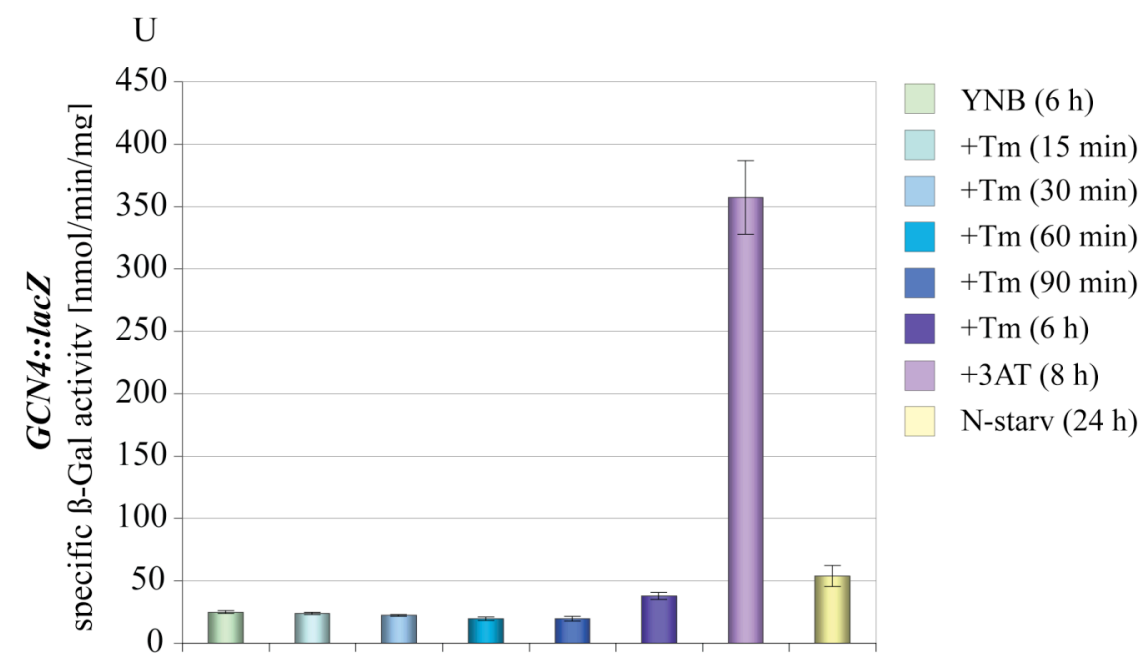

Fig. 18: Repression of GCN4 expression by ER stress in haploid S288c cells.

Haploid S288c wild type strain RH2520 was transformed with plasmid p180 to express the GCN4::lacZ reporter gene. Cells were cultivated as described in Fig. 16 before specific $\beta$ galactosidase activities were assayed. Units of specific $\beta$-galactosidase activities are shown in nanomoles per minutes per milligram. The bars represent the mean value of at least three independent measurements. 
These data suggest that ER stress is a further signal beside nitrogen starvation, which leads to repression of eIF2 $\alpha$ p phosphorylation followed by repressed GCN4 mRNA translation and target gene expression. Indeed, Haclp itself does not influence eIF2 $\alpha$ p phosphorylation and GCN4 mRNA translation but is responsible fur full activation of Gcn4p target gene expression upon amino acid starvation, which suggests an independent role of Haclp in activation of GCREs. It is demonstrated that Gen $4 p$ directly interacts with UPRE-1 (CAGNGTG) and UPRE-2 (TACGTG) (Patil et al., 2004). Both share 'half-site' similarity having a three base identity at the 3 ' end (GTG) and for Gen $4 p$ it is known that it can bind to half-sites (Hollenbeck and Oakley, 2000) and the potential UPRE-half-site is present in the GCRE consensus sequence (RRRWGASTCA; with $\mathrm{R}=$ purine, $\mathrm{W}=\mathrm{T}$ or $\mathrm{A}$, and $\mathrm{S}=\mathrm{G}$ or $\mathrm{C}$ ) (Natarajan et al., 2001). Therefore, it could be possible, that both Gen4p and Haclp, regulate the activation of the other target genes by binding to half-sites in their promoter regions. In contrast, Gcn $4 p$ influences UPR-activated Haclp expression in concurrent presence of 3AT.

\subsubsection{Repression of Gcn4p-dependent gene expression in diploid homozygous $\Delta h a c 1$ and $\Delta g c n 4$ strains}

Furthermore, we were interested whether our findings concerning the reduced Gcn $4 p$ target gene expression upon amino acid starvation in haploid $\Delta h a c 1$ cells could be confirmed in diploids, since most natural yeasts are dimorphic and diploid (Mortimer, 2000). Therefore, the GCRE6::lacZ reporter gene containing haploid MATa strains were crossed with respective $M A T \alpha$ strains to obtain homo- and heterozygous diploid strains deleted for $H A C 1, G C N 4$ or both. Expression of Gen4p reporter gene was monitored in sated and amino acid starved cells (Fig. 19).

With the exception of the heterozygous $\Delta g c n 4 / \Delta h a c 1$ strain, we found that expression of the GCRE6::lacZ reporter is insignificantly reduced in heterozygous $\Delta h a c l$ and $\Delta g c n 4$ strains under both conditions when compared to the expression obtained in diploid wild type cells. As expected, expression was strong decreased in diploid homozygous strains deleted for GCN4. However, GCRE-driven gene expression also was significantly reduced in homozygous $\Delta h a c l$ cells. No intrinsic activation upon amino acid starvation could be detected as indicated for haploid $\Delta$ hacl cells. 


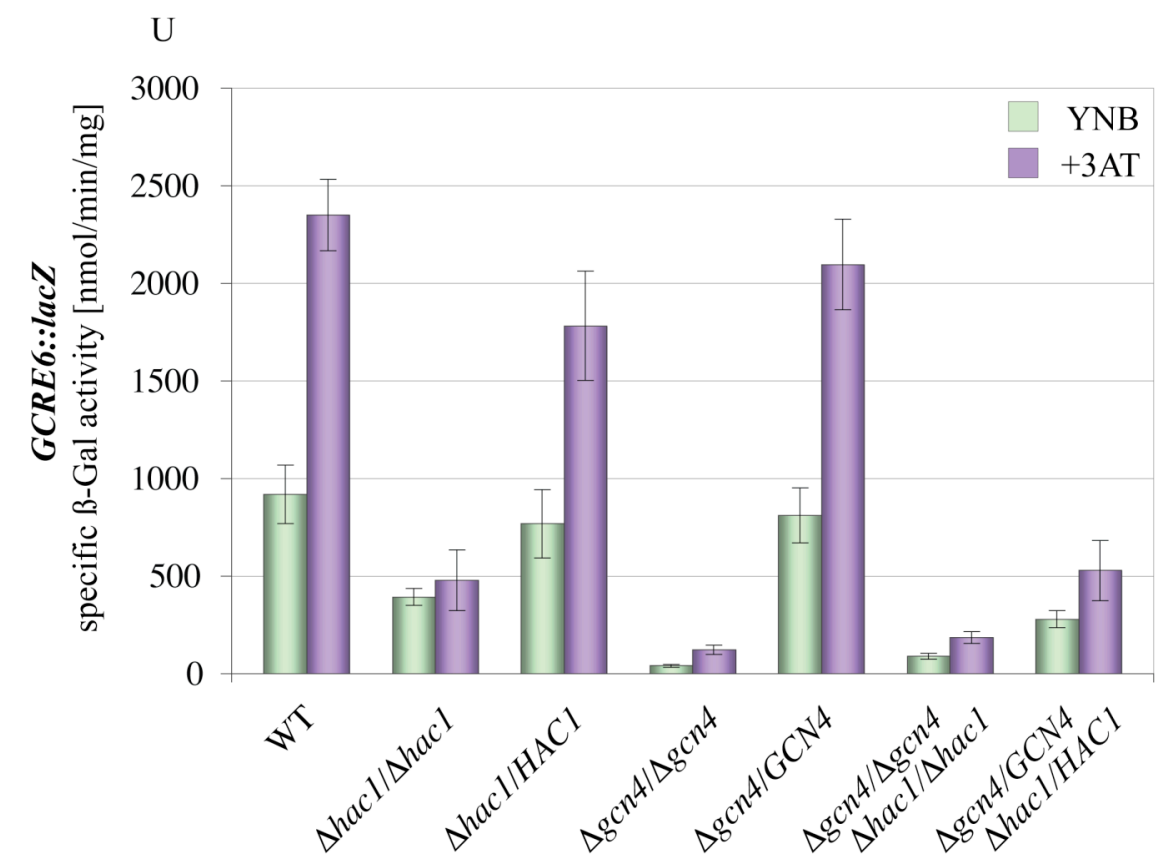

Fig. 19: Gcn4p-dependent reporter gene expression is repressed in diploid homozygous $\Delta$ hac1 and $\Delta$ gcn 4 cells.

Diploid wild type yeast strain (WT) (RH3421) as well as homo- and heterozygous $\Delta$ hacl/Ahacl (RH3422), $\Delta$ hac1/HACl (RH3423), $\Delta g c n 4 / \Delta g c n 4$ (RH2398), $\Delta g c n 4 / G C N 4$ (RH3424), $\Delta g c n 4 / \Delta g c n 4 / \Delta h a c 1 / \Delta h a c 1$ (RH3350) and $\Delta g c n 4 / G C N 4 / \Delta h a c 1 / H A C 1$ (RH3425) mutant strains each carrying a chromosomally integrated GCRE6::lacZ reporter were grown to log-phase in YNB in absence (green bars, YNB) or presence of $10 \mathrm{mM} 3 \mathrm{AT}$ (purple bars, +3AT) before specific $\beta$-galactosidase activities were assayed.

These findings further confirm our assumption that not only Gcn4p is required for the activation UPREs upon ER stress but also Hac1p influences activation of Gcn $4 p$ specific target genes in response to amino acid starvation in haploids and as well in diploids. However, heterozygous diploids compensate the decreased expression.

\subsubsection{Hac1p reduces $F L O 11$ expression and adhesive growth in haploid cells}

Beside this activation of target genes by direct binding to specific Gen4presponse elements in their promoter regions Gcn $4 p$ evokes a strong adhesion of yeast cells on surfaces or on each other upon amino acid starvation, which is mediated by the floccolin Flo11p (Braus et al., 2003). Flo11p is classified as indirect target gene of Gcn $4 \mathrm{p}$ since the promoter of FLO11 does not possess direct binding sites for Gen $4 \mathrm{p}$ and direct binding has not been shown so far. We investigated whether Haclp also influence expression of Gcn $4 p$ unspecific target genes using a FLO11::lacZ reporter construct. Therefore, the FLO11::lacZ reporter that contains 3,500 base pairs of the FLO11 
promoter in front of a $C Y C 1:: l a c Z$ minimal promoter was integrated into the URA3 locus of haploid wild type as well as into $\Delta h a c l$ and $\Delta g c n 4$ single or double mutant strains, respectively. $\beta$-galactosidase activities of resulting strains were determined under non-starvation conditions (YNB) and in amino acid starved cells (+3AT).

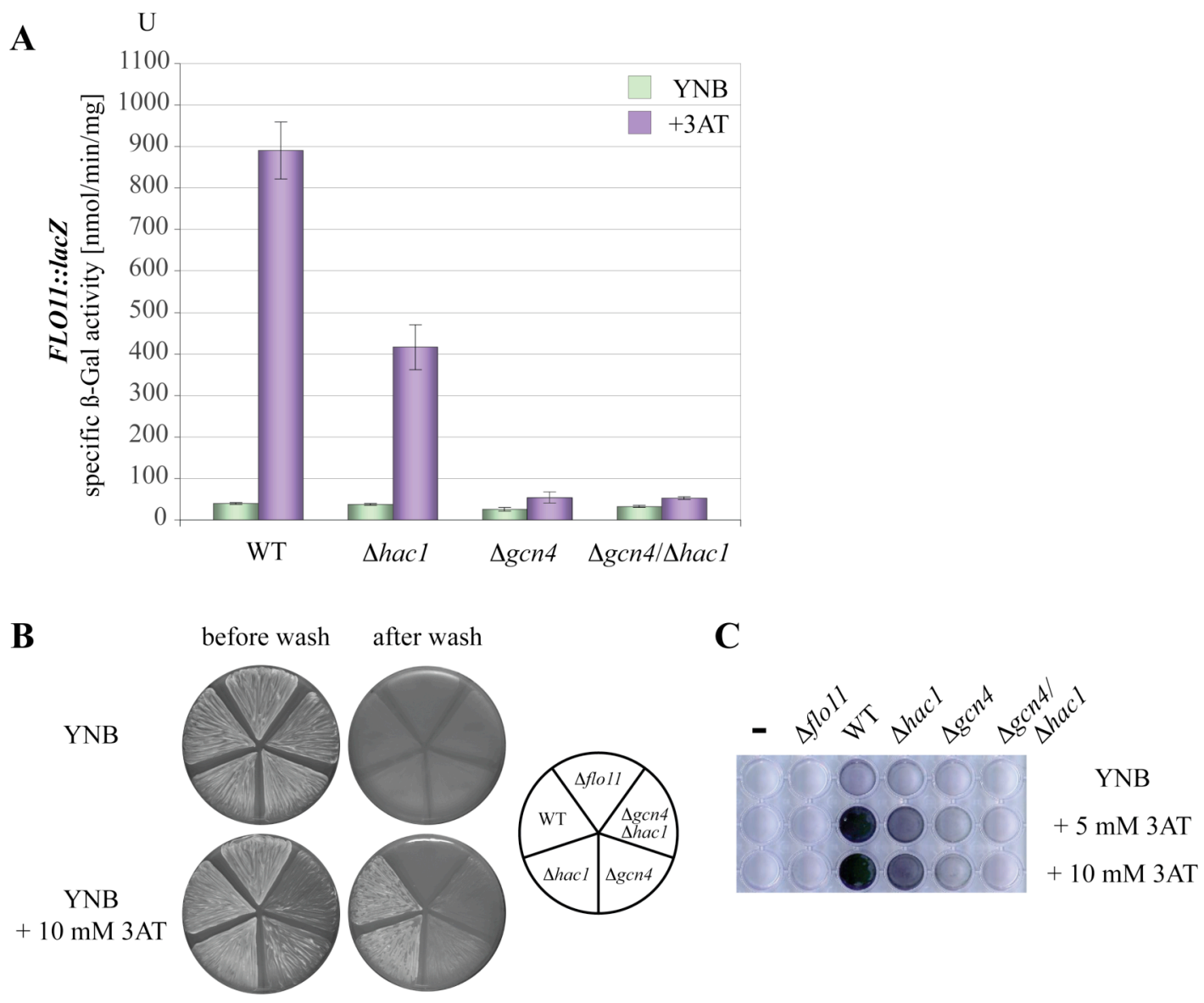

Fig. 20: FLO11::lacZ expression and adhesive growth are partially reduced in haploid $\Delta$ hac1 cells.

(A) Expression of FLO11::lacZ was assayed in haploid $51278 \mathrm{~b}$ wild type yeast strain (WT) (RH3406) as well as in $\Delta h a c 1$ (RH3360), $\Delta g c n 4$ (RH3407) and $\Delta g c n 4 / \Delta h a c l$ (RH3408) mutant strains each carrying a chromosomally integrated $F L O 11::$ lacZ reporter. Cultures were grown to log-phase in YNB in absence (green bars, YNB) or presence of $10 \mathrm{mM}$ 3AT (purple bars, $+3 \mathrm{AT}$ ) before specific $\beta$-galactosidase activities were measured.

(B) Haploid $51278 \mathrm{~b} \Delta$ floll (RH2681), wild type (WT) (RH2816), $\Delta$ hacl (RH3351), $\Delta$ gcn 4 (RH2676) and $\Delta g c n 4 / \Delta h a c 1$ (RH3402) yeast strains were streaked out on solid YNB medium (non-starved cells) and with $10 \mathrm{mM} 3 \mathrm{AT}$ (histidine starved cells), respectively. After incubation for three days at $30^{\circ} \mathrm{C}$ adhesive growth was determined. Plates were photographed prior (before wash) and after washing under a stream of water (after wash) to document remaining cells on the agar surface.

(C) The same yeast strains as described in (B) were grown in liquid YNB media until an optical density of 0.6 before $300 \mu \mathrm{l}$ of each culture were transferred in a microtiter well. Cells were grown in absence or presence of 5 or $10 \mathrm{mM} 3 \mathrm{AT}$ to induce starvation dependent adhesive growth. After incubation for $24 \mathrm{~h}$ at $30^{\circ} \mathrm{C}$, sedimented cells were dyed with crystal violet and carefully washed. Finally, plates were photographed to document adhesive growth. 
Amino acid starvation led to a significant induction of $\beta$-galactosidase activity in haploid wild type cells (891 U) (Fig. 20A). In contrast, only a partial induction could be detected in $\triangle h a c 1$ cells $(416 \mathrm{U})$ corresponding to $\sim 50 \%$ of the FLO11::lacZ expression measured in wild type cells when treated with 3AT. As expected, haploid cells containing a gcn4 deletion showed no induction upon amino acid starvation (54 $\mathrm{U}$ for $\Delta g c n 4,52 \mathrm{U}$ for $\Delta g c n 4 / \Delta h a c 1)$. Similar results were obtained for the activation of the GCRE6::lacZ reporter whereas basal activity was higher which is due to the Gcn4pdependent basal expression of genes involved in different amino acid biosynthetic pathways regulated by the general control system. However, Flo11p is highly upregulated when haploid cells are starved for either glucose or amino acids (Cullen and Sprague, 2000; Braus et al., 2003), which enables cells to grow adhesively. We investigated whether the reduced FLO11::lacZ expression of $\Delta$ hacl cells is sufficient to grow adhesively when starved for amino acids. Adhesion was analyzed either on agar or on plastic. As expected, all strains did not adhere to the agar substrate or to plastic under non-starvation conditions (Fig. 20B and C). Consistent to the FLO11::lacZ expression, haploid wild type and $\Delta h a c l$ cells became adhesive when treated with $3 \mathrm{AT}$ whereas cells deleted for GCN4 were not able to grow adhesively comparable to the $\Delta$ flo 11 strain. Furthermore, $\Delta$ hacl cells showed a constricted adhesive growth on plastic which reflected the halved FLO11::lacZ expression. The reduced growth of strains lacking GCN4 was already investigated in Fig. 15 and is due to an inactivated general control system, which is regulated by Gcn4p. We conclude that Hac1p is not only responsible for activation of Gen $4 p$ specific target genes but also for Gen $4 p$ unspecific target genes such as Flo11p, nevertheless, is over a threshold which enables haploid $\Delta$ hacl cells to grow adhesively.

\subsubsection{Diploid homozygous hac1 and gcn4 deletion strains repress FLO11::lacZ expression and adhesive growth in response to amino acid starvation}

Since we have shown that the effects of a hacl deletion on GCRE6::lacZ expression are heightened in diploid cells, we analyzed whether this was also valid for the expression of the FLO11::lacZ reporter. Therefore, the FLO11::lacZ reporter gene containing haploid MATa strains were crossed with respective MAT $\alpha$ strains to obtain homo- and heterozygous diploid strains deleted for $H A C 1, G C N 4$ or both. Expression of 
FLO11::lacZ was determined in sated and amino acid starved cells, respectively. As documented for the expression of GCRE6::lacZ (Fig. 19), we found that starvationdependent FLO11::lacZ expression is strongly decreased in diploid homozygous $\Delta$ hacl and $\Delta g c n 4$ strains (Fig. 21A) and cells were not able to grow adhesively (Fig. 21B). Expression was fully restored in heterozygous $\Delta h a c 1$ cells, which allowed adhesive growth. Indeed, FLO11::lacZ expression of heterozygous $\Delta g c n 4$ containing cells was reduced in comparison to the expression obtained in wild type or rather heterozygous $\Delta$ hacl cells but was still sufficient to grow adhesively. However, adhesive growth is reduced when compared with wild type and heterozygous $\Delta h a c 1$ cells, respectively.

Starvation for nitrogen is a further nutritional signal in diploid cells, which triggers developmental changes. In response to nitrogen starvation diploid yeast cells can switch to a filamentous growth form, which is called pseudohyphae (Gimeno et al., 1992; Mösch, 2000). Due to the fact that the flocculin Flo11p is required for adhesive growth in response to amino acid starvation as well as for filamentous growth in response to nitrogen starvation in diploids (Gimeno et al., 1992), we examined pseudohyphal growth. Commensurate to our previous findings, all homozygous deletion strains were suppressed in forming pseudohyphae comparable with a $\Delta$ flo $11 / \Delta$ flo 11 mutant strain (Fig. 21C). In contrast, all heterozygous strains developed pseudohyphae.

The results of this section show, that not only direct target genes of Gen $4 p$ are influenced by Hac1p but also indirect target genes such as Flo11p. As shown in previous section, consequences are less intense in haploids. Effects caused by diploid homozygous mutants can be compensated in respective heterozygous strains. 
A

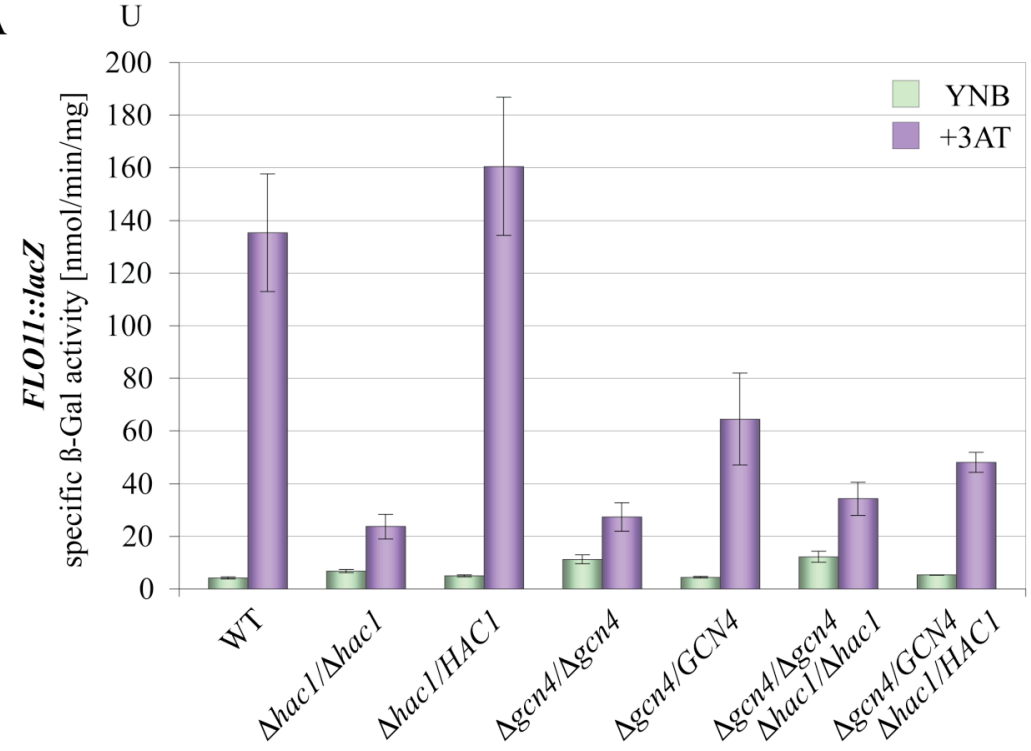

B

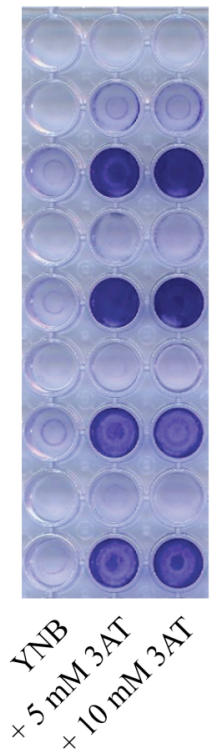

C

$\Delta$ flo11/4flo11

$\Delta$ flo11/4flo11
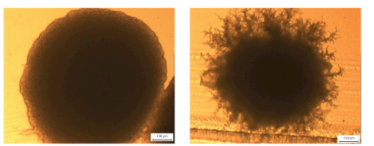

WT

WT

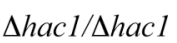

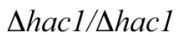
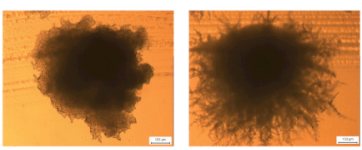

$\triangle h a c 1 / H A C l$

$\triangle h a c 1 / H A C l$

$\Delta g c n 4 / \Delta g c n 4$

$\triangle g c n 4 / G C N 4$

$\Delta g c n 4 / \Delta g c n 4$

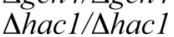

$\Delta \mathrm{gcn} 4 / \mathrm{GCN} 4$ $\triangle$ hacl/HACl

$\Delta g c n 4 / \Delta g c n 4$
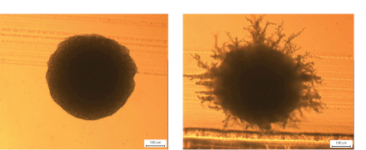

$\triangle g c n 4 / G C N 4$

$\Delta g c n 4 / \Delta g c n 4$

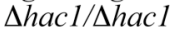
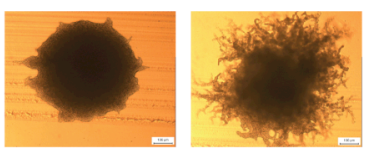

$\triangle g c n 4 / G C N 4$ $\triangle h a c 1 / H A C l$

Fig. 21: FLO11::lacZ expression, adhesion and pseudohyphal growth are repressed in diploid homozygous $\Delta$ hacl and $\Delta$ gen 4 strains.

(A) FLO11::lacZ expression was determined in diploid $\Sigma 1278 \mathrm{~b}$ wild type yeast strain (WT)

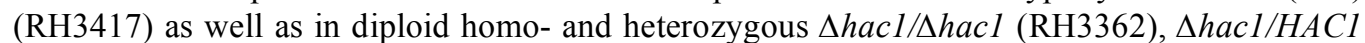
(RH3418), $\Delta g c n 4 / \Delta g c n 4$ (RH2695), $\Delta g c n 4 / G C N 4$ (RH3419), $\Delta g c n 4 / \Delta g c n 4 / \Delta h a c 1 / \Delta h a c 1$ (RH3349) and $\Delta g c n 4 / G C N 4 / \Delta h a c 1 / H A C 1$ (RH3420) mutant yeast strains each carrying a chromosomally integrated $F L O 11: \because$ lacZ reporter.

(B) For testing amino acid starvation induced adhesive growth, diploid wild type yeast strain (WT)

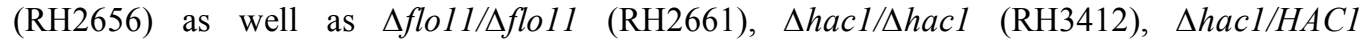
(RH3413), $\Delta g c n 4 / \Delta g c n 4$ (RH2658), $\Delta g c n 4 / G C N 4$ (RH3414), $\Delta g c n 4 / \Delta g c n 4 / \Delta h a c 1 / \Delta h a c 1$ (RH3415) and $\Delta g c n 4 / G C N 4 / \Delta h a c 1 / H A C l$ (RH3416) mutant strains were used and assay was performed as described in Fig. 20.

(C) The same yeast strains as described in (B) were streaked out on solid nitrogen starvation medium (SLAD) containing only $50 \mu \mathrm{M}$ ammonium sulfate as nitrogen source to induce pseudohyphal growth. After incubation for five days at $30^{\circ} \mathrm{C}$ pseudohyphal colonies were visualized with an Axiovert microscope and photographed. Bar equals $100 \mu \mathrm{m}$. 


\subsubsection{Identification of FLO11 promoter elements mediating regulation by Hac1p and $G c n 4 p$ in response to amino acid starvation}

Our previous analysis of the FLO11 promoter, which spans approximately 3.6 $\mathrm{kb}$ and therefore is presumably the longest promoter in S. cerevisiae, has identified one

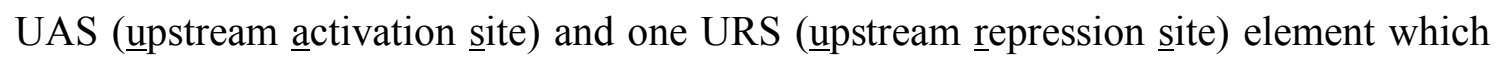
are necessary for regulation of FLO11 expression under amino acid starvation (Braus et $a l .$, 2003). Since our results indicate that beside Gcn4p, Haclp is also required for activation of FLO11 expression upon amino acid limitation we asked whether this influence was due to a specific region in the FLO11 promoter. Therefore a set of 14 reporter constructs containing individual $400 \mathrm{bp}$ FLO11 promoter fragments that overlap by $200 \mathrm{bp}$ and were cloned in front of a CYC1::lacZ fusion gene (Rupp et al., 1999) were used. They were transformed into the diploid wild type strain as well as into the diploid strains deleted for either GCN4 or $H A C l$, respectively.

In wild type cells this series of reporter constructs confirmed our previous findings where we identified four strong UAS elements in the segments FLO11-3/2, FLO11-6/5, FLO11-7/6 and FLO11-10/9 (Table IV) (Braus et al., 2003). Additionally, the element present in FLO11-11/10 increased the expression of $C Y C 1: \because$ lacZ at least five-fold compared with the reporter without any insert (Table IV). Due to the fact that the elements present in FLO11-3/2 (base pairs -620 to -182), FLO11-7/6 (base pairs 1421 to -981 ) and FLO11-11/10 (base pairs -2220 to -1781) were not regulated by amino acid starvation they indicate for basal UAS elements $\left(\mathrm{UAS}^{\mathrm{B}}\right)$. In contrast, activity in response to amino acid starvation was at least 2.3-fold induced in segments FLO116/5 (base pairs -1120 to -779) and FLO11-10/9 (base pairs -2020 to -1573) suggesting that these segments contain UAS elements that confer regulation by amino acid starvation $\left(\mathrm{UAS}^{\mathrm{R}}\right)$.

Deletion of $\mathrm{HACl}$ only led to a more than three-fold reduction in the expression of FLO11-7/6 in response to amino acid starvation when compared with the activity of this element in the wild type strain whereas induction by amino acid starvation was not observed (Table IV and Fig. 22). These results suggest that the element present in FLO11-7/6 (base pairs -1421 to -981) represents a Hac1p dependent UAS which is not inducible by $3 \mathrm{AT}$ in principle but activation upon amino acid starvation was 3.6-fold decreased when compared to the same segment expressed in wild type cells. 


\begin{tabular}{|c|c|c|c|c|c|c|c|c|c|c|c|}
\hline \multicolumn{4}{|c|}{$\begin{array}{l}\text { Table IV. } \beta \text {-Galactosidase assay } \\
\text { of a } C Y C 1: \because \text { lacZ repor } \\
\text { Wild type }(\text { Mata } / \alpha) \\
\text { Units } \\
(\mathrm{nmol} / \mathrm{min} / \mathrm{mg})\end{array}$} & \multicolumn{2}{|c|}{ 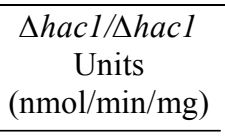 } & \multicolumn{2}{|c|}{$\begin{array}{c}\text { Expression } \\
\text { relative to WT } \\
\text { WT/Ahacl }\end{array}$} & \multicolumn{2}{|c|}{$\begin{array}{c}\Delta g c n 4 / \Delta g c n 4 \\
\text { Units } \\
(\mathrm{nmol} / \mathrm{min} / \mathrm{mg}) \\
\end{array}$} & \multicolumn{2}{|c|}{$\begin{array}{c}\text { Expression } \\
\text { relative to WT } \\
\text { WT/Agcn4 }\end{array}$} \\
\hline & YNB & $+3 \mathrm{AT}$ & $\begin{array}{l}3 \mathrm{AT} / \\
\mathrm{YNB}\end{array}$ & YNB & $+3 \mathrm{AT}$ & YNB & $+3 \mathrm{AT}$ & YNB & $+3 \mathrm{AT}$ & YNB & $+3 \mathrm{AT}$ \\
\hline FLO11 & 27 & 227 & 8,4 & 27 & 75 & 1,0 & 3,0 & 12 & 28 & 2,3 & 8,1 \\
\hline $\begin{array}{l}\text { No } \\
\text { insert }\end{array}$ & 19 & 39 & 2,0 & 22 & 50 & 0,9 & 0,8 & 8 & 17 & 2,4 & 2,3 \\
\hline $2 / 1$ & 36 & 61 & 1,7 & 40 & 82 & 0,9 & 0,7 & 15 & 30 & 2,4 & 2,0 \\
\hline $3 / 2$ & 107 & 121 & 1,1 & 123 & 138 & 0,9 & 0,9 & 33 & 69 & 3,2 & 1,8 \\
\hline $4 / 3$ & 61 & 78 & 1,3 & 46 & 106 & 1,3 & 0,7 & 12 & 25 & 5,1 & 3,1 \\
\hline $5 / 4$ & 36 & 60 & 1,7 & 35 & 64 & 1,0 & 0,9 & 8 & 23 & 4,5 & 2,6 \\
\hline $6 / 5$ & 674 & 1530 & 2,3 & 336 & 768 & 2,0 & 2,0 & 120 & 176 & 5,6 & 8,7 \\
\hline $7 / 6$ & 806 & 920 & 1,1 & 323 & 254 & 2,5 & 3,6 & 108 & 158 & 7,5 & 3,6 \\
\hline $8 / 7$ & 58 & 69 & 1,2 & 34 & 50 & 1,7 & 1,4 & 9 & 15 & 6,4 & 4,6 \\
\hline $9 / 8$ & 70 & 92 & 1,3 & 60 & 121 & 1,2 & 0,8 & 21 & 44 & 3,3 & 2,1 \\
\hline $10 / 9$ & 100 & 333 & 3,3 & 69 & 211 & 1,4 & 1,6 & 27 & 72 & 3,7 & 4,6 \\
\hline $11 / 10$ & 287 & 255 & 0,9 & 822 & 537 & 0,3 & 0,5 & 172 & 463 & 1,7 & 0,6 \\
\hline $12 / 11$ & 92 & 99 & 1,1 & 95 & 94 & 1,0 & 1,1 & 23 & 55 & 4,0 & 1,8 \\
\hline $13 / 12$ & 33 & 64 & 1,9 & 31 & 59 & 1,1 & 1,1 & 11 & 28 & 3,0 & 2,3 \\
\hline $14 / 13$ & 33 & 64 & 1,9 & 29 & 81 & 1,1 & 0,8 & 12 & 30 & 2,8 & 2,1 \\
\hline $15 / 14$ & 28 & 68 & 2,4 & 35 & 101 & 0,8 & 0,7 & 11 & 34 & 2,5 & 2,0 \\
\hline
\end{tabular}

The diploid wild type strain (RH2656) as well as diploid $\Delta h a c 1 / \Delta h a c 1$ (RH3412) and $\Delta g c n 4 / \Delta g c n 4$ (RH2658) mutant strains were transformed with indicated $C Y C 1:: l a c Z$ reporter constructs (Rupp et al., 1999) and expression was assayed under non-starvation conditions (YNB) compared to amino acid starvation induced by adding $10 \mathrm{mM} 3 \mathrm{AT}$ (3AT). The received $\beta$-galactosidase units $(\mathrm{nmol} / \mathrm{min} / \mathrm{mg}$ ) are given for each sequence element in each strain. Values with at least five-fold elevation of the reporter over a plasmid without an insert expressed in the wild type strain are highlighted in bold. In the column $3 \mathrm{AT} / \mathrm{YNB}$, the ratio of activities obtained for a given reporter construct in the wild type strain in the presence or absence of 3AT is presented. Additionally, the values for the diploid homozygous hacl and gcn 4 deletion strains are listed relative to the respective wild type data and marked in bold when it is repressed at least three-fold. The segment which is regulated by both, Gcn4p and Hac1p, is framed.

Deletion of GCN4 led to more than three-fold reduction in the expression of almost all reporter constructs whereas upon amino acid starvation only expression of FLO11-4/3, FLO11-6/5, FLO11-7/6, FLO11-8/7 and FLO11-10/9 was more than threefold reduced. However, induction of these elements by amino acid starvation was not considerable and stretched from 1.5 for elements FLO11-6/5 and FLO11-7/6 to maximum 2.6 for element FLO11-10/9. Since the FLO11 promoter neither contains a specific binding site for Gen4p nor direct binding was observed so far, Flo11p represents an indirect target gene of Gen $4 p$. Therefore, the influence of Gen $4 p$ on most constructs could be due to its indirect influence over other transcription factors involved 
in Flo11p regulation. Element FLO11-7/6 was targeted both by Gcn4p and Hac1p upon amino acid starvation which provides existence of comprehensive domains in the FLO11 promoter influenced by more than one transcription factor and therefore indicates for an associated function on FLO11 expression.

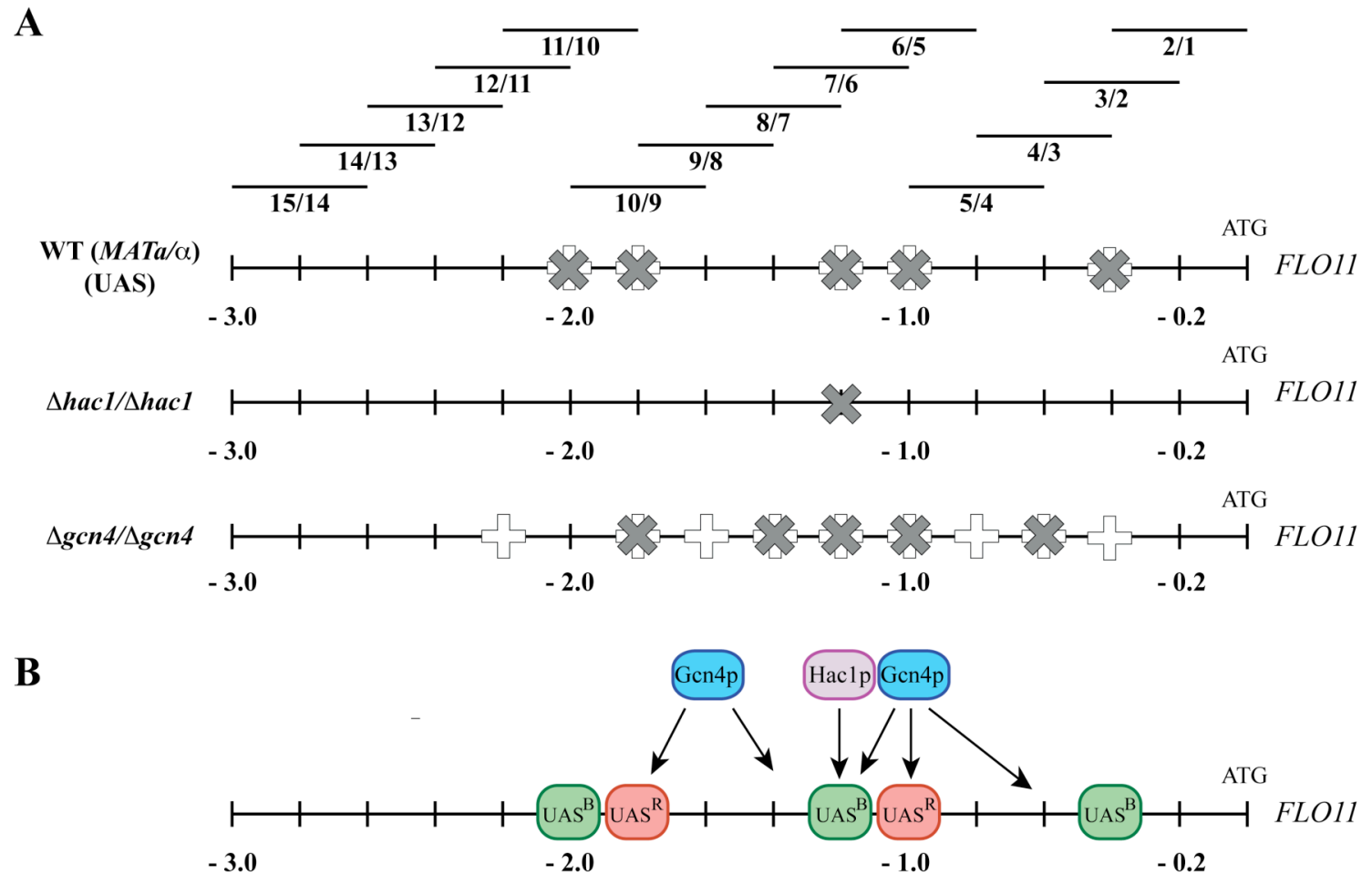

Fig. 22: Sequence elements involved in regulation of FLO11.

(A) The $\beta$-galactosidase activity of 14 isolated 400 bp elements of the FLO11 promoter region was assayed in diploid wild type cells or in corresponding cells deleted for the transcription factors HACl or GCN4 (Table IV). The activity was determined under non-starvation conditions (YNB) or in the presence of amino acid starvation (3AT) induced by the addition of $10 \mathrm{mM} 3 \mathrm{AT}$. Each line represents the FLO11 promoter in the indicated genetic background. The symbols (white cross $=$ non-starvation conditions; gray cross $=$ starvation conditions) are placed on a line in a position that indicates which of the $400 \mathrm{bp}$ fragments stimulated $\beta$-galactosidase activity. The first row (WT MATa/ $\alpha$ UAS) denotes sequence elements showing a $>5$-fold elevation of the reporter over a plasmid without an insert (pME2212) as measured in wild type cells. The next two lines $(\Delta h a c l / \Delta h a c l$ and $\Delta g c n 4 / \Delta g c n 4)$ represent sequence elements showing a $>3$-fold reduction of the $\beta$-galactosidase activity in the mutants as compared with the activity of the same element in wild type strain.

(B) Summary of the identified elements, which were regulated by Gcn $4 p$ and Haclp in response to amino acid starvation. Both, Gcn $4 \mathrm{p}$ and Haclp, influenced element FLO11-7/6, which represents a basal upstream activation sequence (UAS ${ }^{\mathrm{B}}$ ). Elements FLO11-6/5 and FLO11-11/09 where at least 2.3-fold induced when starved for amino acids and therefore represent amino acid starvation dependent upstream repression sites $\left(\mathrm{UAS}^{\mathrm{R}}\right)$. 


\subsubsection{Reduced Hac1 protein levels upon amino acid starvation are independent of the Pho85p-Pcl5p complex}

Rapid turnover of Gen $4 p$ and Haclp is regulated by phosphorylation by the cyclin-dependent kinase Srb10p and that followed ubiquitination by the $\mathrm{SCF}^{\mathrm{Cdc} 4}$ ligase complex, which results in degradation of both, Gcn $4 p$ and Hac1p, by the $26 \mathrm{~S}$ proteasom (Irniger and Braus, 2003; Pal et al., 2007). Additionally, stability of Gcn4p is regulated by the CDK Pho85p in interaction with Pcl5p (Irniger and Braus, 2003). To investigate the role of the Pho85p-Pcl5p complex in Hac1p degradation, we analyzed the decay of Hac1p in haploid $\Delta p h o 85$ and $\Delta p c l 5$ strains by synthesis shut-off assays. Additionally, stability of Haclp in haploid strains deleted for GCN4 was determined. Furthermore, we examined Hac1p turnover under amino acid starvation conditions, which leads to a stabilization of Gcn4p (Bömeke et al., 2006).

The half life of Haclp in $\Sigma 1278$ b wild type cells was $\sim 1.5$ min (Fig. 23A). Degradation in $\Delta p c l 5$ was not influenced whereas Haclp was minimally stabilized in $\Delta g c n 4$ cells, nevertheless, is very insignificant compared to the stabilization documented in $\Delta$ srb10 cells (Pal et al., 2007). Deletion of PHO85 pointed into the opposite direction and caused a destabilization of Hac1p. This could be explained by either general growth deficit of $\Delta$ pho85 cells (Huang et al., 2007) or Pho85p usually stabilizes Hac1p. Amino acid starvation induced by $100 \mathrm{mM}$ 3AT repressed Hac1p expression in all cells. Similar results were obtained when eIF2 $\alpha$ p phosphorylation was determined (Fig. 16B), however with less intense. This could be due to either 10-fold concentrations of $3 \mathrm{AT}$ or the time span or both, respectively. As shown in Fig. 16B longer treatment (for $60 \mathrm{~min}$, lane $30 \mathrm{~min}$ post $\mathrm{Tm}$ induction) with $10 \mathrm{mM} 3 \mathrm{AT}$ repressed Haclp expression in haploid $\Delta g c n 4$ cells whereas after 30 min Haclp was still detectable. Cells were further tested for resistance to ER stress wherein no significant growth differences were obtained (Fig. 23B). Since $\Delta p h o 85$ cells are characterized by a general growth deficit no precise conclusion could be observed. Similar results were achieved using S288c wild type and $\Delta g c n 4$ or rather $\Delta p h o 85$ deletion strains of the Euroscarf strain collection (Brachmann et al., 1998).

The findings of this section indicate a Pho85p-Pcl5p independent degradation of Haclp whereas the other components (CDK Srb10p and $\mathrm{SCF}^{\mathrm{Cdc} 4}$ ubiquitin ligase) of Gcn $4 p$ stability regulation are involved in the turnover of Hac1p. Neither stabilization of Haclp in $\Delta g c n 4$ cells nor destabilization of Haclp in $\Delta p h o 85$ cells are well defined 
so that no precise conclusion is possible. The CDK Pho85p can interact with ten different cyclins and possibly Hac1p will be regulated by Pho85p together with another cyclin. However, amino acid starvation, a signal for up-regulation of Gcn $4 p$, results in repression of Haclp. Similar results were shown for GCN4 mRNA translation upon ER stress conditions.

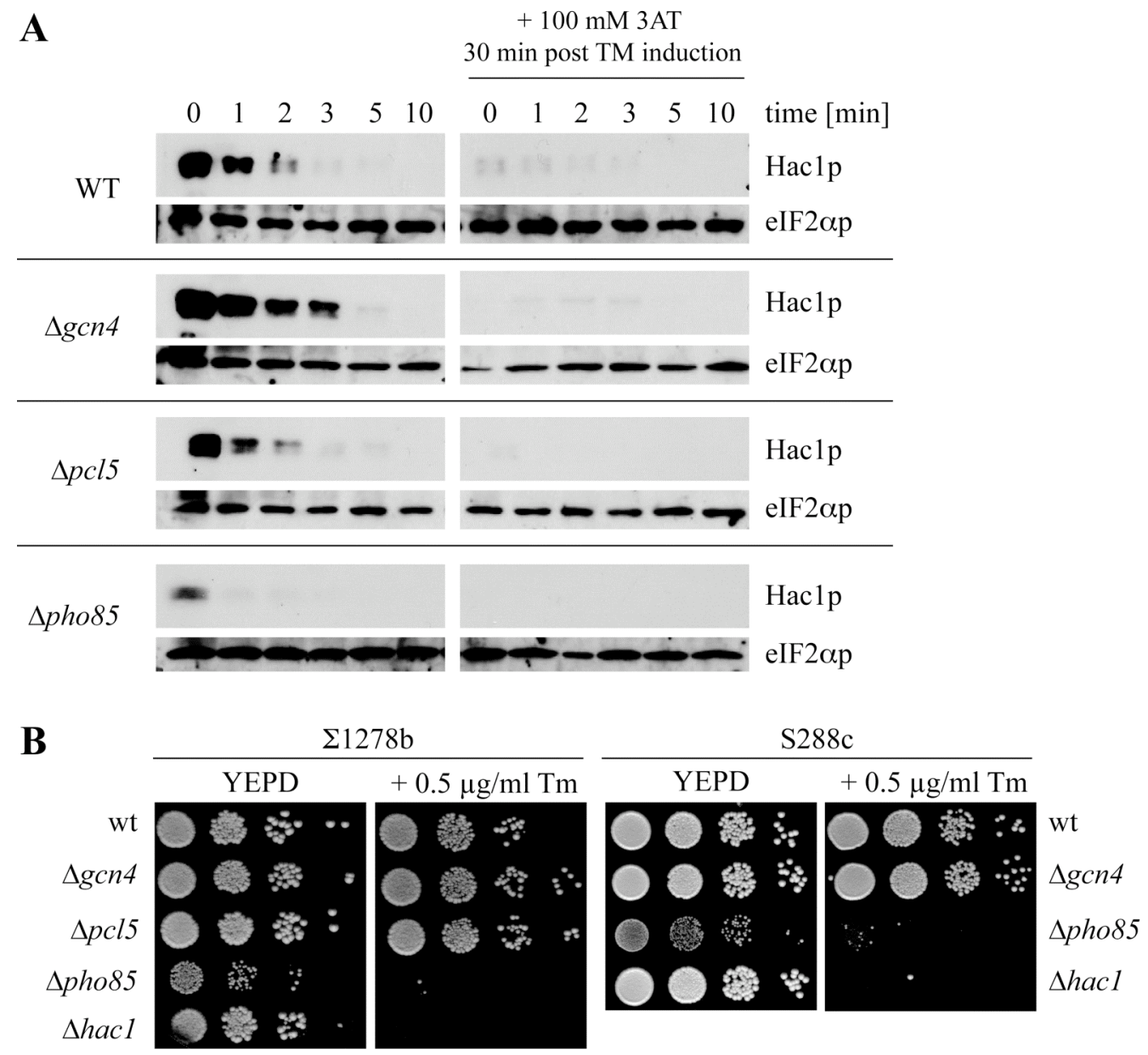

Fig. 23: Hac1p is hardly detectable upon amino acid starvation.

(A) Haploid $\Sigma 1278$ b wild type strain (WT) (RH2816) as well as haploid $\Delta g c n 4$ (RH2676), $\Delta p c l 5$ (RH3279) and $\Delta$ pho85 (RH3426) mutant strains were grown in YNB to $\mathrm{OD}_{600} \sim 0.6$ before dividing in two independent cultures, respectively. ER stress was mediated in all cultures by 5 $\mu \mathrm{g} / \mathrm{ml}$ tunicamycin ( $\mathrm{Tm}$ ) to induce synthesis of Haclp. After 30 minutes post tunicamycin treatment, additional amino acid starvation was achieved by the addition of $100 \mathrm{mM}$ 3AT. 90 minutes post tunicamycin induction $1 \mathrm{mg} / \mathrm{ml}$ cycloheximide was added to all cultures to halt protein synthesis und samples were taken at the indicated time points after addition. Protein levels of Hac1p were analyzed by Western hybridisation and eIF2 $\alpha$ p was used as loading control.

(B) The same haploid $\Sigma 1278$ b strains described in (A) and additional haploid S288c wild type strain (BY4741) as well as $\Delta g c n 4$ (Y00249), $\Delta p h o 85$ (Y02797) and $\Delta h a c 1$ (Y05650) mutant strains were spotted in 10-fold dilutions on either solid YEPD medium alone or in presence of 0.5 $\mu \mathrm{g} / \mathrm{ml}$ tunicamycin to induce ER stress. After incubation for $3-4$ days at $30^{\circ} \mathrm{C}$ plates were photographed. 


\subsubsection{Stabilization of Hac1p by sumoylation}

Recent publication predicts sumoylation of XBP1 which encodes for the mammalian homologue of Haclp (Chen and Qi, 2010). Actually, a predict SUMO consensus site $(\psi \mathrm{KXD} / \mathrm{E})$ is located in the C-terminus of Haclp. To determine a possible Haclp sumoylation in S. cerevisiae we analyzed its stability in a haploid W303 wild type strain in comparison to strains carrying temperature sensitive mutations in either $U B C 9$ or SMT3 gene. Smt3p encodes for the yeast SUMO protein whereas Ubc9p represents the SUMO-conjugating enzyme.

$\mathbf{A}$

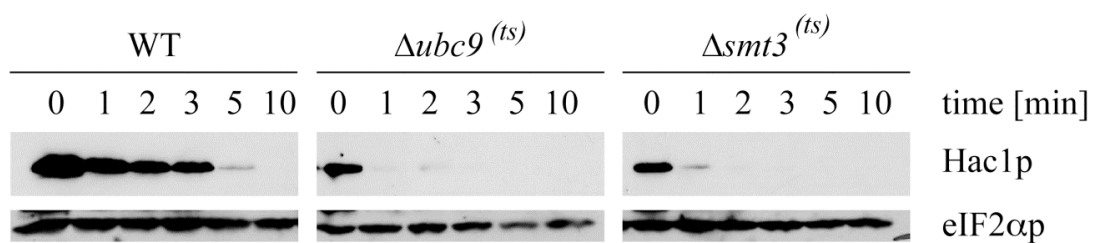

B

$25^{\circ} \mathrm{C}$

$30^{\circ} \mathrm{C}$

$37^{\circ} \mathrm{C}$

permessive temp.

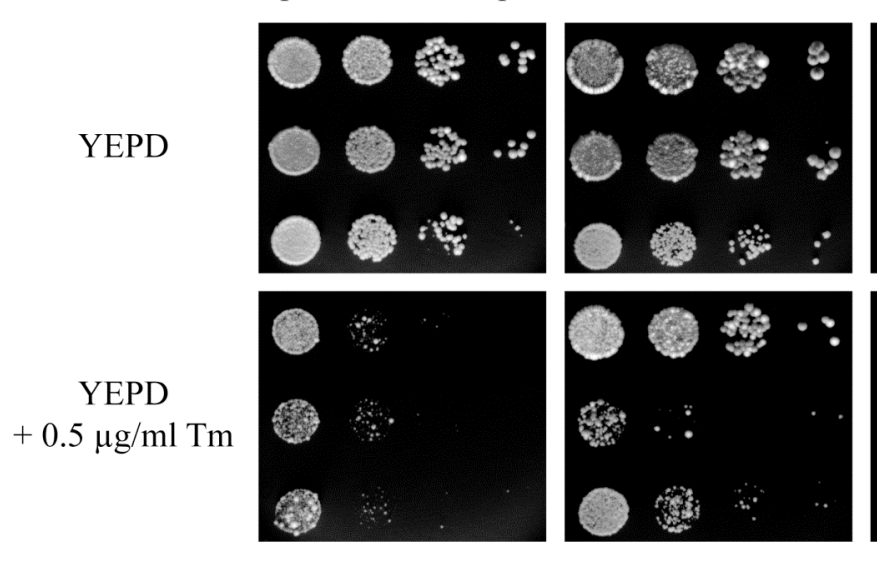

restrictive temp.

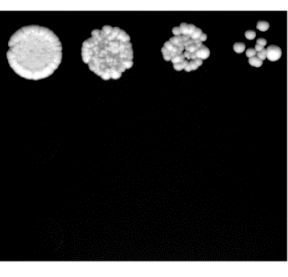

WT

$\Delta u b c 9^{(t s)}$

$\Delta s m t 3^{(t s)}$

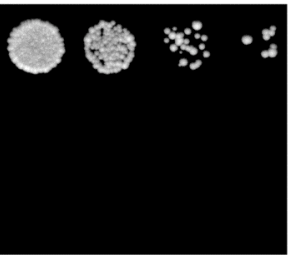

WT

$\Delta u b c 9^{(t s)}$

$\Delta s m t 3^{(t s)}$

Fig. 24: Hac1p stability is regulated by sumoylation.

(A) Haploid W303 temperature sensitive strains $\Delta u b c 9^{(t s)}$ (S099) and $\Delta s m t 3^{(t s)}$ (S542) as well as haploid W303 wild type strain (S001) were grown in liquid YEPD media at $23^{\circ} \mathrm{C}$ or rather $30^{\circ} \mathrm{C}$ to an optical density of 0.6 before ER stress was induced by addition of $5 \mu \mathrm{g} / \mathrm{ml}$ tunicamycin. After 90 minutes post induction temperature sensitive cultures were shifted to the restrictive temperature of $37^{\circ} \mathrm{C}$ for 30 minutes. Protein synthesis was blocked by adding $1 \mathrm{mg} / \mathrm{ml}$ cycloheximide and samples were taken at the indicated time points after addition. Protein levels of Haclp were determined by immunoblotting. eIF2 $\alpha \mathrm{p}$ was used as loading control.

(B) The same yeast strains as described in (A) were spotted in 10-fold dilutions on either solid YEPD medium alone or in presence of $0.5 \mu \mathrm{g} / \mathrm{ml}$ tunicamycin to induce ER stress. After incubation for $3-4$ days at $23^{\circ} \mathrm{C}, 30^{\circ} \mathrm{C}$ and $37^{\circ} \mathrm{C}$ plates were photographed. 
The half life of Haclp in the parental W303 cells was $~ 3$ min (Fig. 24A). By contrast, the rate of degradation of Haclp was significantly increased in temperature sensitive $\Delta u b c 9^{(t s)}$ and $\Delta s m t 3^{(t s)}$ cells indicating a possible stabilization of Haclp by SUMO. Consistent with this instability of Haclp, $\Delta u b c 9^{(t s)}$ and $\Delta s m t 3^{(t s)}$ cells were more sensitive to ER stress than were wild type cells (Fig. 24B). We conclude that Haclp is activated and stabilized by sumoylation. This function is contrary to the role of SUMO modification of XBP1 in mammalian where sumoylation represses transcriptional activity.

Taken together, our findings indicate a so far unknown function of Haclp in metabolic and developmental processes regulated by Gen4p. Not only Gen4p is able to activate Haclp specific target genes but also Haclp is involved in Gen $4 p$ target gene expression. Indeed, haploid $\Delta h a c 1$ cells are able to survive amino acid starvation and to activate Gen $4 p$ specific and unspecific target genes upon amino acid starvation but is partial reduced in both cases. This partial reduction affects resistance and adhesive growth when compared to wild type cells. Since diploids are more complex, effects are stronger in homozygous $\Delta h a c l$ cells, which are compensated in heterozygous $\Delta h a c 1$ cells. Furthermore, our data indicate for a possible regulation of Haclp by Gcn $4 p$ in response to amino acid starvation whereas Gcn4p-regulation is independent of Haclp. Transcription factor specific stress situation (amino acid starvation for Gen $4 p$ and ER stress for Haclp) results finally in repression of the respective antagonist. First results suggest regulation of Hac1p by SUMO/Smt3p. 


\section{DISCUSSION}

\subsection{Dissection of the dual function of Gen4p}

Gcn $4 p$ of $S$. cerevisiae encodes the founding member of a global transcriptional metabolic activator for a genetic system that secures the appropriate response to amino acid starvation. Gcn $4 p$ of yeast is conserved and corresponds to ATF4 in human (Hinnebusch, 2005; Ameri and Harris, 2008). In diploids, the metabolic function of yeast Gen $4 p$ is combined with adhesive growth and pseudohyphal development upon nutrient starvation (Braus et al., 2003). The metabolic and the developmental functions of the transcription factor Gcn $4 p$ could be dissected by abolishing the developmental function, which allows pseudohyphae formation in yeast and maintaining the potential to survive in amino acid starvation conditions. Fig. 25 illustrates our findings schematically.
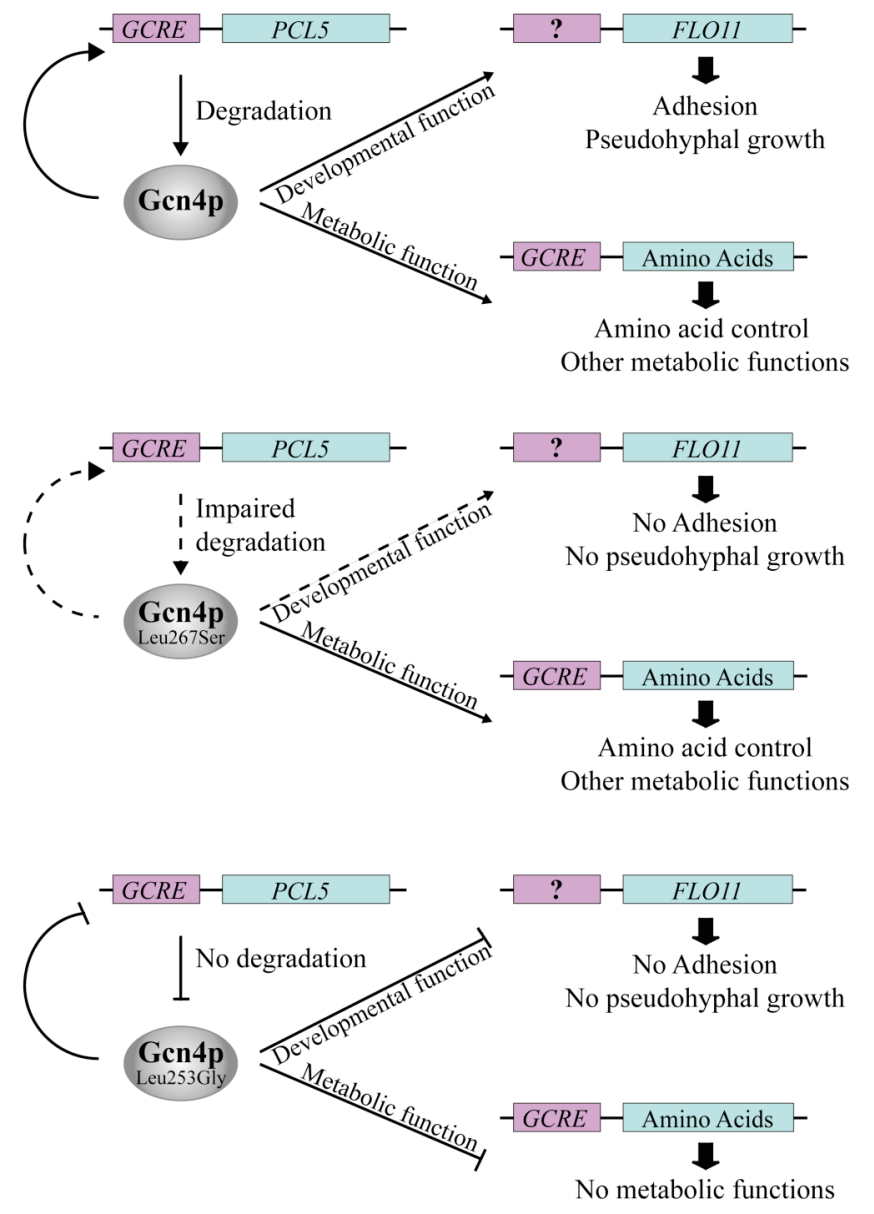

Fig. 25: Model for self-regulation of Gen4p.

Shown is the self-controlled degradation of Gcn $4 p$. Transcriptional activity of wild type Gcn $4 p$ enables to fulfill its dual function as metabolic and developmental regulator. Furthermore, Gcn $4 p$ regulates its own degradation by activating Pc15p. Substitution of Leu267Ser results in a partial active but more stable transcription factor, which only fulfills metabolic processes. Substitution with helix breakers lead to a strong stabilized Gcn $4 p$ because Gcn $4 p$ is completely transcriptionally inactive. 
Leu267Ser represents a single mutant allele of GCN4, which was isolated in a screen for a separation of the dual function. Analogous in vitro designed derivatives have similar consequences in diploids: (i) they have a reduced affinity for dimerization, which decreases transcriptional activation, (ii) this results in a reduced activation of the Gcn $4 p$ destruction pathway and therefore an increased protein stability, (iii) partial Gen $4 p$ activity is sufficient to provide growth under amino acid starvation conditions, but is below the threshold, which is necessary to activate FLO11 sufficiently to grow adhesively or as pseudohyphae. The impact on haploid yeasts is similar, nevertheless, the observed effects are less pronounced than those determined in diploids.

\subsubsection{Gen4p as conserved global transcription factor}

A combination of metabolic and developmental functions is not only a feature of yeast Gcn $4 p$. Various Gcn4p counterparts in other eukaryotic organisms have a similar metabolic function but are additionally involved in different developmental processes. The cross pathway control (CPC) of amino acid biosynthesis in filamentous fungi is similar to the general control system of yeast and functions as a general stress response system (Sachs, 1996). In the filamentous fungus Aspergillus nidulans the Gcn4p-related CpcA provides sufficient amino acid during starvation but can also induce an arrest in fruit body formation in response to amino acid starvation, indicating a connection between metabolism and sexual development (Hoffmann et al., 2000). CpcA of Aspergillus fumigatus also controls amino acid supply but plays an additional important role in the virulence of this opportunistic human fungal pathogen (Krappmann et al., 2004). Similarly, the Gcn $4 p$ homologue VlCpcA of the fungal plant pathogen Verticillium longisporum is induced in infected plants (Singh et al., 2010). The dimorphic human pathogen Candida albicans is able to switch from a unicellular yeast form to a multicellular hyphal form, which causes disseminated systemic infections in immuno-compromised individuals. This infective hyphal form is also induced by various environmental stimuli, like carbon or nitrogen starvation or elevated temperatures (Ernst, 2000; Sánchez-Martinez and Pérez-Martin, 2001). Homologous proteins for Gcn $4 p$ and Pcl5p were identified in C. albicans and are necessary for amino acid biosynthesis and the induction of filamentous growth in response to amino acid starvation (Tripathi et al., 2002; Gildor et al., 2005). 
The Gcn4p like ATF4 of mammalian cells also combines its metabolic function with a developmental function. ATF4 fulfills its metabolic function to ensure cell survival in response to amino acid starvation, but also to react to different stress signals like ER stress or oxidative stress (Harding et al., 2003; Ameri and Harris, 2008). ATF4s' developmental functions include cell proliferation and eye or rather bone development as well as processes like learning and long-term memory (Masuoka and Townes, 2002; Chen et al., 2003; Costa-Mattioli et al., 2005). It will be interesting to analyze whether these Gcn $4 p$ related proteins show a similar pattern of self control mediated by the interplay of transcriptional activation and protein turnover.

\subsubsection{Protection against hyperactive $G C N 4$}

The metabolic function of Gcn $4 p$ results in the up-regulation of hundreds of genes in yeast. Misregulation of this global transcriptional activator may therefore result in a liability for the cell. This might require a certain degree of insensitivity to variations in Gen $4 p$ activity. Increased activity is neutralized by reduced Gcn4p stability. Wild type Gcn $4 p$ has only a half life of a few minutes in sated cells and therefore, the cell can cope with more active alleles as well as with overexpression of the transcription factor. When a deficient Gcn $4 p$ degradation pathway is combined with overexpression of the transcription factor, this results in a toxic effect that causes growth inhibition (Tavernarakis and Thireos, 1995; Shemer et al., 2002).

The rapid decay of Gen $4 p$ is initiated within the nucleus by phosphorylation by two independent cyclin-dependent kinases, Pho85p and Srb10p. Srb10p phosphorylation occurs constitutively and might be necessary for transcriptional activation. One possibility is that Srb10p action is required for promoter clearing after the transcription factor has promoted transcription (Chi et al., 2001; Irniger and Braus, 2003) This could explain why mutations in the $\mathrm{E} 3$ ubiquitin ligase $\mathrm{SCF}^{\mathrm{Cdc} 4}$ or inhibition of the proteasome can decrease the transcription of Gcn $4 p$ targets. Therefore, a certain turnover rate is necessary for Gcn4p gene activation function (Lipford et al., 2005). The kinase cyclin complex Pho85p-Pcl5p phosphorylates Gen4p when amino acids are present but is less active when amino acids are limited. The kinase reaction is the committing step in Gcn $4 p$ degradation, because phosphorylation at the residue Thr165 is necessary to mark Gcn $4 p$ for poly-ubquitination by the E2 ubiquitin-conjugating enzyme Cdc34p together with the E3 $\mathrm{SCF}^{\mathrm{Cdc} 4} \mathrm{RING}$ ligase. The final step is the 
degradation in the 26S proteasome (Kornitzer et al., 1994; Meimoun et al., 2000; Shemer et al., 2002).

The PCL5 gene itself is a target gene of Gcn $4 \mathrm{p}$, which results in the paradox situation that Gen $4 p$ controls a gene, which is responsible for its own degradation. Under amino acid starvation conditions the Gcn $4 \mathrm{p}$ mediated increased PCL5 mRNA levels do not result in increased Pcl5 protein levels in wild type yeasts (Jia et al., 2000; Shemer et al., 2002). This has been explained by the reduced overall translational efficiency during amino acid starvation combined with the even lower protein stability of Pcl5p in comparison to Gen4p (Kornitzer et al., 1994). In addition, the Pho85p-Pcl5p complex dissociates during amino acid starvation (Bömeke et al., 2006). In wild type cells, Gen $4 p$ is stabilized in the nucleus to an increased half life of 5 min to up to 20 min (Kornitzer et al., 1994; Irniger and Braus, 2003). Although amino acid starvation decreases overall translation, it improves GCN4 mRNA translation and therefore increases the amount of Gcn4 protein in the cytoplasm (Hinnebusch, 1984; Dever et al., 1992).

Our data suggest that the Gen4p controlled expression of PCL5 is a backup system which is important to adapt Gen $4 p$ stability to its own transcriptional activity providing an additional level for genetic robustness against variations in the expression or structure of the GCN4 gene itself.

\subsubsection{A fine-tuned circuit of self-control of a leucine zipper transcription factor}

The feedback control of Gen $4 p$ stability and activation function might be necessary because the Gcn $4 p$ controlled network comprises several hundreds of genes for the biosynthesis of metabolites as amino acids or purines. The regulation of numerous genes by one transcription factor might require the potential for gradual modification of transcription circuits, in particular, when target genes are involved in so many different processes all over the cell (Tuch et al., 2008). The fact that uncontrolled Gen4p overexpression is toxic might support this view. Unprotected overexpression might result in the interference of too many transcriptional activation pathways (Tavernarakis and Thireos, 1995; Shemer et al., 2002).

This study revealed that self-controlled degradation of Gen4p regulated by its transcriptional activity can follow two metabolic possibilities: (i) Gen4p is partially active but nevertheless more stable or (ii) Gen $4 p$ is more active resulting in a faster 
degradation and therefore a less stable protein. We have shown that both options are not only possible, but also enable Gen4p to fulfill its metabolic function. This is not only feasible due to the circuit of self-control of protein stability and function, but also because of the metabolic excess capacity, which is provided by a high Gcn $4 p$ independent basal activity of transcription of metabolic genes (Braus et al., 1988; Paravicini et al., 1988).

The developmental function of Gcn $4 p$ differs from the metabolic function in that it has no residual basal activity. Therefore reduced activity provides a phenotype, which consists in impairment of diploid adhesive growth upon amino acid starvation and formation of pseudohypae in response to nitrogen starvation. Only diploid cells expressing wild type GCN4, in which transcriptional activity and stability of Gcn4p are optimized, show an intact developmental function. Diploid development might require a distinct decision for a given cell, which is either a yes or a no.

The rewiring of pathways over evolutionary time scales can lead to morphologic and physiologic differences of closely related organisms (Tuch et al., 2008). It is interesting to note that the sequence comparison of S. cerevisiae GCN4 reveals that only the Gen $4 p$ homologues of $C$. albicans and the human ATF4 feature an adequate leucine zipper structure consisting of four leucines each separated with seven amino acids (Landschulz et al., 1988). Since we were able to separate the metabolic from the developmental function of the global transcription factor Gcn $4 p$ in diploid yeasts, it would be interesting to see the consequences of such a mutation in higher eukaryotes. 


\subsection{Crosstalk between the 'Unfolded Protein Response' and the 'General Amino Acid Control' via their regulators Hac1p and Gen4p}

The 'unfolded protein response' (UPR) and its key regulator XBP1, the mammalian homologue of Haclp, play important roles in tumorogenesis of mammals and UPR suppressor are proposed as therapeutic agents (Saito et al., 2009; Shajahan et al., 2009; Wang et al., 2010). Cell differentiation and dimorphism, respectively, therefore are of fundamental relevance. Similarly, CaHaclp and HacA, the Haclp homologues of $C$. albicans and A. fumigatus, play important roles in regulating the morphology in both organisms, which in turn is important for virulence of these pathogenic fungi (Wimalasena et al., 2008; Richie et al., 2009). Furthermore, both CaGen $4 p$ and $\mathrm{CpcA}$, the Gen4p homologues proteins, are also involved in their pathogenicity (Tripathi et al., 2002; Krappmann et al., 2004; Gildor et al., 2005). In S. cerevisiae, Gcn $4 p$ is required for adhesion and pseudohyphal development upon nutrient starvation (Braus et al., 2003). In contrast, Hac1p is described as repressor of differentiation in S. cerevisiae, which is oppositional to its role in higher eukaryotes (Schröder et al., 2000). In this study we could not only disprove this evidence but also were able to define a region in the FLO11 promoter where Hac1p potentially could act. Flo11p represents the main adhesion in $\Sigma 1278$ b cells required for nutritionally induced cell-cell and cell-surface adhesion during invasive growth, biofilm formation and pseudohyphal development (Lo and Dranginis, 1998; Guo et al., 2000; Reynolds and Fink, 2001).

\subsubsection{Analysis of FLO11 promoter elements}

Initially, we found that diploid homozygous $\Delta$ hacl/Dhacl yeast cells neither were able to activate FLO11 and therefore adhesive growth in response to amino acid starvation nor to develop pseudohyphae upon nitrogen starvation. Similar results were obtained for Gcn4p, previously (Braus et al., 2003). The FLO11 promoter spans approximately $3 \mathrm{~kb}$ and therefore is presumably the longest promoter in $S$. cerevisiae. Using a set of divers FLO11 promoter constructs we identified at least one element (FLO11-7/6), which is regulated by both, Gcn $4 \mathrm{p}$ and Hac1p, in response to amino acid starvation (Fig. 26). This element is the only element influenced by Haclp upon amino 
acid starvation whereas Gcn $4 p$ reduces activity in five different elements in response to amino acid starvation and mostly all elements under basal conditions. These findings confirm our previous assumption, that expression of FLO11 might not involve direct binding of Gen $4 p$ but rather in combination with other transcriptional regulators. The overlapping elements, which are influenced by different transcription factors, support this hypothesis. Similar to Gcn4p, we suppose an indirect binding of Haclp to the FLO11 promoter since sequence analysis does neither predict any Gen4p-recognition element nor a Hac1p specific UPR element.

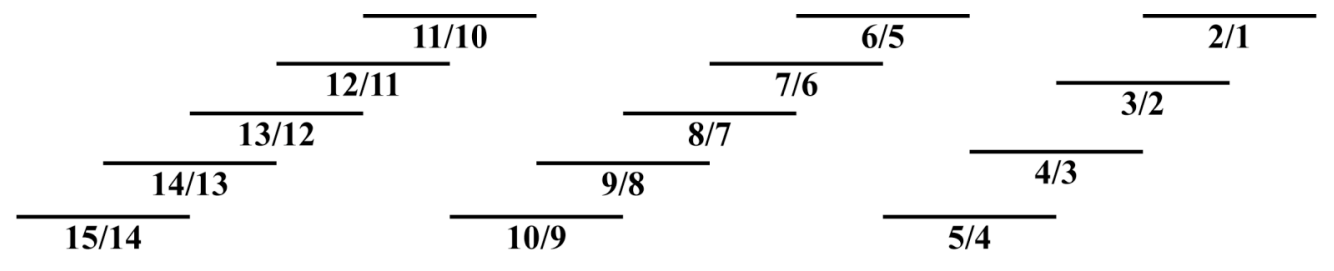

Elements regulated by Gcn $4 p$ and Hac1p in response to amino acid starvation

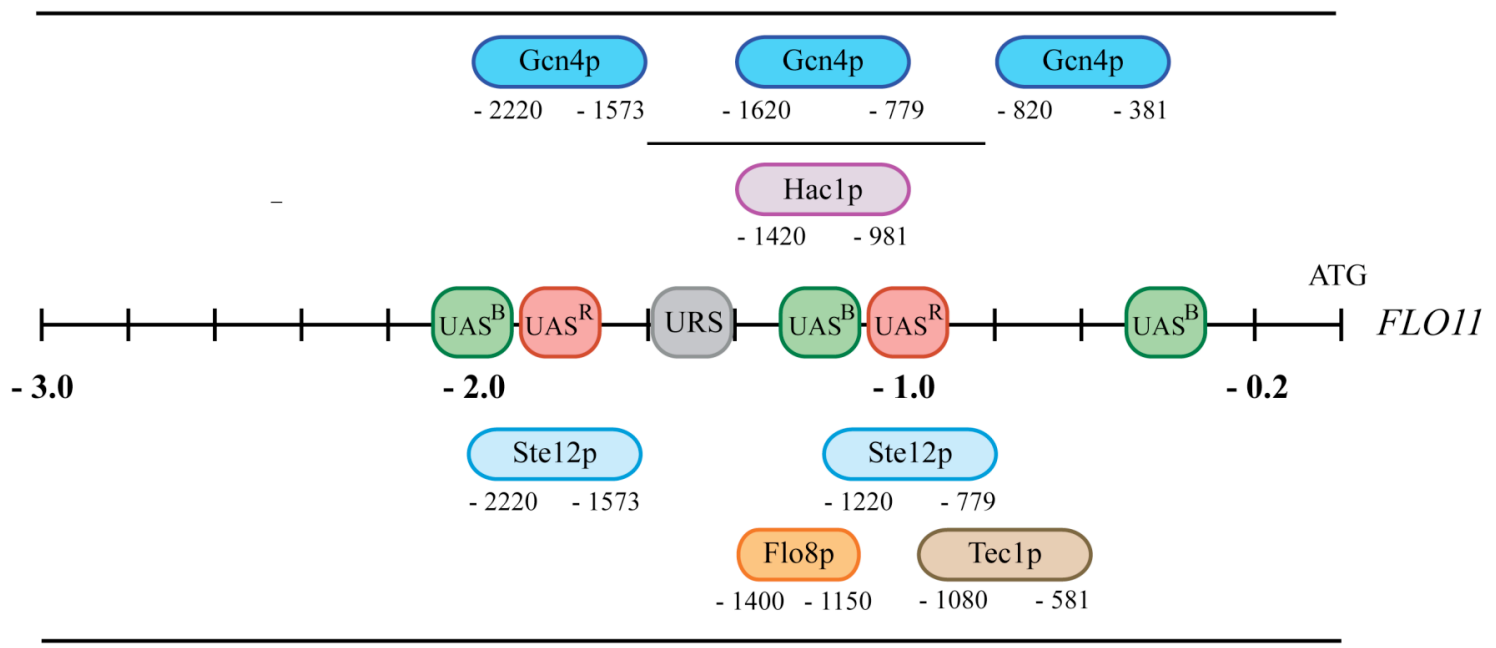

Elements regulated by other transcription factors

Fig. 26: Summary of FLO11 promoter elements regulated by Gen4p and Hac1p in response to amino acid starvation as well as by other transcription factors (see text for details).

Elements which are regulated by Ste12p, Tec1p and Flo8p, respectively, derive from Rupp et al. (1999) and Pan and Heitman (2002). The URS was defined by Braus et al. (2003).

However, numerous Gcn4p half-site are distributed over the FLO11 promoter, which possibly could explain the activation of mostly elements on the one hand and indicate for an indirect regulation together in combination with another transcription factor. By scanning the Yeastract Database (http://www.yeastract.com/) we identified at 
least four potential transcription factors, which are documented as indirect targets of Gen $4 p$ (Table V). These transcription factors, namely Ste11p, Ste12p, Tpk2p, and Tpk3p, are all involved in Flo11p regulation by either cAMP or MAPK pathway (for details see section 1.1.4). Furthermore, STE12 and in addition TEC1 represent potential target genes of Gcn $4 p$ since both carrying at least one Gcn $4 p$ recognition element in their promoters. Indeed, neither direct nor indirect regulation by Haclp is documented but its specific binding consensus sequence (CCAGC) is present in numerous important transcription factors involved in Flo11p regulation, namely Flo8p, Ste11p, Tec1p, Tpk1p and Tpk2p. The promoter of TEC1 actually contains five independent UPREs whereas three of them are arranged on the complementary strand. These findings enforce our hypothesis that both, Gcn $4 p$ and Hac1p, are involved in Flo11p regulation per se, however, presumably by binding to another transcription factor. In fact, first Western experiments indicated reduced Tec1p levels in cells deleted for GCN4 and $H A C 1$, respectively (data not shown).

Table V: Documented and potential target genes of Gcn4p and Hac1p.

\begin{tabular}{|l|c|c|c|c|c|c|}
\hline & \multicolumn{5}{|c|}{ Genes regulated by Gcn4p } & Genes regulated by Hac1p \\
\cline { 2 - 7 } & $\begin{array}{c}\text { Document. } \\
\text { direct }\end{array}$ & $\begin{array}{c}\text { Document. } \\
\text { indirect }\end{array}$ & $\begin{array}{c}\text { Potential } \\
\text { direct } \\
\text { TGACTMT }\end{array}$ & $\begin{array}{c}\text { Potential } \\
\text { direct } \\
\text { TGACTC }\end{array}$ & $\begin{array}{c}\text { Document. } \\
\text { direct }\end{array}$ & $\begin{array}{c}\text { Potential } \\
\text { direct } \\
\text { CCAGC }\end{array}$ \\
\hline GCN4 & & $\mathrm{X}$ & & & $\mathrm{X}$ & $\mathrm{XX}$ \\
\hline HAC1 & $\mathrm{X}$ & & & & & $\mathrm{X}$ \\
\hline ARO4 & $\mathrm{X}$ & $\mathrm{X}$ & & & & $\mathrm{X}^{\mathrm{C}}$ \\
\hline FLO8 & & $\mathrm{X}$ & $\mathrm{X}$ & & & $\mathrm{X}$ \\
\hline HIS7 & $\mathrm{X}$ & $\mathrm{X}$ & $\mathrm{X}$ & & $\mathrm{XX}(\mathrm{XXX})^{\mathrm{C}}$ \\
\hline STE11 & & $\mathrm{X}$ & & & & $\mathrm{X}^{\mathrm{C}}$ \\
\hline STE12 & & $\mathrm{X}$ & & & & $\mathrm{XX}^{\mathrm{C}}$ \\
\hline TEC1 & & & & & & $\mathrm{X}^{\mathrm{C}}$ \\
\hline TPK1 & & & & & & $\mathrm{X}(\mathrm{XXX})^{\mathrm{C}}$ \\
\hline TPK2 & & $\mathrm{X}$ & & & & \\
\hline TRP2 & $\mathrm{X}$ & & & & & \\
\hline TRP3 & $\mathrm{X}$ & & & & & \\
\hline
\end{tabular}

Documented and potential target genes of Gen4p and Hac1p, which are involved in FLO11 expression identified by scanning the Yeastract Database (http://www.yeastract.com/). Furthermore, Gcn4p specific target genes are listed. Crosses depict the numbers of specific consensus sequence in the respective promoter. ' $\mathrm{C}$ ' reflects its localization on the complementary strand. 
The conflicting findings of other groups could be explained for instance by strain differences. Schröder and co-workers used yeasts with either W303 or SK1 strain background (Schröder et al., 2000) whereas we used yeasts with $\Sigma 1278$ b strain background, which is the most common background to study differentiation processes such as pseudohyphal development of yeasts. Furthermore, their used strains possess many auxotrophic markers, e.g. uracil, leucine and tryptophan, which could influence pseudohyphal development. The more amino acids you have to supplement the more ammonium gets indirect to your media which can in turn act suppressive or permissive (Gimeno et al., 1992). Finally, the concentration of ammonium is a crucial factor for these processes.

\subsubsection{Role of Hac1p in the 'general amino acid control' of $S$. cerevisiae}

Patil and co-workers discovered that Gen $4 p$ is required for the activation of the 'unfolded protein response' by direct binding to two of three UPR elements (Patil et al., 2004). We therefore were interested whether this also applies accordingly vice versa. We could demonstrate that Haclp itself is not responsible for basal expression of Gen $4 p$ target genes in haploids but in response to amino acid starvation failed to excess the basal level and therefore haploid cells showed a higher sensitivity adverse 3AT. In diploid homozygous $\Delta$ hacl cells basal expression was additionally reduced. The question arise whether Hac1p itself activates Gcn4p targets, but than with less intense, or whether activation upon amino acid starvation depends on Haclp, e.g. by stabilization of Gen4p. The amino acid biosynthetic genes ARO4, TRP2, TRP3 and HIS7 represent direct target genes of Gcn $4 p$, which are up-regulated upon amino acid starvation. Each gene also contains at least one Hac1p specific consensus sequence in its promoter and therefore a direct binding cannot be excluded (Table V).

A regulation or rather stabilization of Gen $4 p$ by Hac1p, as it is supposed by Patil and co-workers, can be excluded since our data point at opposite direction (Patil et al., 2004). We found that Haclp was hardly detectable in $\Delta g c n 4$ cells upon both amino acid starvation and ER stress conditions, which could be compensated in wild type cells. Together with the Gcn $4 p$ reporter gene assays, where deletion of GCN4 resulted in a loss of activation we expect that Gen $4 p$ regulates Hac1p under amino acid starvation conditions. Furthermore, Hac1p contains two Gen4p specific consensus sequences it its promoter, nevertheless, direct interaction has not been proven yet. Furthermore, Gcn $4 p$ 
has a weak but distinct ribonuclease activity and therefore it might be possible that Gcn4p regulates Hac1p by splicing (Nikolaev et al., 2010). A regulation of Gen4p by Haclp can be further excluded since expression of GCN4: lacZ fusion gene did not alter in $\Delta$ hacl cells when compared with wild type cells. Indeed, we can confirm a transient increase of GCN4 mRNA translation in response to ER stress, nevertheless, GCN4 mRNA translation and therefore Gcn4p specific target gene expression is finally repressed upon ER stress, namely a fortiori the longer. Consistently, phosphorylation of the eukaryotic translational inititiation factor eIF2 $\alpha$ is repressed after 90 min ER stress which can be derepressed by additional amino acid starvation. Furthermore, concurrent amino acid starvation reduces Hac1p levels.

We therefore conclude, that transcription factor specific stress situations finally results in repression of the respective antagonist. The fact that higher concentrations of 3AT (mimics amino acid starvation) repress Haclp expression despite ER stress, support this suggestion. Nevertheless, the dual stress liability could also result in stressinduced apoptosis, which is regulated by both eIF $2 \alpha$ phosphorylation and Gen $4 p$ (Tallóczy et al., 2002; Ecker et al., 2010). Recent study demonstrated that the Gcn4p mammalian homologue ATF4 mediates autophagy in response to ER stress and therefore provides a direct mechanistic link between the UPR and the autophagic machinery (Rzymski et al., 2010). As demonstrated, ER stress finally results in repression of eIF2 $\alpha$ phosphorylation and thus in decreased GCN4 mRNA translation, which can be derepressed by additional amino acid starvation. This in turn stabilizes Gcn $4 p$ and could result in autophagy.

\subsubsection{Consequences of phosphorylation and sumoylation}

Post-translational modifications are chemical modifications of proteins after translation and enable cells to adapt to environmental changes, e.g. starvation for nutrients. Different post-translational modifications such as phosphorylation, ubiquitination and sumoylation influence a variety of cellular processes like activity, degradation, cell cycle or transcription. In eukaryotic cells, most instable proteins, such as transcription factors, are degraded via the ubiquitin-proteasome pathway (Varshavsky, 1997; Hershko and Ciechanover, 1998). The regulated turnover of Hac1p shares many features with that of Gen $4 p$. Both, Gen $4 p$ and Haclp, are bZIP transcription factors whose cellular levels are regulated on translational level 
(Hinnebusch, 1984; Kawahara et al., 1997) and by degradation by the proteasome (Kornitzer et al., 1994; Pal et al., 2007). The initial step of degradation is phosphorlyation by a cyclin-dependent kinase. The CDK Srb10p phosphorylates both, Gcn4p and Haclp (Irniger and Braus, 2003; Pal et al., 2007), whereas a phosphorylation by Pho85p is only documented for Gen4p (Irniger and Braus, 2003). Therefore, we determined Hac1p turnover in $\Delta p h o 85$ cells as well as in $\Delta p c l 5$ and $\Delta g c n 4$ cells, respectively. Pcl5p represents the specific Pho85p cyclin required for phosphorylation of Gen $4 p$ (Shemer et al., 2002). We could not detect significant alterations of Haclp turnover in $\Delta p c l 5$ and $\Delta g c n 4$, however, Haclp was hardly detectable in $\Delta$ pho85 cells which was in contrast to our assumption that Haclp is also a target of the Pho85p-Pc15p complex. One possible explanation for the rapid turnover of Haclp in $\Delta p h o 85$ cells could be either due to a general growth deficit of $\Delta p h o 85$ cells (Huang et al., 2007) or Pho85p usually stabilizes Haclp in interaction with another cyclin, since Hac1p levels did not alter in $\Delta p c l 5$ cells. Due to the fact, that other groups identified $\Delta$ pho85 cells as sensitive towards tunicamycin our second hypothesis that Pho85p in association with another cyclin is involved in Haclp stability control is supported (Huang et al., 2002). Pho80p represents a further cyclin of Pho85p and $\Delta$ pho80 cells are also sensitive towards tunicamycin (Huang et al., 2002; Chen et al., 2005). The Pho80p-Pho85p complex regulates the transcription factor Pho4p and phosphorylates Pho4p on at least five different sites promoting either nuclear export or nuclear import as well as interaction with another transcription factor can be blocked (O'Neill et al., 1996; Komeili and O'Shea, 1999). Therefore, our hypothesis can be modified as follows: the Pho80p-Pho85p complex possibly phosphorylates Hac1p, this in turn imports Hac1p into the nucleus where it can finally bind to the promoter regions of its target genes. Recent studies verified a direct interaction of Haclp and Pho80p, which support our hypothesis (Costanzo et al., 2010). Indeed, Pal and co-workers identified a classical nuclear localization sequence (cNLS) in the N-terminus of Hac1p (aa 29 -35), but further particulars of nuclear import of Haclp are unknown so far (Pal et al., 2007).

This cNLS in turn could be of further interest since Haclp was not only hardly detectable in $\Delta p h o 85$ cells but also in $\Delta u b c 9^{(t s)}$ and $\Delta s m t 3^{(t s)}$ cells. Smt3p encodes for

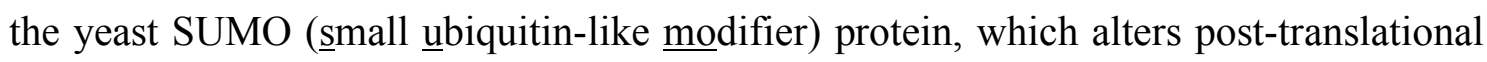
modifications and Ubc9p represents the SUMO-conjugating enzyme. SUMO is 
structurally related to ubiquititin. In contrast to ubiquitination, sumoylation does not generally direct target proteins to degradation but influences properties such as subcellular localization, protein activity and protein stability (Geiss-Friedlander and Melchior, 2007). Thus, the rapid turnover of Haclp could be due to either activation or stabilization by sumoylation. Alternatively, sumoylation is a prerequisite for nuclear import or a combination of both. In general post-translational modifications with SUMO are associated with transcriptional repression. In contrast, recent studies identified novel roles of sumoylation in yeast (Rosonina et al., 2010). They demonstrate that sumoylation can also result in both constitutive and activated transcription. Therefore, it is possible that SUMO modifications of Haclp could alter its activity by stabilization. In contrast, our second hypothesis is supported by the N-terminal cNLS. SUMO modification in yeast plays an important role in nucleocytoplasmic trafficking and cNLS dependent protein import was impaired in mutants with defective enzymes involved in the SUMO conjugation reaction (Stade et al., 2002). Recent publication identified that Drosophila Sall proteins can be sumoylated and this modification influences their nuclear localization and therefore modulates its activity (Sánchez et al., 2010). In the case, that sumoylation of Haclp is required for nuclear import inter alia, a prevention of this post-translational modification would result in an instable protein. A possible sumoylation of Haclp is supported by demonstrated sumoylation of XBP1, the mammalian homologue (Chen and Qi, 2010) and additionally by existence of a predicted SUMO consensus site $(\psi \mathrm{KXD} / \mathrm{E})$ located in the C-terminus of Haclp. In contrast to our assumption regarding sumoylation of Haclp in $S$. cerevisiae, XBP1 sumoylation results in the most common effect, namely transcriptional repression.

A summary of all aspects is given in Fig. 27. Our data indicate a so far unknown function of Haclp in metabolic and developmental processes generally regulated by Gcn $4 p$ in response to amino acid starvation, nevertheless, Gcn4p appears to be involved in Haclp regulation and thus has an epistatic effect on Haclp upon amino acid starvation. An oppositional function of Gcn $4 p$ in regulating Hac1p target genes was described in the past (Patil et al., 2004). Furthermore, we demonstrate that transcription factor specific stress situation results finally in repression of the respective antagonist. Finally our study establishes novel aspects in Haclp regulation. 


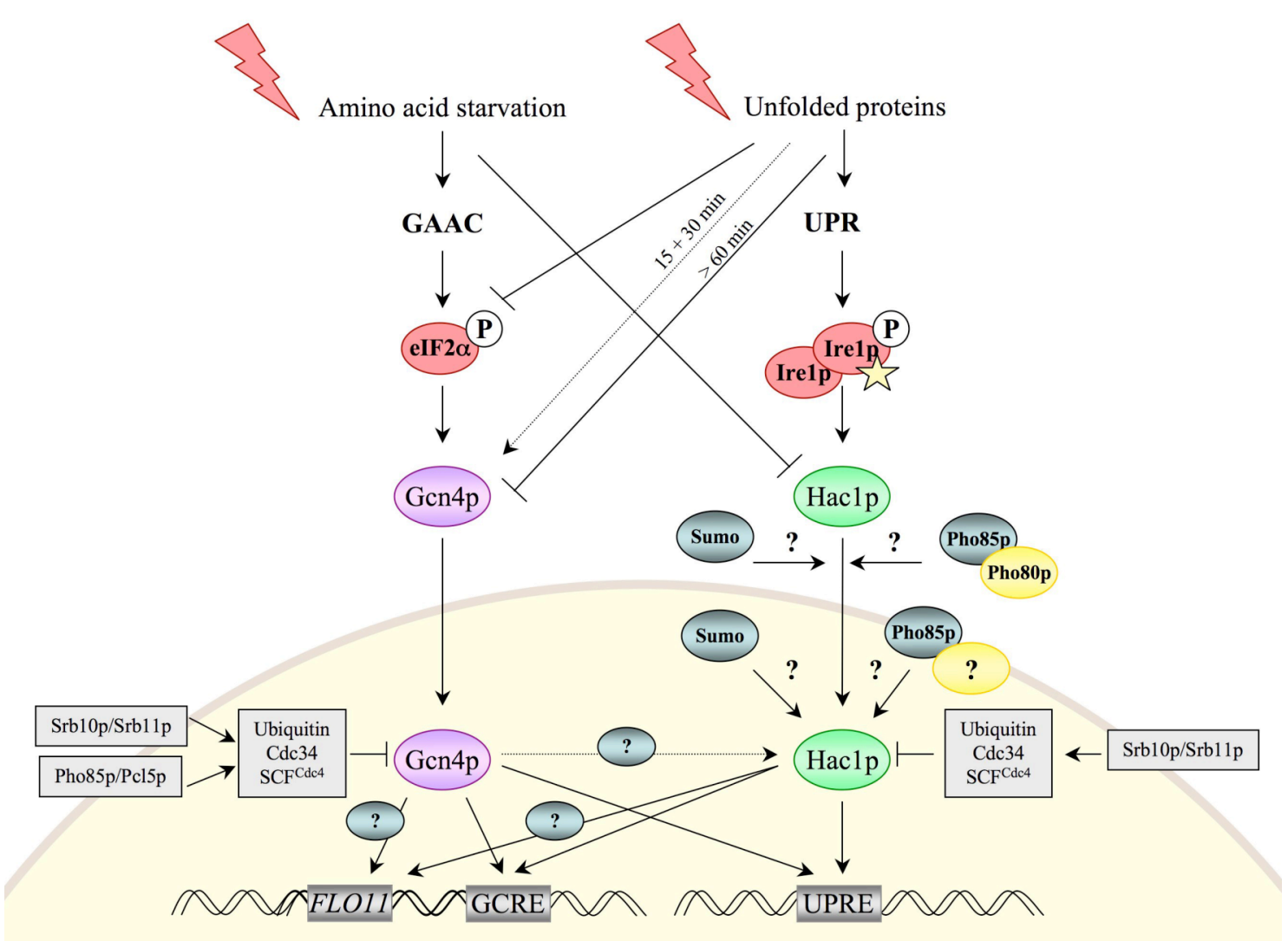

Fig. 27: Current model for the developmental and metabolic regulation conferred by Gen4p and Hac1p (see text for details).

At least 13 bZIP transcription factor exist in S. cerevisiae whereas there are minimum 51 in humans (Amoutzias et al., 2008). This reflects the increasing complexity during evolution. The bakers' yeast $S$. cerevisiae represents an established unicellular model system for the eukaryotic cell since most relevant genes are conserved from yeast to human. Both ATF4 and XBP1, the mammalian homologues of Gcn $4 p$ and Haclp, represent essential genes involved in a multiplicity of metabolic and developmental processes ensuring the survival of the organism. Furthermore, XBP1 plays an important role in tumorogenesis whereas ATF4 mediates ER stress-induced cell death of tumor cells. Understanding the complex regulation of dimorphism, stability control, nuclear trafficking and cell death pathways are relevant for tumor therapy in human and thus this study indicates important aspects, which could be useful for clarification of differentiation processes as well as for the crosstalk between the UPR and the GAAC in yeast and higher organisms. 


\section{REFERENCES}

Albrecht, G., Mösch, H.U., Hoffmann, B., Reusser, U., and Braus, G.H. (1998). Monitoring the Gcn4 protein-mediated response in the yeast Saccharomyces cerevisiae. J Biol Chem 273, 12696-12702.

Ameri, K., and Harris, A.L. (2008). Activating transcription factor 4. Int J Biochem Cell Biol 40, 14-21.

Amoutzias, G.D., Robertson, D.L., Van de Peer, Y., and Oliver, S.G. (2008). Choose your partners: dimerization in eukaryotic transcription factors. Trends Biochem Sci 33, 220-229.

Ansari, K., Martin, S., Farkasovsky, M., Ehbrecht, I.M., and Küntzel, H. (1999). Phospholipase $\mathrm{C}$ binds to the receptor-like GPR1 protein and controls pseudohyphal differentiation in Saccharomyces cerevisiae. J Biol Chem 274, 30052-30058.

Armstrong, J.L., Flockhart, R., Veal, G.J., Lovat, P.E., and Redfern, C.P. (2010). Regulation of endoplasmic reticulum stress-induced cell death by ATF4 in neuroectodermal tumor cells. J Biol Chem 285, 6091-6100.

Auf, G., Jabouille, A., Guerit, S., Pineau, R., Delugin, M., Bouchecareilh, M., Magnin, N., Favereaux, A., Maitre, M., Gaiser, T., von Deimling, A., Czabanka, M., Vajkoczy, P., Chevet, E., Bikfalvi, A., and Moenner, M. (2010). Inositolrequiring enzyme $1 \alpha$ is a key regulator of angiogenesis and invasion in malignant glioma. Proc Natl Acad Sci US A 107, 15553-15558.

Aviram, S., Simon, E., Gildor, T., Glaser, F., and Kornitzer, D. (2008). Autophosphorylation-induced degradation of the Pho85 cyclin Pc15 is essential for response to amino acid limitation. Mol Cell Biol 28, 6858-6869.

Back, S.H., Schröder, M., Lee, K., Zhang, K., and Kaufman, R.J. (2005). ER stress signaling by regulated splicing: IRE1/HAC1/XBP1. Methods 35, 395-416.

Bardwell, L., Cook, J.G., Voora, D., Baggott, D.M., Martinez, A.R., and Thorner, J. (1998). Repression of yeast Ste12 transcription factor by direct binding of unphosphorylated Kss1 MAPK and its regulation by the Ste7 MEK. Genes Dev 12, 2887-2898.

Barthelmess, I.B., and Kolanus, J. (1990). The range of amino acids whose limitation activates general amino-acid control in Neurospora crassa. Genet Res 55, 7-12.

Bernales, S., Papa, F.R., and Walter, P. (2006). Intracellular signaling by the unfolded protein response. Annu Rev Cell Dev Biol 22, 487-508. 
Bertolotti, A., Zhang, Y., Hendershot, L.M., Harding, H.P., and Ron, D. (2000). Dynamic interaction of BiP and ER stress transducers in the unfolded-protein response. Nat Cell Biol 2, 326-332.

Bi, M., Naczki, C., Koritzinsky, M., Fels, D., Blais, J., Hu, N., Harding, H., Novoa, I., Varia, M., Raleigh, J., Scheuner, D., Kaufman, R.J., Bell, J., Ron, D., Wouters, B.G., and Koumenis, C. (2005). ER stress-regulated translation increases tolerance to extreme hypoxia and promotes tumor growth. Embo J 24, 3470-3481.

Blondel, A., and Bedouelle, H. (1991). Engineering the quaternary structure of an exported protein with a leucine zipper. Protein Eng 4, 457-461.

Bömeke, K. (2006). Stability regulation of Gen4p in Saccharomyces cerevisiae. Dissertation. Göttingen, Georg-August-University.

Bömeke, K., Pries, R., Korte, V., Scholz, E., Herzog, B., Schulze, F., and Braus, G.H. (2006). Yeast Gen $4 p$ stabilization is initiated by the dissociation of the nuclear Pho85p/Pcl5p complex. Mol Biol Cell 17, 2952-2962.

Brachmann, C.B., Davies, A., Cost, G.J., Caputo, E., Li, J., Hieter, P., and Boeke, J.D. (1998). Designer deletion strains derived from Saccharomyces cerevisiae S288C: a useful set of strains and plasmids for PCR-mediated gene disruption and other applications. Yeast 14, 115-132.

Bradford, M.M. (1976). A rapid and sensitive method for the quantitation of microgram quantities of protein utilizing the principle of protein-dye binding. Anal Biochem 72, 248-254.

Braus, G.H., Grundmann, O., Brückner, S., and Mösch, H.U. (2003). Amino acid starvation and Gcn $4 p$ regulate adhesive growth and FLO11 gene expression in Saccharomyces cerevisiae. Mol Biol Cell 14, 4272-4284.

Braus, G.H., Luger, K., Paravicini, G., Schmidheini, T., Kirschner, K., and Hütter, R. (1988). The role of the TRPI gene in yeast tryptophan biosynthesis. J Biol Chem 263, 7868-7875.

Braus, G.H., Pries, R., Düvel, K., and Valerius, O. (2004). Molecular biology of fungal amino acid biosynthesis regulation. In: The Mycota II, Kück U. (ed.), BerlinHeidelberg, Springer-Verlag, 239-269.

Breeden, L., and Nasmyth, K. (1987). Cell cycle control of the yeast $H O$ gene: cisand trans-acting regulators. Cell 48, 389-397.

Brega, E., Zufferey, R., and Mamoun, C.B. (2004). Candida albicans Csylp is a nutrient sensor important for activation of amino acid uptake and hyphal morphogenesis. Eukaryot Cell 3, 135-143. 
Broach, J.R. (1991a). $R A S$ genes in Saccharomyces cerevisiae: signal transduction in search of a pathway. Trends Genet 7, 28-33.

Broach, J.R. (1991b). Ras-regulated signaling processes in Saccharomyces cerevisiae. Curr Opin Genet Dev 1, 370-377.

Brown, A.J., Odds, F.C., and Gow, N.A. (2007). Infection-related gene expression in Candida albicans. Curr Opin Microbiol 10, 307-313.

Bürglin, T.R. (1991). The TEA domain: a novel, highly conserved DNA-binding motif. Cell 66, 11-12.

Calfon, M., Zeng, H., Urano, F., Till, J.H., Hubbard, S.R., Harding, H.P., Clark, S.G., and Ron, D. (2002). IRE1 couples endoplasmic reticulum load to secretory capacity by processing the XBP-1 mRNA. Nature 415, 92-96.

Cappellaro, C., Baldermann, C., Rachel, R., and Tanner, W. (1994). Mating typespecific cell-cell recognition of Saccharomyces cerevisiae: cell wall attachment and active sites of a- and $\alpha$-agglutinin. Embo J 13, 4737-4744.

Carsiotis, M., and Jones, R.F. (1974). Cross-pathway regulation: tryptophan-mediated control of histidine and arginine biosynthetic enzymes in Neurospora crassa. $J$ Bacteriol 119, 889-892.

Carsiotis, M., Jones, R.F., and Wesseling, A.C. (1974). Cross-pathway regulation: histidine-mediated control of histidine, tryptophan, and arginine biosynthetic enzymes in Neurospora crassa. J Bacteriol 119, 893-898.

Chan, I.S., Fedorova, A.V., and Shin, J.A. (2007). The GCN4 bZIP targets noncognate gene regulatory sequences: quantitative investigation of binding at full and half sites. Biochemistry 46, 1663-1671.

Chapman, R.E., and Walter, P. (1997). Translational attenuation mediated by an mRNA intron. Curr Biol 7, 850-859.

Chen, A., Muzzio, I.A., Malleret, G., Bartsch, D., Verbitsky, M., Pavlidis, P., Yonan, A.L., Vronskaya, S., Grody, M.B., Cepeda, I., Gilliam, T.C., and Kandel, E.R. (2003). Inducible enhancement of memory storage and synaptic plasticity in transgenic mice expressing an inhibitor of ATF4 (CREB-2) and C/EBP proteins. Neuron 39, 655-669.

Chen, H., and Qi, L. (2010). SUMO modification regulates the transcriptional activity of XBP1. Biochem J 429, 95-102. 
Chen, Y., Feldman, D.E., Deng, C., Brown, J.A., De Giacomo, A.F., Gaw, A.F., Shi, G., Le, Q.T., Brown, J.M., and Koong, A.C. (2005). Identification of mitogenactivated protein kinase signaling pathways that confer resistance to endoplasmic reticulum stress in Saccharomyces cerevisiae. Mol Cancer Res 3, 669-677.

Cherkasova, V.A., and Hinnebusch, A.G. (2003). Translational control by TOR and TAP42 through dephosphorylation of eIF2 $\alpha$ kinase GCN2. Genes Dev 17, 859-872.

Chevray, P.M., and Nathans, D. (1992). Protein interaction cloning in yeast: identification of mammalian proteins that react with the leucine zipper of Jun. Proc Natl Acad Sci U S A 89, 5789-5793.

Chi, Y., Huddleston, M.J., Zhang, X., Young, R.A., Annan, R.S., Carr, S.A., and Deshaies, R.J. (2001). Negative regulation of Gen4 and Msn2 transcription factors by Srb10 cyclin-dependent kinase. Genes Dev 15, 1078-1092.

Costa-Mattioli, M., Gobert, D., Harding, H., Herdy, B., Azzi, M., Bruno, M., Bidinosti, M., Ben Mamou, C., Marcinkiewicz, E., Yoshida, M., Imataka, H., Cuello, A.C., Seidah, N., Sossin, W., Lacaille, J.C., Ron, D., Nader, K., and Sonenberg, N. (2005). Translational control of hippocampal synaptic plasticity and memory by the eIF2 $\alpha$ kinase GCN2. Nature 436, 1166-1173.

Costanzo, M., Baryshnikova, A., Bellay, J., Kim, Y., Spear, E.D., Sevier, C.S., Ding, H., Koh, J.L., Toufighi, K., Mostafavi, S., Prinz, J., St Onge, R.P., VanderSluis, B., Makhnevych, T., Vizeacoumar, F.J., Alizadeh, S., Bahr, S., Brost, R.L., Chen, Y., Cokol, M., Deshpande, R., Li, Z., Lin, Z.Y., Liang, W., Marback, M., Paw, J., San Luis, B.J., Shuteriqi, E., Tong, A.H., van Dyk, N., Wallace, I.M., Whitney, J.A., Weirauch, M.T., Zhong, G., Zhu, H., Houry, W.A., Brudno, M., Ragibizadeh, S., Papp, B., Pal, C., Roth, F.P., Giaever, G., Nislow, C., Troyanskaya, O.G., Bussey, H., Bader, G.D., Gingras, A.C., Morris, Q.D., Kim, P.M., Kaiser, C.A., Myers, C.L., Andrews, B.J., and Boone, C. (2010). The genetic landscape of a cell. Science 327, 425-431.

Cox, J.S., Shamu, C.E., and Walter, P. (1993). Transcriptional induction of genes encoding endoplasmic reticulum resident proteins requires a transmembrane protein kinase. Cell 73, 1197-1206.

Cox, J.S., and Walter, P. (1996). A novel mechanism for regulating activity of a transcription factor that controls the unfolded protein response. Cell 87, 391-404.

Credle, J.J., Finer-Moore, J.S., Papa, F.R., Stroud, R.M., and Walter, P. (2005). On the mechanism of sensing unfolded protein in the endoplasmic reticulum. Proc Natl Acad Sci U S A 102, 18773-18784.

Cullen, P.J., and Sprague, G.F., Jr. (2000). Glucose depletion causes haploid invasive growth in yeast. Proc Natl Acad Sci U S A 97, 13619-13624. 
Dever, T.E., Feng, L., Wek, R.C., Cigan, A.M., Donahue, T.F., and Hinnebusch, A.G. (1992). Phosphorylation of initiation factor $2 \alpha$ by protein kinase GCN2 mediates gene-specific translational control of GCN4 in yeast. Cell 68, 585-596.

Dickinson, J.R. (1996). 'Fusel' alcohols induce hyphal-like extensions and pseudohyphal formation in yeasts. Microbiology 142, 1391-1397.

Dickinson, J.R. (2008). Filament formation in Saccharomyces cerevisiae--a review. Folia Microbiol (Praha) 53, 3-14.

Dieckhoff, P., Bolte, M., Sancak, Y., Braus, G.H., and Irniger, S. (2004). Smt3/SUMO and Ubc9 are required for efficient APC/C-mediated proteolysis in budding yeast. Mol Microbiol 51, 1375-1387.

Dowell, R.D., Ryan, O., Jansen, A., Cheung, D., Agarwala, S., Danford, T., Bernstein, D.A., Rolfe, P.A., Heisler, L.E., Chin, B., Nislow, C., Giaever, G., Phillips, P.C., Fink, G.R., Gifford, D.K., and Boone, C. (2010). Genotype to phenotype: a complex problem. Science 328, 469.

Dranginis, A.M., Rauceo, J.M., Coronado, J.E., and Lipke, P.N. (2007). A biochemical guide to yeast adhesins: glycoproteins for social and antisocial occasions. Microbiol Mol Biol Rev 71, 282-294.

Drysdale, C.M., Duenas, E., Jackson, B.M., Reusser, U., Braus, G.H., and Hinnebusch, A.G. (1995). The transcriptional activator GCN4 contains multiple activation domains that are critically dependent on hydrophobic amino acids. Mol Cell Biol 15, 1220-1233.

Duplay, P., Bedouelle, H., Fowler, A., Zabin, I., Saurin, W., and Hofnung, M. (1984). Sequences of the malE gene and of its product, the maltose-binding protein of Escherichia coli K12. J Biol Chem 259, 10606-10613.

Ecker, N., Mor, A., Journo, D., and Abeliovich, H. (2010). Induction of autophagic flux by amino acid deprivation is distinct from nitrogen starvation-induced macroautophagy. Autophagy 6, 879-890.

Elion, E.A., Qi, M., and Chen, W. (2005). Signal transduction. Signaling specificity in yeast. Science 307, 687-688.

Ellgaard, L., and Helenius, A. (2003). Quality control in the endoplasmic reticulum. Nat Rev Mol Cell Biol 4, 181-191.

Engelberg, D., Klein, C., Martinetto, H., Struhl, K., and Karin, M. (1994). The UV response involving the Ras signaling pathway and AP-1 transcription factors is conserved between yeast and mammals. Cell 77, 381-390. 
Ernst, J.F. (2000). Regulation of dimorphism in Candida albicans. Contrib Microbiol 5, 98-111.

Fichtner, L., Schulze, F., and Braus, G.H. (2007). Differential Flo8p-dependent regulation of FLO1 and FLO11 for cell-cell and cell-substrate adherence of S. cerevisiae S288c. Mol Microbiol 66, 1276-1289.

Gagiano, M., Bauer, F.F., and Pretorius, I.S. (2002). The sensing of nutritional status and the relationship to filamentous growth in Saccharomyces cerevisiae. FEMS Yeast Res 2, 433-470.

Garcia-Barrio, M., Dong, J., Ufano, S., and Hinnebusch, A.G. (2000). Association of GCN1-GCN20 regulatory complex with the N-terminus of eIF2 $\alpha$ kinase GCN2 is required for GCN2 activation. Embo J 19, 1887-1899.

Geiss-Friedlander, R., and Melchior, F. (2007). Concepts in sumoylation: a decade on. Nat Rev Mol Cell Biol 8, 947-956.

Gerke, J., Lorenz, K., and Cohen, B. (2009). Genetic interactions between transcription factors cause natural variation in yeast. Science 323, 498-501.

Gething, M.J., and Sambrook, J. (1992). Protein folding in the cell. Nature 355, 3345.

Gildor, T., Shemer, R., Atir-Lande, A., and Kornitzer, D. (2005). Coevolution of cyclin Pcl5 and its substrate Gen4. Eukaryot Cell 4, 310-318.

Gimeno, C.J., Ljungdahl, P.O., Styles, C.A., and Fink, G.R. (1992). Unipolar cell divisions in the yeast $S$. cerevisiae lead to filamentous growth: regulation by starvation and RAS. Cell 68, 1077-1090.

Goldstein, A.L., and McCusker, J.H. (1999). Three new dominant drug resistance cassettes for gene disruption in Saccharomyces cerevisiae. Yeast 15, 1541-1553.

Goossens, A., Dever, T.E., Pascual-Ahuir, A., and Serrano, R. (2001). The protein kinase Gen2p mediates sodium toxicity in yeast. J Biol Chem 276, 30753-30760.

Grundmann, O., Mösch, H.U., and Braus, G.H. (2001). Repression of GCN4 mRNA translation by nitrogen starvation in Saccharomyces cerevisiae. J Biol Chem 276, 25661-25671.

Guarente, L., and Ptashne, M. (1981). Fusion of Escherichia coli lacZ to the cytochrome c gene of Saccharomyces cerevisiae. Proc Natl Acad Sci U S A 78, 21992203. 
Guo, B., Styles, C.A., Feng, Q., and Fink, G.R. (2000). A Saccharomyces gene family involved in invasive growth, cell-cell adhesion, and mating. Proc Natl Acad Sci US A 97, 12158-12163.

Hahn, M.W., De Bie, T., Stajich, J.E., Nguyen, C., and Cristianini, N. (2005). Estimating the tempo and mode of gene family evolution from comparative genomic data. Genome Res 15, 1153-1160.

Halme, A., Bumgarner, S., Styles, C., and Fink, G.R. (2004). Genetic and epigenetic regulation of the FLO gene family generates cell-surface variation in yeast. Cell 116, 405-415.

Harashima, S., and Hinnebusch, A.G. (1986). Multiple $G C D$ genes required for repression of $G C N 4$, a transcriptional activator of amino acid biosynthetic genes in Saccharomyces cerevisiae. Mol Cell Biol 6, 3990-3998.

Harding, H.P., Novoa, I., Zhang, Y., Zeng, H., Wek, R., Schapira, M., and Ron, D. (2000). Regulated translation initiation controls stress-induced gene expression in mammalian cells. Mol Cell 6, 1099-1108.

Harding, H.P., Zhang, Y., and Ron, D. (1999). Protein translation and folding are coupled by an endoplasmic-reticulum-resident kinase. Nature 397, 271-274.

Harding, H.P., Zhang, Y., Zeng, H., Novoa, I., Lu, P.D., Calfon, M., Sadri, N., Yun, C., Popko, B., Paules, R., Stojdl, D.F., Bell, J.C., Hettmann, T., Leiden, J.M., and Ron, D. (2003). An integrated stress response regulates amino acid metabolism and resistance to oxidative stress. Mol Cell 11, 619-633.

Haze, K., Yoshida, H., Yanagi, H., Yura, T., and Mori, K. (1999). Mammalian transcription factor ATF6 is synthesized as a transmembrane protein and activated by proteolysis in response to endoplasmic reticulum stress. Mol Biol Cell 10, 3787-3799.

Heise, B., van der Felden, J., Kern, S., Malcher, M., Brückner, S., and Mösch, H.U. (2010). The TEA transcription factor Tec1 confers promoter-specific gene regulation by Ste12-dependent and -independent mechanisms. Eukaryot Cell 9, 514-531.

Hendershot, L.M. (2004). The ER function BiP is a master regulator of ER function. Mt Sinai J Med 71, 289-297.

Hershko, A., and Ciechanover, A. (1998). The ubiquitin system. Annu Rev Biochem 67, 425-479.

Hinnebusch, A.G. (1984). Evidence for translational regulation of the activator of general amino acid control in yeast. Proc Natl Acad Sci U S A 81, 6442-6446. 
Hinnebusch, A.G. (1985). A hierarchy of trans-acting factors modulates translation of an activator of amino acid biosynthetic genes in Saccharomyces cerevisiae. Mol Cell Biol 5, 2349-2360.

Hinnebusch, A.G. (1997). Translational regulation of yeast GCN4. A window on factors that control initiator-tRNA binding to the ribosome. J Biol Chem 272, 2166121664.

Hinnebusch, A.G. (2005). Translational regulation of GCN4 and the general amino acid control of yeast. Annu Rev Microbiol 59, 407-450.

Hoffman, C.S., and Winston, F. (1987). A ten-minute DNA preparation from yeast efficiently releases autonomous plasmids for transformation of Escherichia coli. Gene 57, 267-272.

Hoffmann, B., Wanke, C., Lapaglia, S.K., and Braus, G.H. (2000). c-Jun and RACK1 homologues regulate a control point for sexual development in Aspergillus nidulans. Mol Microbiol 37, 28-41.

Hollenbeck, J.J., and Oakley, M.G. (2000). GCN4 binds with high affinity to DNA sequences containing a single consensus half-site. Biochemistry 39, 6380-6389.

Hollien, J., and Weissman, J.S. (2006). Decay of endoplasmic reticulum-localized mRNAs during the unfolded protein response. Science 313, 104-107.

Hope, I.A., and Struhl, K. (1986). Functional dissection of a eukaryotic transcriptional activator protein, GCN4 of yeast. Cell 46, 885-894.

Hope, I.A., and Struhl, K. (1987). GCN4, a eukaryotic transcriptional activator protein, binds as a dimer to target DNA. Embo J 6, 2781-2784.

Huang, D., Friesen, H., and Andrews, B. (2007). Pho85, a multifunctional cyclindependent protein kinase in budding yeast. Mol Microbiol 66, 303-314.

Huang, D., Moffat, J., and Andrews, B. (2002). Dissection of a complex phenotype by functional genomics reveals roles for the yeast cyclin-dependent protein kinase Pho85 in stress adaptation and cell integrity. Mol Cell Biol 22, 5076-5088.

Huang, D., Moffat, J., Wilson, W.A., Moore, L., Cheng, C., Roach, P.J., and Andrews, B. (1998). Cyclin partners determine Pho85 protein kinase substrate specificity in vitro and in vivo: control of glycogen biosynthesis by Pcl8 and Pcl10. Mol Cell Biol 18, 3289-3299.

Inoue, H., Nojima, H., and Okayama, H. (1990). High efficiency transformation of Escherichia coli with plasmids. Gene 96, 23-28. 
Irniger, S., and Braus, G.H. (2003). Controlling transcription by destruction: the regulation of yeast Gcn $4 p$ stability. Curr Genet 44, 8-18.

Ito, H., Fukuda, Y., Murata, K., and Kimura, A. (1983). Transformation of intact yeast cells treated with alkali cations. J Bacteriol 153, 163-168.

Jeffrey, P.D., Russo, A.A., Polyak, K., Gibbs, E., Hurwitz, J., Massague, J., and Pavletich, N.P. (1995). Mechanism of CDK activation revealed by the structure of a cyclinA-CDK2 complex. Nature 376, 313-320.

Jia, M.H., Larossa, R.A., Lee, J.M., Rafalski, A., Derose, E., Gonye, G., and Xue, Z. (2000). Global expression profiling of yeast treated with an inhibitor of amino acid biosynthesis, sulfometuron methyl. Physiol Genomics 3, 83-92.

Johnson, D.I. (1999). Cdc42: An essential Rho-type GTPase controlling eukaryotic cell polarity. Microbiol Mol Biol Rev 63, 54-105.

Kaufman, R.J. (2004). Regulation of mRNA translation by protein folding in the endoplasmic reticulum. Trends Biochem Sci 29, 152-158.

Kawahara, T., Yanagi, H., Yura, T., and Mori, K. (1997). Endoplasmic reticulum stress-induced mRNA splicing permits synthesis of transcription factor Hac1p/Ern $4 p$ that activates the unfolded protein response. Mol Biol Cell 8, 1845-1862.

Kim, T.S., Kim, H.Y., Yoon, J.H., and Kang, H.S. (2004). Recruitment of the Swi/Snf complex by Ste12-Tec1 promotes Flo8-Mss11-mediated activation of STA1 expression. Mol Cell Biol 24, 9542-9556.

Kimata, Y., Kimata, Y.I., Shimizu, Y., Abe, H., Farcasanu, I.C., Takeuchi, M., Rose, M.D., and Kohno, K. (2003). Genetic evidence for a role of BiP/Kar2 that regulates Ire1 in response to accumulation of unfolded proteins. Mol Biol Cell 14, 25592569.

Kimata, Y., Oikawa, D., Shimizu, Y., Ishiwata-Kimata, Y., and Kohno, K. (2004). A role for $\mathrm{BiP}$ as an adjustor for the endoplasmic reticulum stress-sensing protein Ire1. $J$ Cell Biol 167, 445-456.

Klein, B.S., and Tebbets, B. (2007). Dimorphism and virulence in fungi. Curr Opin Microbiol 10, 314-319.

Klopotowski, T., and Wiater, A. (1965). Synergism of aminotriazole and phosphate on the inhibition of yeast imidazole glycerol phosphate dehydratase. Arch Biochem Biophys 112, 562-566.

Kobayashi, O., Hayashi, N., Kuroki, R., and Sone, H. (1998). Region of FLO1 proteins responsible for sugar recognition. J Bacteriol 180, 6503-6510. 
Köhler, T., Wesche, S., Taheri, N., Braus, G.H., and Mösch, H.U. (2002). Dual role of the Saccharomyces cerevisiae TEA/ATTS family transcription factor Tec1p in regulation of gene expression and cellular development. Eukaryot Cell 1, 673-686.

Kohno, K. (2007). How transmembrane proteins sense endoplasmic reticulum stress. Antioxid Redox Signal 9, 2295-2303.

Kokame, K., Kato, H., and Miyata, T. (2001). Identification of ERSE-II, a new cisacting element responsible for the ATF6-dependent mammalian unfolded protein response. J Biol Chem 276, 9199-9205.

Kolanus, J., Michalczyk, J., Flint, H.J., and Barthelmess, I.B. (1990). Restricted activation of general amino acid control under conditions of glutamine limitation in Neurospora crassa. Mol Gen Genet 223, 443-448.

Kolmar, H., Frisch, C., Götze, K., and Fritz, H.J. (1995a). Immunoglobulin mutant library genetically screened for folding stability exploiting bacterial signal transduction. J Mol Biol 251, 471-476.

Kolmar, H., Frisch, C., Kleemann, G., Götze, K., Stevens, F.J., and Fritz, H.J. (1994). Dimerization of Bence Jones proteins: linking the rate of transcription from an Escherichia coli promoter to the association constant of REIV. Biol Chem Hoppe Seyler 375, 61-70.

Kolmar, H., Hennecke, F., Götze, K., Janzer, B., Vogt, B., Mayer, F., and Fritz, H.J. (1995b). Membrane insertion of the bacterial signal transduction protein ToxR and requirements of transcription activation studied by modular replacement of different protein substructures. Embo J 14, 3895-3904.

Komeili, A., and O'Shea, E.K. (1999). Roles of phosphorylation sites in regulating activity of the transcription factor Pho4. Science 284, 977-980.

Koo, E.H., Lansbury, P.T., Jr., and Kelly, J.W. (1999). Amyloid diseases: abnormal protein aggregation in neurodegeneration. Proc Natl Acad Sci U S A 96, 9989-9990.

Koong, A.C., Chauhan, V., and Romero-Ramirez, L. (2006). Targeting XBP-1 as a novel anti-cancer strategy. Cancer Biol Ther 5, 756-759.

Kornitzer, D., Raboy, B., Kulka, R.G., and Fink, G.R. (1994). Regulated degradation of the transcription factor Gcn4. Embo J 13, 6021-6030.

Kozutsumi, Y., Segal, M., Normington, K., Gething, M.J., and Sambrook, J. (1988). The presence of malfolded proteins in the endoplasmic reticulum signals the induction of glucose-regulated proteins. Nature 332, 462-464. 
Kraakman, L., Lemaire, K., Ma, P., Teunissen, A.W., Donaton, M.C., Van Dijck, P., Winderickx, J., de Winde, J.H., and Thevelein, J.M. (1999). A Saccharomyces cerevisiae G-protein coupled receptor, Gprl, is specifically required for glucose activation of the cAMP pathway during the transition to growth on glucose. Mol Microbiol 32, 1002-1012.

Krappmann, S., Bignell, E.M., Reichard, U., Rogers, T., Haynes, K., and Braus, G.H. (2004). The Aspergillus fumigatus transcriptional activator CpcA contributes significantly to the virulence of this fungal pathogen. Mol Microbiol 52, 785-799.

Kron, S.J., Styles, C.A., and Fink, G.R. (1994). Symmetric cell division in pseudohyphae of the yeast Saccharomyces cerevisiae. Mol Biol Cell 5, 1003-1022.

Kronstad, J., De Maria, A.D., Funnell, D., Laidlaw, R.D., Lee, N., de Sa, M.M., and Ramesh, M. (1998). Signaling via cAMP in fungi: interconnections with mitogenactivated protein kinase pathways. Arch Microbiol 170, 395-404.

Laemmli, U.K. (1970). Cleavage of structural proteins during the assembly of the head of bacteriophage T4. Nature 227, 680-685.

Lambrechts, M.G., Bauer, F.F., Marmur, J., and Pretorius, I.S. (1996). Muc1, a mucin-like protein that is regulated by Mss10, is critical for pseudohyphal differentiation in yeast. Proc Natl Acad Sci U S A 93, 8419-8424.

Landschulz, W.H., Johnson, P.F., and McKnight, S.L. (1988). The leucine zipper: a hypothetical structure common to a new class of DNA binding proteins. Science $\mathbf{2 4 0}$, 1759-1764.

Lanker, S., Bushman, J.L., Hinnebusch, A.G., Trachsel, H., and Mueller, P.P. (1992). Autoregulation of the yeast lysyl-tRNA synthetase gene $G C D 5 / K R S 1$ by translational and transcriptional control mechanisms. Cell 70, 647-657.

Leber, J.H., Bernales, S., and Walter, P. (2004). IRE 1-independent gain control of the unfolded protein response. PLoS Biol 2, e235, 1197-1207.

Lee, A.S. (2001). The glucose-regulated proteins: stress induction and clinical applications. Trends Biochem Sci 26, 504-510.

Lipford, J.R., Smith, G.T., Chi, Y., and Deshaies, R.J. (2005). A putative stimulatory role for activator turnover in gene expression. Nature 438, 113-116.

Lipke, P.N., and Ovalle, R. (1998). Cell wall architecture in yeast: new structure and new challenges. J Bacteriol 180, 3735-3740. 
Liu, C.Y., Wong, H.N., Schauerte, J.A., and Kaufman, R.J. (2002). The protein kinase/endoribonuclease IRE1 $\alpha$ that signals the unfolded protein response has a luminal $\mathrm{N}$-terminal ligand-independent dimerization domain. J Biol Chem 277, 18346-18356.

Liu, H., Styles, C.A., and Fink, G.R. (1993). Elements of the yeast pheromone response pathway required for filamentous growth of diploids. Science 262, 1741-1744.

Liu, H., Styles, C.A., and Fink, G.R. (1996). Saccharomyces cerevisiae S288C has a mutation in FLO8, a gene required for filamentous growth. Genetics 144, 967-978.

Lo, H.J., Köhler, J.R., DiDomenico, B., Loebenberg, D., Cacciapuoti, A., and Fink, G.R. (1997). Nonfilamentous C. albicans mutants are avirulent. Cell 90, 939-949.

Lo, W.S., and Dranginis, A.M. (1998). The cell surface flocculin Flo11 is required for pseudohyphae formation and invasion by Saccharomyces cerevisiae. Mol Biol Cell 9, 161-171.

Lorenz, M.C., Cutler, N.S., and Heitman, J. (2000a). Characterization of alcoholinduced filamentous growth in Saccharomyces cerevisiae. Mol Biol Cell 11, 183-199.

Lorenz, M.C., and Heitman, J. (1998). The MEP2 ammonium permease regulates pseudohyphal differentiation in Saccharomyces cerevisiae. Embo J 17, 1236-1247.

Lorenz, M.C., Pan, X., Harashima, T., Cardenas, M.E., Xue, Y., Hirsch, J.P., and Heitman, J. (2000b). The G protein-coupled receptor Gpr1 is a nutrient sensor that regulates pseudohyphal differentiation in Saccharomyces cerevisiae. Genetics 154, 609622.

Lu, P.D., Harding, H.P., and Ron, D. (2004). Translation reinitiation at alternative open reading frames regulates gene expression in an integrated stress response. $J$ Cell Biol 167, 27-33.

Ma, Y., and Hendershot, L.M. (2004). The role of the unfolded protein response in tumour development: friend or foe? Nat Rev Cancer 4, 966-977.

Madhani, H.D., and Fink, G.R. (1997). Combinatorial control required for the specificity of yeast MAPK signaling. Science 275, 1314-1317.

Martínez-Espinoza, A.D., Léon, C., Elizarraraz, G., and Ruiz-Herrera, J. (1997). Monomorphic nonpathogenic mutants of Ustilago maydis. Phytopathology 87, 259-265.

Mascarenhas, C., Edwards-Ingram, L.C., Zeef, L., Shenton, D., Ashe, M.P., and Grant, C.M. (2008). Gen4 is required for the response to peroxide stress in the yeast Saccharomyces cerevisiae. Mol Biol Cell 19, 2995-3007. 
Masuoka, H.C., and Townes, T.M. (2002). Targeted disruption of the activating transcription factor 4 gene results in severe fetal anemia in mice. Blood 99, 736-745.

Mayor, T., Lipford, J.R., Graumann, J., Smith, G.T., and Deshaies, R.J. (2005). Analysis of polyubiquitin conjugates reveals that the Rpn10 substrate receptor contributes to the turnover of multiple proteasome targets. Mol Cell Proteomics 4, 741751.

Meimoun, A., Holtzman, T., Weissman, Z., McBride, H.J., Stillman, D.J., Fink, G.R., and Kornitzer, D. (2000). Degradation of the transcription factor Gen 4 requires the kinase Pho85 and the $\mathrm{SCF}^{\mathrm{Cdc} 4}$ ubiquitin-ligase complex. Mol Biol Cell 11, 915-927.

Meussdoerffer, F., and Fink, G.R. (1983). Structure and expression of two aminoacyltRNA synthetase genes from Saccharomyces cerevisiae. J Biol Chem 258, 6293-6299.

Miller, V.L., Taylor, R.K., and Mekalanos, J.J. (1987). Cholera toxin transcriptional activator ToxR is a transmembrane DNA binding protein. Cell 48, 271-279.

Mori, K., Kawahara, T., Yoshida, H., Yanagi, H., and Yura, T. (1996). Signalling from endoplasmic reticulum to nucleus: transcription factor with a basic-leucine zipper motif is required for the unfolded protein-response pathway. Genes Cells 1, 803-817.

Mori, K., Ma, W., Gething, M.J., and Sambrook, J. (1993). A transmembrane protein with a $c d c 2+/ C D C 28$-related kinase activity is required for signaling from the ER to the nucleus. Cell 74, 743-756.

Mori, K., Sant, A., Kohno, K., Normington, K., Gething, M.J., and Sambrook, J.F. (1992). A 22 bp cis-acting element is necessary and sufficient for the induction of the yeast KAR2 (BiP) gene by unfolded proteins. Embo J 11, 2583-2593.

Mortimer, R.K. (2000). Evolution and variation of the yeast (Saccharomyces) genome. Genome Res 10, 403-409.

Mösch, H.U. (2000). Pseudohyphal development of Saccharomyces cerevisiae. Contrib Microbiol 5, 185-200.

Mösch, H.U., and Fink, G.R. (1997). Dissection of filamentous growth by transposon mutagenesis in Saccharomyces cerevisiae. Genetics 145, 671-684.

Mösch, H.U., Kübler, E., Krappmann, S., Fink, G.R., and Braus, G.H. (1999). Crosstalk between the Ras2p-controlled mitogen-activated protein kinase and cAMP pathways during invasive growth of Saccharomyces cerevisiae. Mol Biol Cell 10, 13251335. 
Mösch, H.U., Roberts, R.L., and Fink, G.R. (1996). Ras2 signals via the Cdc42/Ste20/mitogen-activated protein kinase module to induce filamentous growth in Saccharomyces cerevisiae. Proc Natl Acad Sci U S A 93, 5352-5356.

Mösch, H.U., Scheier, B., Lahti, R., Mantsala, P., and Braus, G.H. (1991). Transcriptional activation of yeast nucleotide biosynthetic gene ADE4 by GCN4. J Biol Chem 266, 20453-20456.

Mueller, P.P., and Hinnebusch, A.G. (1986). Multiple upstream AUG codons mediate translational control of GCN4. Cell 45, 201-207.

Mulder, H.J., Saloheimo, M., Penttilä, M., and Madrid, S.M. (2004). The transcription factor HACA mediates the unfolded protein response in Aspergillus niger, and up-regulates its own transcription. Mol Genet Genomics 271, 130-140.

Mumberg, D., Müller, R., and Funk, M. (1994). Regulatable promoters of Saccharomyces cerevisiae: comparison of transcriptional activity and their use for heterologous expression. Nucleic Acids Res 22, 5767-5768.

Munro, S., and Pelham, H.R. (1986). An Hsp70-like protein in the ER: identity with the $78 \mathrm{kd}$ glucose-regulated protein and immunoglobulin heavy chain binding protein. Cell 46, 291-300.

Natarajan, K., Meyer, M.R., Jackson, B.M., Slade, D., Roberts, C., Hinnebusch, A.G., and Marton, M.J. (2001). Transcriptional profiling shows that Gen4p is a master regulator of gene expression during amino acid starvation in yeast. Mol Cell Biol 21, 4347-4368.

Nikawa, J., and Yamashita, S. (1992). IRE1 encodes a putative protein kinase containing a membrane-spanning domain and is required for inositol phototrophy in Saccharomyces cerevisiae. Mol Microbiol 6, 1441-1446.

Nikolaev, Y., Deillon, C., Hoffmann, S.R., Bigler, L., Friess, S., Zenobi, R., Pervushin, K., Hunziker, P., and Gutte, B. (2010). The leucine zipper domains of the transcription factors GCN4 and c-Jun have ribonuclease activity. PLoS One 5, e10765.

Niwa, M., Patil, C.K., DeRisi, J., and Walter, P. (2005). Genome-scale approaches for discovering novel nonconventional splicing substrates of the Ire1 nuclease. Genome Biol 6, R3.

O'Neill, E.M., Kaffman, A., Jolly, E.R., and O'Shea, E.K. (1996). Regulation of PHO4 nuclear localization by the PHO80-PHO85 cyclin-CDK complex. Science 271, 209-212.

O'Shea, E.K., Klemm, J.D., Kim, P.S., and Alber, T. (1991). X-ray structure of the GCN4 leucine zipper, a two-stranded, parallel coiled coil. Science 254, 539-544. 
Oikawa, D., Kimata, Y., and Kohno, K. (2007). Self-association and BiP dissociation are not sufficient for activation of the ER stress sensor Ire1. J Cell Sci 120, 1681-1688.

Oikawa, D., Tokuda, M., Hosoda, A., and Iwawaki, T. (2010). Identification of a consensus element recognized and cleaved by IRE1 $\alpha$. Nucleic Acids Res, Epub, 1-9.

Oliphant, A.R., Brandl, C.J., and Struhl, K. (1989). Defining the sequence specificity of DNA-binding proteins by selecting binding sites from random-sequence oligonucleotides: analysis of yeast GCN4 protein. Mol Cell Biol 9, 2944-2949.

Pal, B., Chan, N.C., Helfenbaum, L., Tan, K., Tansey, W.P., and Gething, M.J. (2007). $\mathrm{SCF}^{\mathrm{Cdc4}}$-mediated degradation of the Hac1p transcription factor regulates the unfolded protein response in Saccharomyces cerevisiae. Mol Biol Cell 18, 426-440.

Pan, X., and Heitman, J. (1999). Cyclic AMP-dependent protein kinase regulates pseudohyphal differentiation in Saccharomyces cerevisiae. Mol Cell Biol 19, 48744887.

Pan, X., and Heitman, J. (2002). Protein kinase A operates a molecular switch that governs yeast pseudohyphal differentiation. Mol Cell Biol 22, 3981-3993.

Paravicini, G., Braus, G., and Hütter, R. (1988). Structure of the ARO3 gene of Saccharomyces cerevisiae. Mol Gen Genet 214, 165-169.

Patil, C., and Walter, P. (2001). Intracellular signaling from the endoplasmic reticulum to the nucleus: the unfolded protein response in yeast and mammals. Curr Opin Cell Biol 13, 349-355.

Patil, C.K., Li, H., and Walter, P. (2004). Gen4p and novel upstream activating sequences regulate targets of the unfolded protein response. PLoS Biol 2, e246, 12081222 .

Petkova, A.T., Ishii, Y., Balbach, J.J., Antzutkin, O.N., Leapman, R.D., Delaglio, F., and Tycko, R. (2002). A structural model for Alzheimer's $\beta$-amyloid fibrils based on experimental constraints from solid state NMR. Proc Natl Acad Sci U S A 99, 16742-16747.

Piotrowska, M., Kruszewska, A., and Paszewski, A. (1980). Effect of regulatory mutations of sulphur metabolism on the levels of cysteine- and homocysteinesynthesizing enzymes in Neurospora crassa. Acta Biochim Pol 27, 395-403.

Pittet, M., and Conzelmann, A. (2007). Biosynthesis and function of GPI proteins in the yeast Saccharomyces cerevisiae. Biochim Biophys Acta 1771, 405-420. 
Pries, R., Bömeke, K., Draht, O., Künzler, M., and Braus, G.H. (2004). Nuclear import of yeast Gcn $4 p$ requires karyopherins Srp1p and Kap95p. Mol Genet Genomics 271, 257-266.

Pries, R., Bömeke, K., Irniger, S., Grundmann, O., and Braus, G.H. (2002). Amino acid-dependent Gcn $4 p$ stability regulation occurs exclusively in the yeast nucleus. Eukaryot Cell 1, 663-672.

Prostko, C.R., Brostrom, M.A., and Brostrom, C.O. (1993). Reversible phosphorylation of eukaryotic initiation factor $2 \alpha$ in response to endoplasmic reticular signaling. Mol Cell Biochem 127-128, 255-265.

Qi, M., and Elion, E.A. (2005). MAP kinase pathways. J Cell Sci 118, 3569-3572.

Rasheva, V.I., and Domingos, P.M. (2009). Cellular responses to endoplasmic reticulum stress and apoptosis. Apoptosis 14, 996-1007.

Rechsteiner, M., and Rogers, S.W. (1996). PEST sequences and regulation by proteolysis. Trends Biochem Sci 21, 267-271.

Reynolds, T.B., and Fink, G.R. (2001). Bakers' yeast, a model for fungal biofilm formation. Science 291, 878-881.

Richarme, G. (1982). Associative properties of the Escherichia coli galactose binding protein and maltose binding protein. Biochem Biophys Res Commun 105, 476-481.

Richie, D.L., Hartl, L., Aimanianda, V., Winters, M.S., Fuller, K.K., Miley, M.D., White, S., McCarthy, J.W., Latge, J.P., Feldmesser, M., Rhodes, J.C., and Askew, D.S. (2009). A role for the unfolded protein response (UPR) in virulence and antifungal susceptibility in Aspergillus fumigatus. PLoS Pathog 5, e1000258, 1-17.

Roberts, R.L., and Fink, G.R. (1994). Elements of a single MAP kinase cascade in Saccharomyces cerevisiae mediate two developmental programs in the same cell type: mating and invasive growth. Genes Dev 8, 2974-2985.

Robertson, L.S., Causton, H.C., Young, R.A., and Fink, G.R. (2000). The yeast A kinases differentially regulate iron uptake and respiratory function. Proc Natl Acad Sci U S A 97, 5984-5988.

Robertson, L.S., and Fink, G.R. (1998). The three yeast A kinases have specific signaling functions in pseudohyphal growth. Proc Natl Acad Sci U S A 95, 1378313787. 
Romero-Ramirez, L., Cao, H., Nelson, D., Hammond, E., Lee, A.H., Yoshida, H., Mori, K., Glimcher, L.H., Denko, N.C., Giaccia, A.J., Le, Q.T., and Koong, A.C. (2004). XBP1 is essential for survival under hypoxic conditions and is required for tumor growth. Cancer Res 64, 5943-5947.

Ron, D. (2002). Translational control in the endoplasmic reticulum stress response. J Clin Invest 110, 1383-1388.

Ron, D., and Walter, P. (2007). Signal integration in the endoplasmic reticulum unfolded protein response. Nat Rev Mol Cell Biol 8, 519-529.

Rose, M., and Botstein, D. (1983). Construction and use of gene fusions to lacZ ( $\beta$-galactosidase) that are expressed in yeast. Methods Enzymol 101, 167-180.

Rosonina, E., Duncan, S.M., and Manley, J.L. (2010). SUMO functions in constitutive transcription and during activation of inducible genes in yeast. Genes Dev 24, 1242-1252.

Roy, A., Lu, C.F., Marykwas, D.L., Lipke, P.N., and Kurjan, J. (1991). The $A G A 1$ product is involved in cell surface attachment of the Saccharomyces cerevisiae cell adhesion glycoprotein a-agglutinin. Mol Cell Biol 11, 4196-4206.

Ruegsegger, U., Leber, J.H., and Walter, P. (2001). Block of HACl mRNA translation by long-range base pairing is released by cytoplasmic splicing upon induction of the unfolded protein response. Cell 107, 103-114.

Rupp, S., Summers, E., Lo, H.J., Madhani, H., and Fink, G. (1999). MAP kinase and cAMP filamentation signaling pathways converge on the unusually large promoter of the yeast FLO11 gene. EMBO J 18, 1257-1269.

Rutherford, J.C., Chua, G., Hughes, T., Cardenas, M.E., and Heitman, J. (2008). A Mep2-dependent transcriptional profile links permease function to gene expression during pseudohyphal growth in Saccharomyces cerevisiae. Mol Biol Cell 19, 30283039 .

Rzymski, T., Milani, M., Pike, L., Buffa, F., Mellor, H.R., Winchester, L., Pires, I., Hammond, E., Ragoussis, I., and Harris, A.L. (2010). Regulation of autophagy by ATF4 in response to severe hypoxia. Oncogene 29, 4424-4435.

Sachs, M.S. (1996). General and cross-pathway controls of amino acid biosynthesis. In: The Mycota III. Berlin Heidelberg, Springer Verlag, 315-345.

Saiki, R.K., Scharf, S., Faloona, F., Mullis, K.B., Horn, G.T., Erlich, H.A., and Arnheim, N. (1985). Enzymatic amplification of $\beta$-globin genomic sequences and restriction site analysis for diagnosis of sickle cell anemia. Science 230, 1350-1354. 
Saito, S., Furuno, A., Sakurai, J., Sakamoto, A., Park, H.R., Shin-Ya, K., Tsuruo, T., and Tomida, A. (2009). Chemical genomics identifies the unfolded protein response as a target for selective cancer cell killing during glucose deprivation. Cancer Res 69, 4225-4234.

San-Blas, G., Travassos, L.R., Fries, B.C., Goldman, D.L., Casadevall, A., Carmona, A.K., Barros, T.F., Puccia, R., Hostetter, M.K., Shanks, S.G., Copping, V.M., Knox, Y., and Gow, N.A. (2000). Fungal morphogenesis and virulence. Med Mycol 38, 79-86.

Sánchez, J., Talamillo, A., Lopitz-Otsoa, F., Pérez, C., Hjerpe, R., Sutherland, J.D., Herboso, L., Rodríguez, M.S., and Barrio, R. (2010). Sumoylation modulates the activity of Spalt-like proteins during wing development in Drosophila. J Biol Chem 285, 25841-25849.

Sánchez-Martínez, C., and Pérez-Martín, J. (2001). Dimorphism in fungal pathogens: Candida albicans and Ustilago maydis--similar inputs, different outputs. Curr Opin Microbiol 4, 214-221.

Sattlegger, E., and Hinnebusch, A.G. (2005). Polyribosome binding by GCN1 is required for full activation of eukaryotic translation initiation factor $2 \alpha$ kinase GCN2 during amino acid starvation. $J$ Biol Chem 280, 16514-16521.

Schröder, M., Chang, J.S., and Kaufman, R.J. (2000). The unfolded protein response represses nitrogen-starvation induced developmental differentiation in yeast. Genes Dev 14, 2962-2975.

Schröder, M., and Kaufman, R.J. (2005). ER stress and the unfolded protein response. Mutat Res 569, 29-63.

Schürch, A., Miozzari, J., and Hütter, R. (1974). Regulation of tryptophan biosynthesis in Saccharomyces cerevisiae: mode of action of 5-methyl-tryptophan and 5-methyl-tryptophan-sensitive mutants. J Bacteriol 117, 1131-1140.

Sengupta, N., Vinod, P.K., and Venkatesh, K.V. (2007). Crosstalk between cAMPPKA and MAP kinase pathways is a key regulatory design necessary to regulate FLO11 expression. Biophys Chem 125, 59-71.

Seong, K.M., Baek, J.H., Ahn, B.Y., Yu, M.H., and Kim, J. (2007). Rpn10p is a receptor for ubiquitinated Gcn4p in proteasomal proteolysis. Mol Cells 24, 194-199.

Shajahan, A.N., Riggins, R.B., and Clarke, R. (2009). The role of X-box binding protein-1 in tumorigenicity. Drug News Perspect 22, 241-246. 
Shamu, C.E., and Walter, P. (1996). Oligomerization and phosphorylation of the Ire1p kinase during intracellular signaling from the endoplasmic reticulum to the nucleus. Embo J 15, 3028-3039.

Shemer, R., Meimoun, A., Holtzman, T., and Kornitzer, D. (2002). Regulation of the transcription factor Gcn4 by Pho85 cyclin PCL5. Mol Cell Biol 22, 5395-5404.

Shen, J., Snapp, E.L., Lippincott-Schwartz, J., and Prywes, R. (2005). Stable binding of ATF6 to BiP in the endoplasmic reticulum stress response. Mol Cell Biol 25, 921-932.

Shen, X., Ellis, R.E., Lee, K., Liu, C.Y., Yang, K., Solomon, A., Yoshida, H., Morimoto, R., Kurnit, D.M., Mori, K., and Kaufman, R.J. (2001). Complementary signaling pathways regulate the unfolded protein response and are required for C. elegans development. Cell 107, 893-903.

Sherman, F., Fink, G.R., and Hicks, J.B. (1986). Cold Spring Harbour Laboratories Methods in yeast genetics. In: Cold Spring Harbor Laboratory, Cold Spring Harbor, New York.

Shi, Y., An, J., Liang, J., Hayes, S.E., Sandusky, G.E., Stramm, L.E., and Yang, N.N. (1999). Characterization of a mutant pancreatic eIF-2 $\alpha$ kinase, PEK, and colocalization with somatostatin in islet delta cells. J Biol Chem 274, 5723-5730.

Shi, Y., Vattem, K.M., Sood, R., An, J., Liang, J., Stramm, L., and Wek, R.C. (1998). Identification and characterization of pancreatic eukaryotic initiation factor 2 $\alpha$-subunit kinase, PEK, involved in translational control. Mol Cell Biol 18, 7499-7509.

Sidrauski, C., and Walter, P. (1997). The transmembrane kinase Irelp is a sitespecific endonuclease that initiates mRNA splicing in the unfolded protein response. Cell 90, 1031-1039.

Sikorski, R.S., and Hieter, P. (1989). A system of shuttle vectors and yeast host strains designed for efficient manipulation of DNA in Saccharomyces cerevisiae. Genetics $\mathbf{1 2 2}$, 19-27.

Singh, S., Braus-Stromeyer, S.A., Timpner, C., Tran, V.T., Lohaus, G., Reusche, M., Knufer, J., Teichmann, T., von Tiedemann, A., and Braus, G.H. (2010). Silencing of Vlaro2 for chorismate synthase revealed that the phytopathogen Verticillium longisporum induces the cross-pathway control in the xylem. Appl Microbiol Biotechnol 85, 1961-1976.

Southern, E.M. (1975). Detection of specific sequences among DNA fragments separated by gel electrophoresis. J Mol Biol 98, 503-517. 
Stade, K., Vogel, F., Schwienhorst, I., Meusser, B., Volkwein, C., Nentwig, B., Dohmen, R.J., and Sommer, T. (2002). A lack of SUMO conjugation affects cNLSdependent nuclear protein import in yeast. J Biol Chem 277, 49554-49561.

Streckfuss-Bömeke, K., Schulze, F., Herzog, B., Scholz, E., and Braus, G.H. (2009). Degradation of Saccharomyces cerevisiae transcription factor Gcn4 requires a C-terminal nuclear localization signal in the cyclin Pcl5. Eukaryot Cell 8, 496-510.

Strittmatter, A.W., Fischer, C., Kleinschmidt, M., and Braus, G.H. (2006). FLO11 mediated filamentous growth of the yeast Saccharomyces cerevisiae depends on the expression of the ribosomal RPS26 genes. Mol Genet Genomics 276, 113-125.

Tallóczy, Z., Jiang, W., Virgin, H.W.t., Leib, D.A., Scheuner, D., Kaufman, R.J., Eskelinen, E.L., and Levine, B. (2002). Regulation of starvation- and virus-induced autophagy by the eIF2 $\alpha$ kinase signaling pathway. Proc Natl Acad Sci U S A 99, 190195.

Tavernarakis, N., and Thireos, G. (1995). Transcriptional interference caused by GCN4 overexpression reveals multiple interactions mediating transcriptional activation. Mol Gen Genet 247, 571-578.

Tesfaigzi, J., Smith-Harrison, W., and Carlson, D.M. (1994). A simple method for reusing western blots on PVDF membranes. Biotechniques 17, 268-269.

Thireos, G., Penn, M.D., and Greer, H. (1984). 5' untranslated sequences are required for the translational control of a yeast regulatory gene. Proc Natl Acad Sci U S A 81, 5096-5100.

Tirasophon, W., Welihinda, A.A., and Kaufman, R.J. (1998). A stress response pathway from the endoplasmic reticulum to the nucleus requires a novel bifunctional protein kinase/endoribonuclease (Ire1p) in mammalian cells. Genes Dev 12, 1812-1824.

Tournu, H., Tripathi, G., Bertram, G., Macaskill, S., Mavor, A., Walker, L., Odds, F.C., Gow, N.A., and Brown, A.J. (2005). Global role of the protein kinase Gen2 in the human pathogen Candida albicans. Eukaryot Cell 4, 1687-1696.

Travers, K.J., Patil, C.K., Wodicka, L., Lockhart, D.J., Weissman, J.S., and Walter, P. (2000). Functional and genomic analyses reveal an essential coordination between the unfolded protein response and ER-associated degradation. Cell 101, 249258 .

Tripathi, G., Wiltshire, C., Macaskill, S., Tournu, H., Budge, S., and Brown, A.J. (2002). Gcn 4 co-ordinates morphogenetic and metabolic responses to amino acid starvation in Candida albicans. Embo J 21, 5448-5456. 
Tuch, B.B., Li, H., and Johnson, A.D. (2008). Evolution of eukaryotic transcription circuits. Science 319, 1797-1799.

Urano, F., Wang, X., Bertolotti, A., Zhang, Y., Chung, P., Harding, H.P., and Ron, D. (2000). Coupling of stress in the ER to activation of JNK protein kinases by transmembrane protein kinase IRE1. Science 287, 664-666.

Valenzuela, L., Aranda, C., and Gonzalez, A. (2001). TOR modulates GCN4dependent expression of genes turned on by nitrogen limitation. J Bacteriol 183, 23312334.

Valerius, O., Kleinschmidt, M., Rachfall, N., Schulze, F., López Marín, S., Hoppert, M., Streckfuss-Bömeke, K., Fischer, C., and Braus, G.H. (2007). The Saccharomyces homolog of mammalian RACK1, Cpc2/Asc1p, is required for FLO11dependent adhesive growth and dimorphism. Mol Cell Proteomics 6, 1968-1979.

van Anken, E., and Braakman, I. (2005). Endoplasmic reticulum stress and the making of a professional secretory cell. Crit Rev Biochem Mol Biol 40, 269-283.

van Dyk, D., Pretorius, I.S., and Bauer, F.F. (2005). Mss11p is a central element of the regulatory network that controls FLO11 expression and invasive growth in Saccharomyces cerevisiae. Genetics 169, 91-106.

Varshavsky, A. (1997). The ubiquitin system. Trends Biochem Sci 22, 383-387.

Vattem, K.M., and Wek, R.C. (2004). Reinitiation involving upstream ORFs regulates ATF4 mRNA translation in mammalian cells. Proc Natl Acad Sci U S A 101, 1126911274.

Verstrepen, K.J., Jansen, A., Lewitter, F., and Fink, G.R. (2005). Intragenic tandem repeats generate functional variability. Nat Genet 37, 986-990.

Verstrepen, K.J., Reynolds, T.B., and Fink, G.R. (2004). Origins of variation in the fungal cell surface. Nat Rev Microbiol 2, 533-540.

Wang, G., Yang, Z.Q., and Zhang, K. (2010). Endoplasmic reticulum stress response in cancer: molecular mechanism and therapeutic potential. Am J Transl Res 2, 65-74.

Wang, Y., Shen, J., Arenzana, N., Tirasophon, W., Kaufman, R.J., and Prywes, R. (2000). Activation of ATF6 and an ATF6 DNA binding site by the endoplasmic reticulum stress response. J Biol Chem 275, 27013-27020.

Weiss, M.A., Ellenberger, T., Wobbe, C.R., Lee, J.P., Harrison, S.C., and Struhl, K. (1990). Folding transition in the DNA-binding domain of GCN4 on specific binding to DNA. Nature 347, 575-578. 
Wimalasena, T.T., Enjalbert, B., Guillemette, T., Plumridge, A., Budge, S., Yin, Z., Brown, A.J., and Archer, D.B. (2008). Impact of the unfolded protein response upon genome-wide expression patterns, and the role of Hacl in the polarized growth, of Candida albicans. Fungal Genet Biol 45, 1235-1247.

Woodcock, D.M., Crowther, P.J., Doherty, J., Jefferson, S., DeCruz, E., NoyerWeidner, M., Smith, S.S., Michael, M.Z., and Graham, M.W. (1989). Quantitative evaluation of Escherichia coli host strains for tolerance to cytosine methylation in plasmid and phage recombinants. Nucleic Acids Res 17, 3469-3478.

Yang, R., Wek, S.A., and Wek, R.C. (2000). Glucose limitation induces GCN4 translation by activation of Gen2 protein kinase. Mol Cell Biol 20, 2706-2717.

Ye, J., Rawson, R.B., Komuro, R., Chen, X., Dave, U.P., Prywes, R., Brown, M.S., and Goldstein, J.L. (2000). ER stress induces cleavage of membrane-bound ATF6 by the same proteases that process SREBPs. Mol Cell 6, 1355-1364.

Yoshida, H., Haze, K., Yanagi, H., Yura, T., and Mori, K. (1998). Identification of the cis-acting endoplasmic reticulum stress response element responsible for transcriptional induction of mammalian glucose-regulated proteins. Involvement of basic leucine zipper transcription factors. J Biol Chem 273, 33741-33749.

Yoshida, H., Okada, T., Haze, K., Yanagi, H., Yura, T., Negishi, M., and Mori, K. (2000). ATF6 activated by proteolysis binds in the presence of NF-Y (CBF) directly to the cis-acting element responsible for the mammalian unfolded protein response. Mol Cell Biol 20, 6755-6767.

Yoshida, H., Oku, M., Suzuki, M., and Mori, K. (2006). pXBP1(U) encoded in XBP1 pre-mRNA negatively regulates unfolded protein response activator pXBP1(S) in mammalian ER stress response. J Cell Biol 172, 565-575.

Yun, C.W., Tamaki, H., Nakayama, R., Yamamoto, K., and Kumagai, H. (1998). Gprlp, a putative G-protein coupled receptor, regulates glucose-dependent cellular cAMP level in yeast Saccharomyces cerevisiae. Biochem Biophys Res Commun 252, 29-33.

Zeller, C.E., Parnell, S.C., and Dohlman, H.G. (2007). The RACK1 ortholog Asc1 functions as a G-protein $\beta$-subunit coupled to glucose responsiveness in yeast. $J$ Biol Chem 282, 25168-25176.

Zupancic, M.L., Frieman, M., Smith, D., Alvarez, R.A., Cummings, R.D., and Cormack, B.P. (2008). Glycan microarray analysis of Candida glabrata adhesin ligand specificity. Mol Microbiol 68, 547-559. 



\section{Publication}

Herzog, B., Streckfuss-Bömeke, K., and Braus G.H.. A feedback circuit between transcriptional activation and self-destruction of Gen4p separates its metabolic and morphogenic function in diploid yeasts. Journal of Molecular Biology. Under Review. 



\section{CURriculum Vitae}

NAME: Britta Herzog

GEBURTSDATUM: 27.03.1979

GEBURTSORT: Nürnberg

Nationalität: deutsch

FAMILIENSTAND: ledig

SCHULBILDUNG:

1985-1989:

1989-1995:

1995-1998:

\section{STUDIUM:}

1998-2001:

2001-2004:

Mai 2004:

Mai 2004-März 2005:

Prof. Dr. Gerhard H. Braus

Thema:

'Einfluss verschiedener Gcn4p-Aminosäuresubstitutionen auf den Phänotyp des Sigmastammes $\Sigma 1278$ b'

Juni 2005-Sept. 2010: Doktorarbeit am Institut für Mikrobiologie und Genetik der Georg-August-Universität zu Göttingen bei Prof. Dr. Gerhard H. Braus

Dissertationsthema:

'Metabolic and developmental functions of the transcription factor Gcn4p of Saccharomyces cerevisiae’ 
